\title{
ANÁLISE DE DISPONIBILIDADE EM MÁQUINAS OPERATRIZES: UMA APLICAÇÃO A MÁQUINAS TÊXTEIS
}

\author{
Dissertação apresentada à Escola \\ Politécnica da Universidade de São \\ Paulo para obtenção de título de Mestre \\ em Engenharia
}




\section{ANÁLISE DE DISPONIBILIDADE EM MÁQUINAS OPERATRIZES: UMA APLICAÇÃO A MÁQUINAS TÊXTEIS}

Dissertação apresentada à Escola Politécnica da Universidade de São Paulo para obtenção de título de Mestre em Engenharia

Área de Concentração:

Engenharia Mecânica

Orientador:

Professor Dr.

Gilberto Francisco Martha Souza

São Paulo 
Este exemplar foi revisado e alterado em relação à versão original, sob responsabilidade única do autor e com a anuência de seu orientador.

São Paulo, 22 de setembro de 2008.

Assinatura do autor

Assinatura do orientador

FICHA CATALOGRÁFICA

Simões, Teixeira, Bruno

Análise de disponibilidade em máquinas operatrizes: uma aplicação a máquinas têxteis / B.S. Teixeira. -- ed.rev. -- São Paulo, 2008.

$126 \mathrm{p}$.

Dissertação (Mestrado) - Escola Politécnica da Universidade de São Paulo. Departamento de Engenharia Mecatrônica e de Sistemas Mecânicos.

1.Máquinas têxteis (Confiabilidade;Manutenção) I.Universidade de São Paulo. Escola Politécnica. Departamento de Engenharia Mecatrônica e de Sistemas Mecânicos Il.t. 


\section{DEDICATÓRIA}

A todos aqueles que contribuem para

o desenvolvimento científico e industrial deste país 


\section{AGRADECIMENTOS}

A meus pais, Alcione e Roberto, por fazerem de mim quem sou.

A minha irmã, Marcela, pela companhia de todos esses anos.

A meus familiares, pela união.

A meus amigos, por todos os momentos de diversão.

Ao prof. Dr. Gilberto Francisco Martha de Souza, por ter me orientado e pela confiança.

Aos engenheiros M.Sc. Érico Pessoa Felix e M.Sc. Fernando Jesús Guevara Carazas, e demais colegas do Laboratório de Confiabilidade da Escola Politécnica da Universidade de São Paulo, pelas dicas.

Aos colegas de trabalho, e pelo aprendizado do dia-a-dia.

A Deus. 


\section{RESUMO}

Os estudos de confiabilidade e disponibilidade encontram grandes aplicações no meio industrial. Neste trabalho é avaliada sob esta ótica um parque de uma indústria têxtil com diversas unidades de máquinas retorcedeiras, que realizam uma etapa do processo de produção de fios de nylon conhecido como retorção. Este processo consiste em torcer dois fios um contra o outro, dando origem a um fio duplo.

Estas máquinas contam com dezenas de componentes que podem apresentar falhas. Ao longo de um período, foi colhido um banco de dados que foi tomado como base para este estudo. Este banco de dados foi filtrado, processo que à primeira vista pode parecer simples mas se não for feito criteriosamente pode comprometer toda a seqüência do trabalho.

Após a definição de um procedimento para a validação de um modelo, são determinadas as confiabilidades com base nos dados de falha, e mantenabilidades com base nos dados de reparo, para os diversos modos de falha considerados. A partir de então, são feitas algumas simulações do comportamento da disponibilidade.

Verifica-se quais são os modos de falha críticos e quais os seus impactos. Investigações adicionais são feitas, revelando alguns comportamentos não esperados. São então dadas orientações para a definição das políticas de manutenção e sugestões de onde atacar eventuais esforços de melhoria. O modelo de simulação é utilizado por final para verificar os resultados de uma possível melhoria futura no modo de falha mais crítico.

Ao final, são apresentadas as conclusões do trabalho e recomendações para estudos futuros.

Palavras chave: confiabilidade, manutenção, máquinas têxteis. 


\begin{abstract}
Reliability and availability studies find themselves very useful among industries. In the present work, the machinery of a textile company is evaluated concerning this topic. This company uses machines that perform the process of twisting, which is one step in the whole process of producing nylon textile yarns. In the twisting, two single yarns are twisted against each other, producing a double yarn.

In these machines there are dozens of parts that may fail. During a period of time, data was collected to this work. This data are then filtered. This may seems simple at a first sight, but it may compromise the whole work if not done in a carefully way.

In the sequence a procedure to validate a model is established. Right after, the reliabilities are evaluated, based on the failures data, to all considered failures modes. Maintainabilities are also evaluated, based on repair data. Then, some simulations are made upon the availability behavior.

The critical failure modes are found and their impacts are showed. Additional investigations are done, and this leads to some behaviors that are not expected. Some guidelines are given to the maintenance policy definition, and to where eventually improvement efforts should focus on. Finally, the simulation model is used to check the results of a possible future improvement in the most critical failure mode.
\end{abstract}

At the end, conclusions and recommendations to future works are presented.

Key words: reliability, maintenance, textile machines. 


\section{LISTA DE FIGURAS}

FIGURA 1-1 - DESENVOLVIMENTO DAS POLÍTICAS DE MANUTENÇÃO (ARUNRAJ, 2007).......... 1

FIGURA 2-1 - FLUXOGRAMA DO PROCESSO DE PRODUÇÃO DO NYLON....................................... 5

FIGURA 2-2 - MÁQUINAS NO LOCAL DE INSTALAÇÃO. ............................................................ 6

FIGURA 2-3 - ESQUEMA DE FUNCIONAMENTO DA MÁQUINA................................................. 7

FigurA 2-4 - DESENHO DE MONTAGEM DE UM BOLSTER E PEÇAS QUE COMPÕE O CONJUNTO: AMORTECEDOR, MOLA, PORCA DE APERTO, CONTRAPESO_................................................. 8

FIGURA 2-5 - FUSO E BOLSTER EM CORTE, COM A INDICAÇÃO DAS PARTES INTERNAS

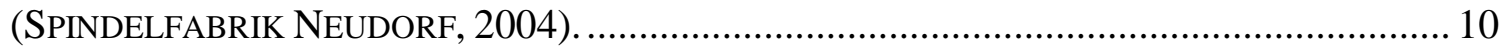

Figura 3-1 - FunÇÃo de ProbabiLidade ACUMUlada F(T) (LEITCH, 1995)..................... 13

FIGURA 3-2 - FunÇÃO DE CONFIABILIDADE $R(T)$ (LEITCH, 1995) ....................................... 14

FiguRA 3-3 - REPRESENTAÇÃo DA CURVA DA BANHEIRA (CARAZAS, 2006). ....................... 16

FIGURA 3-4 - DADOS SUSPENSOS OU CENSURADOS (LEMES, 2006)..................................... 18

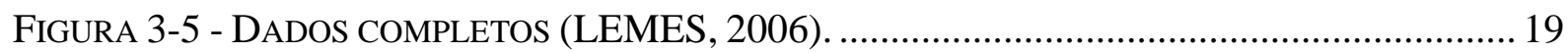

FIGURA 3-6 - FUNÇÕES DENSIDADE DE PROBABILIDADE E PROBABILIDADE ACUMULADA PARA A

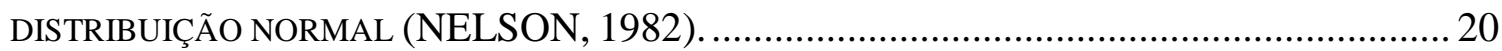

FIGURA 3-7 - FUNÇÕES DENSIDADE DE PROBABILIDADE E PROBABILIDADE ACUMULADA PARA A

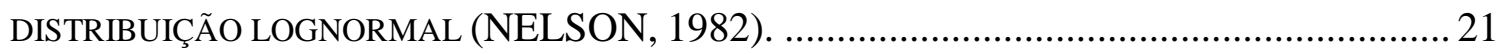

FIGURA 3-8 - FUNÇÕES DENSIDADE DE PROBABILIDADE E PROBABILIDADE ACUMULADA PARA A

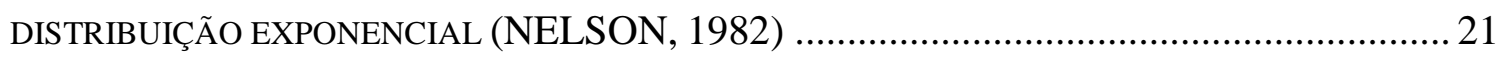

FIGURA 3-9 - VARIAÇÃO DE UMA $F(T)$ DE WEIBULL EM FUNÇÃO DO PARÂMETRO $B$

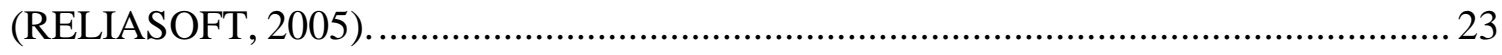

FIGURA 3-10 - VARIAÇÃO DE UMA $F(T)$ DE WEIBULL EM FUNÇÃO DO PARÂMETRO $H$

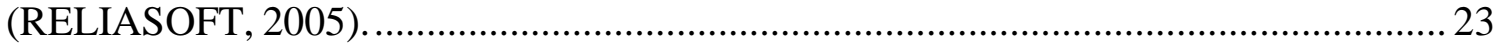

Figura 3-11 - MÉTOdo dos Mínimos QuAdRAdos (RELIASOFT, 2005)............................. 25

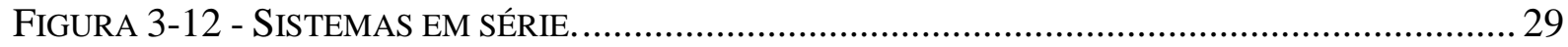


FIGURA 3-13 - CONFIABILIDADE DE SISTEMAS EM SÉRIE EM FUNÇÃO DO NÚMERO DE COMPONENTES QUE O COMPÕE (N) (CARAZAS, 2006)................................................ 30

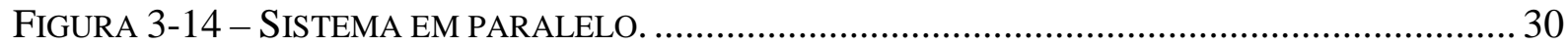

FIGURA 3-15 - COMPARATIVO DA EVOLUÇÃO DA CONFIABILIDADE PARA COMPONENTES E SISTEMAS NO MODO PARALELO ATIVO (CARAZAS, 2006) .............................................. 31

Figura 3-16 - EFEITO dA MANUTENÇÃo PREVEnTIVA NA CONFIABILIDAdE (LEWIS, 1996). 41

Figura 3-17 - EFeIto da MANUTENÇÃo PREVEntiva e do FAtor $B$ NA CONFIABILIDAde (LEWIS, 1996).

FIgURA 3-18 - CURVA DE TENDÊNCIA PARA UM PARÂMETRO DE INTERESSE (XENOS, 2004). 44

FIGURA 4-1 - ÁRVORE FUNCIONAL DO SISTEMA. ........................................................... 48

FIGURA 4-2 - ÁRVORE FUNCIONAL DE UMA POSIÇÃO. .......................................................... 49

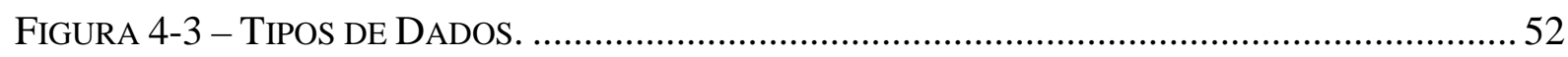

FIGURA 4-4 - FLUXOGRAMA DE ANÁLISE DE DiSPONIBILIDADE. ........................................... 56

FIGURA 4-5 - ÁRVORE DE FALHAS CONSIDERADA PARA A FALHA DE UMA POSIÇÃO. ................. 59

FIGURA 4-6 - PARETO DE OCORRÊNCIAS DE FALHA ENTRE OS DIFERENTES MODOS DE FALHA. . 61

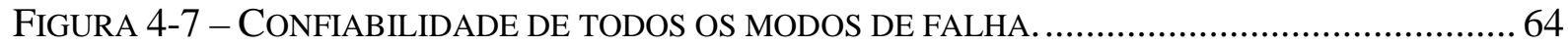

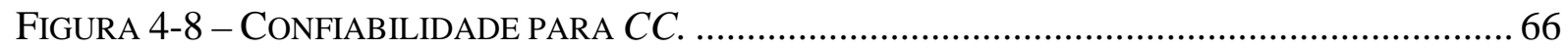

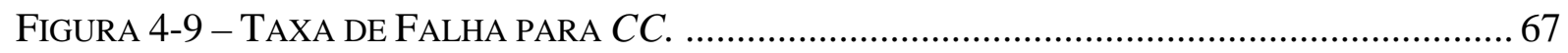

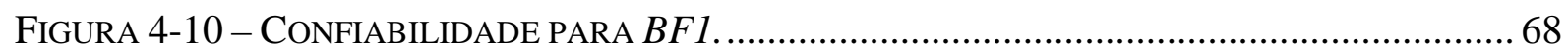

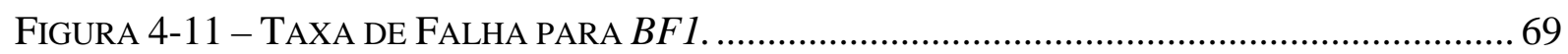

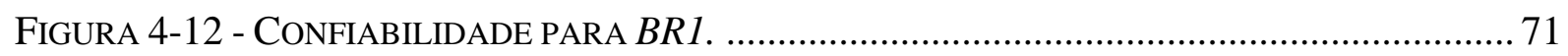

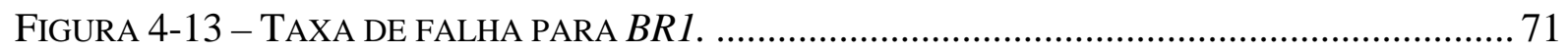

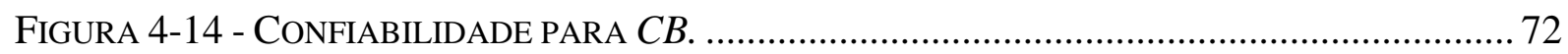

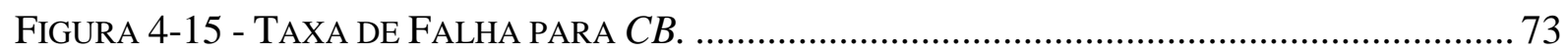

Figura 4-16 - PROBABILIDADES DE FALHA PARA $C C$, PARA DIFERENTES DiSTRIBUIÇÕES. ...... 74

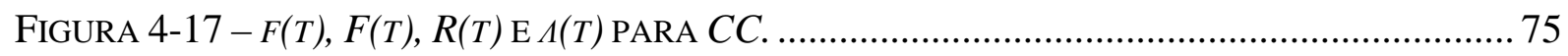

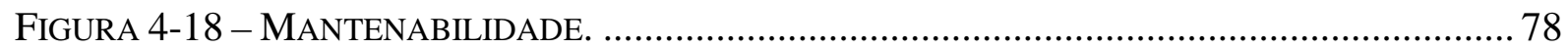


FIGURA 4-19 - REPRESENTAÇÃO DE UMA POSIÇÃO DE UMA MÁQUINA NO BLOCKSIM.. 79

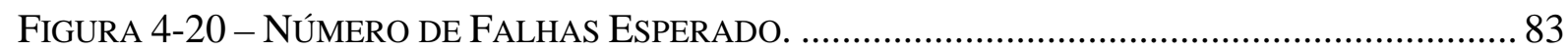

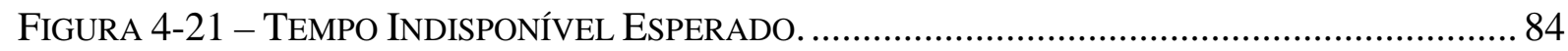

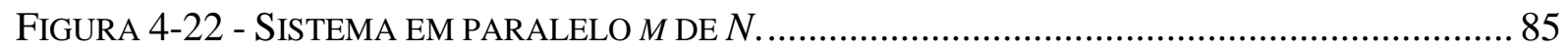

FIGURA 4-23 - REPRESENTAÇÃO DO CONJUNTO DE MÁQUINAS NO BLOCKSIM (VISÃO PARCIAL).

FIGURA 4-24 - RESULTADOS DAS SIMULAÇÕES VARIANDO M/N ........................................ 87

FIGURA 4-25 - CONFIABILIDADE DE UMA EVENTUAL MELHORIA NO MODO DE FALHA $C C . . . . . .89$

FIgURA 4-26 - TAXA DE FALHA DE UMA EVENTUAL MELHORIA NO MODO DE FALHA $C C . . . . . . .89$

FIGURA 4-27 - COMPARAÇÃO ENTRE O NÚMERO DE FALHAS ESPERADO PARA AS DUAS

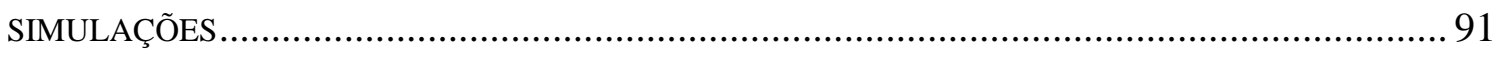

FIgURA A-1 - Probabilidades de FALHA PARA AN, PARA DifERENTES DistribuiÇÕES ........ 101

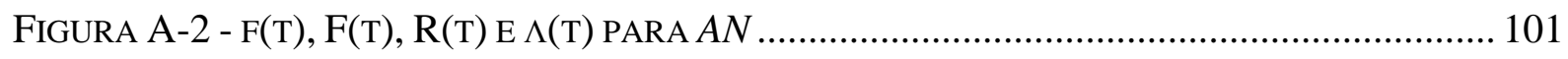

Figura A-3 - Probabilidades de FALHA PARA BF1, PARA DIFERENTES DISTRIBUiÇÕES....... 102

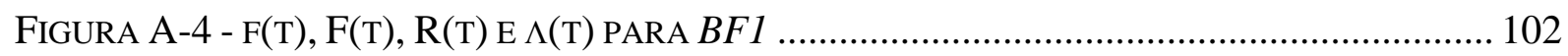

Figura A-5 - Probabilidades de FALHA PARA BF2, PARA DIFERENTES DISTRIBUIÇÕES....... 103

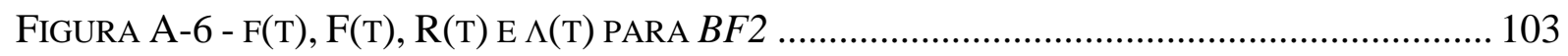

Figura A-7 - PROBABILIDAdES DE FALHA PARA BRI, PARA DIFERENTES DISTRIBUIÇÕES....... 104

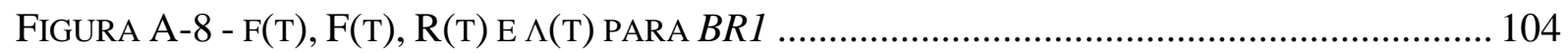

Figura A-9 - Probabilidades de FALHA PARA BR2, PARA DIFERENTES DISTRIBUIÇÕES....... 105

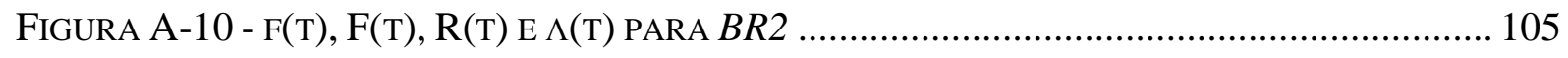

Figura A-11 - Probabilidades de FALHA PARA $C B$, PARA Diferentes Distribuições ..... 106

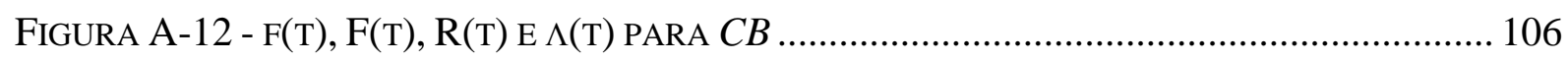

Figura A-13 - Probabilidades de FALHA PARA CC, PARA DiFERENTES DisTRIBUiÇõeS ..... 107

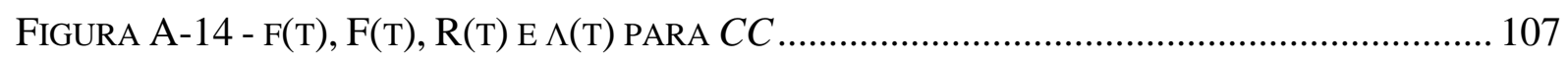

FIgURA A-15 - PROBABILIDAdes de FALHA PARA FF1, PARA DIFERENTES DISTRIBUIÇÕES .... 108

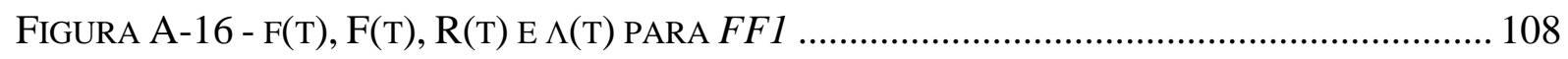


FigurA A-17 - PROBABILIDAdES DE FALHA PARA FF2, PARA DIFERENTES DISTRIBUIÇÕES.... 109

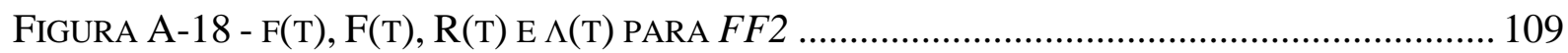

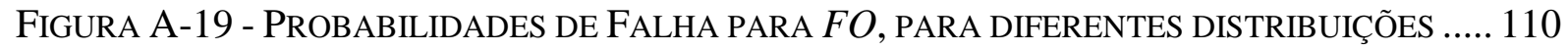

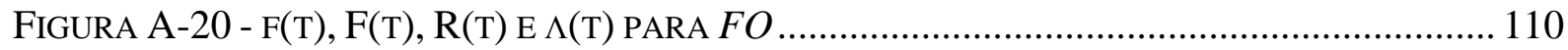

Figura A-21 - PROBABILIDADES DE FALHA PARA $F R$, PARA DIFERENTES DISTRIBUIÇÕES....... 111

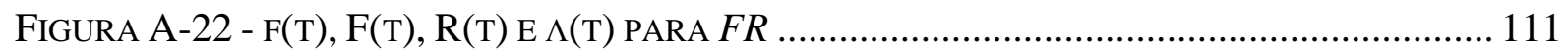

Figura A-23 - Probabilidades de FALHA PARA $O U$, PARA DIFERENTES DistribuiçÕES..... 112

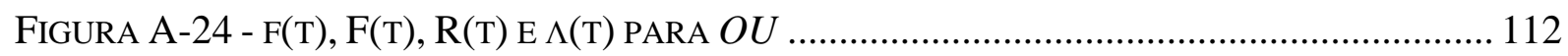

Figura A-25 - Probabilidades de FALHA PARA PT, PARA DIFERENTES DistribuiÇÕES ....... 113

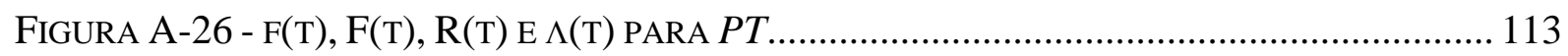

Figura A-27 - PROBABILIDAdes De FALHA PARA $R P$, PARA DIFERENTES DISTRIBUiÇÕES....... 114

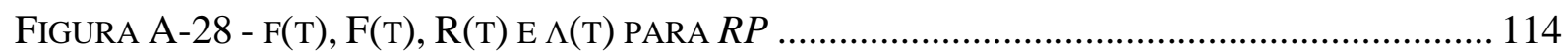

FIgURA B-1 - PRobABILIDADES DE REPARO PARA AN, PARA DIFERENTES DISTRIBUIÇÕES...... 116

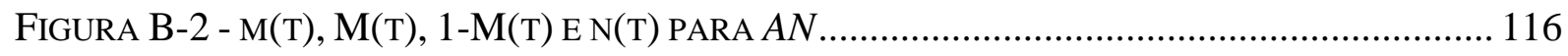

FIgURA B-3 - PRobAbILIDADES DE REPARo PARA $B F$, PARA DIFERENTES DISTRIBUIÇÕES ....... 117

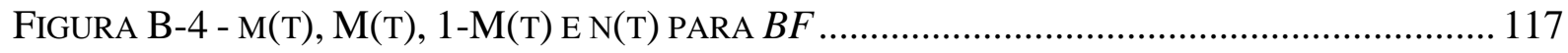

Figura B-5 - PROBABILIDAdES DE REPARO PARA $B R$, PARA DIFERENTES DISTRIBUIÇÕES ....... 118

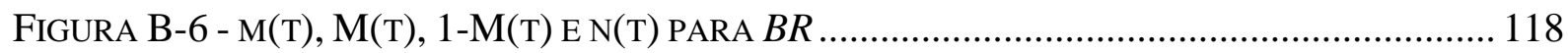

FIgURA B-7 - PRobabilidAdES DE REPARO PARA $C B$, PARA DIFERENTES DISTRIBUIÇÕES...... 119

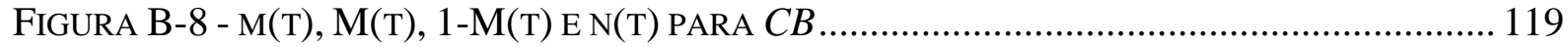

Figura B-9 - PRobabilidAdES DE REPARo PARA $C C$, PARA DIFERENTES DiSTRIBUIÇÕES ..... 120

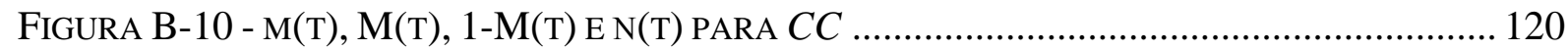

FIGURA B-11 - PROBABILIDADES DE REPARO PARA $F F$, PARA DIFERENTES DISTRIBUIÇÕES .... 121

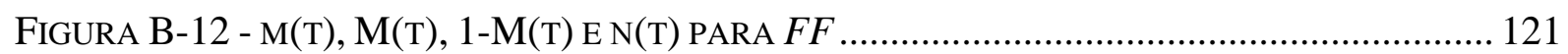

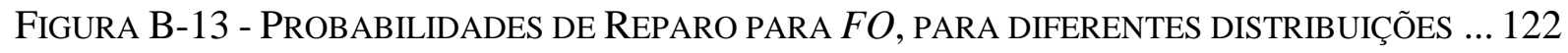

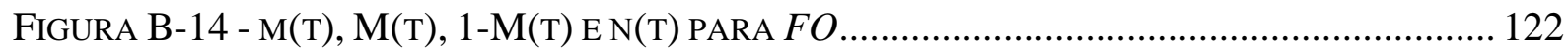


FiguRA B-15 - PROBABILIDADES DE REPARO PARA $F R$, PARA DIFERENTES DISTRIBUIÇÕES .... 123

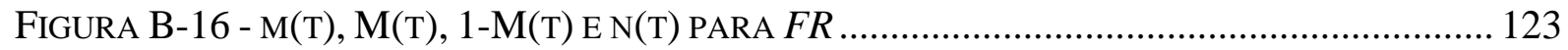

FIgURA B-17 - PRobabilidAdES DE REPARO PARA $O U$, PARA DIFERENTES DistRIBUIÇÕES ... 124

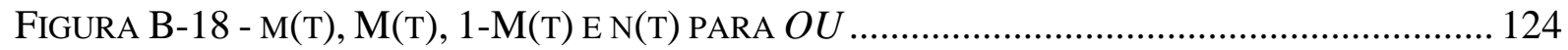

FiguRA B-19 - PROBABILIDADES DE REPARO PARA PT, PARA DIFERENTES DISTRIBUIÇÕES .... 125

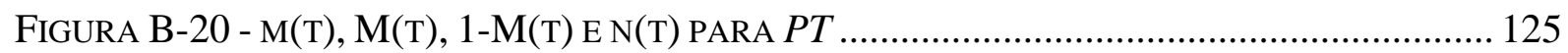

FIGURA B-21 - PROBABILIDADES DE REPARO PARA RP, PARA DIFERENTES DISTRIBUIÇÕES .... 126

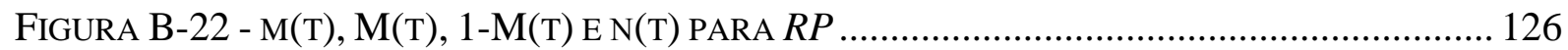




\section{LISTA DE TABELAS}

TABela 3-1 - Matriz Para SEleção PREliminar das Práticas de ManutenÇão (CARDOSO, 2004). 46

TABELA 4-1 - TIPOS DE PROBLEMAS ENCONTRADOS NOS DADOS. 53

TABELA 4-2 - CÓDIGOS DOS MODOS DE FALHA. 60

TABELA 4-3 - OCORRÊNCIAS DE FALHAS ENTRE OS DIFERENTES GRUPOS. 62

TABELA 4-4 - PARÂMETROS DE CONFIABILIDADE PARA TODOS OS MODOS DE FALHA DO MODELO. 63

TABELA 4-5 - CONFIABILIDADES DE CC PARA DIFERENTES MÁQUINAS. 66

TABELA 4-6 - CONFIABILIDADES PARA BF 1 PARA DIFERENTES MÁQUINAS. 68

TABELA 4-7 - CONFIABILIDADES PARA BRl PARA DIFERENTES MÁQUINAS. 70

TABELA 4-8 - CONFIABILIDADES PARA CB PARA DIFERENTES MÁQUINAS. 72

TABELA 4-9 - MODOS DE FALHA CONSIDERADOS NO CÁLCULO DE CONFIABILIDADE E DE MANTENABILIDADE. 76

TABELA 4-10 - DistribuiçõES DE MANTENABILIDADE. 77

TABELA 4-11 - NÚMERO DE FALHAS REAL VERSUS NÚMERO DE FALHAS ESTIMADO. .80

Tabela 4-12 - Resultados de Simulação de Monte CARlo Para DisPonibilidade. ....... 81

TABELA 4-13 - NÚMERO DE FALHAS E TEMPO INDISPONÍVEL ESPERADOS, EXPLODIDOS POR MODOS DE FALHA.

TABELA 4-14 - RESULTADOS DAS SIMULAÇÕES VARIANDO $M / N$. 87

TABELA 4-15 - PARÂMETROS DE CONFIABILIDADE DE UMA EVENTUAL MELHORIA NO MODO DE FALHA $C C$. 88

TABELA 4-16 - RESULTADOS DA SIMULAÇÃO CONSIDERANDO UMA EVENTUAL MELHORIA NO MODO DE FALHA $C C$. 90 


\title{
LISTA DE SÍMBOLOS
}

\author{
$A(t) \quad$ Disponibilidade instantânea no tempo $t$ \\ $A^{*}(T) \quad$ Disponibilidade média no intervalo de tempo $T$ \\ $A^{*}(\infty) \quad$ Disponibilidade assintótica \\ $F(t) \quad$ Função de probabilidade acumulada de falha no tempo $t$ \\ $f(t) \quad$ Função densidade de probabilidade de falha no tempo $t$ \\ $m(t) \quad$ Função densidade de probabilidade para execução do reparo no tempo $t$ \\ $M(t) \quad$ Função de probabilidade acumulada para execução do reparo antes do \\ tempo $t$ \\ $R(t) \quad$ Confiabilidade no tempo $t$ \\ $R m(t) \quad$ Confiabilidade de um Sistema após Manutenção Preventiva \\ T Tempo até ocorrer a falha \\ $t_{0} \quad$ Mediana de $t$ na distribuição Lognormal \\ $t_{0} \quad$ Constante de localização na distribuição de Weibull. \\ $\beta \quad$ Constante de forma na distribuição de Weibull. \\ $\eta \quad$ Constante de escala na distribuição de Weibull. \\ $\lambda \quad$ Taxa de falha constante no tempo \\ $\lambda(t) \quad$ Taxa de falha no tempo $t$ \\ $\mu \quad$ Média de um conjunto de dados \\ $\sigma \quad$ Desvio padrão de um conjunto de dados
}


$t_{\text {rep }} \quad$ Tempo de reparo do equipamento

$v(t) \quad$ Taxa de reparo 


\section{LISTA DE ABREVIAÇÕES}

AN Modo de Falha relativo ao conjunto Anel.

BF Modo de Falha relativo ao conjunto Bolster Filage. Utilizado somente para o cálculo de mantenabilidade.

BF1 Dentro do conjunto Bolster Filage, representa o modo de falha causado por falha com componente amortecedor. Utilizado para cálculo de confiabilidade.

BF2 Dentro do conjunto Bolster Filage, representa o modo de falha causado por falhas de quaisquer componentes exceto o amortecedor. Utilizado para cálculo de confiabilidade.

BR Modo de Falha relativo ao conjunto Bolster Retordage. Utilizado somente para o cálculo de mantenabilidade.

BRI Dentro do conjunto Bolster Filage, representa o modo de falha causado por falha com componente amortecedor. Utilizado para cálculo de confiabilidade.

BR2 Dentro do conjunto Bolster Filage, representa o modo de falha causado por falhas de quaisquer componentes exceto o amortecedor. Utilizado para cálculo de confiabilidade.

CB Modo de Falha relativo ao conjunto do Cabestã.

CC Modo de Falha relativo ao componente Correia Cadarço.

FF Modo de Falha relativo ao Fuso Filage. Utilizado somente para o cálculo de mantenabilidade.

FF1 Modo de Falha do Fuso Filage causado exclusivamente por acúmulo de refugo

FF2 Modo de Falha do Fuso Filage causado por fatores mecânicos diversos.

FO Modo de Falha relativo ao conjunto de Freio.

FR Modo de Falha relativo ao Fuso Retordage. 
OU Modos de Falha relativos a outros componentes.

$P B \quad$ Modo de Falha relativo ao Pára-balão.

PT Modo de Falha relativo ao conjunto do Pote.

RP Modo de Falha relativo ao conjunto do Rabo de Porco.

FMEA Análise dos Modos e Efeitos de Falha (Failure Modes and Effects Analysis)

FTA Análise de Árvore de Falhas (Fault Tree Analysis)

MTBF Tempo médio entre falhas (Mean Time Between Failures)

MTTR Tempo médio de reparo (Mean Time To Repair)

RCM Manutenção Centrada em Confiabilidade (Reliability Centered Maintenance)

TDF Tempo de Desenvolvimento da Falha 


\section{SUMÁRIO}

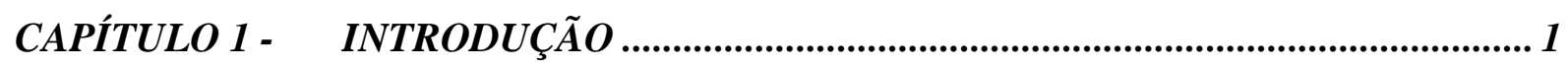

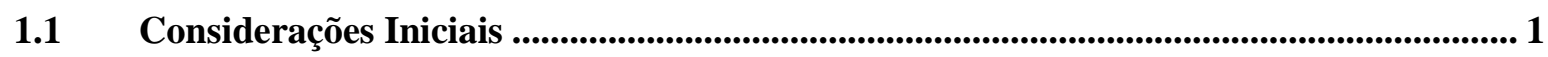

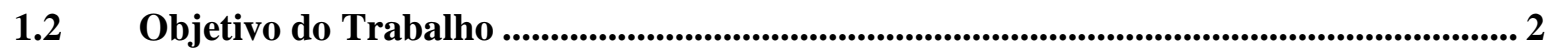

$1.3 \quad$ Escopo do Trabalho ............................................................................................................... 2

CAPÍTULO 2 - MÁQUINAS TÊXTEIS RETORCEDEIRAS........................................ 4

2.1 Considerações Iniciais ................................................................................................................ 4

2.2 Funcionamento de Máquinas Têxteis Retorcedeiras ................................................................. 6

CAPÍTULO 3 - PRINCÍPIOS DE CONFIABILIDADE ........................................... 11

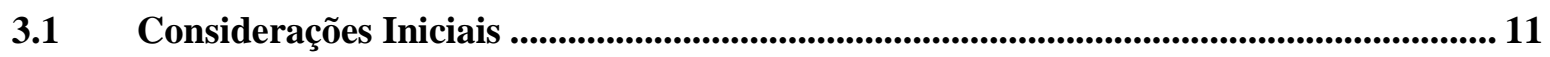

3.2 Conceitos de Confiabilidade................................................................................................ 12

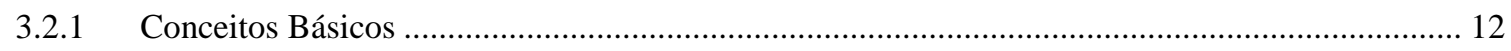

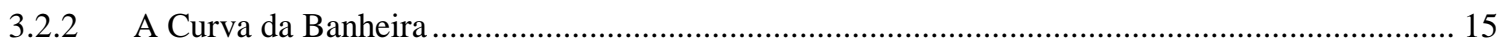

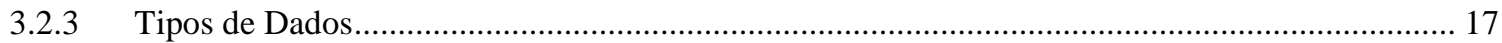

3.2.4 Principais Distribuições em Confiabilidade ................................................................................ 19

3.2.5 Cálculo dos Parâmetros de Distribuição de Probabilidade............................................................. 24

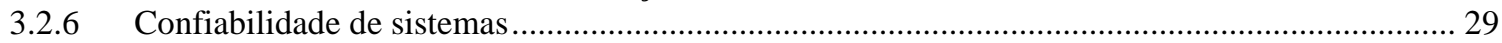

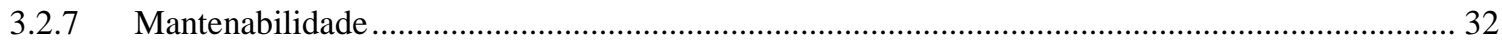

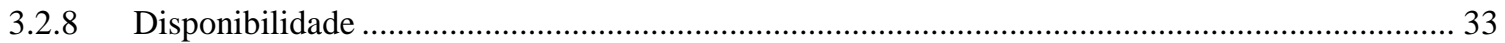

3.2.9 FMEA.

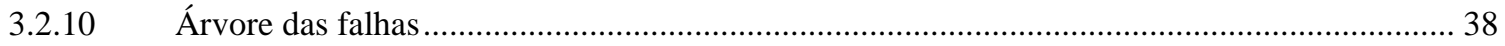

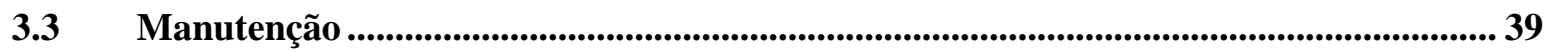

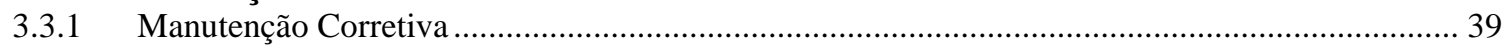

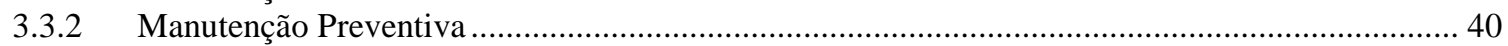

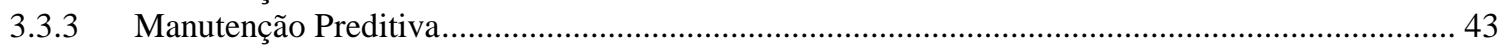

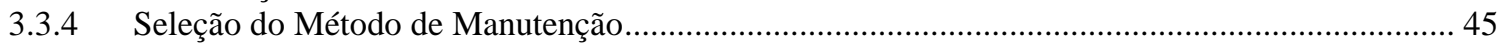

CAPÍTULO 4 - AVALIAÇÃO DA DISPONIBILIDADE PELO HISTÓRICO DE

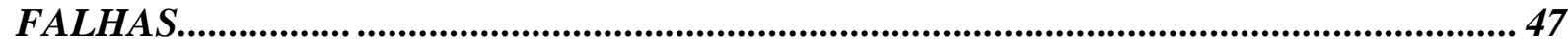

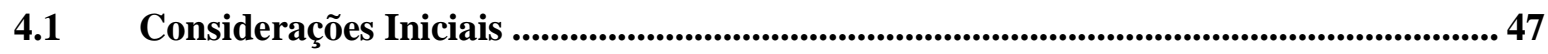

4.2 Montagem da Árvore Funcional do Sistema ................................................................. 47

4.3 Descrição da Filtragem dos Dados ............................................................................51

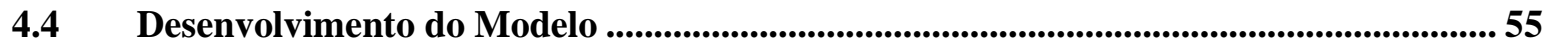

4.5 Determinação das Distribuições da Confiabilidade ......................................................59

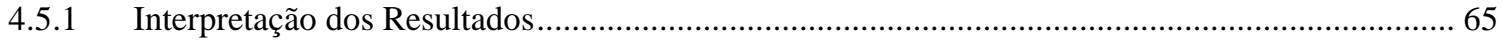

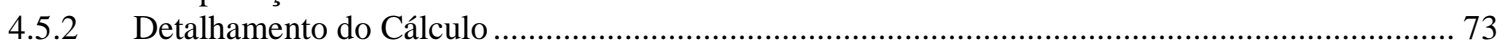

4.6 Determinação das Distribuições de Mantenabilidade ........................................................ 76

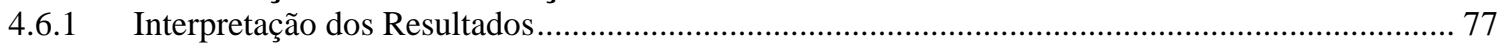

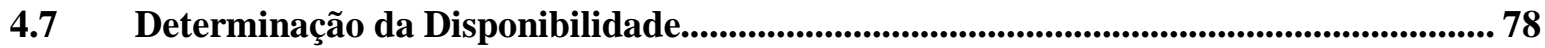

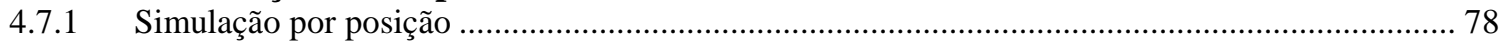

4.7.2 Simulação por posição e por máquina ............................................................................... 80

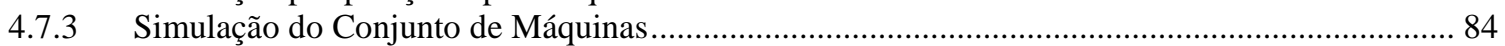

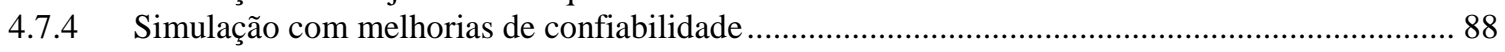

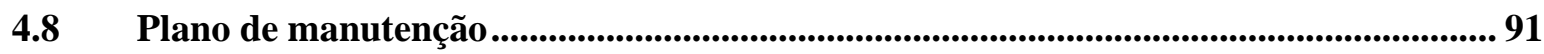




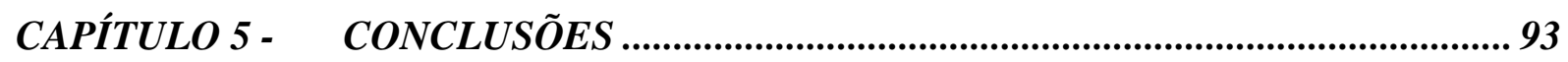

5.1 Conclusões e Recomendações................................................................................................93

5.2 Recomendações para Trabalhos Futuros ....................................................................95

CAPÍTULO 6 - REFERÊNCIAS BIBLIOGRÁFICAS ................................................97

APÊNDICE A - GRÁFICOS UTILIZADOS PARA DETERMINAÇÃO DAS DISTRIBUIÇÕES DE CONFIABILIDADE................................................................... 100

APÊNDICE B - GRÁFICOS UTILIZADOS PARA DETERMINAÇÃO DAS

DISTRIBUIÇÕES DE MANTENABILIDADE ............................................................... 115 


\section{CAPÍTULO 1 - INTRODUÇÃO}

\subsection{Considerações Iniciais}

Quando se avalia as políticas de manutenção de equipamentos industriais, percebese uma grande metamorfose ocorrida nos últimos 60 anos. Esta metamorfose pode ser dividida em 4 gerações, como mostrado na Figura 1-1. No período anterior à $2^{\mathrm{a}}$ Guerra Mundial, as indústrias eram pouco mecanizadas, com equipamentos simples e fáceis de reparar. Não havia método para predizer falhas, e a manutenção corretiva era a predominante.

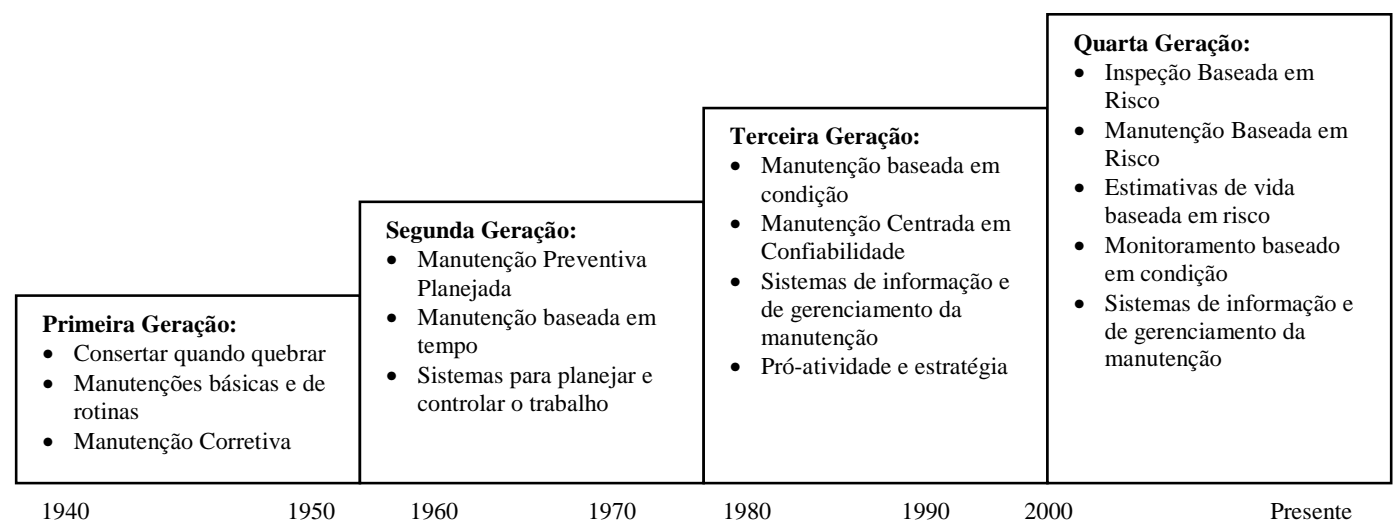

Figura 1-1 - Desenvolvimento das políticas de manutenção (ARUNRAJ, 2007).

No período entre o final da $2^{\mathrm{a}}$ Guerra Mundial e meados dos anos 70 as indústrias ficaram mais complexas, com grande dependência das máquinas, e o custo de manutenção cresceu proporcionalmente a outros custos operacionais. A manutenção preventiva era a predominante, mesmo que em certos casos pudesse impor reparos desnecessários, induzindo falhas a equipamentos que estavam funcionando normalmente.

Entre 1980 e 2000 as indústrias cresceram em complexidade, com maior uso de automação, produção just-in-time, maior demanda por qualidade e legislações mais rigorosas. Técnicas como manutenção preditiva e RCM (Reliability Centered Maintenance) começaram a ser utilizadas.

Desde 2000, têm ganho popularidade metodologias de manutenção que utilizam técnicas de risco em adição às técnicas de RCM e manutenção preditiva (KHAN e HADDARA, 2003; KHAN e HADDARA, 2004; KRISHNASAMY et al, 2005), muito 
embora estas metodologias tenham sido inicialmente propostas nos anos 90 (KUMAMOTO e HENLEY, 1991).

Nesta dissertação são abordados estudos relacionados à Confiabilidade e Disponibilidade de equipamentos, tema que surgiu nos meados da $2^{\mathrm{a}}$ Guerra Mundial como uma necessidade de avaliar a vida de equipamentos mais complexos. Desde então, a Confiabilidade passou a ser aplicada em indústrias nucleares, aeronáuticas, automobilísticas, e recentemente tem se espalhado para diversos outros segmentos da indústria, como químico ou telecomunicações. Colocada na figura acima, a Confiabilidade estaria na Terceira Geração, mas ainda hoje encontra campos totalmente inexplorados dentro da indústria, visto que nem todas estão no estado da arte da manutenção; e de fato existem indústrias onde a única manutenção praticada é a corretiva, ou seja, estariam na Primeira Geração.

O caso de estudo desta dissertação diz respeito a uma indústria têxtil, produtora de fios de nylon. Através das análises de Confiabilidade e Disponibilidade são propostas políticas de manutenção.

\subsection{Objetivo do Trabalho}

Este trabalho tem por objetivo a criação de um modelo para avaliação de disponibilidade para componentes de máquinas têxteis presentes no parque de empresas têxteis, avaliar este modelo com dados de campo e, a partir dos resultados deste modelo, dar direções para a elaboração de um plano de manutenção ótimo.

Isto é feito aplicando-se técnicas de análise estatística de confiabilidade e mantenabilidade a partir de dados de falha e reparo, e, a partir destas análises, a disponibilidade é avaliada computacionalmente através de simulações de Monte Carlo.

\subsection{Escopo do Trabalho}

Visando atingir os objetivos apresentados em 1.2, esta dissertação está dividida em seis capítulos. Após uma breve introdução ao estudo no Capítulo 1, no Capítulo 2 apresenta-se uma descrição da operação de uma máquina têxtil retorcedeira, juntamente com uma descrição dos principais sistemas e componentes. 
No Capítulo 3 são apresentados os principais conceitos de confiabilidade, algumas ferramentas de análise de confiabilidade de sistemas, e o método de cálculo de disponibilidade. São definidos também conceitos de manutenção, a relação entre a aplicação de técnicas de manutenção e a disponibilidade de sistemas.

No Capítulo 4 é apresentada a aplicação dos conceitos desenvolvidos no Capítulo 3, incluindo a apresentação da árvore funcional, a árvore de falhas, e análises e interpretações de confiabilidade, mantenabilidade e disponibilidade baseada no registro de dados de campo. Ainda no Capítulo 4, são feitas considerações a respeito dos resultados e são dadas diretrizes para a definição de políticas de manutenção. Finalmente, o Capítulo 5 apresenta as conclusões do trabalho e recomendações para trabalhos futuros, e o Capítulo 6 contém a bibliografia.

Os apêndices A e B mostram os gráficos utilizados para a definição das distribuições estatísticas de confiabilidade e mantenabilidade, respectivamente. 


\section{CAPÍTULO 2 - MÁQUINAS TÊXTEIS RETORCEDEIRAS}

\subsection{Considerações Iniciais}

O processo de produção dos fios têxteis de nylon tem origem com o petróleo, que é transformado em benzeno, e em seguida em cumeno. Este é transformado em Fenol e em seguida em ciclohexanol. Este, por sua vez, reage com ácido nítrico, que vem da amônia, formando o ácido adípico. $\mathrm{Na}$ outra ponta da cadeia, é formado o Hexametilenodiamina (HMD). Este é misturado ao ácido adípico, e o produto resultante é chamado de Sal Nylon. Num primeiro momento não há reação química entre estes dois componentes, mas sob condições adequadas a reação acontece, recebendo o nome de polimerização. O resultado é o polímero Nylon 6.6, também conhecido como Poliamida. Este processo está descrito em Avallone \& Baumeister (1995).

Dentro das indústrias têxteis, este polímero passa pelo processo conhecido como fiação, no qual o polímero é fundido e extrudado, de forma a compor fios. A seguir estes fios são enrolados em bobinas, e passam pelo processo de estiragem, onde são estirados com deformação plástica até seu comprimento máximo, de tal forma que na sua aplicação a deformação plástica possível seja mínima. Este dois processos, fiação e estiragem, podem ser feitos separadamente ou, nas máquinas mais modernas, em uma única etapa.

Para aplicações onde se exija resistência mecânica dos fios, podem ocorrer ainda os processos de torção e retorção. A torção consiste em torcer um fio ao redor do seu próprio eixo, de tal forma que não seja possível separar de um fio os diversos filamentos que o compõem. A retorção consiste em torcer dois fios já torcidos um contra o outro, formando o chamado cordonel duplo. Estas duas etapas conferem resistência mecânica ao produto.

Todo este ciclo está ilustrado na Figura 2-1. 


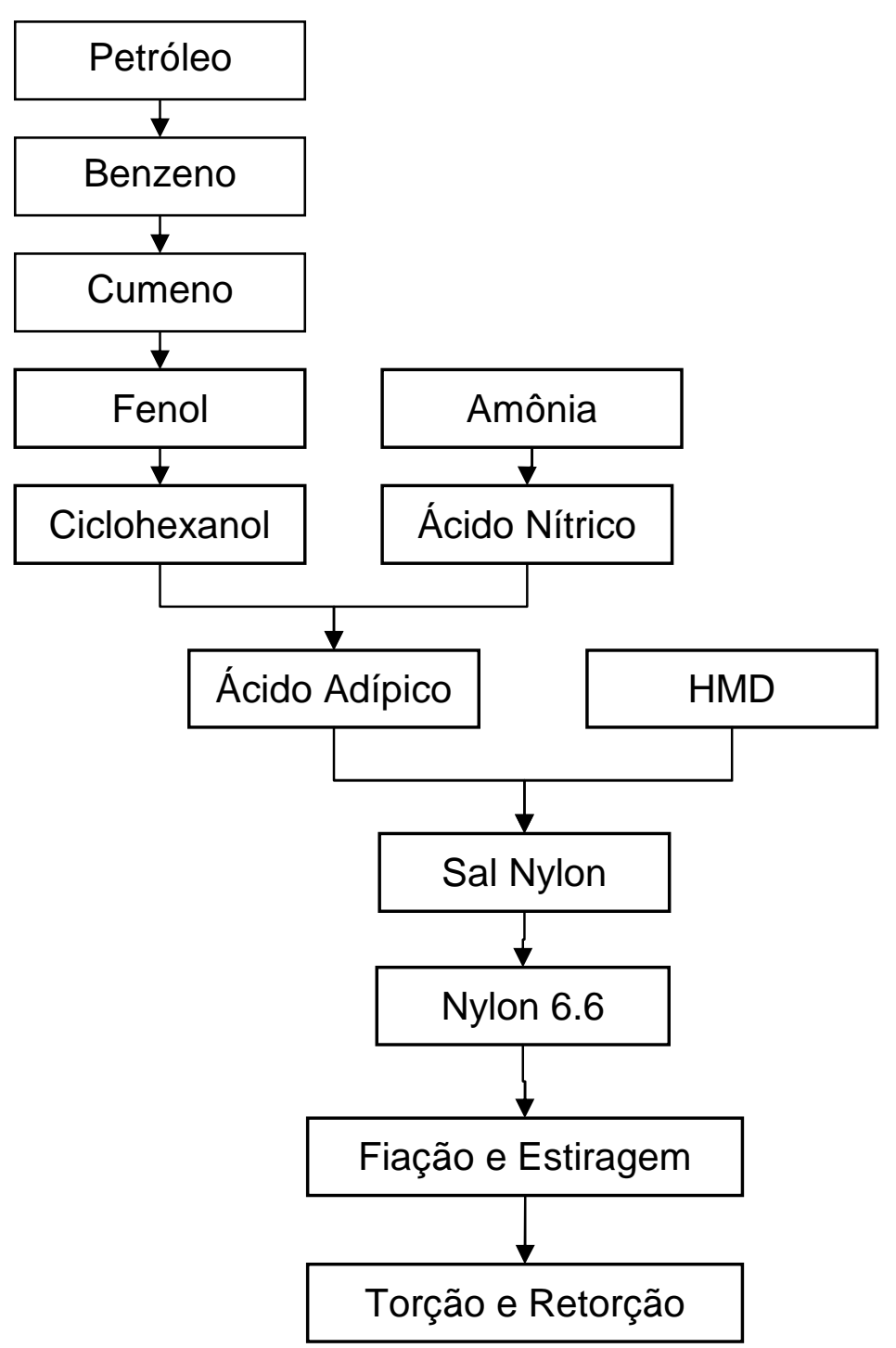

Figura 2-1 - Fluxograma do processo de produção do Nylon.

As máquinas que são estudadas nesta dissertação realizam o processo de retorção, e são conhecidas como retorcedeiras. A Figura 2-2 é uma fotografia da uma das máquinas em seu local de instalação. 


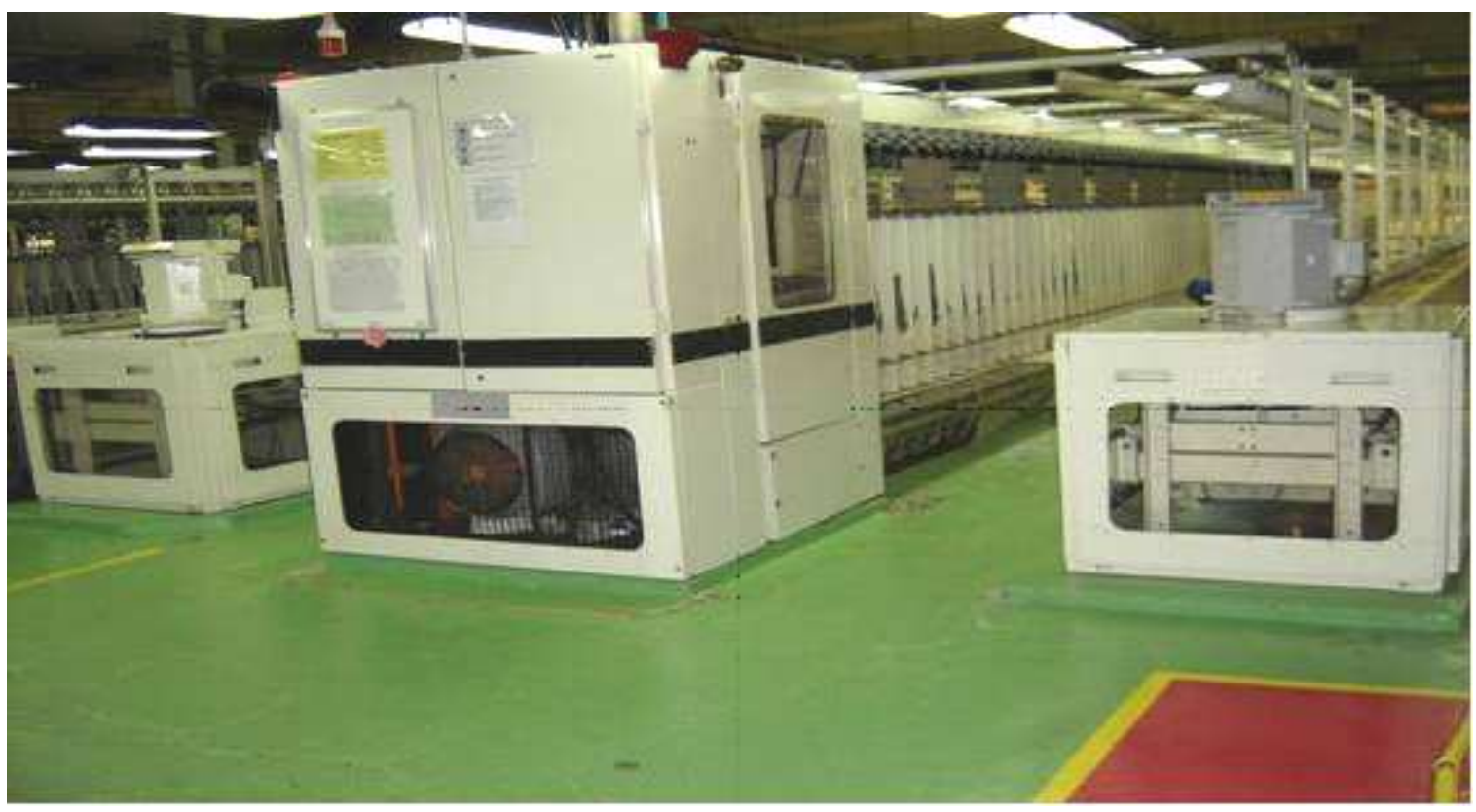

Figura 2-2 - Máquinas no local de instalação.

\subsection{Funcionamento de Máquinas Têxteis Retorcedeiras}

Cada uma das máquinas retorcedeiras é formada por 168 posições, e em cada uma delas um carretel de cordonel duplo é formado. A Figura 2-3 ilustra uma dessas posições. Os dois carretéis à esquerda da figura são de fios que serão desenrolados. Este lado da máquina é conhecido como Filage, que em francês significa fiação. Os fios desenrolados seguem para a parte superior da posição através de guias, conhecidos como rabos de porco, e são enrolados novamente no carretel à direita da figura, no lado da máquina conhecido como Retordage, que em francês significa torção. Durante o enrolamento na Retordage, os dois fios singelos são torcidos entre si, dando origem ao cordonel duplo. Miao \& Chen (1993) descrevem detalhadamente o processo de retorção.

Antes de serem enrolados, os fios passam ainda por um anel giratório, que acompanha a rotação do fuso, e que, através de um movimento vertical cíclico, posiciona o fio de maneira uniforme no carretel.

Quando o carretel com cordonel duplo atinge o peso necessário, a máquina é parada, os carretéis cheios são retirados, e novos carretéis vazios são colocados. Este processo é feito manualmente. Do lado da Filage, os dois carretéis são trocados quando estão vazios, e são substituídos por mais dois carretéis cheios com fios singelos, de modo 
que o ciclo possa recomeçar. Para cada par de carretéis colocados na Filage, são produzidos dois carretéis na Retordage.

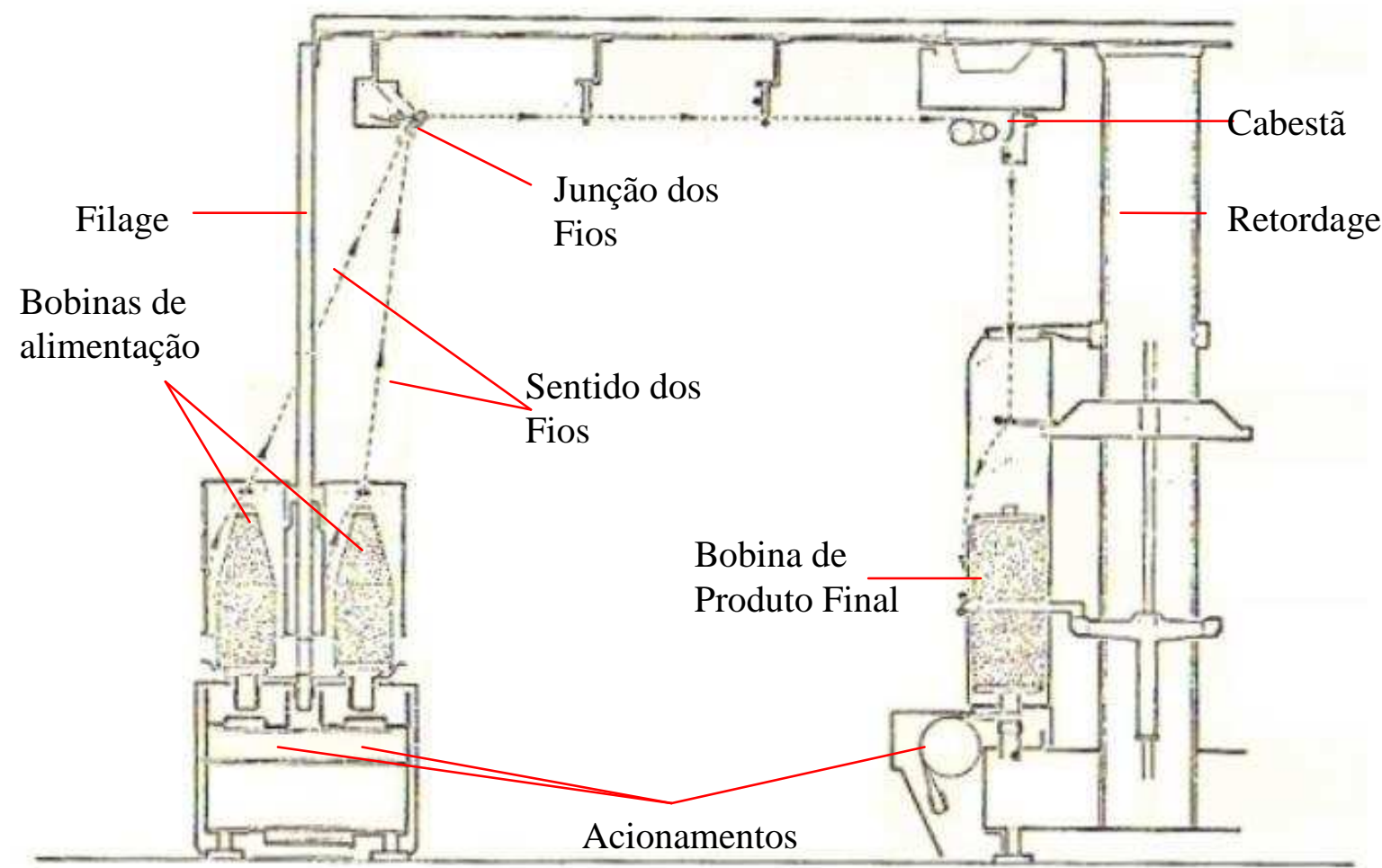

Figura 2-3 - Esquema de funcionamento da máquina.

Para que seja feita a alimentação dos fios da Filage para a Retordage, os carretéis são posicionados sobre fusos, que giram na Filage a 5600 rpm, e na Retordage à 6400 rpm. Essa diferença de velocidades faz com que o fio tenha um pequeno estiramento durante este processo. Outro componente, conhecido como cabestã, contribui para a alimentação dos fios para a Retordage, e também para mantê-los esticados durante o processo. $\mathrm{O}$ cabestã é composto por duas polias nas quais os fios dão algumas voltas, e são acionadas por um par de engrenagens, por sua vez acopladas a um eixo que percorre a máquina toda, que são acionados pelos motores na cabeceira da máquina.

Na Filage, os fusos e carretéis ficam dentro de potes individuais, que evitam a possibilidade de contato entre os fios de diferentes fusos. Na Retordage, essa separação é feita através de um componente conhecido como para-balão, que consiste numa placa colocada entre dois fusos, de material e rugosidade adequados, para que não danifique o fio. 
O acionamento desses fusos é comum a todos os fusos de um mesmo lado da máquina: do lado da Filage o acionamento se dá por uma correia tangencial aos fusos, que por sua vez é acionada por um motor na cabeceira da máquina; do lado da Retordage a transmissão é feita por um eixo que percorre toda a extensão da máquina e possui polias individuais com correias individuais para cada uma das posições. Estas correias são conhecidas como correias cadarço.

Cada posição também possui um sistema de freio. Os freios são acionados em uma posição quando não há fios sendo retorcidos. Isto se dá em duas ocasiões: quando os carretéis da Filage estão vazios, e é o momento de trocá-los, ou quando, por algum motivo, acontece uma quebra do fio durante o processo de retorção.

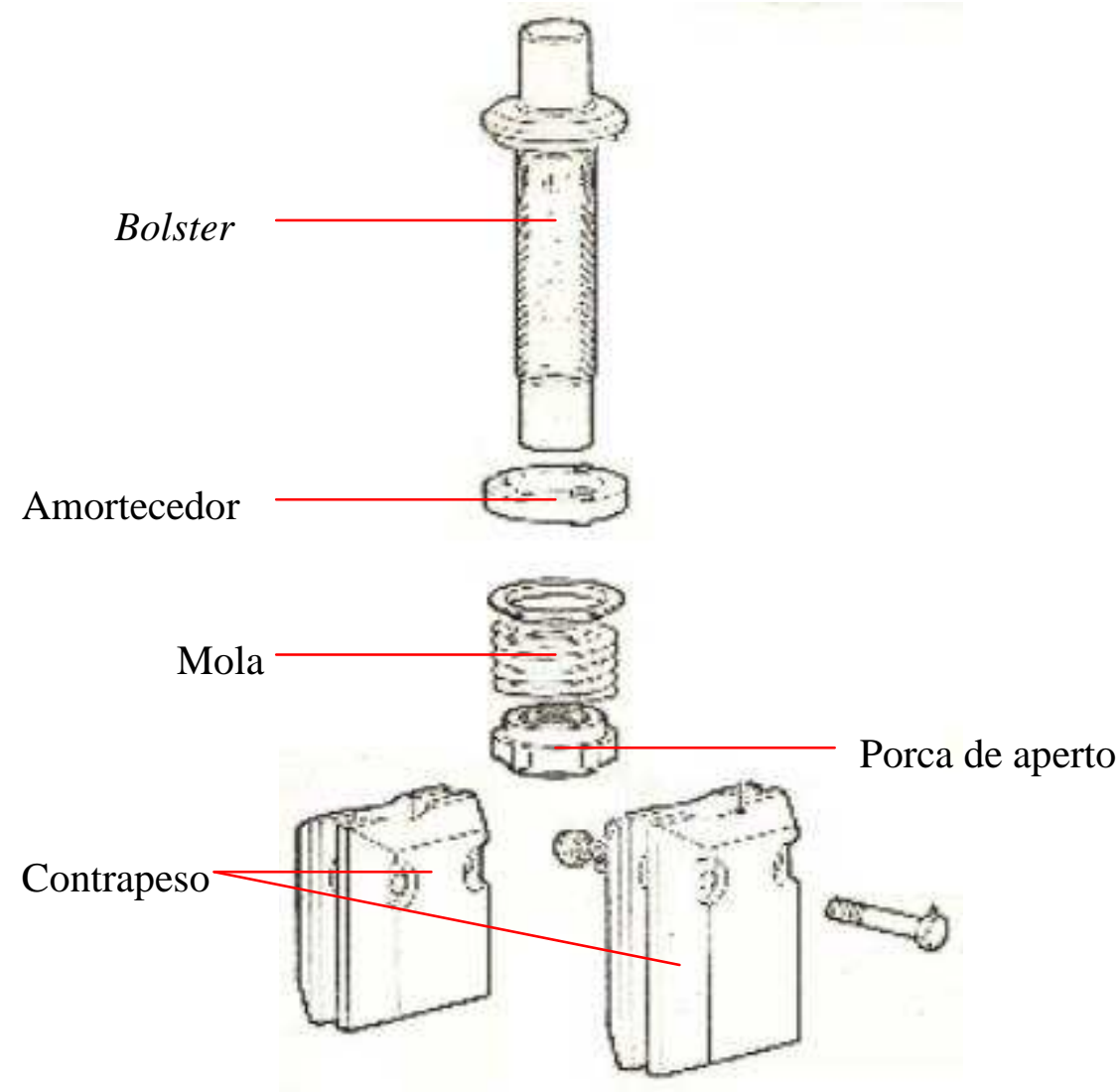

Figura 2-4 - Desenho de montagem de um bolster e peças que compõe o conjunto: amortecedor, mola, porca de aperto, contrapeso.

Cada fuso é sustentado por um mancal conhecido como bolster, que em inglês significa suporte. A Figura 2-4 mostra um bolster e todas as peças acopladas a ele, que, montados adequadamente, garantem o mínimo de vibração. Em seu interior, cada bolster 
possui no topo um rolamento de agulhas que utiliza como pista interna a própria superfície do fuso. No fundo do bolster, a ponta cônica do fuso fica posicionada em uma cunha que funciona como um mancal de deslizamento de escora, sustentando todo o peso do fuso e mais o carretel que está sendo enrolado ou desenrolado. A Figura 2-5 mostra um fuso montado em um bolster em corte, com indicação de todas as partes internas. 


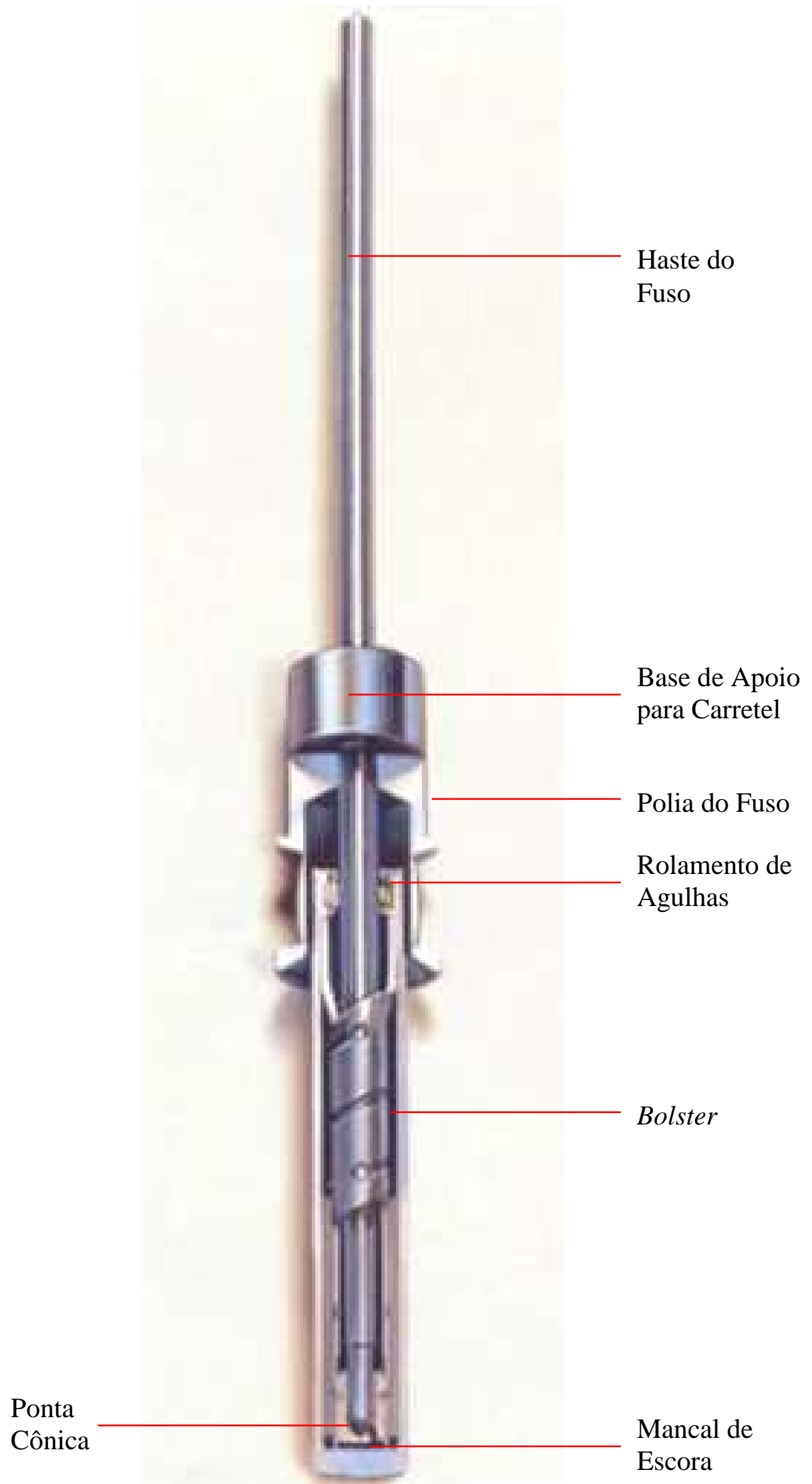

Figura 2-5 - Fuso e Bolster em corte, com a indicação das partes internas (Spindelfabrik Neudorf, 2004). 


\section{CAPÍTULO 3 - PRINCÍPIOS DE CONFIABILIDADE}

\subsection{Considerações Iniciais}

O estudo da Engenharia da Confiabilidade teve seu início nos meados da $2^{\text {a }}$ Guerra Mundial. Em função do desenvolvimento de armamentos de maior complexidade, a indústria bélica passou a necessitar de meios que permitissem estimar a vida ou mesmo a probabilidade de um equipamento operar com sucesso.

Depois do final da $2^{\mathrm{a}}$ Guerra, com o desenvolvimento da energia nuclear, a confiabilidade começou a ser aplicada na redução da probabilidade de falha de sistemas de controle de usinas geradoras dessa energia.

Na década de 70, os conceitos de confiabilidade começaram a ser aplicados no desenvolvimento de projetos estruturais complexos, nos quais uma falha poderia trazer como conseqüências a perda de vida humanas, danos ambientais, além de perdas econômicas elevadas. É possível citar como exemplo as estruturas civis, oceânicas e aeronáuticas (SOUZA, 2003).

No mercado atual, com crescentes exigências por melhores desempenho e menor preço, as empresas têm tomado diversas atitudes para se manterem competitivas, atendendo estas exigências e reduzindo seus custos. Dentre essas atitudes, está a utilização da confiabilidade como forma de reduzir as probabilidades de falha.

Para a análise de engenharia é necessário definir a confiabilidade como uma probabilidade. Assim, uma definição possível é de que a confiabilidade é a probabilidade de um produto, sistema, máquina ou equipamento operar sem falha por um período de tempo determinado (SOUZA, 2003).

Uma falha de um produto ou sistema ocorre quando este para de realizar a função desejada. Quando a função é totalmente interrompida, um motor que para de girar, por exemplo, o sistema claramente falhou. Entretanto, freqüentemente é necessário definir a falha quantitativamente de modo a ser possível considerar formas mais sutis de falha, como devido a deterioração ou instabilidade no desempenho da função (LEWIS, 1996).

Assim, é necessária uma definição clara de um critério de falha, possibilitando 
determinar com clareza a partir de qual momento o equipamento é considerado com desempenho abaixo do aceitável, ou seja, em falha (CARAZAS, 2006).

\subsection{Conceitos de Confiabilidade}

\subsubsection{Conceitos Básicos}

A confiabilidade $R(t)$ é definida como a probabilidade de que um sistema sobreviva por pelo menos o período de tempo $t$ (LEWIS, 1996):

$$
R(t)=\left\{\begin{array}{l}
\text { Probabilidade de um sistema } \\
\text { operar sem falha por um tempo } t
\end{array}\right\}
$$

Sendo $T$, variável aleatória, o tempo até ocorrer a falha, pode-se definir sua correspondente função densidade de probabilidade $f(t)$ como sendo:

$$
f(t) \cdot \Delta t=P\{t<T<t+\Delta t\}
$$

Sendo $F(t)$ a função probabilidade acumulada, tem-se que:

$$
F(t)=(T<t)
$$

ou seja, $F(t)$ expressa a probabilidade da falha ocorrer até um tempo $t$, enquanto $f(t)$ representa a função densidade de probabilidade da falha.

$F(t)$ é crescente no tempo, atingindo valor unitário quando $t$ tende a infinito, como mostra a Figura 3-1. 


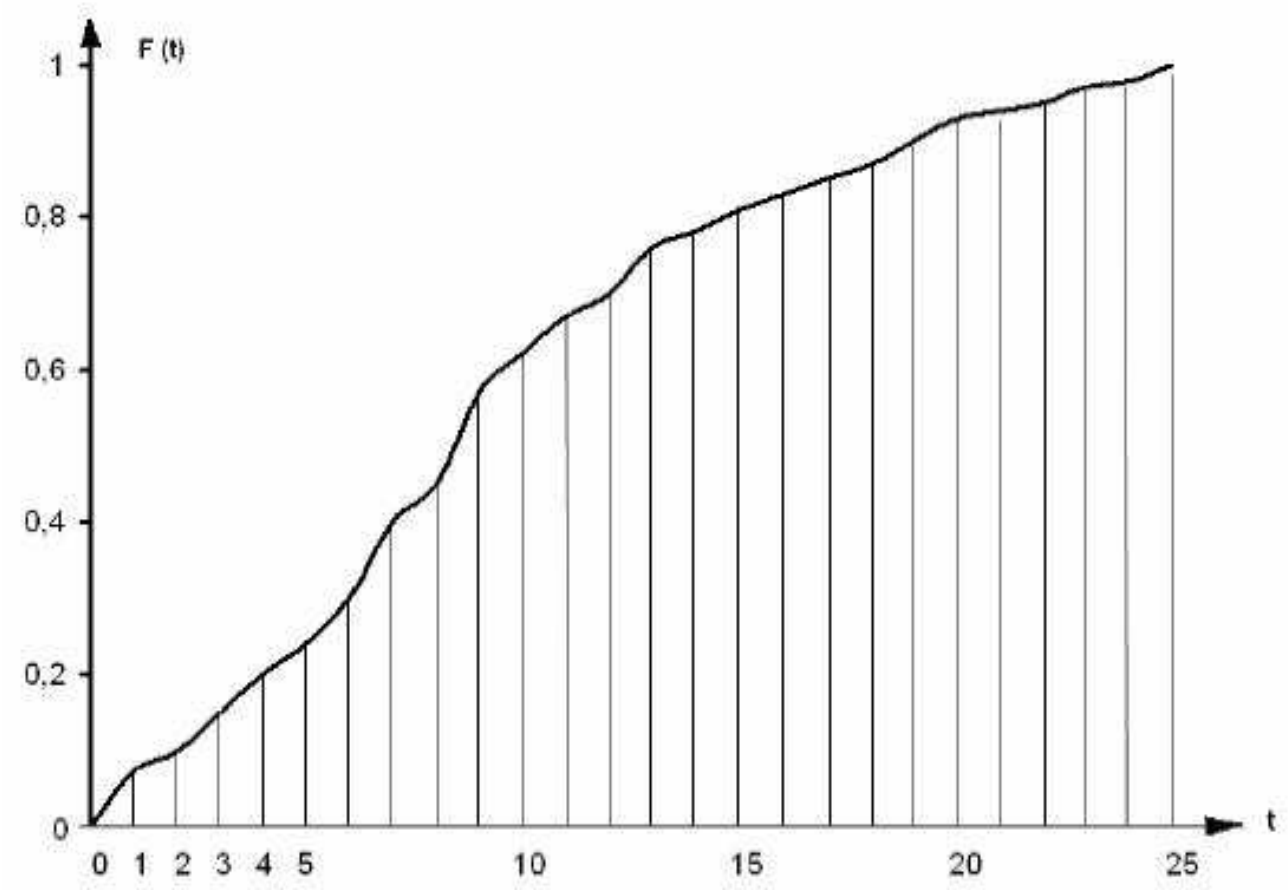

Figura 3-1 - Função de Probabilidade Acumulada F(t) (LEITCH, 1995).

Uma vez que haja um critério objetivo para definição da falha, considera-se que o estado de falha e o estado de operação adequada são mutuamente excludentes. Sendo assim, a confiabilidade pode ser expressa por:

$$
\begin{gathered}
R(t)=P(T>t) \\
F(t)=1-R(t)
\end{gathered}
$$

A Figura 3-2 mostra a função confiabilidade.

Como decorrência desta definição, tem-se que:

$$
\begin{gathered}
R(0)=1 \\
R(\infty)=0
\end{gathered}
$$




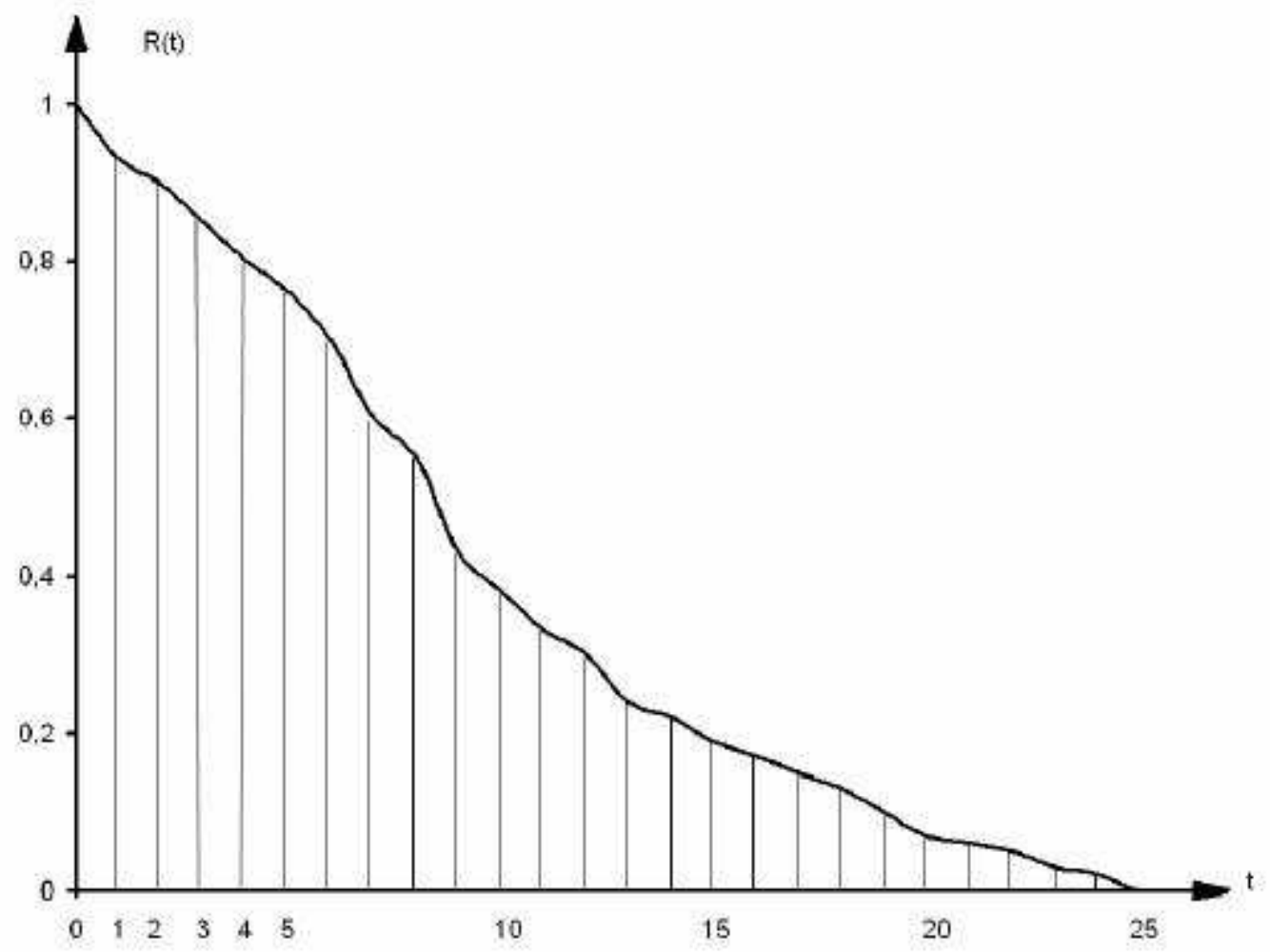

Figura 3-2 - Função de Confiabilidade R(t) (LEITCH, 1995).

$R(t)$ e $f(t)$ são relacionados pela seguinte relação:

$$
f(t)=-\frac{d}{d t} R(t)
$$

$f(t)$ representa a probabilidade de a falha ocorrer num período de tempo específico.

A partir do gráfico apresentado no Figura 3-2 verifica-se, portanto, que a confiabilidade de um produto ou sistema apenas decai ao longo do tempo, ou seja, quanto maior o tempo de operação do mesmo, maior será a probabilidade de apresentar falha. Portanto, apenas no instante em que o equipamento é colocado em operação, sua confiabilidade é de $100 \%$. Adicionalmente, pode-se afirmar que a confiabilidade não é restaurada, ou seja, não dá saltos ao longo da vida operacional, já que há uma degradação contínua do componente ou sistema (SOUZA, 2003).

O comportamento de determinado produto com relação à falha é melhor compreendido pelo exame do comportamento de sua taxa de falha. Esta taxa de falha, $\lambda(t)$, pode ser definida como sendo a probabilidade de que, tendo o equipamento trabalhado 
sem falha até o ciclo $t$ - 1 , ele apresente falha no ciclo $t$. Também pode ser definida como se segue (LEWIS, 1996):

"Sendo $\lambda(t) \Delta t$ a probabilidade de que o sistema falhará em um tempo $T<t+\Delta t$, dado que ainda não falhou até o tempo $T=t$, tem-se que $\lambda(t) \Delta t$ é a probabilidade condicional:"

$$
\lambda(t) \Delta t=P(T<t+\Delta t \mid T>t)
$$

Assim, com base na definição de probabilidade condicional (COSTA NETO, 2005), tem-se:

$$
P(T<t+\Delta t \mid T>t)=\frac{P\{(T>t) \cap(T<t+\Delta t)\}}{P(T>t)}
$$

Como o numerador da equação (3.10) é a própria $f(t)$, e o denominador é a $R(t)$, a taxa de falhas instantânea é expressa por:

$$
\lambda(t)=\frac{f(t)}{R(t)}
$$

\subsubsection{A Curva da Banheira}

O comportamento da taxa de falha $\lambda(t)$ pode ser usado como indicador da causa das falhas (LEWIS, 1996). A curva da banheira ("The Bathtub Curve"), ilustrada na Figura 3-3, representa graficamente esta relação para sistemas ou componentes sem redundâncias. 


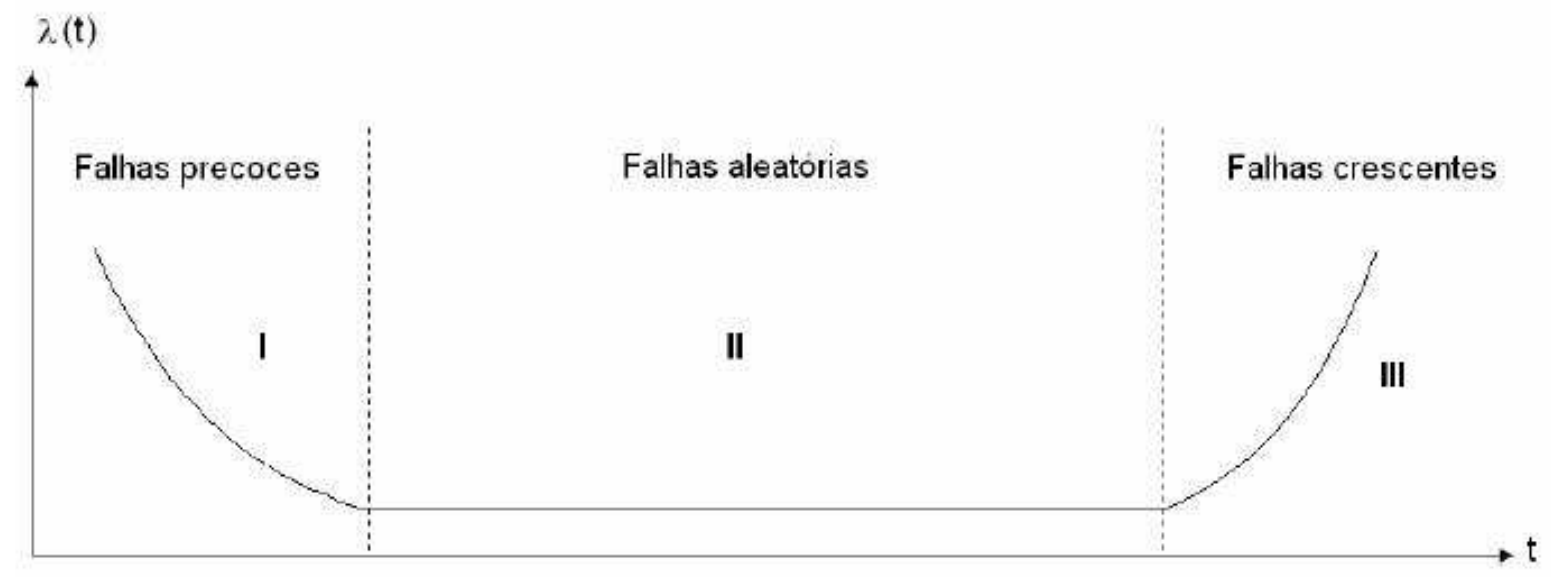

Figura 3-3 - Representação da Curva da Banheira (CARAZAS, 2006).

O primeiro intervalo da curva Figura 3-3 apresenta uma taxa de falha que decresce a partir de $t=0$. Esta região denomina-se de falhas precoces ou, em analogia com seres humanos, de mortalidade infantil. Sob esta analogia, as mortes nesse período são causadas por defeitos congênitos ou fraquezas.

Normalmente, as falhas precoces estão relacionadas com problemas de fabricação, de montagem ou mesmo com o material empregado na fabricação do componente. Estes problemas não são usuais, ou seja, ocorrem esporadicamente, muitas vezes por razões não especificadas. No caso de montagens, é bastante comum a falha estar relacionada a algum erro humano (SOUZA, 2003).

O segundo intervalo da curva contém o período de falha aleatória. Neste intervalo, a taxa de falha é constante. As falhas aqui normalmente ocorrem devido a carregamentos inesperados, não tanto devido a defeitos inerentes ao equipamento em si.

O terceiro e último intervalo da curva mostra o período em que a taxa de falha cresce por envelhecimento, onde fenômenos como desgaste e fadiga passam a ser relevantes. Esta fase é apresentada pela maioria dos sistemas mecânicos.

A curva da banheira é uma representação bastante genérica, já que cada categoria de equipamentos apresenta uma curva característica. Por exemplo, em sistemas eletroeletrônicos a ocorrência de falhas é dominada pelas regiões I e II. Ou seja, o fenômeno de envelhecimento não é relevante. Já em componentes mecânicos, as regiões I e III dominam (SOUZA, 2003). 


\subsubsection{Tipos de Dados}

A análise de dados é uma ferramenta crucial no estudo da confiabilidade. Mais que auxiliar esse estudo, ela é a ferramenta de validação e aprovação do mesmo. Os registros utilizados podem vir de testes realizados em bancos de provas, constituindo a primeira fonte de informação sobre a confiabilidade dos produtos.

Estes dados são obtidos sob condições controladas, o que permite avaliar alguns parâmetros de confiabilidade relevantes, porém os realizados em bancada são caros e podem não representar, em alguns casos, a situação de solicitação encontrada em campo, principalmente quando o efeito do usuário influencia demasiadamente a magnitude da solicitação (LEMES, 2006).

Outra fonte de registros relevantes para o estudo de confiabilidade são os dados obtidos em campo. Estes dados evidenciam o histórico do equipamento em sua íntegra, lidando com dados reais e apresentando dados de falha de cada produto vendido, sistemas críticos que apresentaram falhas em campo e ações tomadas para conserto dessas falhas, além de apresentarem também os defeitos alegados pelos usuários e os realmente encontrados pelo técnico que executa o reparo.

Os dados ainda podem ser classificados em dados suspensos ou dados completos.

\subsubsection{Dados suspensos}

Dados suspensos ou censurados são obtidos quando, ao fim do ensaio realizado, existem ainda equipamentos ou sistemas que não falharam, ou quando a falha ocorreu devido a um modo de falha diferente do que é estudado. Este tipo de dado é mais comum quando utiliza-se registro de avaliações de campo ou de dados de garantia para a análise da confiabilidade, pois, geralmente, nem todos os equipamentos produzidos e em uso no mercado apresentaram falhas, ao final do período de tempo definido para coleta de dados. Ou seja, ainda existem equipamentos funcionando perfeitamente, que devem contribuir para a análise de confiabilidade. Se os dados suspensos não forem considerados, há uma falha na análise, pois assume-se erroneamente que todos os equipamentos ou sistemas falharam (LEMES, 2006). 
A Figura 3-4 representa graficamente o conceito de dados suspensos ou censurados. Nota-se na figura que os itens 1 e 3 continuam em operação ao final do período pré-definido para coleta de dados de falha, sendo assim considerados como amostras suspensas ou censuradas.

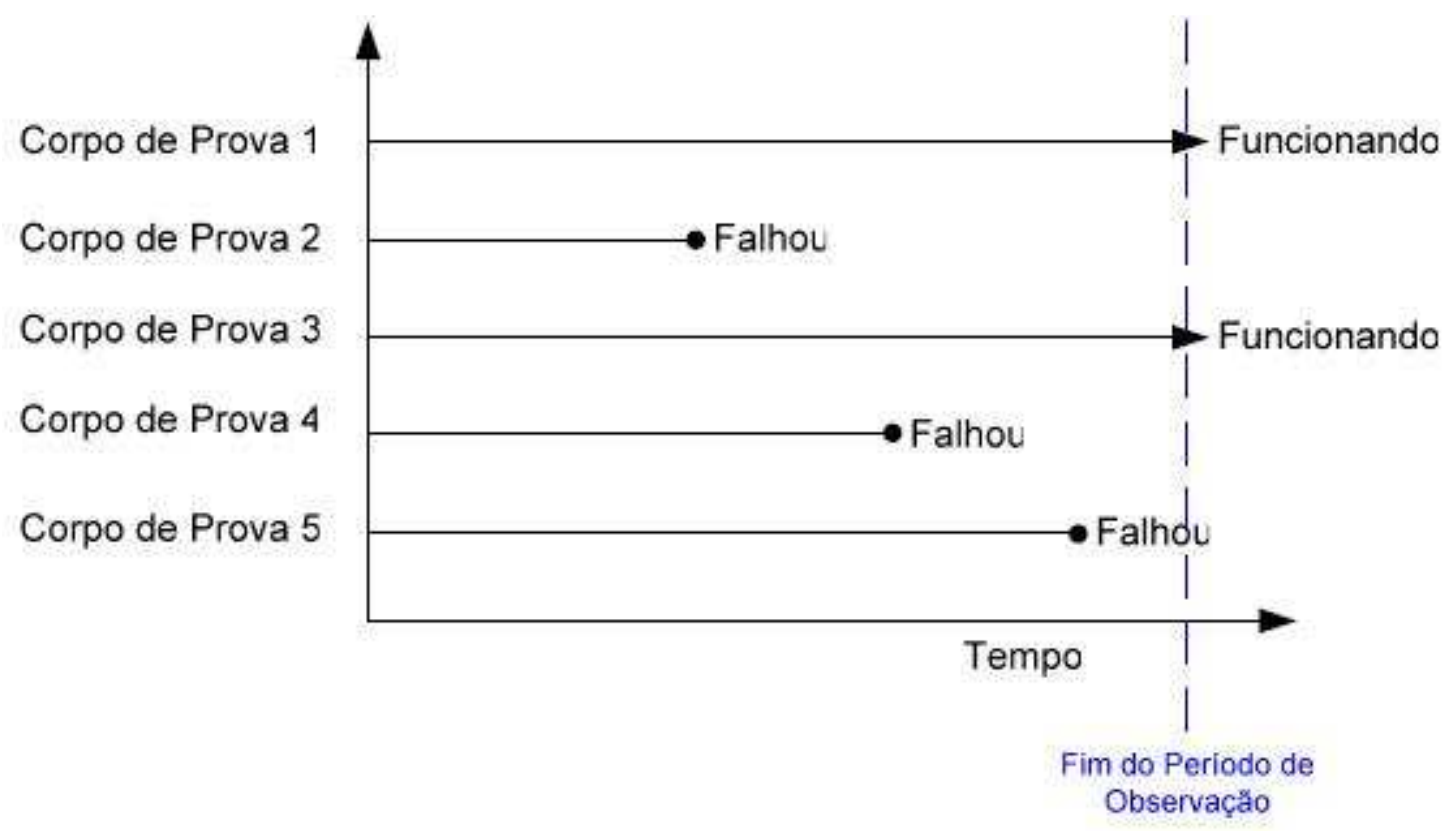

Figura 3-4 - Dados suspensos ou censurados (LEMES, 2006).

\subsubsection{Dados Completos}

Um dado é considerado completo quando se conhece o tempo exato até a falha. Segundo Nelson (1982), o valor do tempo até a falha de cada elemento da amostra é observado e conhecido e, portanto, torna-se mais precisa a determinação dos parâmetros das funções de confiabilidade. 


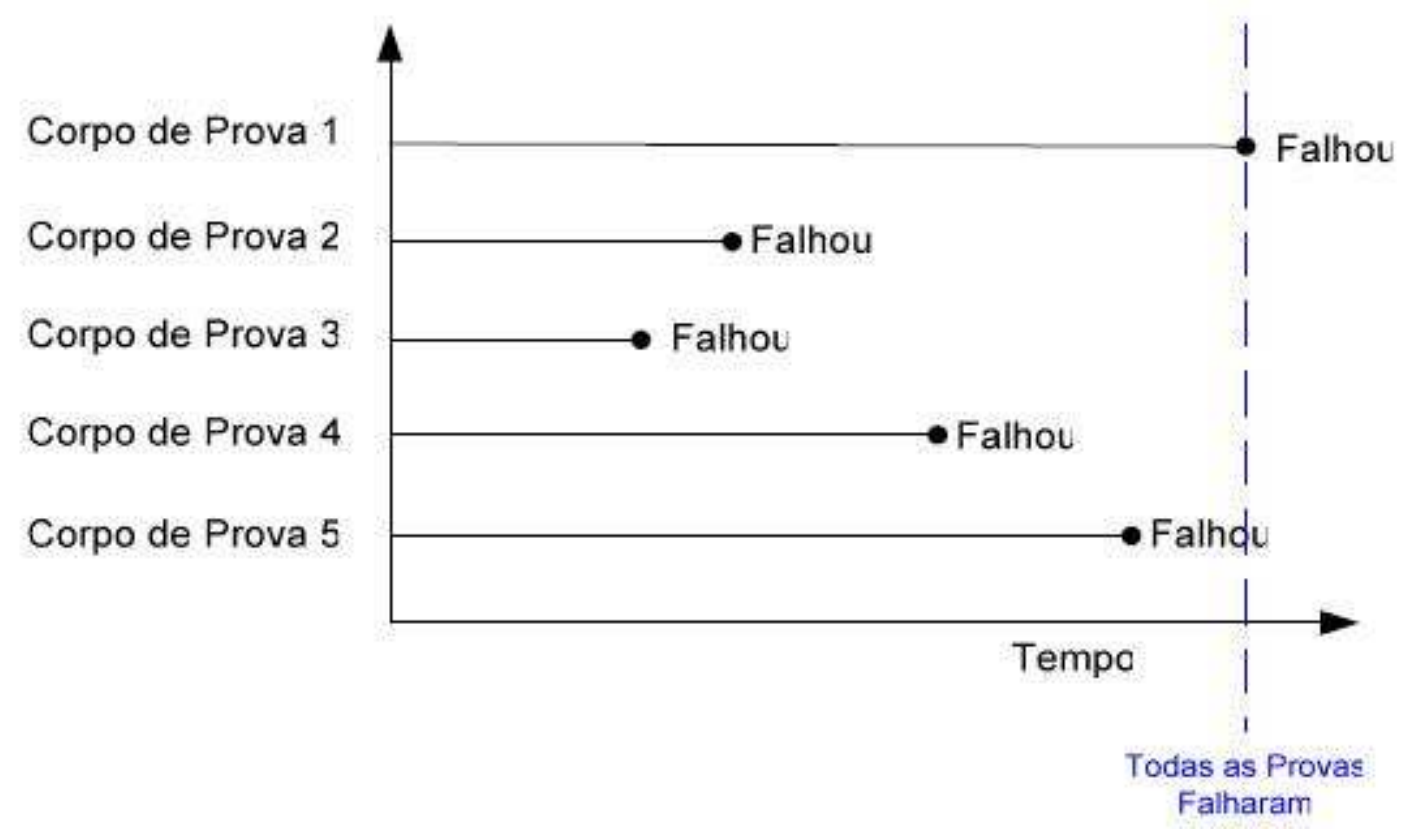

Figura 3-5 - Dados completos (LEMES, 2006).

\subsubsection{Principais Distribuições em Confiabilidade}

Dependendo do sistema a ser estudado, $f(t)$ é representada por uma distribuição estatística diferente. De acordo com Souza (2003) as distribuições mais utilizadas para representar $f(t)$ são Normal, Lognormal, Exponencial e Weibull. Em casos específicos, que não serão tratados neste texto, outras distribuições podem ser usadas. Por exemplo, Lewis (1996) cita que distribuições de valor extremo, como as distribuições de Gumbel podem ser as mais indicadas em situações onde o número de variáveis envolvidas é muito grande.

\subsubsection{Distribuição Normal}

A distribuição Normal representa um conjunto de dados cuja taxa de falha é crescente no tempo, e é usada para representar erros de medição, variabilidade dimensional, e algumas propriedades mecânicas. É representada pela equação:

$$
f(t)=\frac{1}{\sqrt{2 \pi} \sigma} \exp \left[-\frac{1}{2}\left(\frac{t-\mu}{\sigma}\right)^{2}\right]
$$

onde: 
$\sigma:$ Desvio padrão de $t$

$\mu:$ Média de $t$

A Figura 3-6 mostra os gráficos que representam esta distribuição.
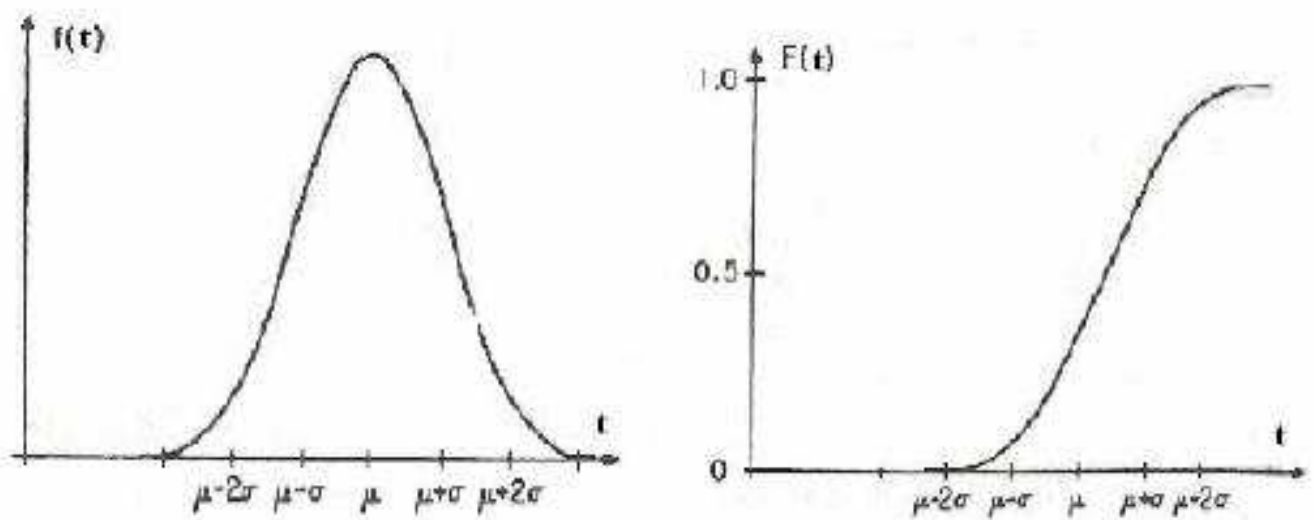

Figura 3-6 - Funções densidade de probabilidade e probabilidade acumulada para a distribuição normal (NELSON, 1982).

\subsubsection{Distribuição Lognormal}

Uma variável aleatória tem distribuição Lognormal quando o logaritmo desta variável tem distribuição Normal. A Lognormal representa dados cuja taxa de falha é crescente e depois decrescente, e é usada para representar principalmente resistência mecânica dos materiais e fadiga. É representada pela equação:

$$
f(t)=\frac{1}{\sqrt{2 \pi} \sigma t} \exp \left[-\frac{1}{2 \sigma^{2}}\left(\ln t-\ln t_{0}\right)^{2}\right]
$$

onde:

$t_{0}:$ mediana de $t$

A Figura 3-7 mostra os gráficos que representam a distribuição Lognormal. 


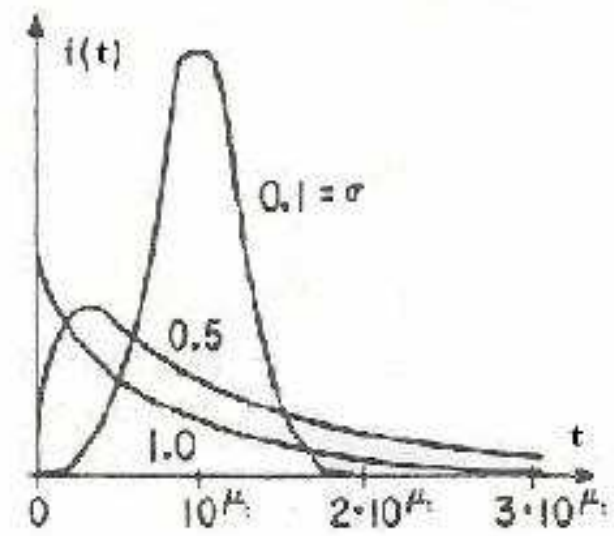

Densidade de Probabilidade de Falha

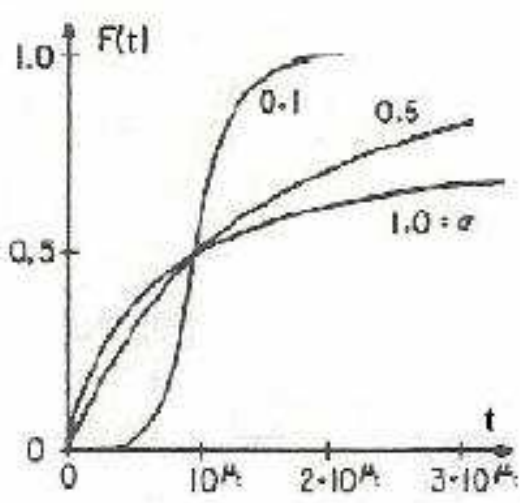

Distribuç̧âo Acumulada

Figura 3-7 - Funções densidade de probabilidade e probabilidade acumulada para a distribuição lognormal (NELSON, 1982).

\subsubsection{Distribuição Exponencial}

A distribuição Exponencial representa dados cuja taxa de falha é constante, e é a distribuição típica de componentes eletro-eletrônicos. É representada pela equação:

$$
f(t)=\lambda e^{-\lambda t}
$$

onde:

$\lambda$ : taxa de falha constante, equivale ao inverso do $M T B F$ (tempo médio entre falhas)

A Figura 3-8 mostra os gráficos que representam essa distribuição.

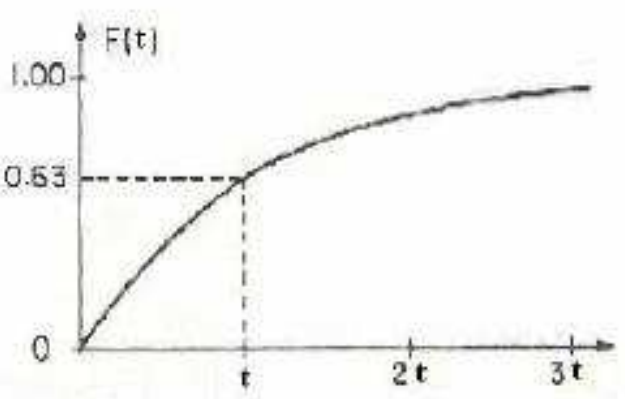

Distribuição Acuunulada

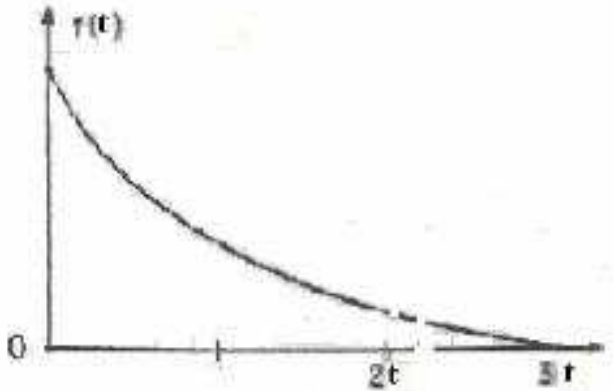

Densidade de Probabilidade de Falla

Figura 3-8 - Funções densidade de probabilidade e probabilidade acumulada para a distribuição exponencial (NELSON, 1982) 


\subsubsection{Distribuição de Weibull}

A distribuição de Weibull tem esse nome pois proposta pelo pesquisador sueco Weibull em 1951 (SOUZA, 2003). É representada pela equação:

$$
f(t)=\frac{\beta}{\eta}\left(\frac{t-t_{0}}{\eta}\right)^{\beta-1} \exp \left[-\left(\frac{t-t_{0}}{\eta}\right)^{\beta}\right]
$$

onde:

$t_{0}$ : Constante de localização. Define a posição em que a função densidade de probabilidade tem origem.

$\eta$ : Constante de escala. Define o espalhamento da distribuição ao longo do eixo das abscissas. É igual ao tempo no qual a probabilidade de falha é de $63,2 \%$.

$\beta$ : Constante de forma.

Pela variação dos seus 3 parâmetros, uma Weibull pode tomar a forma de qualquer uma das três distribuições anteriores, e variações entre elas. Ultimamente tem se firmado como a distribuição mais usada em estudos de confiabilidade.

Tendo $t_{0}$ e $\eta$ fixos, a forma da função densidade de probabilidade de Weibull é bastante dependente de $\beta$, como se pode ver na Figura 3-9. Observando-se essa figura, tem-se:

- Para valores de $\beta<1$, a função densidade de probabilidade é decrescente para um aumento de $t$.

- $\quad \beta=1$, a Weibull torna-se a própria distribuição exponencial

- $\quad \beta>1$, a função densidade de probabilidade apresenta picos bem definidos.

- $\quad \beta=3,44$, a Weibull aproxima-se muito da distribuição Normal, onde a mediana é igual à média. 


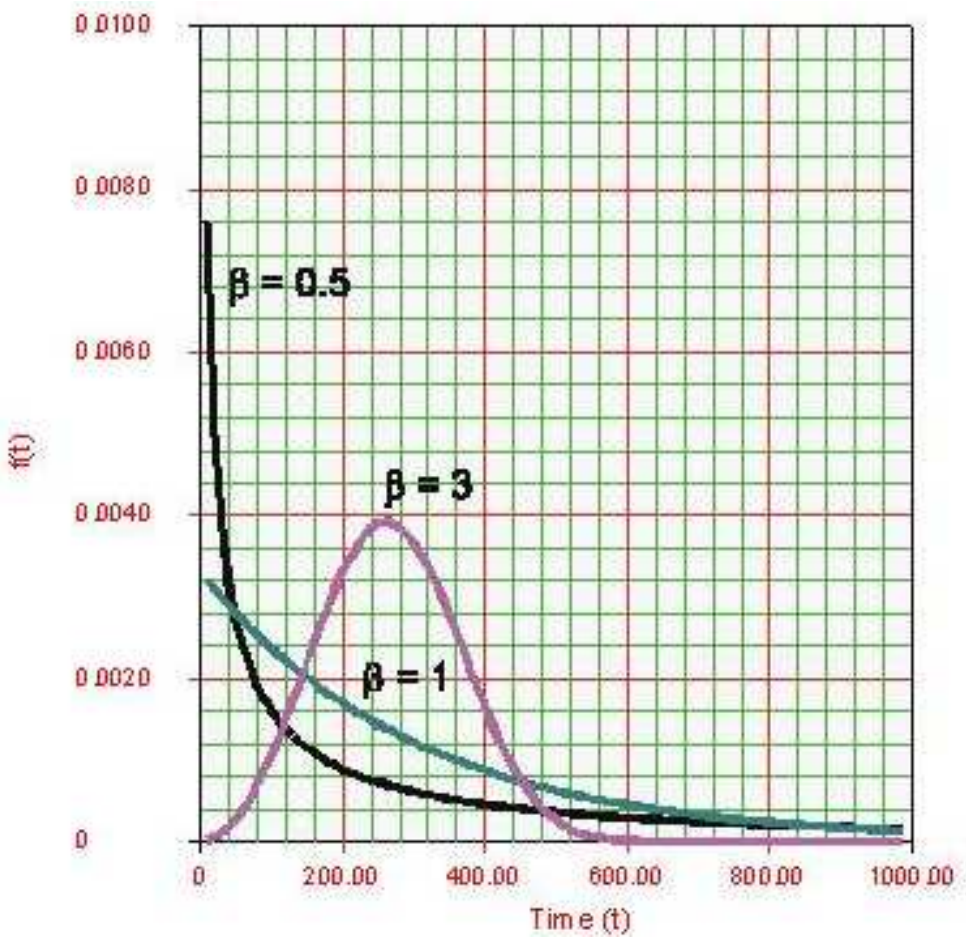

Figura 3-9 - Variação de uma $f(t)$ de Weibull em função do parâmetro $\beta$ (RELIASOFT, 2005).

Se, ao invés de $\beta$, modificar-se $\eta$, fixando $\beta$ e $t_{0}$, tem-se que a variação mostrada na Figura 3-10.

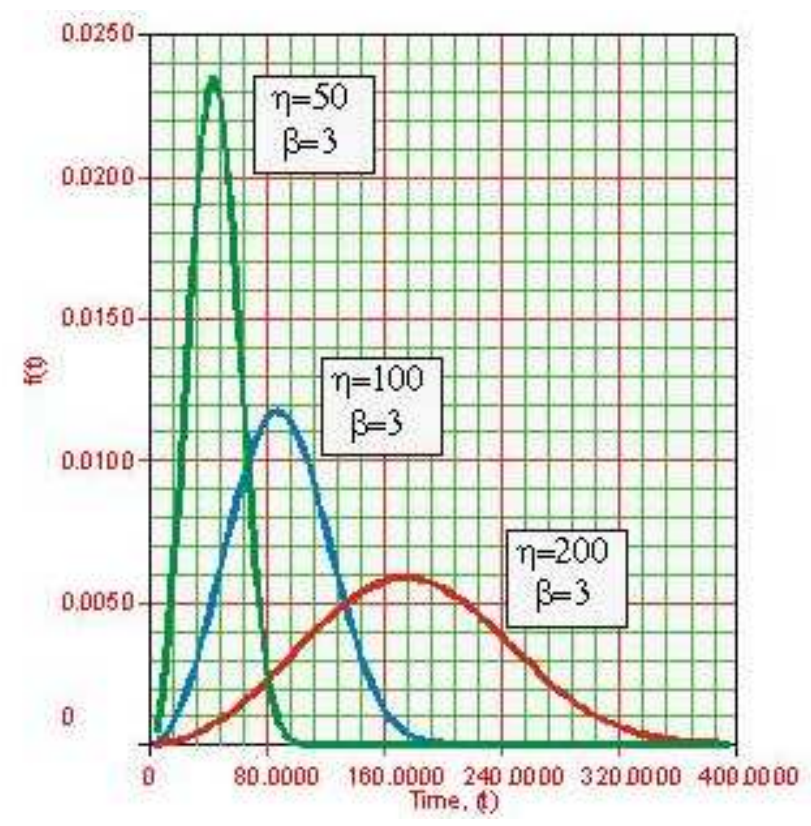

Figura 3-10 - Variação de uma $f(t)$ de Weibull em função do parâmetro $\eta$ (RELIASOFT, 2005). 


\subsubsection{Cálculo dos Parâmetros de Distribuição de Probabilidade}

Uma vez escolhida a distribuição, é necessário determinar seus parâmetros. Os parâmetros são propriedades de uma distribuição de probabilidade através do qual a distribuição é definida. O cálculo desses parâmetros pode ser executado por três métodos distintos: Método Gráfico, Método dos Mínimos Quadrados ou Método da Máxima Verossimilhança.

\subsubsection{Método Gráfico}

A utilização do método gráfico envolve o uso de papéis probabilísticos e é de fácil utilização, especialmente em situações onde os parâmetros precisam ser estimados muito rapidamente, sem o uso de computadores. Porém este método não é muito preciso, pois possui erros de aproximações gráficas manuais, e duas pessoas dificilmente obterão o mesmo resultado com os mesmos dados. O método consiste das seguintes etapas:

1. Ordenação dos dados: Os dados devem ser colocados em ordem crescente de tempos até a falha.

2. Cálculo dos valores a serem plotados: a coordenada $x$ de cada ponto será o tempo até a falha. A coordenada y será uma estimativa de $F(t)$ para o tempo até a falha em questão. Segundo Souza (2003), uma boa estimativa pode ser obtida por:

$$
F\left(t_{i}\right)=\frac{i}{N+1}
$$

onde $N$ é o número total de pontos a serem plotados.

Johnson (1951) cita a seguinte estimativa:

$$
F\left(t_{i}\right)=\frac{i-0,3}{N+0,4}
$$

Qualquer uma das duas formas pode ser usada.

3. Plotar os pontos: Identificar os tempos até a falha e os valores obtidos na etapa 
anterior no papel de probabilidade correspondente à distribuição escolhida.

4. Traçar a reta que melhor se aproxima dos pontos plotados.

5. Obter os Parâmetros da Distribuição: Para cada distribuição existe uma maneira de obter esses parâmetros, a partir de avaliações executadas no próprio papel probabilístico.

\subsubsection{Método dos Mínimos Quadrados}

O Método dos Mínimos Quadrados se baseia no mesmo princípio do método gráfico: adequar uma reta que melhor se aproxima dos pontos plotados. Em uma escala linear, uma reta tem a seguinte equação:

$$
y=a \cdot x+b
$$

Em escalas correspondentes às distribuições de confiabilidade, os parâmetros $a$ e $b$ se transformam nos parâmetros das distribuições. O princípio do método é minimizar o erro correspondente à distância dos pontos à reta. Esta distância pode ser medida tanto na vertical, como na horizontal, como mostra a Figura 3-11.

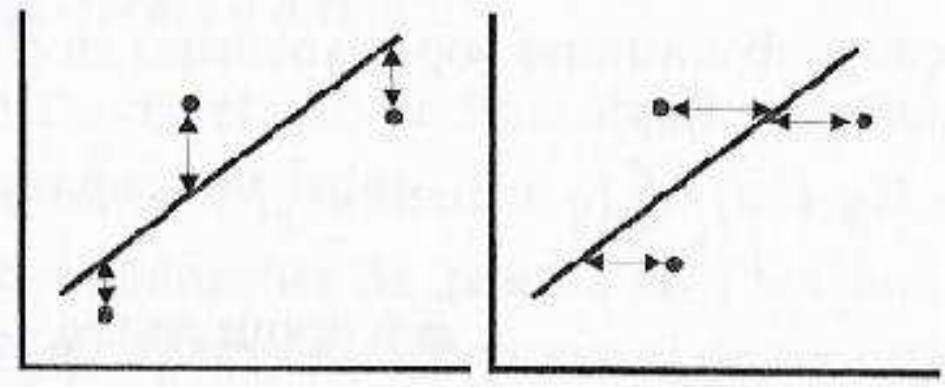

Figura 3-11 - Método dos Mínimos Quadrados (RELIASOFT, 2005).

O desenvolvimento do método para escalas lineares é descrito por Lewis (1996). Este método permite a obtenção do coeficiente de correlação $\rho$ :

$$
\rho=\frac{\sigma_{x y}}{\sigma_{x} \cdot \sigma_{y}}
$$

onde: 


$$
\begin{aligned}
& \sigma_{x y}: \text { Covariância de } x \text { e } y \\
& \sigma_{x}: \text { Desvio padrão de } x \\
& \sigma_{y}: \text { Desvio padrão de } y
\end{aligned}
$$

Este coeficiente varia de 0 a 1 . Quanto mais próximo $\rho$ estiver de 1 , melhor é a aproximação. Numa aproximação perfeita, onde todos os pontos estão em cima da reta, $\rho$ é igual a 1. Quanto menor for o seu valor, menos correlação os pontos tem com a distribuição em questão.

\subsubsection{Método da Máxima Verossimilhança}

O Método da Máxima Verossimilhança é considerado o mais robusto dos métodos de estimação dos parâmetros. Reliasoft (2005) explica que este método estima os valores dos parâmetros da distribuição que maximiza a função verossimilhança. A função de verossimilhança é baseada na função densidade de probabilidade, $f(t)$, para uma dada distribuição. Seja uma $f(t)$ genérica:

$$
f\left(x, \theta_{1}, \theta_{2}, \ldots, \theta_{k}\right)
$$

onde:

x: dado de tempo até falha

$\theta_{1}, \theta_{2}, \ldots, \theta_{k}$ : parâmetros a serem estimados

Para conjuntos de dados não suspensos, a função verossimilhança é o produto das funções $f(t)$ de cada observação do conjunto de dados:

$$
L=\prod_{i=1}^{n} f\left(x_{i}, \theta_{1}, \theta_{2}, \ldots, \theta_{k}\right)
$$

Matematicamente é mais conveniente trabalhar com o logaritmo da função de verossimilhança. A função log-verossimilhança é dada por: 


$$
\Lambda=\ln L=\prod_{i=1}^{n} \ln f\left(x_{i}, \theta_{1}, \theta_{2}, \ldots, \theta_{k}\right)
$$

Os parâmetros são então encontrados maximizando a função da equação (3.22). Isto é feito calculando as derivadas parciais da equação log-linear para cada parâmetro e resolvendo o sistema, igualando-o a zero (LEMES, 2006).

Este processo é facilmente ilustrado com a distribuição Exponencial de um parâmetro. Desde que haja somente um parâmetro, há somente uma equação para ser resolvida. Além disso, a função de verossimilhança da distribuição exponencial é derivável em todos os pontos. Ela é dada por:

$$
\begin{aligned}
& L\left(\lambda \mid t_{1}, t_{2}, \ldots, t_{n}\right)=\prod_{i=1}^{n} f\left(t_{i}\right) \\
& L\left(\lambda \mid t_{1}, t_{2}, \ldots, t_{n}\right)=\prod_{i=1}^{n} \lambda \cdot e^{-\lambda \cdot t_{i}} \\
& L\left(\lambda \mid t_{1}, t_{2}, \ldots, t_{n}\right)=\lambda^{n} \cdot e^{-\lambda \sum_{i=1}^{n} t_{i}}
\end{aligned}
$$

onde $\lambda$ é o parâmetro que se deseja estimar.

A função Log-verossimilhança é dada por:

$$
\Lambda=\ln L=n \cdot \ln \lambda-\lambda \sum_{i=1}^{n} t_{i}
$$

Tomando a derivada da equação (3.26) em relação $\lambda$ e igualando o resultado a zero:

$$
\frac{\partial \Delta}{\partial \lambda}=\frac{n}{\lambda}-\sum_{i=1}^{n} t_{i}=0
$$

Obtém-se então o estimador de máxima verossimilhança, $\hat{\lambda}$ : 


$$
\hat{\lambda}=\frac{n}{\sum_{i=1}^{n} t_{i}}
$$

Este estimador é exatamente o inverso do $M T B F$ do conjunto de dados, o que está de acordo com o que foi explanado em 3.2.4.3.

O método é mais complexo para distribuições com mais de um parâmetro ou com dados suspensos. Essencialmente, tratar de dados suspensos envolve incluir outro termo na função verossimilhança. A função para este caso é dada por:

$$
L=\prod_{i=1}^{n} f\left(x_{i}, \theta_{1}, \theta_{2}, \ldots, \theta_{k}\right) \cdot \prod_{j=1}^{m}\left[1-F\left(y_{j}, \theta_{1}, \theta_{2}, \ldots, \theta_{k}\right)\right]
$$

onde:

$m$ : número de dados suspensos

$y_{j}:$ j-ésima suspensão

$F\left(y_{i}, \theta_{1}, \theta_{2}, \ldots, \theta_{k}\right):$ Função de Probabilidade $F(t)$

Nota-se que o termo que trata dos dados suspensos utiliza a função probabilidade de falha, $F(t)$, ao invés de $f(t)$.

Com esta função, o processo de análise prossegue como descrito anteriormente: toma-se o logaritmo natural da função de verossimilhança, encontram-se as derivadas parciais em relação aos parâmetros e resolve-se o sistema de equações, simultaneamente, igualando a zero. Para um conjunto de dados com uma quantidade relativamente grande de suspensões, o método da máxima verossimilhança consegue aproximações bem mais precisas do que os outros dois métodos (RELIASOFT, 2005).

Para o método da máxima verossimilhança, não existe um coeficiente de correlação que varia sempre de 0 a 1 . Usa-se o coeficiente de Anderson-Darling para averiguar a aderência de uma dada distribuição a um determinado conjunto de dados, conforme proposto por Anderson \& Darling (1952). O valor deste coeficiente varia 
conforme o tamanho da amostra, não possuindo um intervalo definido. Em um teste, a melhor distribuição para um conjunto de dados será, matematicamente, aquela cujo coeficiente de Anderson-Darling tiver o menor valor numérico (KVALOY \& LINDQVIST, 1997).

\subsubsection{Confiabilidade de sistemas}

Na grande maioria das vezes, o que se deseja estudar é a confiabilidade de um sistema com diversos modos de falha, cada um com sua distribuição característica (LEWIS, 1996; SOUZA, 2003). Para isso, avalia-se a confiabilidade de um sistema complexo a partir da confiabilidade de seus componentes. Neste tipo de estudo, os diversos componentes ou diversos modos de falha são agrupados de forma que, a partir das distribuições de probabilidade de falha destes, seja possível obter a confiabilidade do sistema. Estes agrupamentos são representados graficamente por diagramas de blocos, que podem ser do seguinte tipo (CARAZAS, 2006):

\subsubsection{Sistemas em série}

São sistemas em que, se um sistema falhar, todo o sistema falha. O diagrama de blocos é representado da seguinte forma:

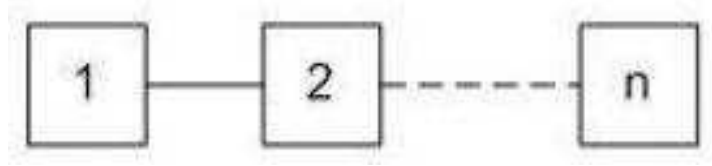

Figura 3-12 - Sistemas em série.

A confiabilidade do sistema é dada por:

$$
R_{s}(t)=R_{1}(t) \cdot R_{2}(t) \cdot \ldots \cdot R_{n}(t)
$$

A utilização de sistemas em série apresenta alguns problemas a serem considerados. A falha de apenas um componente é suficiente para parar a operação do sistema, e quanto maior o número de componentes menor a confiabilidade do sistema, a qualquer tempo. A Figura 3-13 indica a variação temporal da confiabilidade de sistemas em série em função do número de seus componentes. 


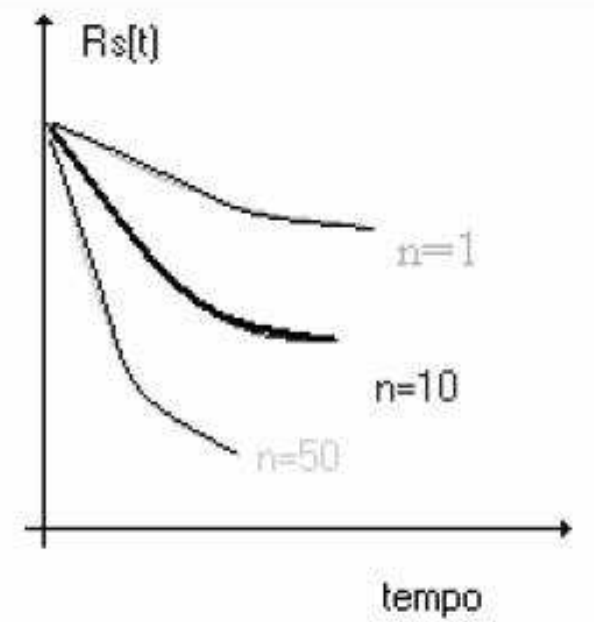

Figura 3-13 - Confiabilidade de sistemas em série em função do número de componentes que o compõe (n) (CARAZAS, 2006).

\subsubsection{Sistemas em paralelo}

São sistemas em que, para haver uma falha do sistema, todos os componentes devem falhar. O diagrama de blocos é ilustrado na Figura 3-14.

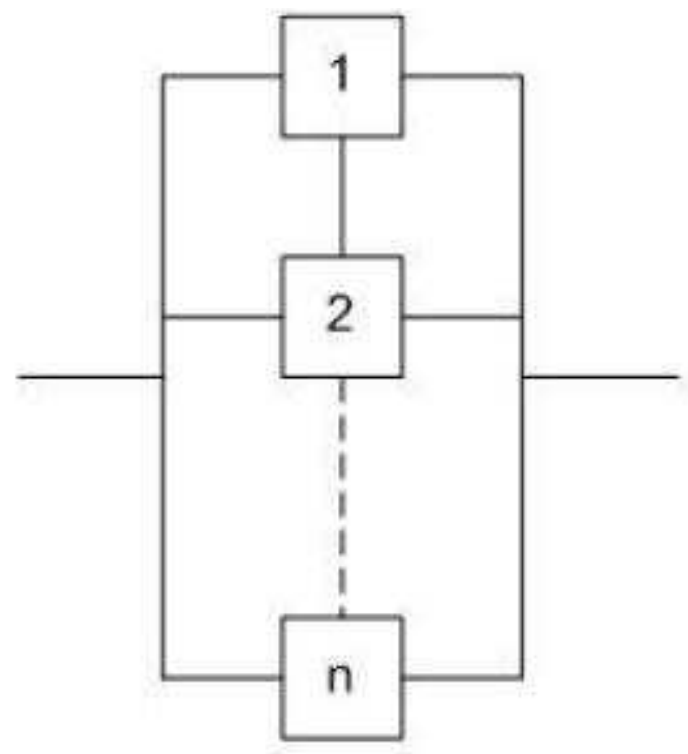

Figura 3-14 - Sistema em paralelo.

Ao analisar sistemas em paralelo, nota-se que com apenas um dos componentes operante, a operação do sistema está garantida, o que constitui uma Redundância Ativa (LEWIS, 1996). Os sistemas em paralelo ativo só falham se todos os seus componentes 
falharem. Neste caso, a função probabilidade de falha do sistema é dada por:

$$
F_{s}(t)=F_{1}(t) \cdot F_{2}(t) \cdot \ldots \cdot F_{n}(t)
$$

e, de (3.5), tem-se que:

$$
R_{s}(t)=1-\left(1-R_{1}(t)\right) \cdot\left(1-R_{2}(t)\right) \cdot \ldots \cdot\left(1-R_{n}(t)\right)
$$

A Figura 3-15 mostra graficamente a diferença da redução no valor da confiabilidade ao longo do tempo entre um sistema em paralelo ativo e um único componente.

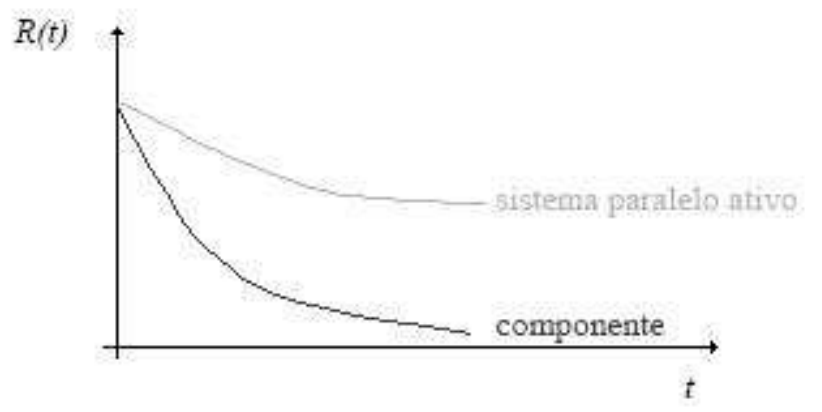

Figura 3-15 - Comparativo da evolução da confiabilidade para componentes e sistemas no modo paralelo ativo (CARAZAS, 2006).

\subsubsection{Sistemas em paralelo $m$ de $N$}

Em um sistema paralelo ativo, quando uma unidade falha, as outras cumprem a sua função. Porém, é possível que haja sobrecargas pois haverá menos unidades para cumprir o mesmo número de tarefas. Um sistema em paralelo ativo nestas condições, em que é necessário que no mínimo $m$ unidades do sistema funcionem de um total de $N$, é chamado de paralelo $m$ de $N$. Considerando que todas as unidades são iguais e possuem uma confiabilidade $R(t)$, a confiabilidade do sistema é dada por (LEWIS, 1996):

$$
R_{s}(t)=\sum_{n=0}^{N-m} C_{n}^{N}(1-R(t))^{n} R(t)^{N-n}
$$

onde: 


$$
C_{m}^{N}=\left(\begin{array}{l}
N \\
n
\end{array}\right)=\frac{N !}{(N-n) ! n !}
$$

Sistemas $m$ de $N$ são muito utilizados para válvulas de alívio, bombas, motores, e outros equipamentos que precisam ter uma capacidade específica para atender a critérios de projeto (LEWIS, 1996).

\subsubsection{Mantenabilidade}

O termo mantenabilidade pode ser entendido como o tempo necessário para executar um reparo em um equipamento, de modo a restaurá-lo a condições operacionais. O tempo para execução desta manutenção pode ser considerado uma variável aleatória, em função das variações inerentes ao processo de manutenção, como a habilidade e conhecimento técnico das equipes de manutenção, disponibilidade de peças de reposição, e dificuldade de diagnose da falha. Em sistemas mecânicos, a diagnose da falha tende a ser direta, sendo a maior parte do tempo gasto na execução do reparo. Em contrapartida, em sistemas eletro-eletrônicos a maior parte do tempo pode ser gasta na diagnose. Tendo sido feito o diagnóstico, a execução do reparo pode ser simples e direta (LEWIS, 1996).

Define-se a função distribuição de probabilidade $m(t)$ do tempo de reparo $t$ como (CARAZAS, 2006):

$$
m(t) \cdot \Delta t=P\left(t<t_{\text {rep }} \leq t+\Delta t\right)
$$

onde:

$t_{\text {rep }}:$ tempo de reparo do equipamento

A função distribuição acumulada associada a $m(t)$ é denominada Mantenabilidade, $M(t)$, e representa a probabilidade de o reparo ser executado em um tempo inferior a $t$. É calculada pela relação:

$$
M(t)=\int_{0}^{t} m\left(t^{\prime}\right) d t^{\prime}=P\left(t_{\text {rep }} \leq t\right)
$$

A partir das duas definições acima, pode-se definir o tempo médio para reparo 
MTTR (Mean Time to Repair) como sendo:

$$
\operatorname{MTTR}=\int_{0}^{\infty} \operatorname{tm}(t) d t
$$

Analogamente à definição da taxa de falha feita no Capítulo 3.2.1, define-se a taxa de reparo, $v(t)$, como:

$$
v(t) \cdot \Delta t=\frac{P\left(t<t_{\text {rep }} \leq t+\Delta t\right)}{P\left(t_{\text {rep }}>t\right)}
$$

Ou, analogamente à equação (3.11):

$$
v(t)=\frac{m(t)}{1-M(t)}
$$

A taxa de reparo representa a probabilidade de que o reparo venha a ser concluído no tempo $t$, uma vez que não foi concluído no tempo $t-1$.

A mantenabilidade tem como distribuição usual a Lognormal. Quando a representação é dada por esta distribuição, o sistema caracteriza-se pela existência de uma zona de reparos de rápida execução, uma zona densa de reparos executados dentro da normalidade de variação do processo, e uma zona na qual os tempos de reparo podem ser muito mais longos do que os da segunda zona. Em geral, nesta zona encontram-se ocorrências de falhas para as quais havia indisponibilidade de peças de reposição, ou para as quais houve problemas na execução da diagnose.

\subsubsection{Disponibilidade}

A Disponibilidade $A(t)$ é definida como a probabilidade do equipamento ou sistema estar operando satisfatoriamente no determinado tempo $t$. $A(t)$ também é chamada de disponibilidade pontual, por se referir exclusivamente ao instante $t$. Seu valor é binário: 1, para condição operacional, ou 0 , para condição de falha.

Entretanto, freqüentemente é necessária a determinação da disponibilidade ao longo de um intervalo de tempo. Normalmente, ao longo da chamada vida útil 
operacional. Essa disponibilidade é expressa pela seguinte relação (LEWIS, 1996):

$$
A^{*}(T)=\frac{1}{T} \int_{0}^{T} A(t) d t
$$

ou seja, é a média da disponibilidade instantânea no intervalo $(0, T)$.

Além disso, é freqüentemente encontrado que depois de certo tempo de efeitos transientes, a disponibilidade média assume um valor independente do tempo. Nestes casos, a chamada disponibilidade assintótica é definida por:

$$
A^{*}(\infty)=\lim _{T \rightarrow \infty} \frac{1}{T} \int_{0}^{T} A(t) d t
$$

Para equipamentos operando em regime de 24 horas por dia, 7 dias por semana, o tempo de 6 meses costuma ser suficiente para a disponibilidade média se tornar assintótica. Para equipamentos que trabalham 8 horas por dia, 5 dias por semana, 1 ano costuma ser suficiente.

Em sistemas não reparáveis, a disponibilidade pontual é igual à confiabilidade, ou seja:

$$
A(t)=R(t)
$$

e a disponibilidade num intervalo de tempo é definida por:

$$
A^{*}(T)=\frac{1}{T} \int_{0}^{T} R(t) d t
$$

A disponibilidade assintótica tende a zero $\left(A^{*}(\infty)=0\right)$, o que está de acordo com a definição de confiabilidade, onde há um instante de tempo em que o equipamento falha, e, portanto, torna-se indisponível caso este não possa sofrer reparo (CARAZAS, 2006).

Para se determinar a disponibilidade de um equipamento em constante operação, Lewis (1996) propõe duas hipóteses diferentes: taxa de reparo constante, e tempo de reparo constante. É feito o desenvolvimento independentemente para cada uma das hipóteses, e o resultado de $A^{*}(t)$ é o mesmo para $t \rightarrow \infty$, embora haja certa variação para 
os valores transientes iniciais. Lewis conclui que os valores de disponibilidade dependem muito mais do MTTR (tempo médio entre reparos), do que dos detalhes da distribuição. A seguir, é mostrado desenvolvimento considerando a hipótese de taxa de reparo constante:

$$
v(t)=v
$$

desta forma, $m(t)$ é exponencial:

$$
m(t)=v e^{-v t}
$$

e, assim:

$$
\operatorname{MTTR}=1 / v
$$

Define-se aqui o conceito de indisponibilidade $\hat{A}(t)$ como sendo complementar à disponibilidade:

$$
\hat{A}(t)+A(t)=1
$$

Para calcular a disponibilidade, considera-se a variação de $A(t)$ num intervalo de tempo $\Delta t$. Neste intervalo, duas situações podem alterar $A(t)$ :

- A perda de disponibilidade associada com a probabilidade de o equipamento vir a falhar no intervalo $\Delta t$, dado que estava disponível no instante $t$, sendo expressa por $\lambda(t) \Delta t A(t)$.

- O ganho de disponibilidade associado com a probabilidade de o equipamento vir a sofrer reparos e voltar a operar no intervalo $\Delta t$, dado que estava indisponível no instante $t$, sendo expresso por $v(t) \Delta t \tilde{A}(t)$.

Assim:

$$
A(t+\Delta t)=A(t)-\lambda \Delta t A(t)+v \Delta t \tilde{A}(t)
$$

ou: 


$$
A(t+\Delta t)=A(t)-\lambda \Delta t A(t)+v \Delta t(1-A(t))
$$

ou:

$$
\frac{A(t+\Delta t)-A(t)}{\Delta t}=-(\lambda+v) A(t)+v
$$

ou:

$$
\frac{d A(t)}{d t}=-(\lambda+v) A(t)+v
$$

Para a solução da equação diferencial acima se utiliza a condição de contorno de que no início da vida o equipamento está disponível: $A(0)=1$. Assim:

$$
A(t)=\frac{v}{\lambda+v}+\frac{\lambda}{\lambda+v} e^{-(\lambda+v) t}
$$

A disponibilidade em intervalo de tempo é dada por:

$$
A^{*}(T)=\frac{v}{\lambda+v}+\frac{\lambda}{(\lambda+v)^{2} T}\left[1-e^{-(\lambda+v) T}\right]
$$

A disponibilidade assintótica é dada por:

$$
A^{*}(\infty)=\frac{v}{v+\lambda}
$$

Considerando as propriedades da distribuição exponencial, tem-se:

$$
A^{*}(\infty)=\frac{M T B F}{M T B F+M T T R}
$$

Esta expressão é genericamente utilizada para o cálculo da disponibilidade, independentemente das distribuições envolvidas, como descrito acima. Esta aproximação é válida quando o intervalo de tempo tomado para a avaliação de disponibilidade é muito maior que o $M T B F$, o que permite verificar a insensibilidade desta disponibilidade em relação à distribuição de confiabilidade. Se isto se verificar, este valor de disponibilidade 
também é insensível à distribuição de mantenabilidade, já que $M T B F \gg M T T R$ (O`CONNOR, 1985).

\subsubsection{Disponibilidade de sistemas}

As equações para Disponibilidade de sistemas são análogas às equações para Confiabilidade de sistemas, e seu desenvolvimento também é análogo (LEWIS, 1996). Logo, a Disponibilidade para sistema em série, é dada por:

$$
A_{s}(t)=A_{1}(t) \cdot A_{2}(t) \cdot \ldots \cdot A_{n}(t)
$$

Para sistema em paralelo:

$$
A_{s}(t)=1-\left(1-A_{1}(t)\right) \cdot\left(1-A_{2}(t)\right) \cdot \ldots \cdot\left(1-A_{n}(t)\right)
$$

E para sistemas em paralelo $m$ de $N$, supondo que todos os componentes possuem Disponibilidade $A(t)$ :

$$
A_{s}(t)=\sum_{n=0}^{N-m} C_{n}^{N}(1-A(t))^{n} A(t)^{N-n}
$$

\subsubsection{FMEA}

A análise de confiabilidade de sistemas é o único método que fornece a probabilidade de um determinado equipamento operar num determinado tempo sem apresentar falha. Porém, este método não diz o que acontece ao equipamento quando a falha ocorre, uma vez que uma falha pode ter diferentes intensidades de conseqüência (SOUZA, 2003).

Uma vez que é necessário avaliar não só as probabilidades, mas também as consequiências das falhas para ser possível tomar ações a respeito, existe a metodologia FMEA (Failure Modes and Effects Analysis, ou Análise dos Modos e Efeitos de Falha). Esta metodologia foi proposta inicialmente pelo US Department of Defense (1974), e depois se tornou de domínio público, com citações em diversos livros e artigos (LEWIS, 1996; SOUZA, 2003; IRESON, 1995; PALADY, 2004). No FMEA, um sistema é dissecado em todos os seus dispositivos, e para cada dispositivo são analisados seus 
modos de falha, e as conseqüências atreladas à ocorrência destes (dispositivo deve ser entendido como o menor item a ser estudado em um determinando sistema, não chegando necessariamente a representar peça a peça do sistema. A escolha do que considerar como sendo um 'dispositivo' do sistema varia de caso a caso).

A partir de então são classificados qualitativamente quanto à severidade (S), probabilidade de ocorrência $(\mathrm{O})$ e capacidade de detecção (D), e, pela multiplicação destas três classificações, chega-se a um índice conhecido como RPN (Risk Priority Number). Este índice é utilizado para priorizar ações que devem ser tomadas para os índices mais críticos:

$$
R P N=S \times O \times D
$$

O FMEA é um método empregado na melhoria de projetos de sistemas, na determinação de pontos vulneráveis no projeto, na concepção de testes, no projeto de linhas de produção (chão de fábrica) e no planejamento da manutenção, onde a elaboração de rotinas de diagnose e requisitos de manutenção preventiva são benefícios relevantes (CARAZAS, 2006). Apesar de ser inicialmente qualitativo, podem ser incluídas estimativas de cálculo das probabilidades de falha (LEWIS, 1996). Recentemente, o FMEA tem sido também utilizado para avaliar possíveis falhas em processos administrativos, como departamentos comerciais ou de logística (SIX SIGMA ACADEMY, 2002).

A análise de FMEA também é a base da análise de RCM proposta por Moubray (1997). A partir do FMEA, Moubray propõe uma metodologia para tomada de decisão considerando aspectos de higiene, saúde, meio ambiente, operacionais, técnicos e financeiros. Esta metodologia se baseia em perguntas com respostas "sim" ou "não", formando um diagrama em forma de árvore. Para cada ramo final do diagrama, são propostas ações técnicas possíveis de serem implantadas.

\subsubsection{0 Árvore das falhas}

Embora o FMEA analise os modos de falha associados a cada dispositivo de um sistema, podem existir falhas no sistema que só acontecerão quando dois ou mais eventos de falha de dispositivos acontecerem simultaneamente, e o FMEA não é capaz de 
perceber esta interação entre os diferentes dispositivos. Assim, surge a Análise das Árvores de Falha, ou FTA (Fault Tree Analysis). Kumamoto e Henley (1991) mostram a metodologia para a construção de árvores de falha.

Segundo Souza (2003), árvores de falha são normalmente utilizadas para prever a ocorrência de eventos catastróficos, onde uma série de eventos deve ocorrer para que o envento-topo da árvore se concretize. Uma árvore de falha simples assemelha-se a um diagrama de blocos, sendo resolvida da mesma forma mostrada em 3.2.6. Para árvores mais complexas, os algoritmos de resolução são específicos para árvores de falha, diferindo dos de diagramas de blocos (LEWIS, 1991).

Seguindo o trabalho de Khan e Haddara (2003), neste trabalho serão utilizadas árvores de falha como forma de melhor organizar visualmente os diversos modos de falha dos diversos componentes do sistema.

A FTA também possibilita elaborar procedimentos de diagnose de falhas como o “troubleshooting”, que consiste de um procedimento para a rápida diagnose do sistema, determinando as causas das falhas, e como corrigir os efeitos gerados. Como este procedimento é elaborado a partir da FTA, portanto após a ocorrência de uma falha, o “troubleshooting” caracteriza-se por ser um procedimento de manutenção corretiva.

\subsection{Manutenção}

Dentro da indústria, existem diferentes terminologias para classificar os diversos métodos de manutenção, o que pode gerar aplicações diferentes para o mesmo termo, principalmente quando não há o domínio completo do seu real significado.

Do ponto de vista da confiabilidade, existem três práticas básicas de manutenção: manutenção corretiva, manutenção preventiva, e manutenção preditiva.

\subsubsection{Manutenção Corretiva}

A manutenção corretiva é aquela executada após a ocorrência da falha, sem nenhum tipo de programação ou planejamento. Na grande maioria das vezes, as atividades de manutenção corretiva são as que mais oneram as atividades de manutenção, pois provocam perda de produção e/ou qualidade do produto, aquisição de peças de 
reposição em caráter de urgência, horas-extras, e muitas vezes um tempo maior de execução do que uma atividade de manutenção preventiva, pois a diagnose tende a ser mais demorada.

No entanto, as formas de prevenir falhas tiveram origem na manutenção corretiva. Então, uma das contribuições desta é fornecer dados históricos para o acompanhamento dos sistemas e futuras tomadas de decisão.

Do ponto de vista da confiabilidade, existem componentes ou sistemas que simplesmente não aceitam manutenções preventivas ou preditivas, pois apresentam falhas aleatórias e que não possuem o tempo de desenvolvimento da falhas (TDF). Isto pode se dar por seu arranjo, natureza do fenômeno físico, ou impossibilidade de coleta de medidas. (CARAZAS, 2006). Nestas condições, a manutenção corretiva é a única alternativa.

\subsubsection{Manutenção Preventiva}

A manutenção preventiva caracteriza-se por intervenções regulares em períodos fixos, onde se executam tarefas pré-determinadas. É necessário o conhecimento dos modos de falha mais freqüentes e, principalmente, da periodicidade com que as falhas ocorrem.

Embora a função da manutenção preventiva seja manter a menor degradação possível dos equipamentos, e conseqüente maior confiabilidade, e seja admirada no meio industrial, a manutenção preventiva está envolta em uma série de equívocos. Dois podem ser citados (CARAZAS, 2006):

1. A hipótese de que a manutenção preventiva aumenta a confiabilidade dos sistemas.

Considerando a situação mostrada na Figura 3-16, onde o sistema opera até o instante $T$ no intervalo $[0, T]$. Supondo que a manutenção preventiva retome o sistema à condição de um sistema "novo", ou seja, é $100 \%$ eficaz, e supondo que a manutenção preventiva seja executada em intervalos exatamente iguais, no próximo intervalo $[T, 2 T]$ a confiabilidade neste novo intervalo será, segundo Lewis (1996): 


$$
R_{m}(T+\Delta t)=R(T) \cdot R(\Delta t)
$$

onde $R_{m}(t)$ é a confiabilidade do sistema após manutenção preventiva.

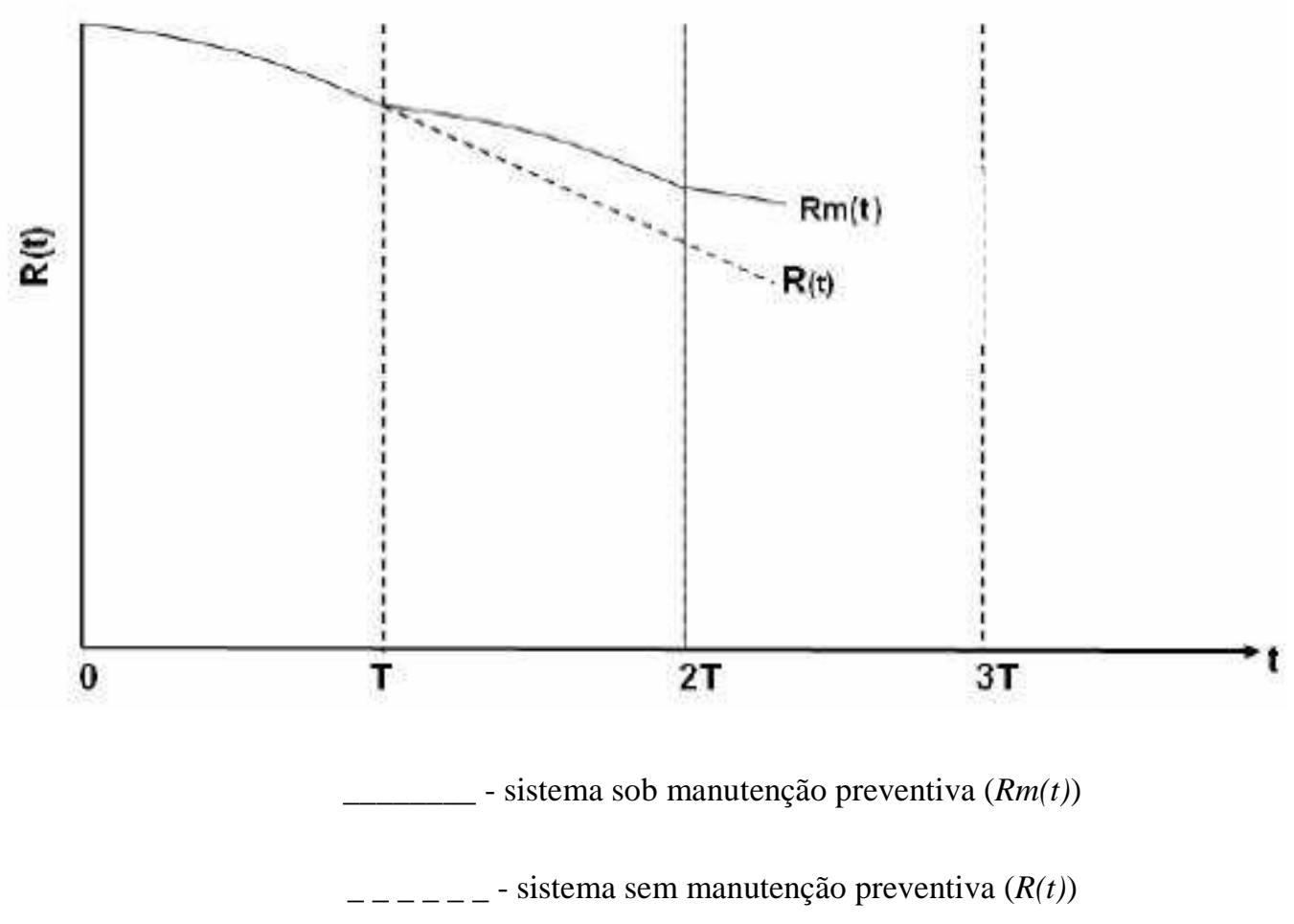

Figura 3-16 - Efeito da Manutenção Preventiva na Confiabilidade (LEWIS, 1996).

A Figura 3-16 mostra com clareza que a confiabilidade não se restaura, apenas a curva da confiabilidade após a ação da manutenção se torna idêntica àquela do instante inicial, quando do início da vida operacional do sistema.

Vale lembrar que a confiabilidade é uma probabilidade que enxerga o equipamento sempre no início da vida operacional. Assim sendo, a confiabilidade nunca aumenta, o que, por si só, é uma negativa da hipótese.

Enxergar a confiabilidade do sistema no instante $T$ após a preventiva, é diferente da confiabilidade do sistema no instante $T$ antes da preventiva, sabendo que o sistema operou sem falha até $T$. Neste caso, tem-se uma probabilidade condicional e, somente com esta condição satisfeita, pode-se dizer que a confiabilidade neste instante é igual à do sistema novo, ou seja, "aumentou”. Na verdade, quando há essa condição, deixa-se de olhar a confiabilidade do sistema a partir do tempo $O$ para olhá-la a partir do tempo $T$, que 
passa a ser o novo 0 . A seguinte equação descreve este comportamento:

$$
R\left(T+\Delta t \mid A^{*}(T)=1\right)=R(0+\Delta t)
$$

2. A hipótese de que a manutenção preventiva é aplicável a todo e qualquer tipo de sistema.

A hipótese acima é um equívoco, pois se deve aplicar a preventiva somente se forem verificados benefícios em termos de confiabilidade. Seja a confiabilidade de um componente descrita pela distribuição de Weibull. Pela simples variação do parâmetro $\beta$ da distribuição, pode-se representar a confiabilidade de componentes com taxa de falha crescente, constante, ou decrescente. Segundo Lewis (1996), $\beta$ tem o seguinte significado:

- $\quad \beta<1$ : Taxa de falha decrescente

- $\beta=1$ : Taxa de falha constante

- $\quad \beta>1$ : Taxa de falha crescente.

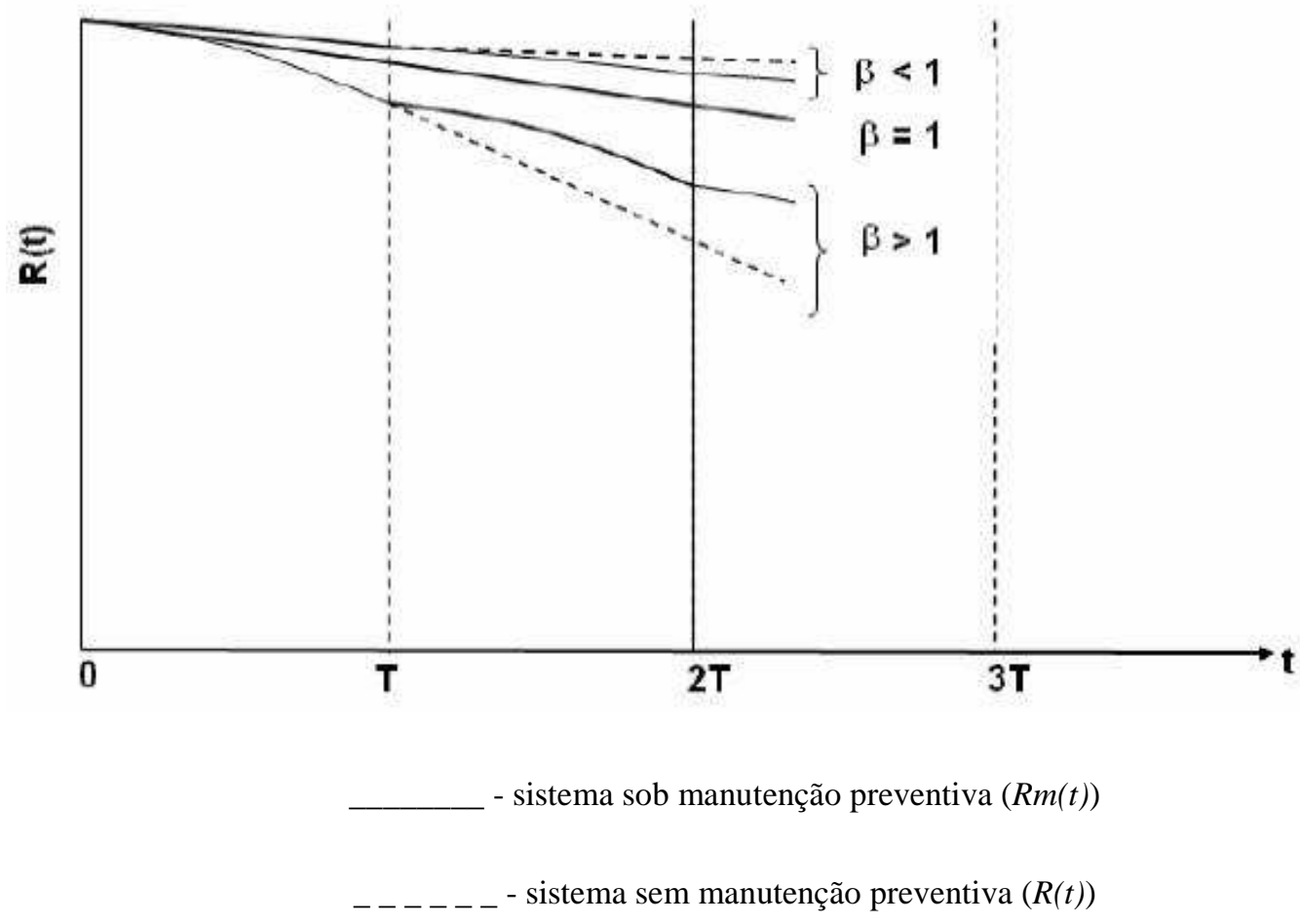

Figura 3-17 - Efeito da Manutenção Preventiva e do Fator $\beta$ na Confiabilidade (LEWIS, 1996). 
A Figura 3-17 mostra que se $\beta=1$, as ações preventivas de manutenção são indiferentes, ou seja, é inútil adotar a manutenção preventiva para sistemas com taxa de falha constante. Se $\beta<1$, a preventiva prejudica ainda mais o equipamento, fazendo com que este volte a operar, após a execução das tarefas da preventiva, em situação pior àquela em que se encontrava anteriormente, pois se retorna à taxa de falha inicial, que é elevada e decrescente com o tempo. E somente se $\beta>1$, a preventiva é adequada para reduzir a degradação da confiabilidade do componente ou equipamento. Este caso é típico de processos de falha associados a fenômenos de desgaste e de fadiga (CARAZAS, 2006).

\subsubsection{Manutenção Preditiva}

A manutenção preditiva trata de estimar o estado de funcionamento do sistema, pela medição de parâmetros vitais de operação. Ou seja, a manutenção preditiva é baseada na condição do parâmetro. Pode-se dizer que a preditiva acompanha o desenvolvimento da falha, apontando o melhor momento para a intervenção. Isto significa dilatar conscientemente a utilização de componente, o que se traduz em economia (CARAZAS, 2006).

Para que seja possível o emprego da manutenção preditiva, as falhas a serem consideradas devem fornecer sintomas que se manifestem nos parâmetros a serem medidos. Isto restringe o emprego desta técnica para equipamentos eletrônicos, por exemplo.

O emprego da manutenção preditiva exige interpretação dos dados coletados, o que por si só já é um fator complicador. A medição e o tratamento dos dados a tornam uma operação sofisticada e cara. Além disso, é necessário que se conheça muito bem o que se está medindo, senão corre-se o risco se tomar decisões baseadas em dados e interpretações errôneas.

Por isso, adotar a manutenção preditiva sem analisar previamente os sistemas ou sem que eles tenham sido projetados com esta possibilidade pode ser uma péssima idéia, que alia altos custos a baixa confiabilidade.

É de vital importância a análise de tendência do parâmetro, pois o estado atual do parâmetro no momento da medição é de pouca utilidade na decisão de parar o 
equipamento ou não, sobretudo na fase de implementação da manutenção preditiva e no caso de utilização de medições discretas. Assim, deve-se ter em mãos os históricos dos parâmetros e recorrer-se a algum método numérico, obtendo-se uma curva semelhante à mostrada na Figura 3-18, para definir o comportamento temporal do parâmetro.

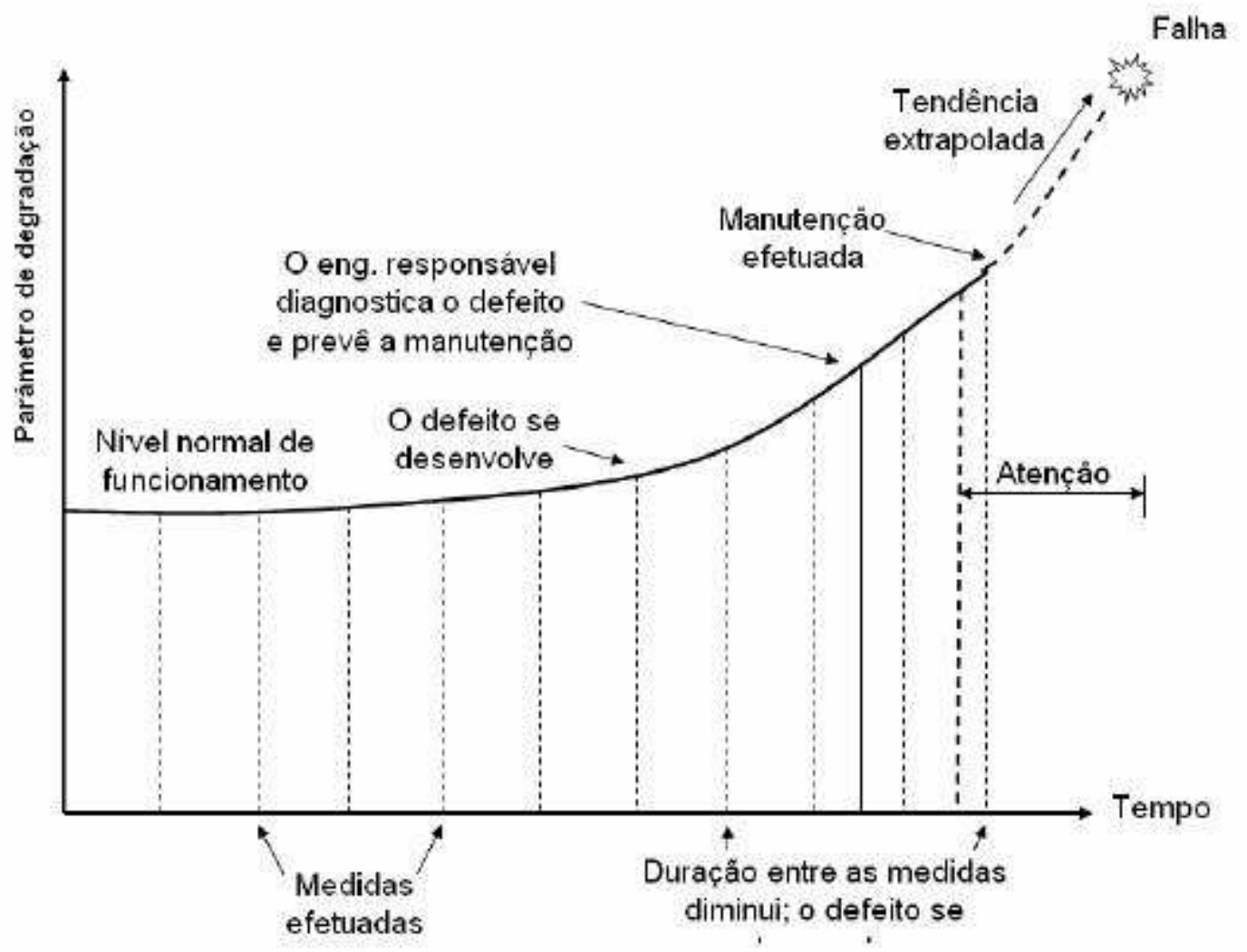

Figura 3-18 - Curva de Tendência para um Parâmetro de Interesse (XENOS, 2004).

A Figura 3-18 mostra que, enquanto não se conhece o valor de perigo (onde se dá a falha), há a necessidade de reduzir o espaço entre as medições quando se nota uma aceleração na deterioração do equipamento. Outra necessidade é que, depois de diagnosticada a falha, necessita-se programar a parada. Logo, entre o instante da detecção e a imobilização do equipamento, este deve operar satisfatoriamente, caso contrário, a preditiva perderia todo o seu significado. Com o passar do tempo, a estimativa desta curva passa a ser bastante fidedigna (CARAZAS, 2006).

As principais técnicas de preditiva são:

- Análise de sinais de vibração 
- Termografia

- Análise de emissões acústicas

- Análises de composição química em óleos lubrificantes e isolantes

- Análise de sinais de corrente elétrica

Embora tenha muito de monitoração, a manutenção preditiva não se restringe a isto. Como exemplo, pode-se citar a análise de trincas em reservatórios de navios petroleiros, técnica à qual este autor foi apresentado. Num determinado caso, os reservatórios eram inspecionados preventivamente a cada 5 anos, à procura de trincas na estrutura. Uma vez encontrada uma trinca, ela não poderia ser corrigida no momento da detecção, pois isso exigiria que o reservatório tivesse sido limpo com um nível que se permitisse soldar no seu interior, o que demanda muito mais tempo do que uma limpeza que apenas libere o reservatório para inspeção. Mapeando-se a trinca, é possível prever em quanto tempo ela vai se expandir até se tornar insegura, pois existe de antemão um modelo em elementos finitos da estrutura do navio. Assim, pode-se programar o momento de um reparo com uma antecedência de até 5 anos.

Embora permita uma prorrogação na utilização de componentes, sob ponto de vista matemático a manutenção preditiva não apresenta novidades, pois uma vez constatada uma situação onde uma falha se torna intolerável, o equipamento é paralisado, e a partir de então o procedimento é semelhante ao da manutenção preventiva.

\subsubsection{Seleção do Método de Manutenção}

Cardoso (2000) propõe a existência de quatro tipos básicos de falha, com relação ao seu comportamento estatístico e ocorrência de sintomas que possibilitem seu diagnóstico antecipado. Ou seja, a falha pode apresentar um comportamento que permita associá-la a uma função densidade de probabilidade - e, de acordo com esta função, ser classificada em aleatória ou não - e, ainda, pode apresentar um tempo para seu desenvolvimento $(T D F)$ ou eclodir repentinamente. Assim, é possível ter:

- Falhas aleatórias com TDF 
- Falhas aleatória sem TDF

- Falhas não aleatórias com TDF

- Falhas não aleatórias sem TDF

A partir destas informações pode-se montar uma simples matriz de decisão, mostrada na Tabela 3-1, acerca da seleção preliminar de uma prática de manutenção com base nas características destas falhas e nos conceitos associadas às práticas básicas de manutenção. Segundo Cardoso (2000), embora seja uma análise superficial, é possível selecionar com rapidez e precisão a prática de manutenção tecnicamente mais indicada a cada tipo de falha.

Tabela 3-1 - Matriz para Seleção Preliminar das Práticas de Manutenção (CARDOSO, 2004).

\begin{tabular}{|c|c|c|}
\hline Característica da Falha: & Aleatória & Não Aleatória \\
\hline & & \\
\hline $\begin{array}{l}\text { Com TDF: } \\
\text { Sem TDF: }\end{array}$ & $\begin{array}{c}\text { Preditiva } \\
\text { Só Corretiva }\end{array}$ & $\begin{array}{c}\text { Preditiva /Preventiva } \\
\text { Preventiva }\end{array}$ \\
\hline
\end{tabular}

Em uma análise um pouco mais aprofundada, mesmo em situações onde é tecnicamente possível a adoção de técnicas preventivas ou preditivas, isto pode não ser economicamente interessante.

Por exemplo, uma vez que um equipamento não seja crítico ou prioritário, a manutenção corretiva pode ser aceitável. Em outras palavras: para esta categoria de equipamentos pode ser mais barato fazer somente a manutenção corretiva quando ocorrer a falha, do que gastar recursos para evitá-la.

Obviamente, para se chegar a esta decisão, um método deve ser utilizado. Como exemplo, Xenos (2004), fornece uma metodologia de avaliar qualitativamente a criticidade de um equipamento de forma a se priorizar os recursos de manutenção. Podem-se usar outras metodologias, como um estudo de RCM (MOUBRAY, 1997), ou uma análise de risco (CARDOSO, 2004). 


\section{CAPÍTULO 4 - AVALIAÇÃO DA DISPONIBILIDADE PELO HISTÓRICO DE FALHAS}

\subsection{Considerações Iniciais}

Neste capítulo, é feita uma análise de confiabilidade e disponibilidade considerando como sistema o conjunto de máquinas do parque da fábrica. É apresentado um método para análise e criação de um modelo. São feitas considerações acerca dos dados, das premissas e das hipóteses, e em seguida é mostrada a metodologia de cálculo. Os resultados de Confiabilidade e Mantenabilidade são então discutidos. Por último, é feito um modelo de Disponibilidade para simulação computacional.

O primeiro passo para se realizar uma análise de deste tipo é determinar a árvore funcional do sistema, ou realizar uma descrição funcional. Particularmente, o autor prefere determinar a árvore, pois a visualização gráfica, embora não seja detalhada, facilita a rápida compreensão, necessária a uma descrição inicial.

Para a elaboração da árvore funcional de um sistema qualquer, é preciso conhecer a sua lógica de operação. No caso do sistema em análise, a árvore é composta por $N$ troncos, onde $N$ é o número de máquinas existentes. Cada um destes troncos se subdivide em um ramo que representa o acionamento de cabeceira, e 168 ramos que representam as 168 posições. Cada um destes ramos pode ainda ser subdividido até chegar ao nível dos componentes mais elementares.

\subsection{Montagem da Árvore Funcional do Sistema}

A Figura 4-1 mostra está árvore para o sistema. Para não sobrecarregar demais a árvore principal, optou-se por criar uma sub-árvore que representa uma posição individualizada, como mostrado na Figura 4-2.

Os acionamentos comuns não são detalhados nas árvores, pois foi considerado que estes têm confiabilidade $100 \%$, e, portanto, somente as posições individualizadas serão analisadas. Isto se deve ao fato de a confiabilidade percebida empiricamente do conjunto de acionamentos ser altíssima em comparação ao conjunto de posições, e talvez esse seja o motivo de não haver para estes dados de falhas organizados, que pudessem ser tratados 
estatisticamente. Conclui-se que, como a confiabilidade é alta, ninguém nunca se preocupou em criar um banco de dados, pois nunca fora motivo de incômodo. Quanto a isto, cabem dois comentários: Primeiro, embora a confiabilidade percebida seja alta, as conseqüências de uma falha são potencialmente muito críticas, pois uma interrupção no funcionamento destes acionamentos interrompe o funcionamento de todas as posições, sem exceção. Segundo, esta alta confiabilidade é mantida à custa de manutenções preventivas não necessariamente otimizadas quanto a prazo e a escopo. Ou seja, é possível que uma reespecificação das atividades de manutenção neste conjunto de acionamentos, através de análises quantitativas, seja um foco de redução de custos.

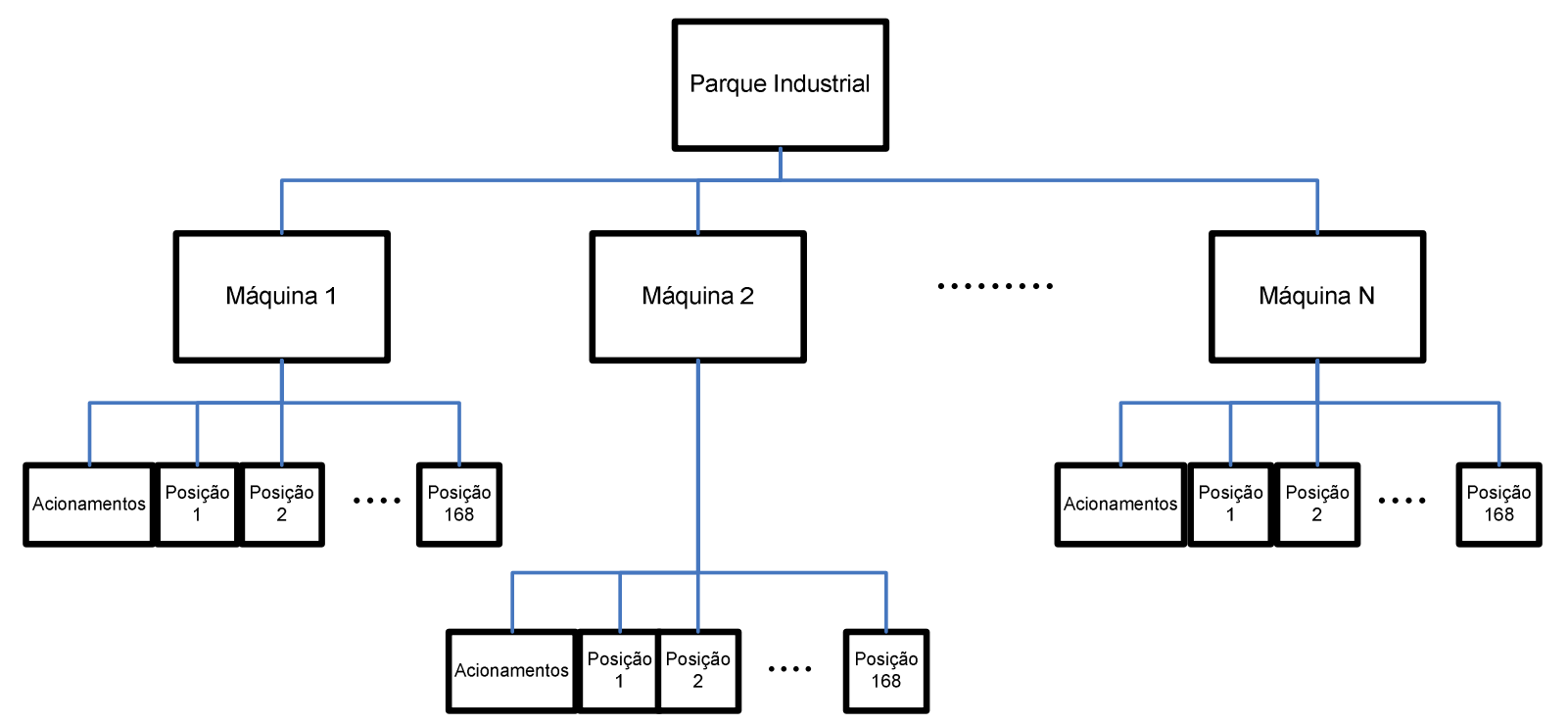

Figura 4-1 - Árvore funcional do sistema. 


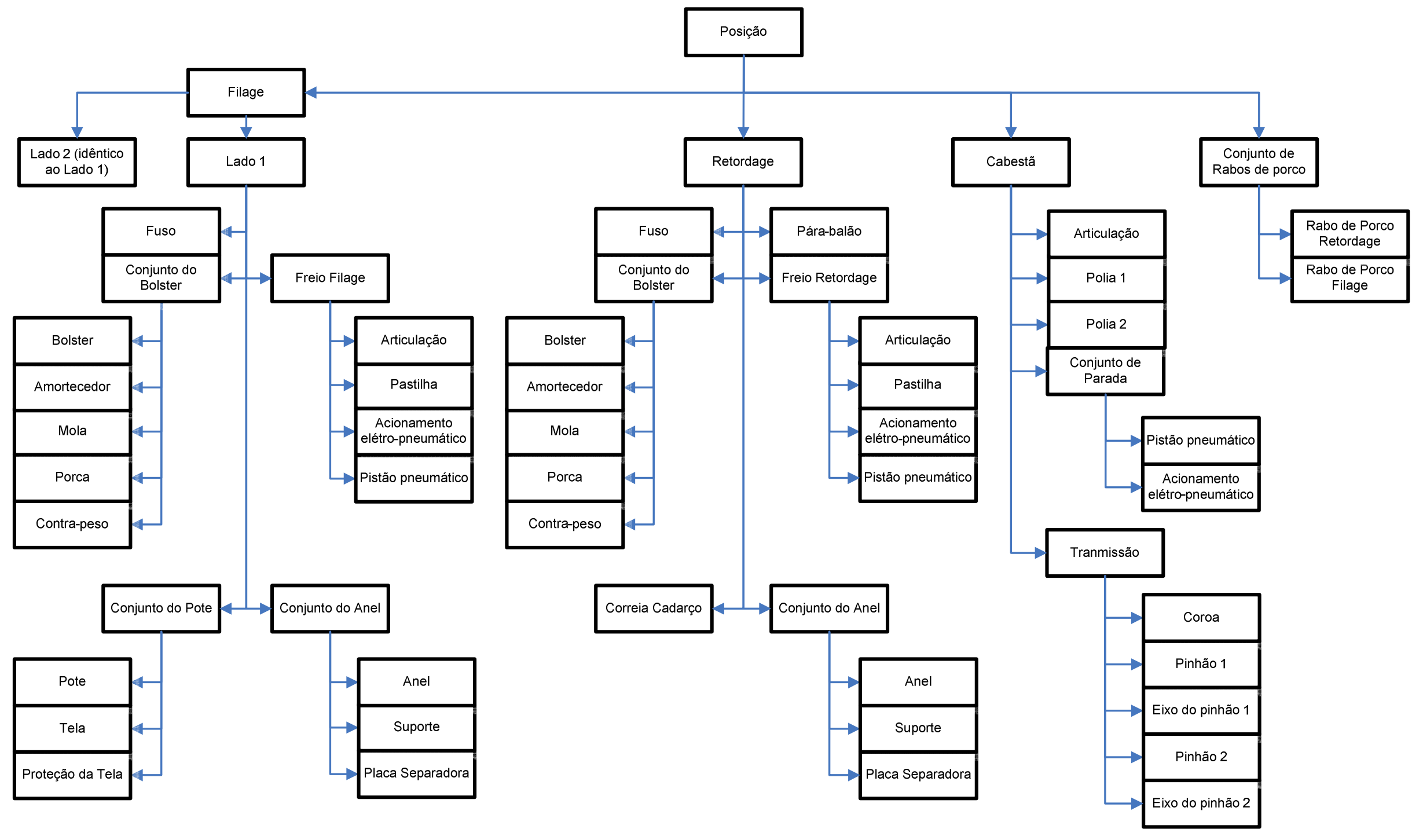

Figura 4-2 - Árvore funcional de uma posição. 
A seguir, deve ser feito um FMEA, com dois objetivos possíveis: caso ainda não existam dados de falha disponíveis, o objetivo é identificar cada um dos modos de falha existentes, para que se possa então projetar um banco de dados, e em seguida colhe-los. No caso de já existirem dados de falha antes do início do estudo, tem-se o segundo objetivo: verificar se os tipos de falha que existem no banco de dados efetivamente são modos de falha, e não efeitos de falha, ou qualquer outro tipo de informação que possa confundir uma análise de confiabilidade. Por exemplo: suponha-se que em determinado equipamento sejam feitas paradas para manutenções preventivas, e que essas paradas sejam inseridas no banco de dados. Se não estiver bem claro que essas paradas são preventivas, estes dados podem eventualmente ser considerados dados de falhas, e o resultado da Confiabilidade certamente será incorreto. Situações como esta são mais comuns do que se imagina.

No caso do sistema em estudo, já havia uma árvore de falhas para este sistema bastante detalhada em operação, e de conhecimento bastante disseminado entre os funcionários. Esta árvore é bem mais detalhada que a da Figura 4-2, chegando ao nível de detalhe de modos de falha. Assim, optou-se por utilizar esta árvore.

O processo de coleta de dados se dá da seguinte forma: toda vez que um operador detecta um problema qualquer em uma posição de qualquer máquina, esta posição é bloqueada para operação (há um mecanismo que permite interromper o funcionamento de uma determinada posição sem interromper o funcionamento das outras). Em seguida, a informação é transferida em um sistema de Kanban (JAPAN MANAGEMENT ASSOCIATION, 1989): É colocada uma etiqueta no local, de cor bem visível, normalmente vermelha ou rosa. Nesta etiqueta, devem ser preenchidos pelo operador data e hora da detecção do problema, e o efeito observado. Os efeitos são codificados para padronizar ao máximo as descrições, e servem de guia para a detecção da causa-raiz da falha. Feito isto, cessa a atividade do operador no processo de análise e correção das falhas.

Em seguida, funcionários da equipe de manutenção, que percorrem a área com a função de solucionar os problemas detectados, avaliam a dificuldade de corrigir as falhas nos diversos locais, e começam a agir: primeiro pelos mais simples, em seguida pelos mais complexos. Quando uma falha é corrigida, a etiqueta é retirada, e a posição é 
liberada para a produção. Na própria etiqueta, o mecânico responsável preenche a data e hora de finalização do reparo, e o modo de falha efetivamente detectado. Em seguida estes dados são encaminhados para digitação.

\subsection{Descrição da Filtragem dos Dados}

Em uma análise de Disponibilidade, a fase mais trabalhosa costuma ser a tratativa que os dados de campo recebem: devem ser filtrados os dados 'bons' e descartados os dados 'ruins', de forma a ser possível gerar uma base de dados sólida e consistente, que possa ser analisada quantitativa e estatisticamente, e que seja representativa da Disponibilidade real dos equipamentos em estudo. A Figura 4-3 mostra quais são os tipos de dados disponíveis através do banco de dados. As linhas em preto representam a evolução no tempo da Disponibilidade instantânea de 3 componentes. Os degraus representam mudanças de estado: estado de falha, ou operacional. O número da linha está indicado à esquerda de cada uma delas. A linha 1 representa um componente que operou sem falha durante todo o período amostrado. Não é possível determinar a data de início de operação, pois foi antes do início da amostragem, tampouco a data de falha, pois ainda não havia ocorrido na data de término da amostragem. A única informação disponível é que o componente operou por pelo menos um determinado período de tempo, ou seja, há

aqui um dado suspenso. É importante notar que esta informação não é evidente no banco de dados de falhas e reparos, pois não há ocorrências de falhas e reparos no período: é necessário comparar a totalidade de componentes com aqueles que apresentaram falhas, para revelar esta informação. Estes dados suspensos, se verdadeiros, representam o que há de melhor em termos de confiabilidade dentro da população de componentes estudados.

Porém, especificamente no caso deste banco de dados, estes dados não foram utilizados. O motivo: não há certeza se um componente realmente não falhou no período de amostragem, ou se ele falhou, mas a falha não foi anotada. Isto pode ter ocorrido principalmente durante as primeiras semanas da amostragem, pois esta forma de kanban para coleta de dados fora iniciada pouco tempo antes, e ainda não estava completamente disseminada. Além disto, como não se sabe quando o componente começou a operar, também não se sabe se as condições de uso e instalação eram as mesmas. 


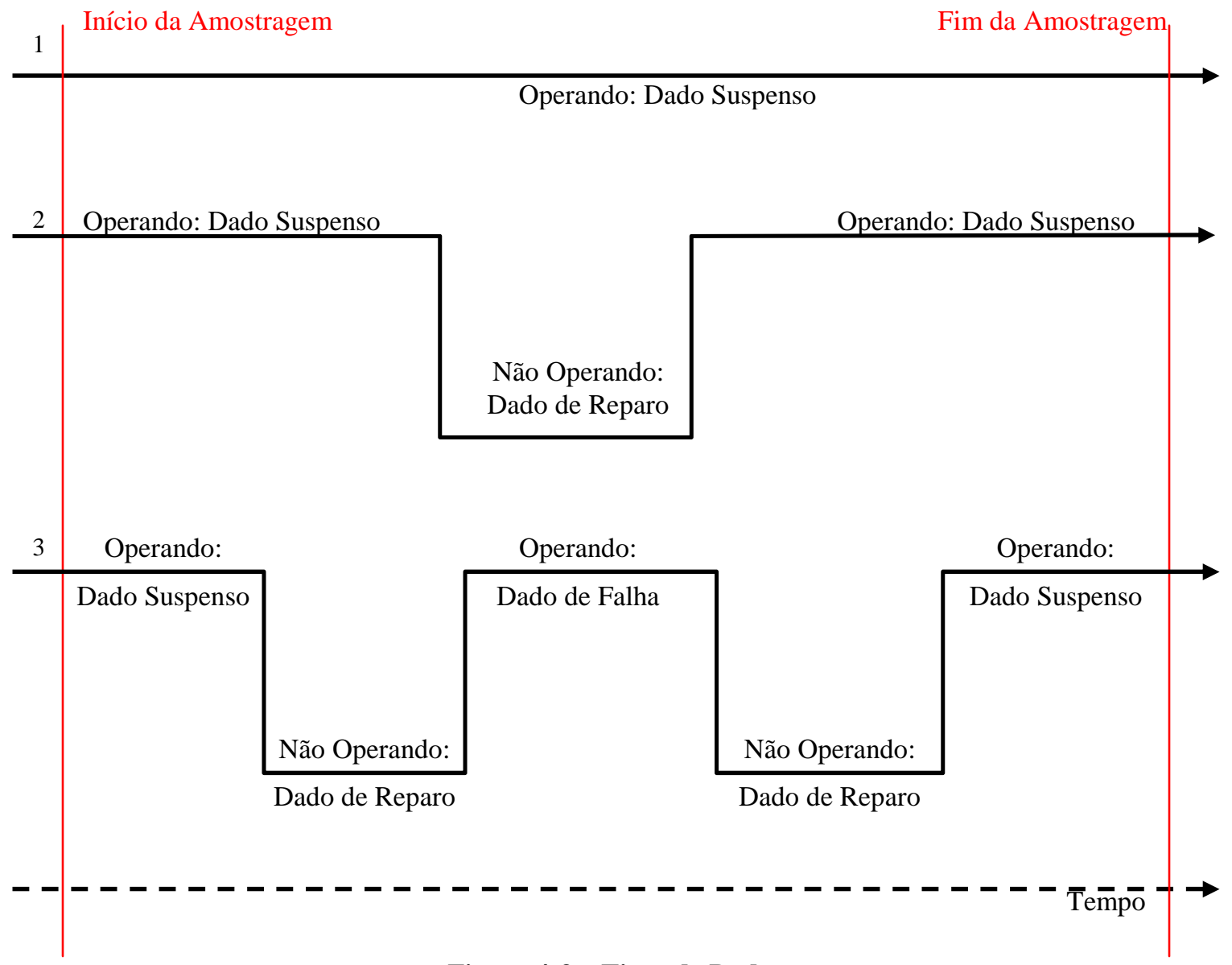

Figura 4-3 - Tipos de Dados.

A linha número 2 representa um componente que, no período de amostragem, apresentou uma falha, um reparo, e voltou a operar até o fim do período. Novamente, não há dados de falhas completos: há um primeiro período onde não se conhece a data de início de operação e se conhece a data de falha, um período de reparo completo, e um segundo período de operação, onde se conhece a data de início, mas não a da falha. Ou seja: há dois dados de falhas suspensos. O dado em que não se conhece a data de início da operação não foi utilizado, pela mesma razão que os dados representados pela linha 1 também não foram.

Finalmente, na linha número 3 existem duas falhas no período de amostragem. Neste caso, há um primeiro e um terceiro períodos de operação equivalentes aos períodos encontrados na linha 2, ou seja, dados suspensos. Apenas no segundo período há efetivamente um dado de falha completo, em que é possível determinar a data de início de operação, a data de falha, e, conseqüentemente, o tempo até a falha. Há, ainda, dois dados 
completos de reparo. Aqui, novamente os dados em que não se conhece a data de início de operação na foram utilizados.

Como se vê, da maneira como foi feita a amostragem, foi necessário que existissem pelo menos duas falhas no período de amostragem para que fosse possível gerar um dado completo de falha. Isto explica a grande quantidade de dados suspensos em comparação com os dados completos de falha.

O banco de dados inicialmente analisado neste estudo continha 16.250 linhas de dados; cada uma dessas linhas contendo informações sobre local da falha, data, hora, modo de falha, nome do operador que detectou o problema, nome do funcionário da manutenção que solucionou a falha, data e hora do reparo. Apesar de ser um banco de dados riquíssimo, muitas das linhas de dados continham problemas que inviabilizavam sua utilização em análises estatísticas. A Tabela 4-1 lista os tipos de problemas encontrados. Após as filtragens, foram retirados cerca de $30 \%$ dos dados.

Assim, este novo banco de dados filtrado pode ser considerado como uma amostra da população de erros. E como os erros acontecem de forma aleatória, é como se este novo banco fosse formado por dados colhidos aleatoriamente de dentro da população, o que esta de acordo com as regras de amostragem, e tornam a amostra representativa.

Tabela 4-1 - Tipos de problemas encontrados nos dados.

\begin{tabular}{|l|l|l|}
\hline 1 & $\begin{array}{l}\text { Sem número de } \\
\text { máquina anotado }\end{array}$ & $\begin{array}{l}\text { Sempre que em um determinado dado havia sido marcado o número da } \\
\text { posição, mas não o da máquina, todos os dados de todas as máquinas com } \\
\text { aquele número de posição e aquele modo de falha foram excluídos. Isto } \\
\text { porque este dado sem indicação poderia pertencer a qualquer máquina, sendo } \\
\text { impossível determinar qual. Se este dado fosse atribuído arbitrariamente a } \\
\text { uma das máquinas, ou mesmo se fosse ignorado, alterar-se-ia possivelmente } \\
\text { de maneira muito forte todos os dados da máquina que originou esta falha, e } \\
\text { da máquina à qual ele foi atribuído. Neste caso, a opção é cautelosa, pois } \\
\text { retira-se também dados 'bons', mas que são impossíveis de separar dos } \\
\text { ruins'. }\end{array}$ \\
\hline 2 & $\begin{array}{l}\text { Sem número de } \\
\text { posição anotado }\end{array}$ & $\begin{array}{l}\text { O raciocínio aqui é o mesmo do item acima. Porém, a decisão é diferente: se } \\
\text { fossem retiradas da análise todas as máquinas que possuem dados em que não } \\
\text { há o número da posição, reduzir-se-ia em 70\% a quantidade de dados } \\
\text { disponíveis. Os 30\% restantes ainda sofreriam as filtrações descritas a seguir. } \\
\text { Optou-se aqui por ignorar estes dados: as eventuais disparidades que possam } \\
\text { causar em situações específicas são compensadas pela abundância de dados } \\
\text { congruentes que deixaram de ser retirados. Em tempo: pode-se assumir } \\
\text { incorporar este erro pela pouca quantidade de erros deste tipo existentes no } \\
\text { banco de dados (13 num total de 16.250, ou 0,08\% do total). }\end{array}$ \\
\hline
\end{tabular}


Tabela 4-1 - Tipos de problemas encontrados nos dados (continuação).

\begin{tabular}{|c|c|c|}
\hline 3 & $\begin{array}{l}\text { Sem número de } \\
\text { posição nem } \\
\text { máquina anotado }\end{array}$ & $\begin{array}{l}\text { Houve apenas uma ocorrência deste tipo de problema. Esta ocorrência foi } \\
\text { ignorada, pela mesma premissa do item acima. Este problema é bem mais } \\
\text { crítico do que os dois anteriores: caso houvesse uma incidência muito grande, } \\
\text { todo o banco de dados poderia ser considerado inválido }\end{array}$ \\
\hline 4 & $\begin{array}{l}\text { Sem data da } \\
\text { falha }\end{array}$ & $\begin{array}{l}\text { A data de falha foi aproximada pela data do reparo. Para o cálculo de } \\
\text { confiabilidade, isto não causa grandes problemas, pois se trabalhar com tempo } \\
\text { de falha que chegam a centenas de dias. Já para o cálculo de mantenabilidade, } \\
\text { esta aproximação é um problema: assim, as linhas de dados com esta } \\
\text { aproximação não foram utilizadas para mantenabilidade. }\end{array}$ \\
\hline 5 & $\begin{array}{l}\text { Sem data do } \\
\text { reparo }\end{array}$ & Idem acima. \\
\hline 6 & $\begin{array}{l}\text { Sem horário da } \\
\text { falha }\end{array}$ & $\begin{array}{l}\text { O horário da falha foi aproximado para 12:00. Estes dados foram utilizados } \\
\text { para cálculo de confiabilidade, mas não de mantenabilidade }\end{array}$ \\
\hline 7 & $\begin{array}{l}\text { Sem horário do } \\
\text { reparo }\end{array}$ & Idem acima. \\
\hline 8 & $\begin{array}{l}\text { Datas de reparo } \\
\text { anteriores à datas } \\
\text { de falhas } \\
\text { respectivas }\end{array}$ & $\begin{array}{l}\text { Pelo menos uma das duas datas foi anotada de forma incorreta. Quando isto } \\
\text { ocorreu, o dado foi desconsiderado, tanto para confiabilidade como para } \\
\text { mantenabilidade. }\end{array}$ \\
\hline 9 & $\begin{array}{l}\text { Mais de um tipo } \\
\text { de falha para } \\
\text { uma mesma } \\
\text { ocorrência }\end{array}$ & $\begin{array}{l}\text { Isto acontece devido ao fato de que dois modos de falha podem se desenvolver } \\
\text { simultaneamente, em paralelo, antes de ocasionar uma falha. No momento em } \\
\text { que esta ocorre, e é feita a análise da falha por parte do funcionário da } \\
\text { manutenção, são descobertos dois ou mais modos de falha. Muitas vezes é } \\
\text { impossível afirmar exatamente qual deles chegou ao seu limite de } \\
\text { desenvolvimento e foi o estopim da falha. Inclusive, em muitas vezes, o efeito } \\
\text { da falha é a soma das contribuições individuais dos dois ou mais modos de } \\
\text { falha que estão se desenvolvendo. Neste caso, são anotados nas etiquetas os } \\
\text { dois ou mais modos. Como todos os modos de falha em desenvolvimento são } \\
\text { reparados em uma intervenção, considerou-se que todos os modos de falha } \\
\text { efetivamente 'falharam'. Assim, gerou-se dados de falha, e não dados } \\
\text { suspensos, para todos os modos de falha envolvidos. Caso estivesse disponível } \\
\text { a informação exata de qual modo de falha efetivamente foi o estopim, poder- } \\
\text { se-ia considerar as intervenções nos outros modos de falha como sendo } \\
\text { manutenções preventivas, e os dados gerados como sendo suspensos. Mas não } \\
\text { foi o caso. }\end{array}$ \\
\hline 10 & $\begin{array}{l}\text { Dados suspensos } \\
\text { sem data de } \\
\text { início de } \\
\text { operação }\end{array}$ & Pelas razões apresentadas no texto, este tipo de dado não foi utilizado \\
\hline
\end{tabular}

Pode ser perfeitamente aceitável ter um banco de dados que não seja $100 \%$ correto, desde que seja possível filtrar os erros, e desde que a quantidade de erros 
existente não leve a uma quantidade de dados restantes insuficientes para se fazer as análises necessárias.

A filtragem em bancos de dados contendo erros é muito trabalhosa. No caso desta dissertação, o autor levou cerca de 120 horas para fazê-la, ou, como trabalhou sozinho, 120 horas-homem. Entretanto, qual seria o custo de manter controles necessários para que o banco de dados não contenha erros? Provavelmente seria maior do que essas 120 horashomem. Isso não significa que não se devem buscar soluções para minimizar a quantidade de erros inseridos.

Para as análises que se seguem, foram pegos dados de falha e de reparo entre 15/09/2005 e 08/03/2007, num total de 540 dias de observação. Foram utilizados os softwares Minitab 14.2, Weibull++ 7 e BlockSim 6.

\subsection{Desenvolvimento do Modelo}

Feitas as hipóteses e filtrações de dados necessárias é hora de efetivamente criar um modelo para fazer análises. A Figura 4-4 mostra um fluxograma para análise de disponibilidade. Carazas et al (2007) e Marquez et al (2005) apresentam metodologias semelhantes à que é apresentada neste texto, porém para uma aplicação onde a quantidade de dados disponíveis é bem menor, então as etapas de verificação são mais limitadas.

Os primeiros passos são estabelecer um modelo inicial e a sua respectiva árvore de falhas. Esta árvore pode ser a própria árvore funcional, uma simplificação desta, ou pode ainda ser estabelecida a partir do FMEA do sistema a ser estudado, onde cada modo de falha de cada componente da árvore funcional será considerado. O limite de detalhamento nesta etapa é arbitrário, mas uma boa escolha inicial pode economizar tempo com várias iterações. O nível detalhamento final do modelo dependerá muito da quantidade de dados disponível, mas não há como fazer este ajuste a priori. 


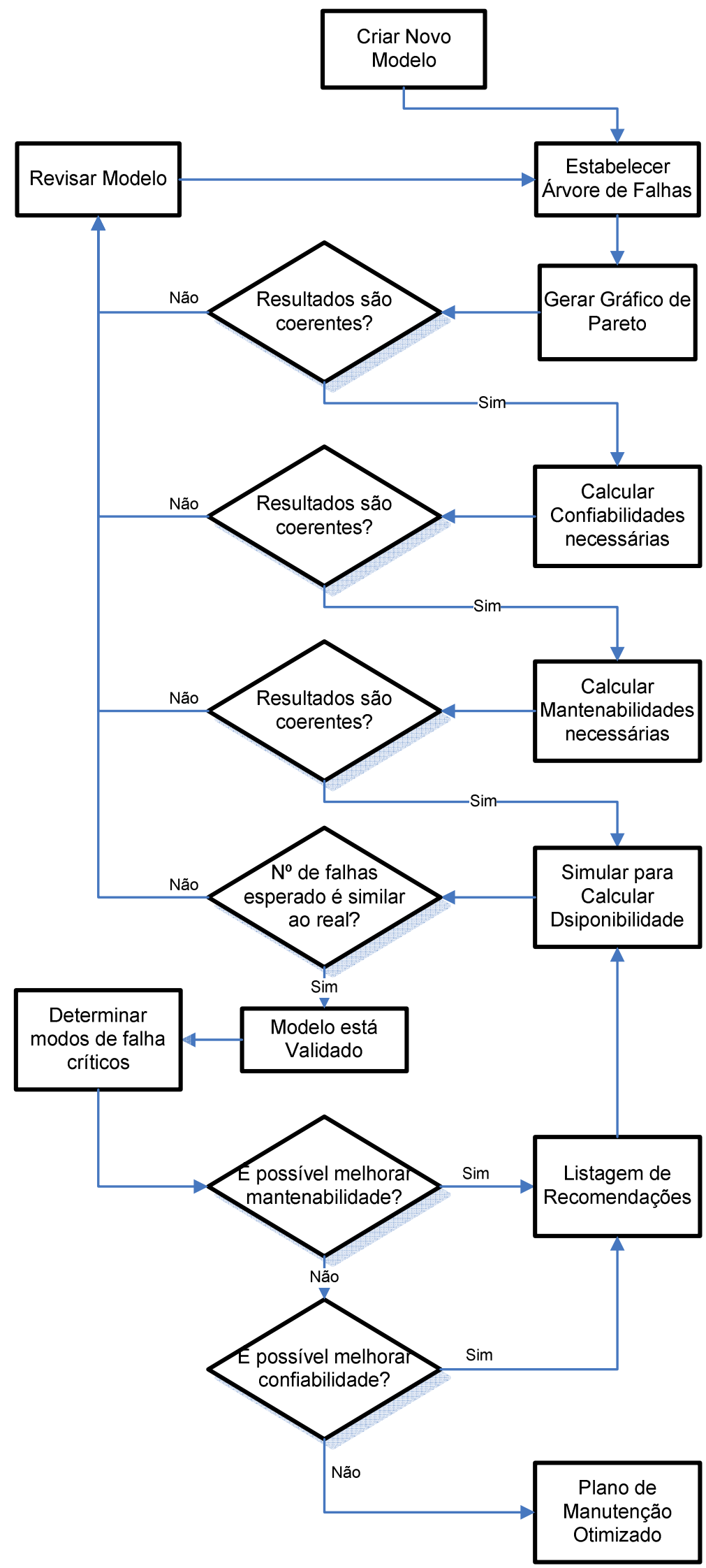

Figura 4-4 - Fluxograma de Análise de Disponibilidade. 
A seguir, deve-se gerar um gráfico de Pareto com número de ocorrências de cada modo de falha considerado na árvore de falhas, e compará-lo com o sentimento e a observação das pessoas envolvidas na manutenção do sistema. Nesta etapa, é importante conversar com pessoas de toda a hierarquia da manutenção - do mais baixo ao mais alto para se ter uma visão bem abrangente do problema. Diferenças muito grandes podem significar que os dados utilizados não são representativos da população, contém muitos erros, ou não estão bem filtrados. Se isto ocorrer, deve-se revisar o modelo, e possivelmente revisar os critérios para a filtragem dos dados.

$\mathrm{Na}$ etapa seguinte, as confiabilidades devem ser calculadas para todos os modos de falha considerados. Ordenando as confiabilidades da pior para a melhor, deve-se obter uma ordenação semelhante à do gráfico de Pareto. Quanto maior for o período de amostragem, maior tende a ser a semelhança entre os resultados. As discrepâncias encontradas devem ser tratadas de forma distinta: caso um modo de falha discrepante possua poucos dados de falha, é um sinal de que a estimativa da confiabilidade não é precisa. Logo, pode ser interessante agrupar este modo de falha em um grupo mais genérico. Por exemplo: um subsistema que contém diversos componentes com poucos dados de falha cada pode ser considerado como um único modo de falha. Desta forma, o número de dados de falha para uma análise de confiabilidade aumenta, aumentando também a precisão.

No entanto, caso os dados para o modo de falha considerado não se ajustem bem à nenhuma distribuição, pode ser sinal de que dois modos de falha com comportamentos distintos foram agrupados, o que mais uma vez diminui a precisão da estimativa de confiabilidade. Neste caso, pode ser interessante explodir este grupo em dois ou mais modos de falha, aumentando o nível de detalhamentos. Em qualquer um dos casos acima, deve-se voltar ao início do fluxograma.

O próximo passo é calcular as mantenabilidades. Os resultados aqui também devem ser comparados com o sentimento e a observação das pessoas envolvidas na manutenção do sistema. Novamente, grandes diferenças podem indicar problemas com os dados, que devem ser revistos.

Finalmente, deve-se fazer uma simulação com o método de Monte Carlo para 
obter os resultados de disponibilidade do sistema. A última etapa de verificação do modelo consiste em obter os números esperados de falha numa simulação em período igual ao do período de amostragem, e comparar os resultados com o número de falhas real. Caso os resultados sejam similares, é sinal de que as estimativas de confiabilidade e mantenabilidade estão precisas, e de que a simulação foi feita corretamente. Sendo assim, o modelo está validado.

Com o modelo validado, é possível trabalhar para melhorar o sistema. Os modos de falha mais críticos podem ser determinados através dos tempos de indisponibilidade esperada causada ao sistema por cada modo de falha. Estes valores podem ser encontrados pela simulação de Monte Carlo. Vale ressaltar que pode acontecer de o modo de falha mais crítico não ser aquele de pior confiabilidade ou pior mantenabilidade, mas aquele que possui os dois ruins, embora não sejam os piores.

Para estes modos de falha críticos vale a pena investigar mais detalhadamente o comportamento da confiabilidade e mantenabilidade e propor melhorias em políticas de manutenção, cronogramas de manutenção, treinamentos para os manutendores, reprojetos de componentes, reespecificação de materiais, etc. Assim, uma lista de recomendações é gerada para ser implantada em momento oportuno.

Com estas mudanças, o comportamento da disponibilidade altera-se, logo as simulações devem ser refeitas. Para que valores reais sejam obtidos, deve-se aguardar novo banco de dados ser gerado após a implantação das modificações, e então recalcular confiabilidades e mantenabilidades. No entanto, pode-se fazer uma análise de sensibilidade e modificar parâmetros de confiabilidade ou mantenabilidade para os valores que se esperam a partir das modificações. Os resultados obtidos desta maneira não serão reais, mas podem orientar muito fortemente tomadas de decisão acerca de quais melhorias implantar primeiro.

Por fim, não há definição universal do que é similar e o que é discrepante neste modelo, a definição variará conforme o caso, e conforme a interpretação do engenheiro ou equipe responsável. Sendo assim, ainda que o fluxograma da Figura 4-4 dê diretrizes claras de como desenvolver um modelo, o papel do engenheiro ou equipe de confiabilidade como tomadores de decisão continua sendo vital. 


\subsection{Determinação das Distribuições da Confiabilidade}

Após percorrer algumas vezes o loop proposto na Figura 4-4, foi validado o modelo que está representado na Figura 4-5, que mostra os modos de falha considerados para uma posição de uma máquina. Os códigos utilizados para os modos de falha são explicados na Tabela 4-2. No restante do texto, sempre que houver menção a um grupo, será através dos códigos nesta tabela.

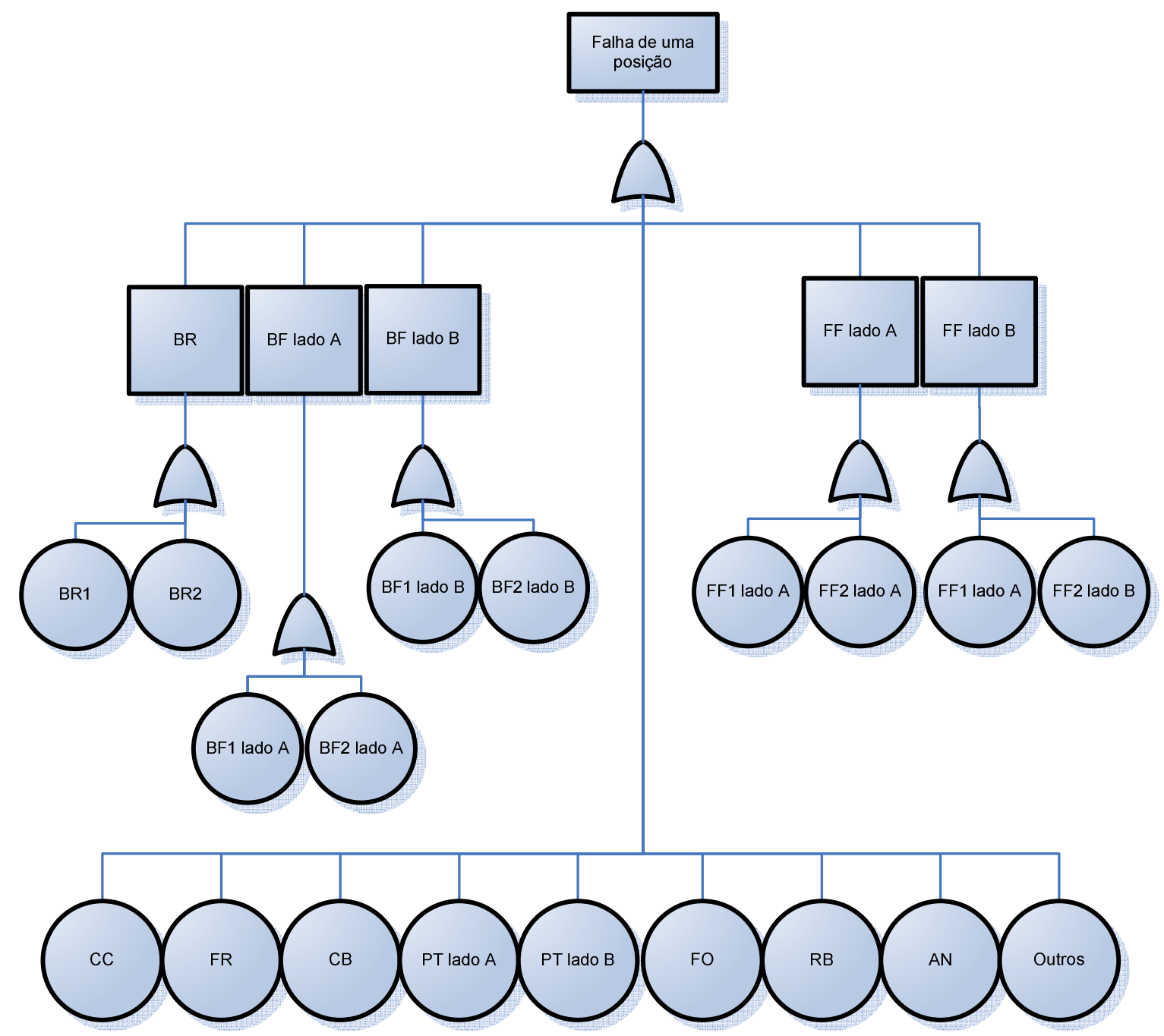

Figura 4-5 - Árvore de Falhas considerada para a falha de uma posição.

Este modelo é uma simplificação da árvore funcional apresentada na Figura 4-2. Esta simplificação é necessária, pois embora já haja uma árvore de falha disponível, que é de onde saem todos os possíveis modos de falha listados no banco de dados, nem todos os modos de falha reais contém uma quantidade de dados suficiente para uma análise 
estatística. Assim, diversos modos de falha reais foram agrupados em alguns modos de falha do modelo.

Tabela 4-2 - Códigos dos modos de falha.

\begin{tabular}{lc}
\hline \multicolumn{1}{c}{ Modo de Falha } & $\begin{array}{c}\text { Código do Modo de } \\
\text { Falha }\end{array}$ \\
\hline Anel & AN \\
Bolster Filage lado A - Mecânico & BF1 lado A \\
Bolster Filage lado A - Refugo & BF2 lado A \\
Bolster Filage lado B - Mecânico & BF1 lado B \\
Bolster Filage lado B - Refugo & BF2 lado B \\
Bolster Retordage - Mecânico & BR1 \\
Bolster Retordage - Refugo & BR2 \\
Cabestã & CB \\
Correia Cadarço & CC \\
Freio & FO \\
Fuso Filage lado A & FF lado A \\
Fuso Filage lado A - Mecânico & FF1 lado A \\
Fuso Filage lado A - Refugo & FF2 lado A \\
Fuso Filage lado B & FF lado B \\
Fuso Filage lado B - Mecânico & FF1 lado B \\
Fuso Filage lado B - Refugo & FF2 lado B \\
Fuso Retordage & FR \\
Outros & OU \\
Pote lado A & PT lado A \\
Pote lado B & PT lado B \\
Rabo de Porco & RP \\
\hline
\end{tabular}

Os grupos $B R, B F$ lado $A, B F$ lado $B, F F$ lado $A$ e $F F$ lado $B$ foram expandidos em dois modos de falha cada um, respectivamente indicados por 1 e 2 . FF1 lado A e FF1 lado $B$ representam falhas dos fusos da Filage causadas exclusivamente por refugo acumulado sobre ou entre os componentes. Já FF2 lado A e FF2 lado B representam falhas desses fusos causadas por fatores mecânicos: desgaste, fadiga, corrosão, etc. BRl, BF1 lado A e BF1 lado B representam falhas do conjunto de peças que são montadas junto com o bolster, conforme apresentado em 2.2, causadas somente pelo amortecedor. $B R 2, B F 2$ lado A, BF2 lado B representam falhas destes conjuntos causadas por falhas de outras peças.

Esta árvore de falhas poderia ser representada por um Diagrama de Blocos em série, e de fato é assim que a Confiabilidade do sistema é calculada. Mas, para efeitos de representação gráfica, devido ao grande número de componentes em série, optou-se por uma árvore de falhas. Note que todas as portas lógicas são do tipo “ou”, o que representa 
ligações em série.

Sabendo-se que os dados são gerados a partir das falhas, quanto menos dados há, menos falhas houve, então a confiabilidade é maior. Esta interpretação é bem intuitiva, e é um ponto de partida para análises mais elaboradas. Uma forma de se representar isto graficamente é pelo gráfico de Pareto, Figura 4-6. As barras representam a porcentagem de cada grupo no total de falhas. A Tabela 4-3 mostra os dados que geraram o gráfico.

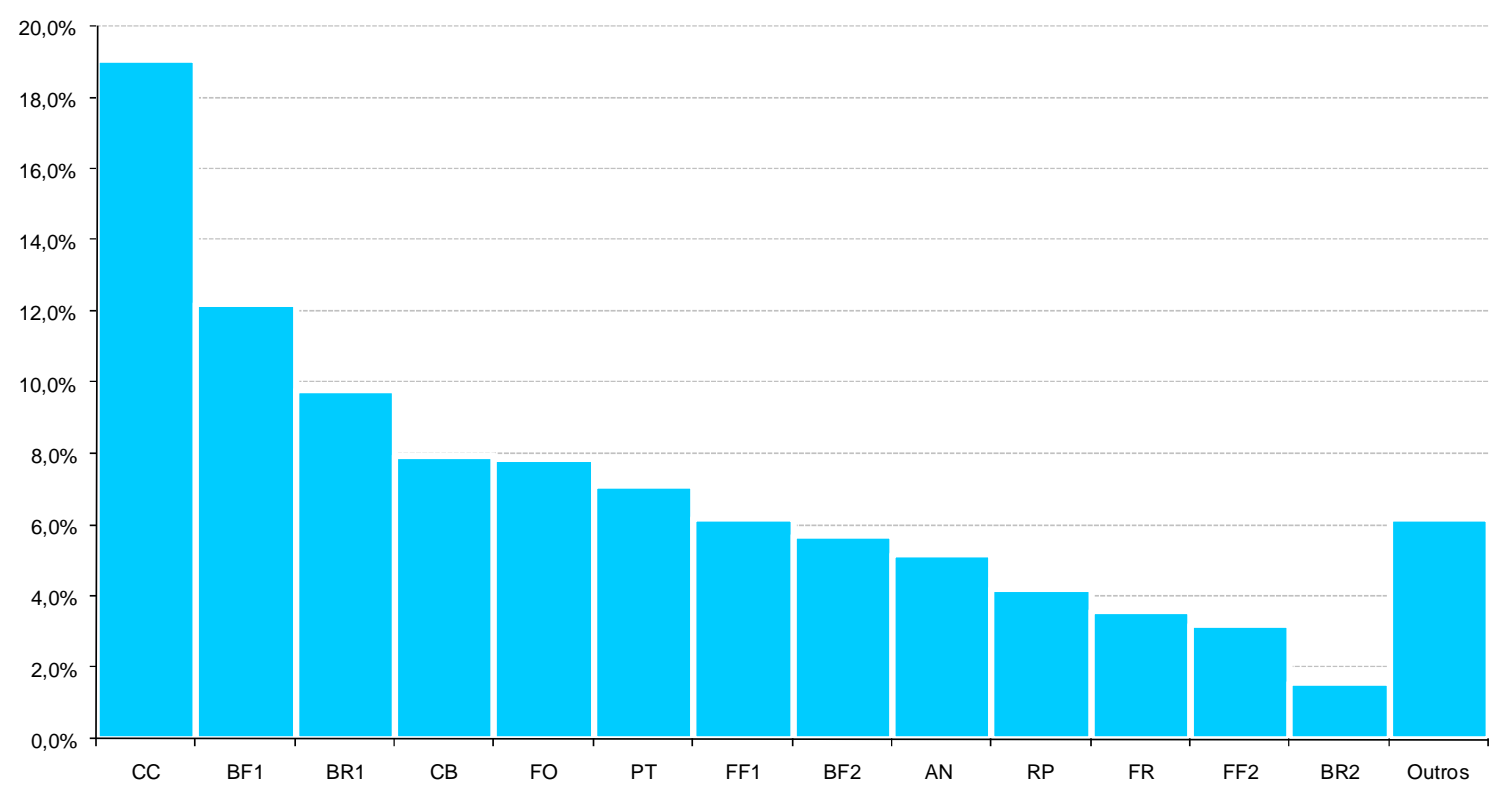

Figura 4-6 - Pareto de ocorrências de falha entre os diferentes modos de falha.

Inicialmente, considerou-se que todas as posições de todas as máquinas possuem a mesma confiabilidade. Esta hipótese facilita a análise, pois aumenta o número de dados para um mesmo cálculo de confiabilidade, o que estreita os intervalos de confiança.

Outra hipótese feita foi a de que para os grupos BF lado $A$ e $B F$ lado $B$ as confiabilidades também são iguais, pois os componentes são exatamente os mesmos, em instalações a princípio idênticas. Esta mesma hipótese também foi feita para $F F$ lados $A$ e $B$, e $P T$ lados $A$ e $B$. Por essa razão, estes grupos não aparecem expandidos em lados $A$ e $B$ no gráfico de Pareto. 
Tabela 4-3 - Ocorrências de falhas entre os diferentes grupos.

\begin{tabular}{lccc}
\hline $\begin{array}{c}\text { Código do Modo } \\
\text { de Falha }\end{array}$ & Falhas & Porcentagem & Acumulado \\
\hline CC & 3111 & $19,1 \%$ & $19,1 \%$ \\
BF1 & 1998 & $12,2 \%$ & $31,3 \%$ \\
BR1 & 1603 & $9,8 \%$ & $41,1 \%$ \\
CB & 1297 & $7,9 \%$ & $49,1 \%$ \\
FO & 1284 & $7,9 \%$ & $56,9 \%$ \\
PT & 1159 & $7,1 \%$ & $64,0 \%$ \\
FF1 & 1009 & $6,2 \%$ & $70,2 \%$ \\
BF2 & 933 & $5,7 \%$ & $75,9 \%$ \\
AN & 850 & $5,2 \%$ & $81,1 \%$ \\
RP & 691 & $4,2 \%$ & $85,4 \%$ \\
FR & 588 & $3,6 \%$ & $89,0 \%$ \\
FF2 & 527 & $3,2 \%$ & $92,2 \%$ \\
BR2 & 259 & $1,6 \%$ & $93,8 \%$ \\
Outros & 1014 & $6,2 \%$ & $100,0 \%$ \\
\hline
\end{tabular}

Para cada modo de falha foi então calculada a confiabilidade. A Tabela 4-4 mostra os resultados para este modelo, e a Figura 4-7 mostra os mesmos resultados graficamente. Nesta tabela são mostrados os valores de confiabilidade para 180, 360, 540 e 720 dias. É preciso ter cautela com os valores para 720 dias: o período de amostragem foi de 540 dias, então as confiabilidades para este tempo são extrapolações. As distribuições estatísticas e seus parâmetros são calculados para se adequar bem aos dados existentes. Quanto maiores forem os tempos, mais distante estará a extrapolação dos dados reais, e conseqüentemente mais largos serão os intervalos de confiança. Por exemplo, pode existir um determinado modo de falha que, dentro do período amostrado, não apresentou um aumento na taxa de falha característico de desgastes mecânicos. Uma extrapolação para períodos maiores mostraria taxas de falhas constantes ou decrescentes no tempo. Caso esse aumento da taxa de falha exista para períodos maiores, o uso de uma extrapolação para tomada de decisões pode ficar comprometido. 
Tabela 4-4 - Parâmetros de confiabilidade para todos os modos de falha do modelo.

\begin{tabular}{|c|c|c|c|c|c|c|c|c|c|c|}
\hline \multicolumn{11}{|c|}{ Confiabilidade } \\
\hline \multirow{2}{*}{$\begin{array}{c}\text { Modo de } \\
\text { Falha }\end{array}$} & \multirow{2}{*}{ Falhas } & \multirow{2}{*}{ Suspensões } & \multirow{2}{*}{ Distribuição } & \multirow{2}{*}{\multicolumn{2}{|c|}{ Parâmetros }} & \multirow{2}{*}{$\begin{array}{c}M T B F \\
(\text { dias })\end{array}$} & \multicolumn{4}{|c|}{ Confiabilidade em (\%): } \\
\hline & & & & & & & 180 dias & 360 dias & 540 dias & 720 dias \\
\hline$\overline{C C}$ & 1688 & 1603 & Weibull & $\beta=0,752$ & $\eta=2,46 E+02$ & $2,93 \mathrm{E}+02$ & $45,4 \%$ & $26,4 \%$ & $16,5 \%$ & $\overline{10,7 \%}$ \\
\hline BR1 & 471 & 948 & Weibull & $\beta=1,125$ & $\eta=5,22 E+02$ & $5,00 \mathrm{E}+02$ & $73,9 \%$ & $51,8 \%$ & $35,4 \%$ & $23,8 \%$ \\
\hline BR2 & 18 & 201 & Weibull & $\beta=0,793$ & $\eta=7,24 \mathrm{E}+03$ & $8,26 \mathrm{E}+03$ & $94,8 \%$ & $91,2 \%$ & $88,0 \%$ & $85,2 \%$ \\
\hline $\mathrm{BF} 1$ & 379 & 1207 & Weibull & $\beta=0,867$ & $\eta=1,15 E+03$ & $1,24 \mathrm{E}+03$ & $81,8 \%$ & $69,4 \%$ & $59,5 \%$ & $51,4 \%$ \\
\hline BF2 & 76 & 695 & Weibull & $\beta=1,018$ & $\eta=2,60 E+03$ & $2,58 E+03$ & $93,6 \%$ & $87,5 \%$ & $81,7 \%$ & $76,3 \%$ \\
\hline $\mathrm{FF} 1$ & 145 & 647 & Lognormal & $\mu=8,019$ & $\sigma=3,33 E+00$ & $7,89 \mathrm{E}+05$ & $80,2 \%$ & $73,9 \%$ & $69,8 \%$ & $66,7 \%$ \\
\hline FF2 & 40 & 448 & Weibull & $\beta=0,934$ & $\eta=2,79 E+03$ & $1,28 E+03$ & $92,6 \%$ & $86,3 \%$ & $80,6 \%$ & $75,4 \%$ \\
\hline FR & 92 & 443 & Weibull & $\beta=0,741$ & $\eta=2,15 E+03$ & $2,58 \mathrm{E}+03$ & $85,3 \%$ & $76,6 \%$ & $69,8 \%$ & $64,1 \%$ \\
\hline CB & 461 & 677 & Weibull & $\beta=0,962$ & $\eta=4,79 E+02$ & $4,88 \mathrm{E}+02$ & $67,7 \%$ & $46,8 \%$ & $32,6 \%$ & $22,8 \%$ \\
\hline PT & 207 & 660 & Weibull & $\beta=0,698$ & $\eta=1,78 E+03$ & $2,26 \mathrm{E}+03$ & $81,7 \%$ & $72,1 \%$ & $64,7 \%$ & $58,8 \%$ \\
\hline AN & 195 & 559 & Weibull & $\beta=0,766$ & $\eta=1,22 E+03$ & $1,43 E+03$ & $79,4 \%$ & $67,6 \%$ & $58,6 \%$ & $51,3 \%$ \\
\hline$R P$ & 140 & 513 & Lognormal & $\mu=7,245$ & $\sigma=2,17 \mathrm{E}+00$ & $1,48 E+04$ & $82,8 \%$ & $73,4 \%$ & $67,0 \%$ & $62,1 \%$ \\
\hline $\mathrm{FO}$ & 145 & 595 & Weibull & $\beta=0,792$ & $\eta=1,32 E+03$ & $1,51 \mathrm{E}+03$ & $81,4 \%$ & $70,0 \%$ & $61,1 \%$ & $53,9 \%$ \\
\hline OU & 229 & 675 & Weibull & $\beta=0,903$ & $\eta=7,43 \mathrm{E}+02$ & $7,80 \mathrm{E}+02$ & $75,7 \%$ & $59,5 \%$ & $47,2 \%$ & $37,8 \%$ \\
\hline
\end{tabular}




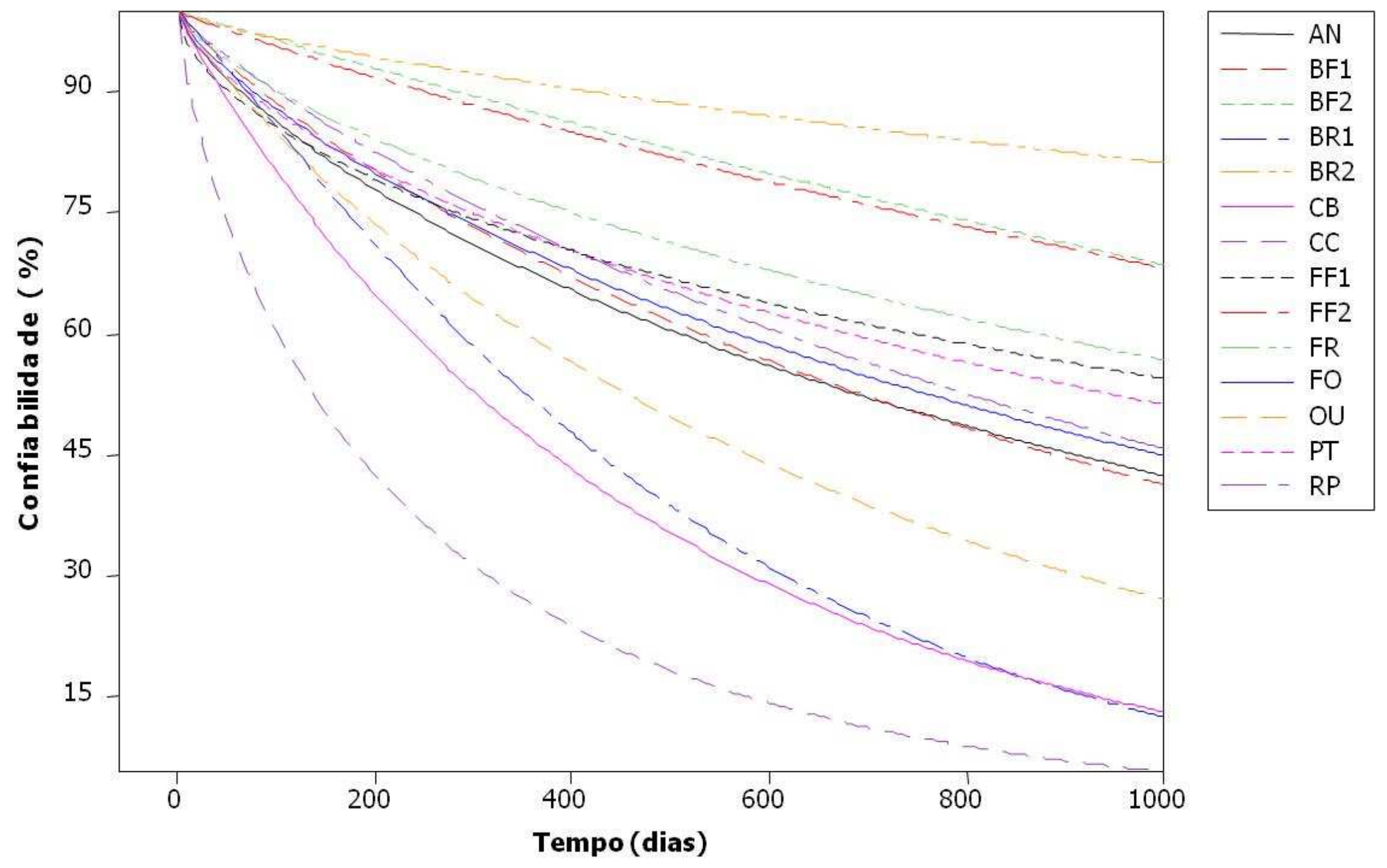

Figura 4-7 - Confiabilidade de todos os modos de falha. 


\subsubsection{Interpretação dos Resultados}

A partir da Figura 4-7 e da Tabela 4-4 é possível fazer diversas interpretações. É possível observar claramente os modos de falha $C C, C B$ e $B R I$ como os mais críticos. $\mathrm{O}$ modo da falha BFl também é considerado como um modo de falha crítico: como mostrado na árvore de falhas da Figura 4-5, este modo de falha pode aparecer tanto no lado A quanto no lado $B$. Sendo assim, o número de falhas e a indisponibilidade resultantes deste modo de falha são o dobro do que seria esperado pela curva mostrada na Figura 4-7.

Da maneira como o modelo foi proposto, cada confiabilidade foi calculada a partir dos dados de falha de todas as posições de todas as máquinas. Para estes quatro modos de falha mais críticos as confiabilidades foram recalculadas máquina a máquina: A confiabilidade das posições de uma determinada máquina foi avaliada utilizando somente os dados de falha das posições daquela máquina em particular. Esta separação é importante pois é possível identificar, dentro de cada modo de falha crítico, quais máquinas são melhores e quais são piores. A partir de então, pode-se avaliar tecnicamente quais as diferenças existentes, e tomar ações no sentido de igualar as piores máquinas às melhores. Estas separações e demais interpretações são apresentadas a seguir.

\subsubsection{Modo de Falha $C C$}

Olhando ainda a Figura 4-7, tem-se que $C C$ é o modo de falha que apresenta a queda de confiabilidade mais brusca, logo no começo de vida. Há aqui muitas falhas precoces, com a taxa de falha sendo decrescente no tempo. A partir destes dados do conjunto de máquinas, eventuais ações de melhoria devem focar somente o começo de vida: ações que tenham por objetivo diminuir o desgaste por uso prolongado não serão eficazes para aumentar a confiabilidade. É interessante inclusive investigar se este grande número de falhas precoces é proveniente de um real comportamento físico dos equipamentos, ou de uma dificuldade de diagnóstico da falha, e consequiente ação incorreta.

No entanto, é possível fazer uma análise mais precisa quando se olham os 
resultados calculados máquina a máquina, como mostra a Tabela 4-5 $5^{1}$. A Figura 4-8 mostra graficamente os resultados de confiabilidade, com as linhas de centro das estimativas de confiabilidade e respectivos intervalos de confiança, representados pelas mesmas cores e tracejados que a linha de centro, e indicados na figura por IC $95 \%$ (intervalo de confiança inferior, representando uma probabilidade de $95 \%$ de a confiabilidade estar acima desta linha) e por IC 5\% (intervalo de confiança superior, representando uma probabilidade de $5 \%$ de a confiabilidade estar acima desta linha). A Figura 4-9 apresenta as Taxas de Falha.

Tabela 4-5 - Confiabilidades de $C C$ para diferentes máquinas.

\begin{tabular}{|c|c|c|c|c|c|c|c|c|c|c|}
\hline \multicolumn{11}{|c|}{ Confiabilidade $C C$} \\
\hline \multirow{2}{*}{ Máq } & \multirow{2}{*}{ Falhas } & \multirow{2}{*}{ Suspensões } & \multirow{2}{*}{ Distribuição } & \multirow{2}{*}{\multicolumn{2}{|c|}{ Parâmetros }} & $M T B F$ & \multicolumn{4}{|c|}{ Confiabilidade em (\%): } \\
\hline & & & & & & (dias) & 180 dias & 360 dias & 540 dias & 720 dias \\
\hline $\bar{A}$ & 178 & 120 & Weibull & $\beta=0,734$ & $\eta=2,18 E+02$ & $2,64 \mathrm{E}+02$ & $41,9 \%$ & $23,6 \%$ & $14,3 \%$ & $9,0 \%$ \\
\hline B & 103 & 110 & Weibull & $\beta=0,645$ & $\eta=2,59 E+02$ & $3,57 E+02$ & $45,4 \%$ & $29,1 \%$ & $20,1 \%$ & $14,5 \%$ \\
\hline C & 116 & 103 & Weibull & $\beta=0,712$ & $\eta=3,98 E+02$ & $4,96 \mathrm{E}+02$ & $56,7 \%$ & $39,4 \%$ & $28,9 \%$ & $21,8 \%$ \\
\hline
\end{tabular}

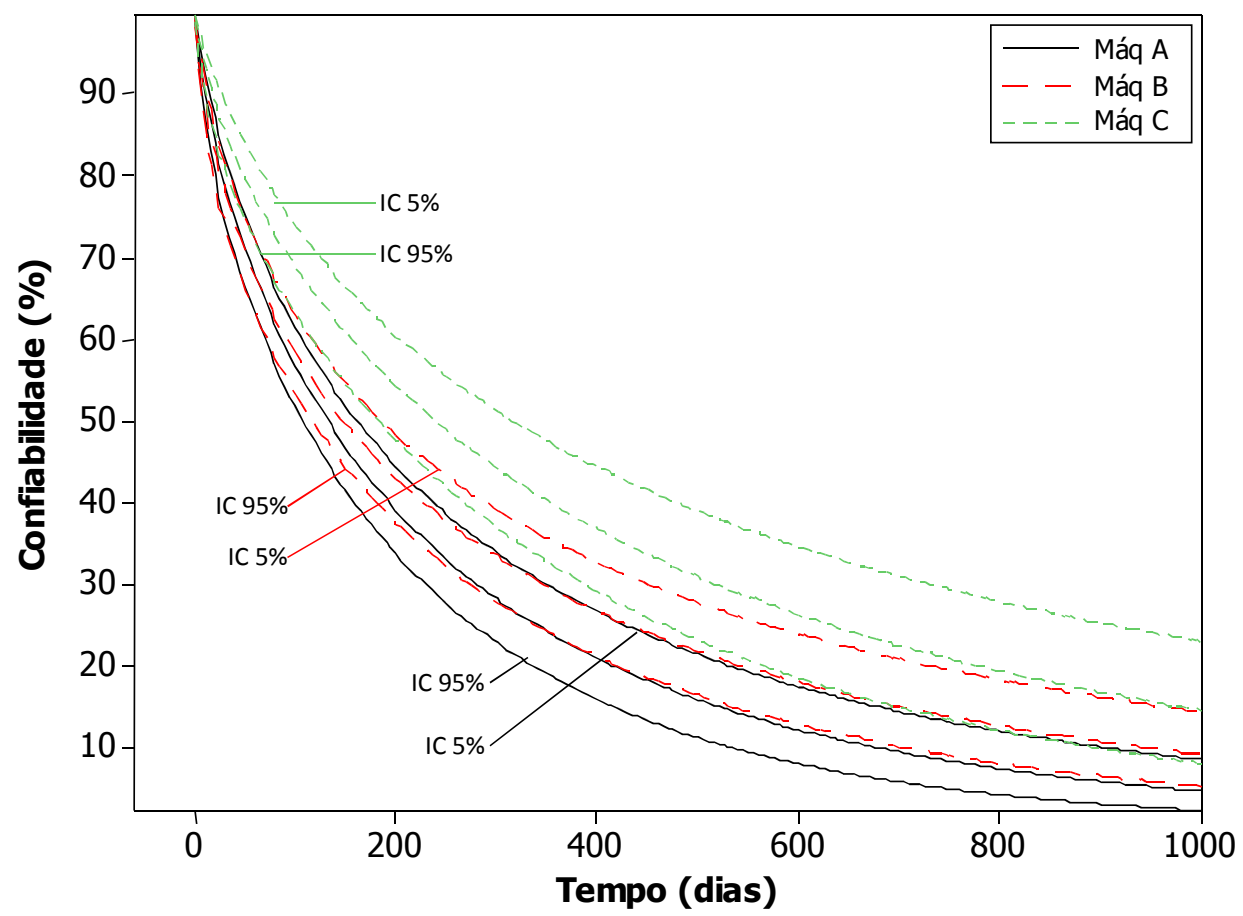

Figura 4-8 - Confiabilidade para $C C$.

\footnotetext{
${ }^{1}$ Por questão de confidencialidade dos dados, não poderão ser apresentados os resultados para todas as máquinas, tampouco a identificação real das máquinas. Essa identificação será feita aqui por letras. Nas análises a seguir, as máquinas $A, B$, e $C$ representam três máquinas distintas, assim como $D, E$, e $F$; e assim por diante
} 


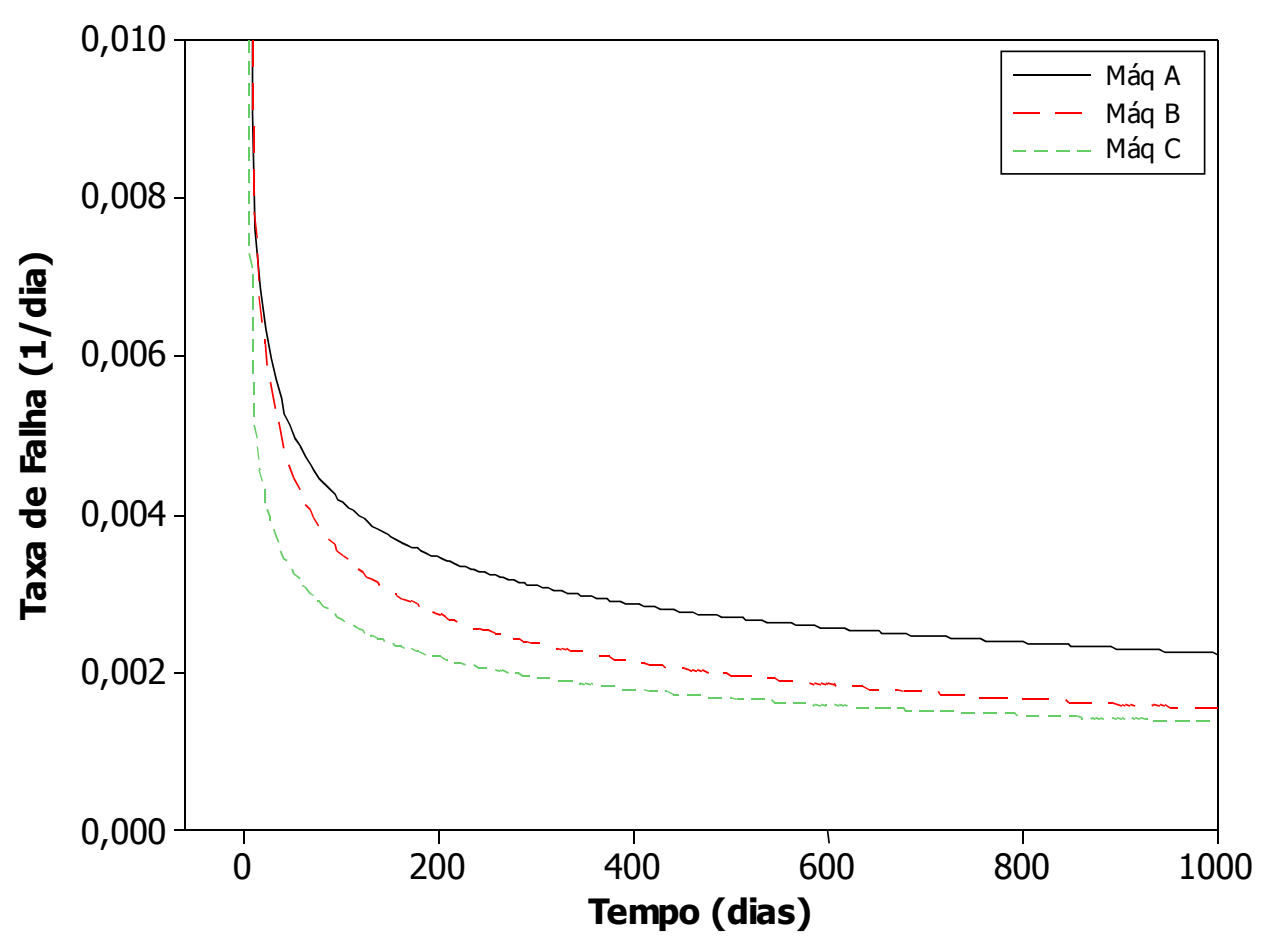

Figura 4-9 - Taxa de Falha para $C C$.

Todas as máquinas apresentam taxa de falha com comportamento semelhante: decrescente, com um grande pico no início. Isto é um indicativo de uma mortalidade infantil. Só diferem na intensidade: A máquina $A$ tem maior taxa de falha no início de vida, e isso se reflete numa menor estimativa da Confiabilidade. No entanto, os intervalos de confiança das máquinas $A$ e $B$ se sobrepõe, logo não é possível concluir que a Confiabilidade de $A$ ao longo do tempo realmente é menor que a de $B$, mas há uma tendência para isso. Já quando se compara $A \operatorname{com} C$, vê-se que os intervalos de confiança não se sobrepõe. Assim, é possível afirmar que a Confiabilidade de $A$ ao longo do tempo $e ́$ menor que a de $C$.

Nenhuma destas máquinas apresenta um aumento da taxa de falha ao final da vida. Isto indica que, neste período, falhas por desgaste não são significativas, somente falhas aleatórias o são. Este modo de falha apresenta um caso típico onde manutenções preventivas não são benéficas: Se, por exemplo, a correia que origina este modo de falha for trocada preventivamente depois do período inicial de vida, a taxa de falha volta a se comportar como no início de vida, ou seja, será sensivelmente maior. Este comportamento é conhecido e está descrito em detalhes na seção 3.3.2: quando $\beta<1$, a manutenção preventiva é prejudicial. 
Vale ressaltar que, apesar de conhecido, este não é um comportamento esperado para um modo de falha como este. Para uma correia, que é um componente mecânico bem convencional, espera-se um comportamento que indique falhas por desgaste, semelhante à região 3 da curva da banheira da Figura 3-3, sem mortalidade infantil considerável. Descobrir o real motivo para a alteração do comportamento esperado pode resultar em grandes benefícios para esta empresa. Possivelmente, podem estar ocorrendo problemas na instalação, como tensão excessiva ou insuficiente, ou algum problema de especificação do componente.

\subsubsection{Modo de Falha BF1}

Ao contrário de $C C, B F 1$ não mostra um comportamento semelhante para todas as máquinas, como mostrado na Tabela 4-6, Figura 4-10 e Figura 4-11.

Tabela 4-6 - Confiabilidades para BF1 para diferentes máquinas.

\begin{tabular}{|c|c|c|c|c|c|c|c|c|c|c|}
\hline \multicolumn{11}{|c|}{ Confiabilidade BF1 } \\
\hline \multirow{2}{*}{ Máq } & \multirow{2}{*}{ Falhas } & \multirow{2}{*}{ Suspensões } & \multirow{2}{*}{ Distribuição } & \multirow{2}{*}{\multicolumn{2}{|c|}{ Parâmetros }} & \multirow{2}{*}{$\begin{array}{c}\text { MTBF } \\
\text { (dias) }\end{array}$} & \multicolumn{4}{|c|}{ Confiabilidade em (\%): } \\
\hline & & & & & & & 180 dias & 360 dias & 540 dias & 720 dias \\
\hline $\mathrm{D}$ & 40 & 102 & Weibull & $\beta=0,649$ & $\eta=1,32 E+03$ & $1,80 \mathrm{E}+03$ & $75,9 \%$ & $65,0 \%$ & $57,1 \%$ & $50,8 \%$ \\
\hline $\mathrm{E}$ & 17 & 91 & Weibull & $\beta=0,966$ & $\eta=1,61 E+03$ & $1,64 \mathrm{E}+03$ & $88,7 \%$ & $79,1 \%$ & $70,7 \%$ & $63,2 \%$ \\
\hline $\mathrm{F}$ & 29 & 114 & Weibull & $\beta=1,749$ & $\eta=7,55 E+02$ & $6,73 \mathrm{E}+02$ & $92,2 \%$ & $76,0 \%$ & $57,3 \%$ & $39,8 \%$ \\
\hline
\end{tabular}

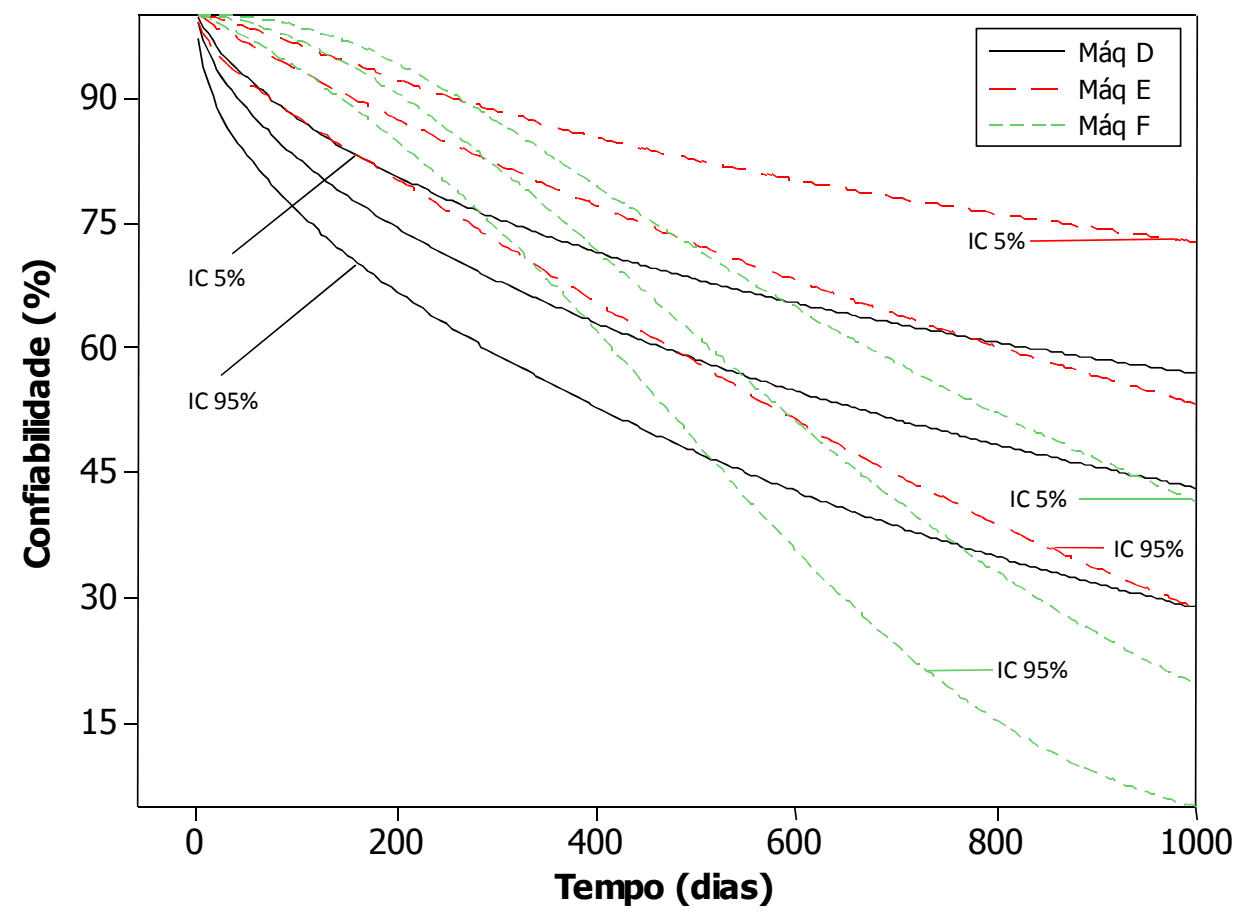

Figura 4-10 - Confiabilidade para BF1. 


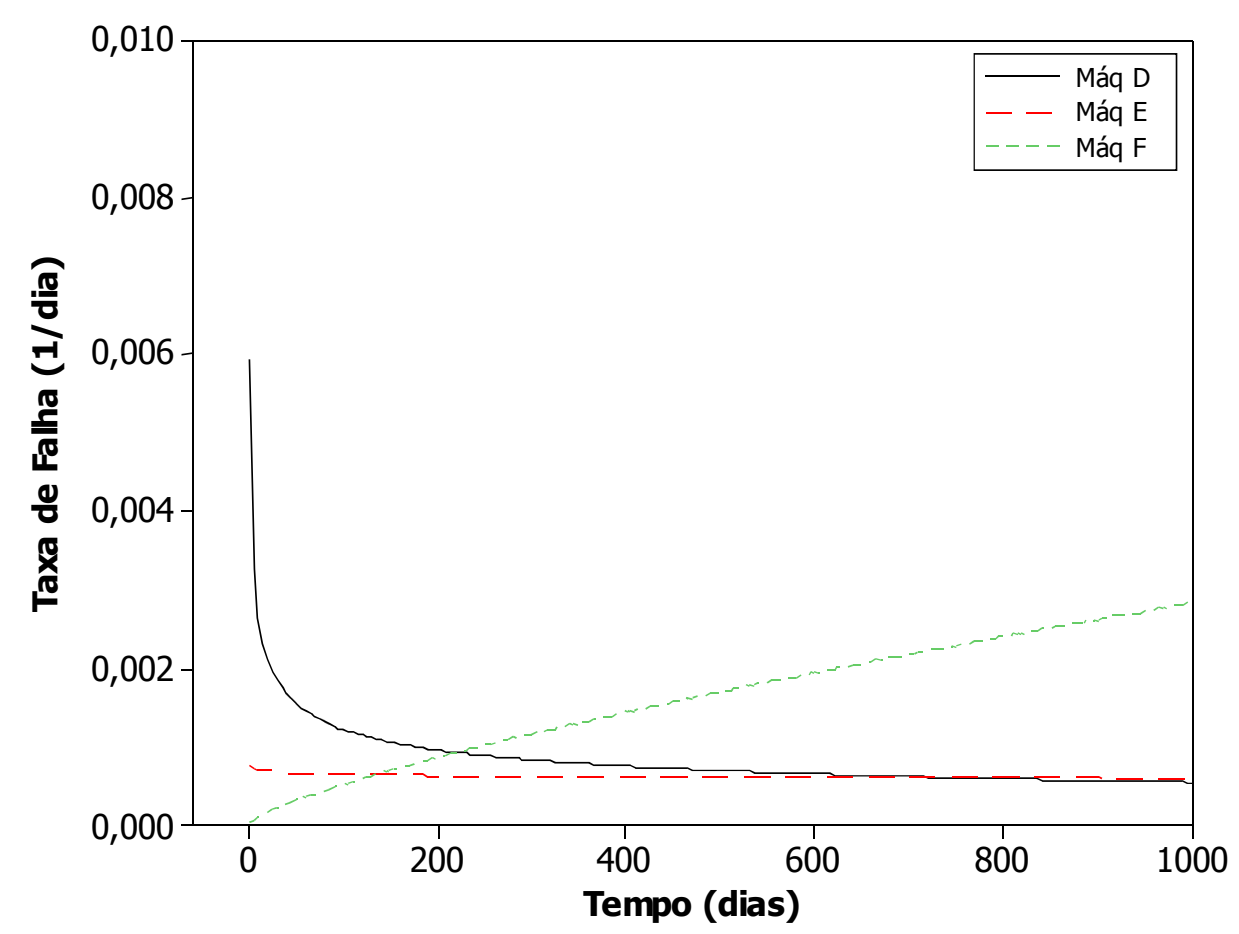

Figura 4-11 - Taxa de Falha para BF1.

Enquanto a máquina $D$ apresenta uma taxa de falha decrescente no início, a de $F$ é crescente, não apresentando mortalidade infantil. Isto se reflete numa maior confiabilidade para $F$ no início de vida. No entanto, a taxa de falha de $F$ se torna maior que a de $D$ acima dos 200 dias de operação. Mais uma vez, isso é refletido na estimativa de Confiabilidade: a de $D$ é maior que $F$ para vidas acima de 550 dias de operação.

Diferentemente de $D$ e $F, E$ apresenta uma taxa de falha praticamente constante ao longo do tempo. Devido ao parâmetro $\beta$ de distribuição de Weibull estimado para $E$ estar muito próximo de 1, a distribuição aproxima-se muito de uma Exponencial, cuja característica principal é ter taxa de falha constante ao longo do tempo, conforme descrito em 3.2.4.

Para $D$ tem-se claramente que a manutenção ideal, assim como para $C C$, é a corretiva, pois a corretiva seria prejudicial. Para $E$, o ideal também é a manutenção corretiva: neste caso, a manutenção preventiva não alteraria em nada a taxa de falha, logo, fazê-la seria um desperdício de recursos.

A taxa de falha crescente de $F$ indica que a manutenção preventiva pode ser a mais indicada. Para determinar o intervalo entre manutenções, pode-se usar um modelo 
que compara os custos da correção e perda de produção com os custos da prevenção. Xenos (2004) apresenta um modelo que segue estas características. Uma alternativa computacional seria utilizar os valores dos custos envolvidos em uma simulação de Monte Carlo, em softwares como o BlockSim (na seção 4.7 são apresentadas simulações feitas no BlockSim, mas com outros objetivos).

É interessante notar como o mesmo modo de falha segue comportamentos completamente distintos em máquinas que deveriam ser iguais. Podem-se especular alguns diferentes fatores que contribuem para isto: a diferença dos fios que são produzidos em cada máquina é um fator que pode ser estudado, já que os fios variam muito em relação ao diâmetro da sua seção transversal e, possivelmente, em relação aos esforços que aplicam nos componentes da máquina.

Outro fator que pode contribuir é a diferença de idade entre as máquinas. Não é possível afirmar que a diferença de idade é a causa da diferença de comportamento, mas faz sentido: fabricantes tendem a inserir em modelos de máquinas mais novos melhorias em relação aos mais antigos, que podem passar despercebidas pelo usuário, e que solucionam problemas eventualmente detectados.

Pode ser ainda que algumas máquinas passaram, em algum momento do passado, por grandes revisões que alteraram de alguma forma o seu comportamento. Mas como não existe histórico maior do que três anos, suposições sobre o que ocorreu no passado são apenas isso: suposições.

\subsubsection{Modo de Falha BRI}

O modo de falha $B R l$ é análogo a $B F 1$, com componentes similares. Tem-se um comportamento em relação à Confiabilidade também muito semelhante, como mostram a Tabela 4-7 e a Figura 4-12. A Figura 4-13 mostra a taxa de falha.

Tabela 4-7 - Confiabilidades para BR1 para diferentes máquinas.

\begin{tabular}{|c|c|c|c|c|c|c|c|c|c|c|}
\hline \multicolumn{11}{|c|}{ Confiabilidade BRI } \\
\hline \multirow{2}{*}{ Máq } & \multirow{2}{*}{ Falhas } & \multirow{2}{*}{ Suspensões } & \multirow{2}{*}{ Distribuição } & \multirow{2}{*}{\multicolumn{2}{|c|}{ Parâmetros }} & \multirow{2}{*}{$\begin{array}{c}\text { MTBF } \\
\text { (dias) }\end{array}$} & \multicolumn{4}{|c|}{ Confiabilidade em (\%): } \\
\hline & & & & & & & 180 dias & 360 dias & 540 dias & 720 dias \\
\hline $\mathrm{G}$ & 38 & 90 & Weibull & $\beta=1,419$ & $\eta=4,97 E+02$ & $4,52 \mathrm{E}+02$ & $78,9 \%$ & $53,1 \%$ & $32,5 \%$ & $18,4 \%$ \\
\hline $\mathrm{H}$ & 65 & 110 & Weibull & $\beta=0,873$ & $\eta=5,33 E+02$ & $5,70 \mathrm{E}+02$ & $67,9 \%$ & $49,1 \%$ & $36,3 \%$ & $27,2 \%$ \\
\hline 1 & 29 & 96 & Weibull & $\beta=1,044$ & $\eta=8,42 E+02$ & $8,28 \mathrm{E}+02$ & $81,9 \%$ & $66,3 \%$ & $53,3 \%$ & $42,8 \%$ \\
\hline
\end{tabular}




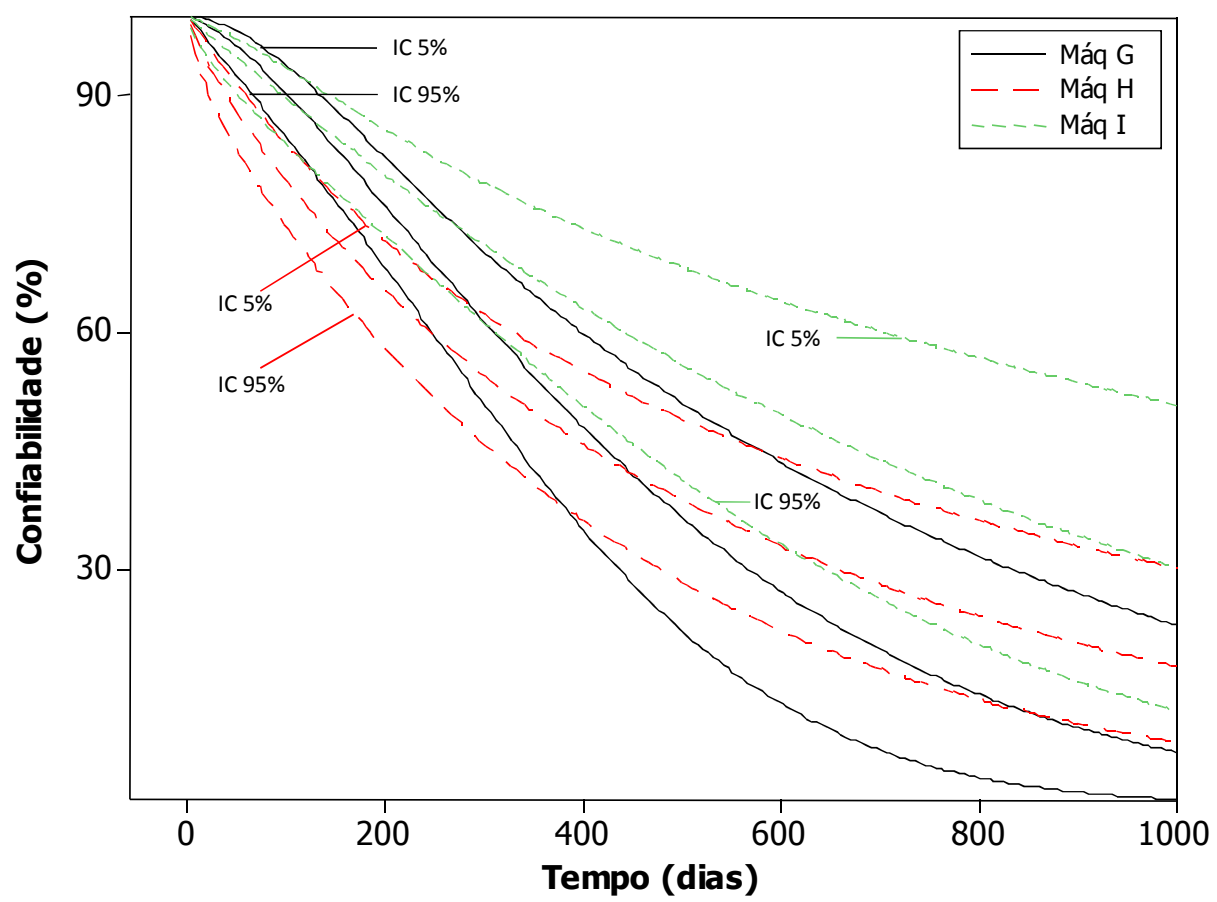

Figura 4-12 - Confiabilidade para $B R 1$.

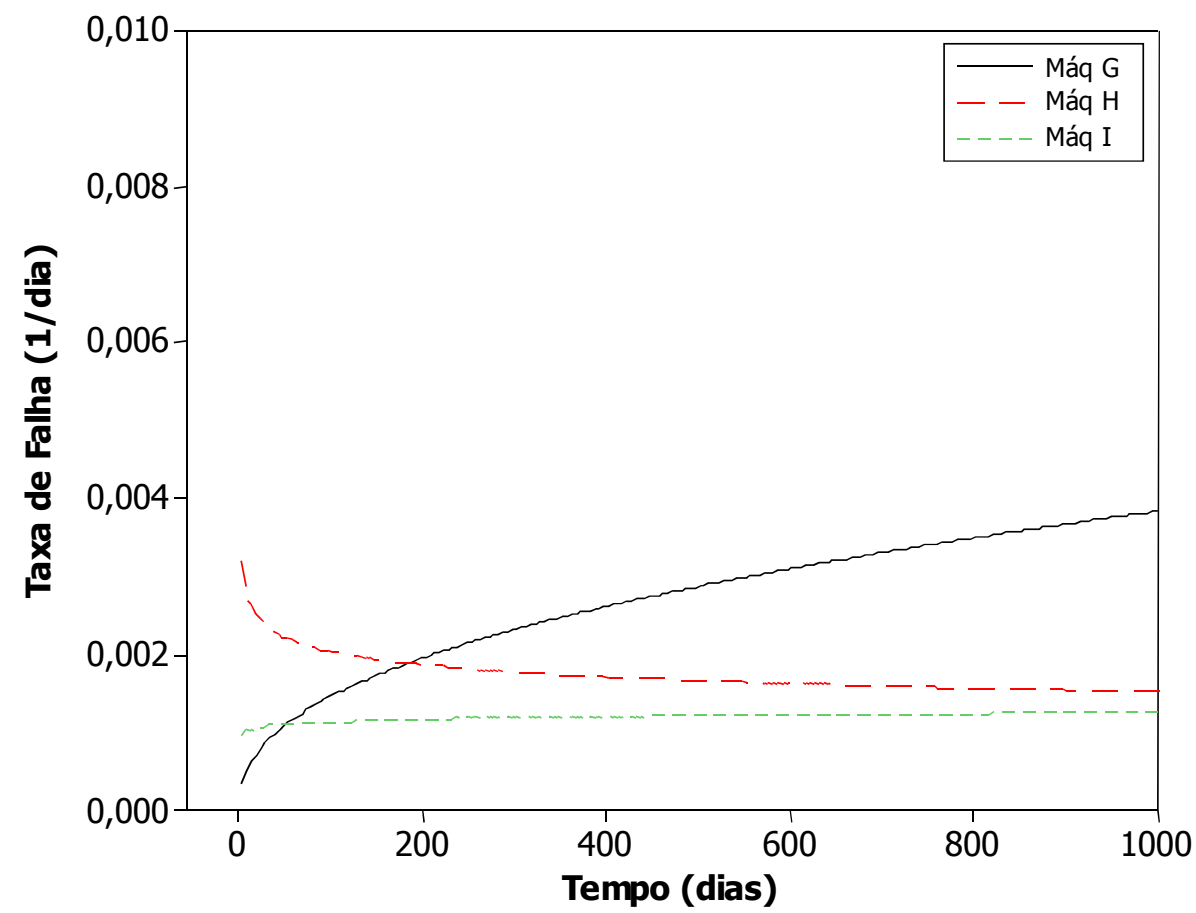

Figura 4-13 - Taxa de falha para $B R 1$.

Assim como para $B F 1$, temos uma máquina com taxa de falha constante, a $I$, uma com taxa de falha decrescente, $H$, e uma última com taxa de falha crescente, $G$. Mais uma 
vez, a manutenção preventiva é indicada somente para $G$. Em $I$ e $H$ sugere-se a manutenção corretiva como a mais indicada.

Para $B R l$, também valem todas as discussões feitas sobre a diferença de comportamentos observada em $B F 1$.

\subsubsection{Modo de Falha $C B$}

Seguem abaixo a Tabela 4-8 e a Figura 4-14, que mostram a confiabilidade do modo de falha $C B$. A Figura 4-15 mostra a sua taxa de falha.

Tabela 4-8 - Confiabilidades para $C B$ para diferentes máquinas.

\begin{tabular}{|c|c|c|c|c|c|c|c|c|c|c|}
\hline \multicolumn{11}{|c|}{ Confiabilidade $C B$} \\
\hline \multirow{2}{*}{ Máq } & \multirow{2}{*}{ Falhas } & \multirow{2}{*}{ Suspensões } & \multirow{2}{*}{ Distribuição } & \multirow{2}{*}{\multicolumn{2}{|c|}{ Parâmetros }} & $M T B F$ & \multicolumn{4}{|c|}{ Confiabilidade em (\%): } \\
\hline & & & & & & (dias) & 180 dias & 360 dias & 540 dias & 720 dias \\
\hline $\bar{J}$ & 32 & 65 & Weibull & $\beta=0,768$ & $\eta=8,33 E+02$ & $9,73 \mathrm{E}+02$ & $73,5 \%$ & $59,1 \%$ & $48,8 \%$ & $40,9 \%$ \\
\hline K & 69 & 75 & Weibull & $\beta=1,169$ & $\eta=3,23 E+02$ & $3,06 \mathrm{E}+02$ & $60,4 \%$ & $32,2 \%$ & $16,2 \%$ & $7,8 \%$ \\
\hline L & 37 & 47 & Weibull & $\beta=0,917$ & $\eta=4,72 E+02$ & $4,92 \mathrm{E}+02$ & $66,2 \%$ & $45,8 \%$ & $32,3 \%$ & $22,9 \%$ \\
\hline
\end{tabular}

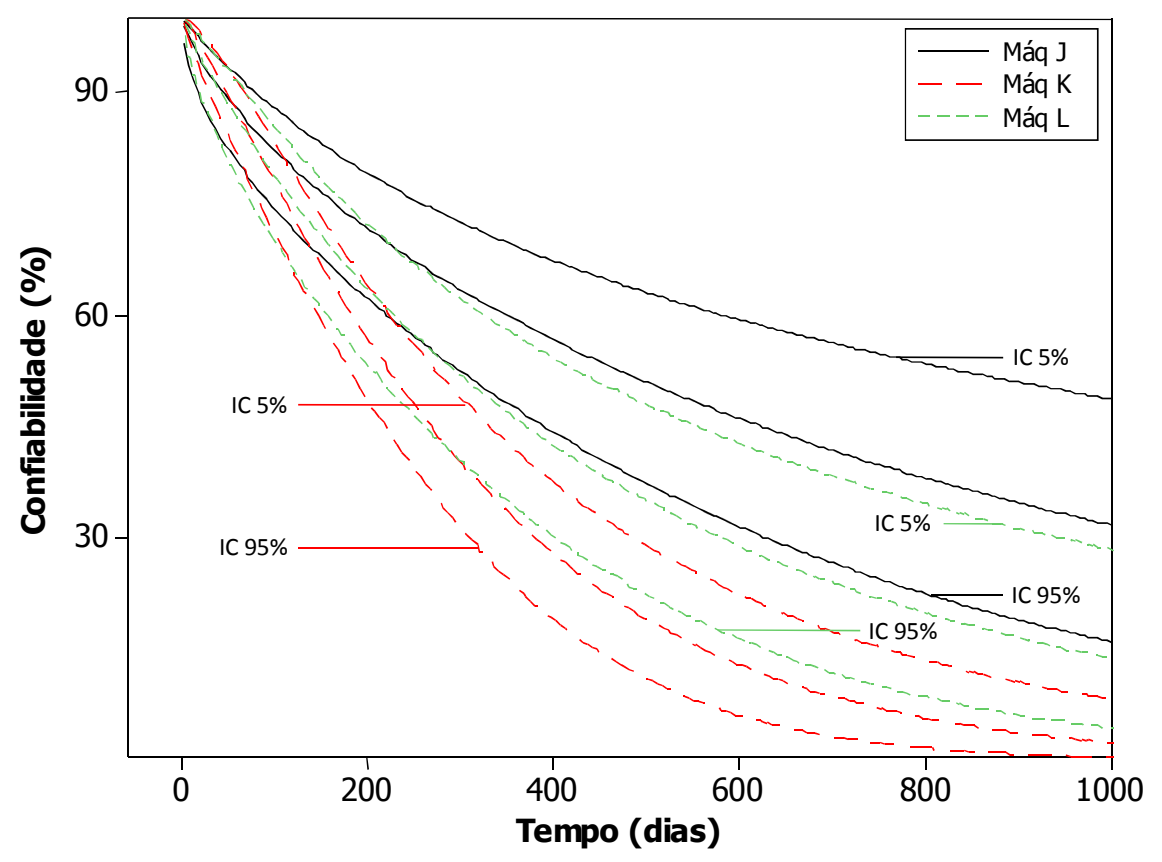

Figura 4-14 - Confiabilidade para $C B$. 


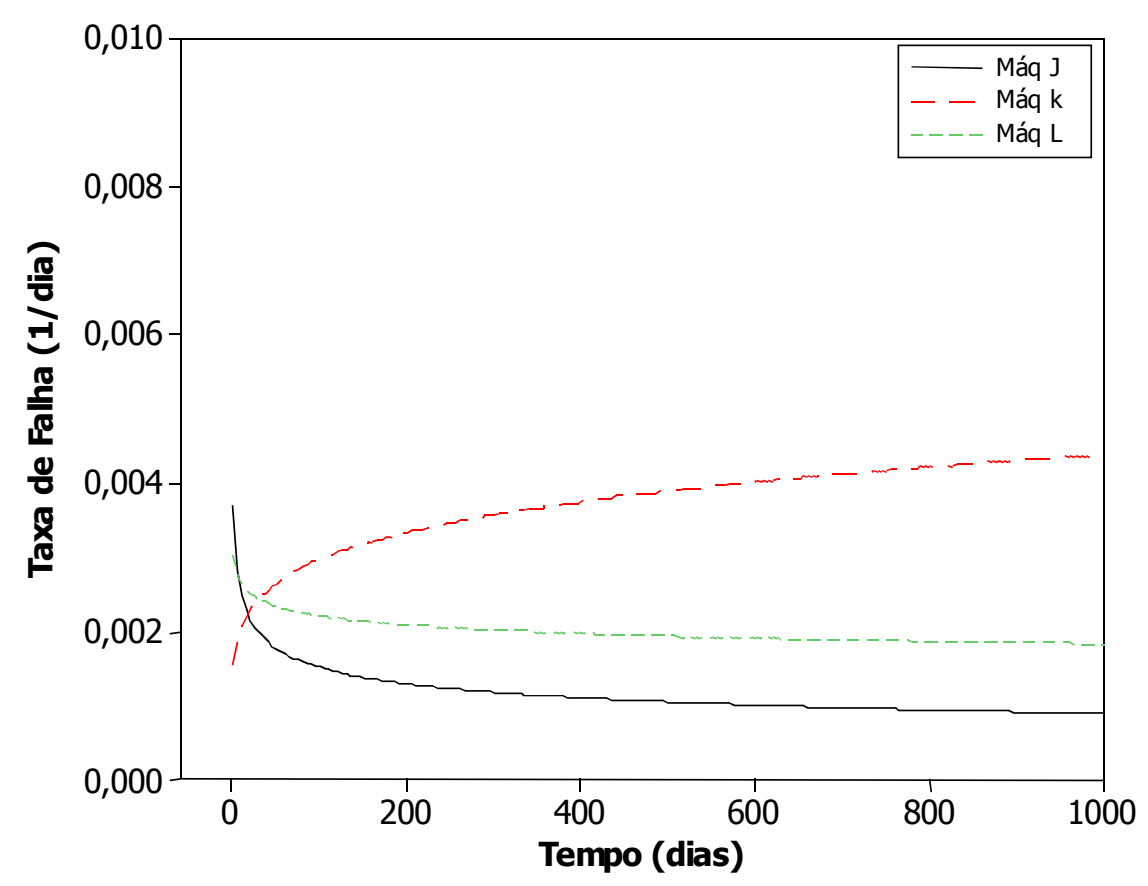

Figura 4-15 - Taxa de Falha para $C B$.

Temos aqui duas máquinas, $J$ e $L$, com taxa de falha decrescente no tempo. A manutenção corretiva é a mais indicada. Já para a máquina $K$, há o que discutir: há um grande aumento da taxa falha nos primeiros 100 dias, e no restante do tempo o aumento é suave. Este aumente suave pode fazer com que, em um modelo que compare os custos da correção e perda de produção com os custos da prevenção, os custos da manutenção corretiva sejam menores. Apesar de ter-se o coeficiente $\beta>1$, este é um caso em que há dúvida a respeito da melhor política de manutenção.

\subsubsection{Detalhamento do Cálculo}

Nesta seção são detalhados os cálculos feitos e discutidos nas seções 4.4 e 4.5.1. Como existem dados suspensos, o método de cálculo utilizado foi o Método da Máxima Verossimilhança. Primeiramente, foi utilizado o software Minitab para gerar gráficos da probabilidade de falha em função do tempo para os dados do modo de falha em estudo, considerando diferentes distribuições. A Figura 4-16 mostra estes gráficos para o modo de falha $C C$. Em cada um dos gráficos é utilizada uma escala de tal forma que a curva da distribuição correspondente seja uma reta. Ao redor desta reta, são plotados os pontos correspondentes aos tempos de falha. Quanto mais próximos estiverem da reta, melhor a adequação da distribuição ao modo de falha. Neste tipo de gráfico são mostrados somente 
os dados de falha; os dados suspensos são devidamente considerados no cálculo, mas não aparecem no gráfico. O Minitab pode gerar gráficos deste tipo para diversas distribuições, e foram escolhidas as 4 distribuições mais comuns para comparação. No caso da Figura 4-17, a melhor distribuição é a Weibull.

Em alguns casos não se chegou a uma conclusão sobre a melhor distribuição graficamente, e então alguns critérios foram usados: Quando houve dúvida entre Exponencial e Weibull, optou-se por Weibull, pois a distribuição de Weibull é igual à Exponencial quando seu parâmetro $\beta=1$. Quando houve dúvida entre Lognormal, Weibull, e Exponencial, avaliou-se o coeficiente de Anderson-Darling, conforme exemplificado na seção 3.2.5.3. Quanto menor o valor deste coeficiente, melhor a aderência dos dados à distribuição em questão.
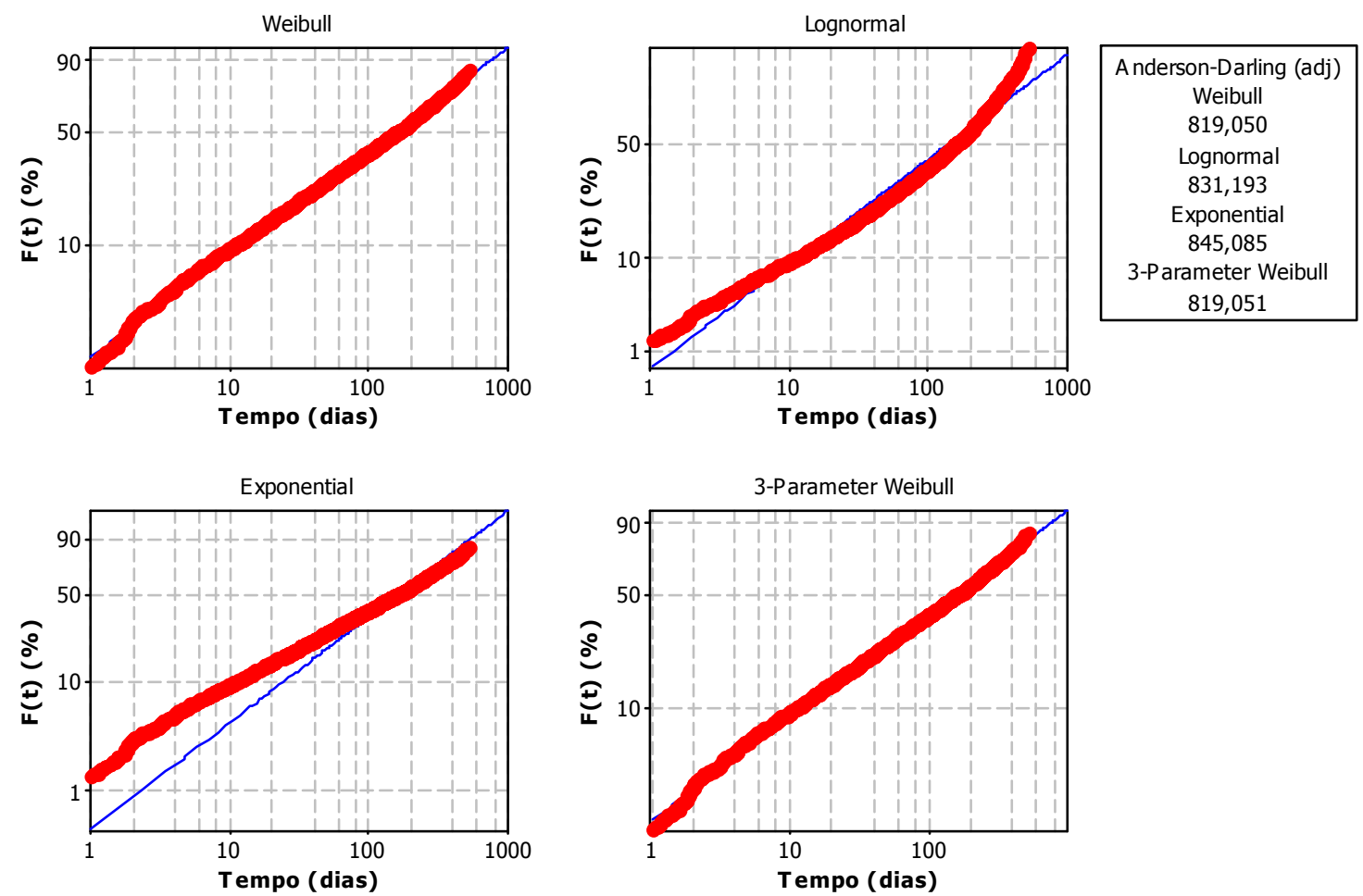

Figura 4-16 - Probabilidades de Falha para $C C$, para diferentes distribuições.

Finalmente, quando houve dúvida entre uma Weibull de 2 parâmetros e uma Weibull de 3 parâmetros, avaliou-se o valor do terceiro parâmetro para a Weibull 3: este parâmetro desloca a curva de Weibull no tempo, e quanto menor, menor a sua influência. Em todos os casos avaliados, o valor deste parâmetro era pequeno o suficiente para que 
fosse desprezado, e fosse utilizada somente a Weibull de 2 parâmetros.

Além disso, é sempre interessante tentar evitar ao máximo a utilização de uma Weibull de 3 parâmetros, pois, numericamente, a estimativa do terceiro parâmetro é problemática, acarretando erros maiores. Não é de estranhar que os softwares Weibull++7 e Minitab dêem resultados diferentes para uma mesma estimativa de Weibull 3 parâmetros: o algoritmo utilizado por cada um deles é diferente. No entanto para todas as outras distribuições os resultados são exatamente os mesmos.

Tendo sido determinada a distribuição mais adequada, foram então gerados gráficos de $R(t), F(t), f(t)$ e $\lambda(t)$. Para a geração destes gráficos, os dois softwares utilizados se equivalem. A Figura 4-17 mostra esses gráficos para $C C$.

O Apêndice A mostra os gráficos com as probabilidades de falha para diferentes distribuições, o coeficiente de Anderson-Darling e os gráficos de $R(t), F(t), f(t)$ e $\lambda(t)$ para todas as outras distribuições.
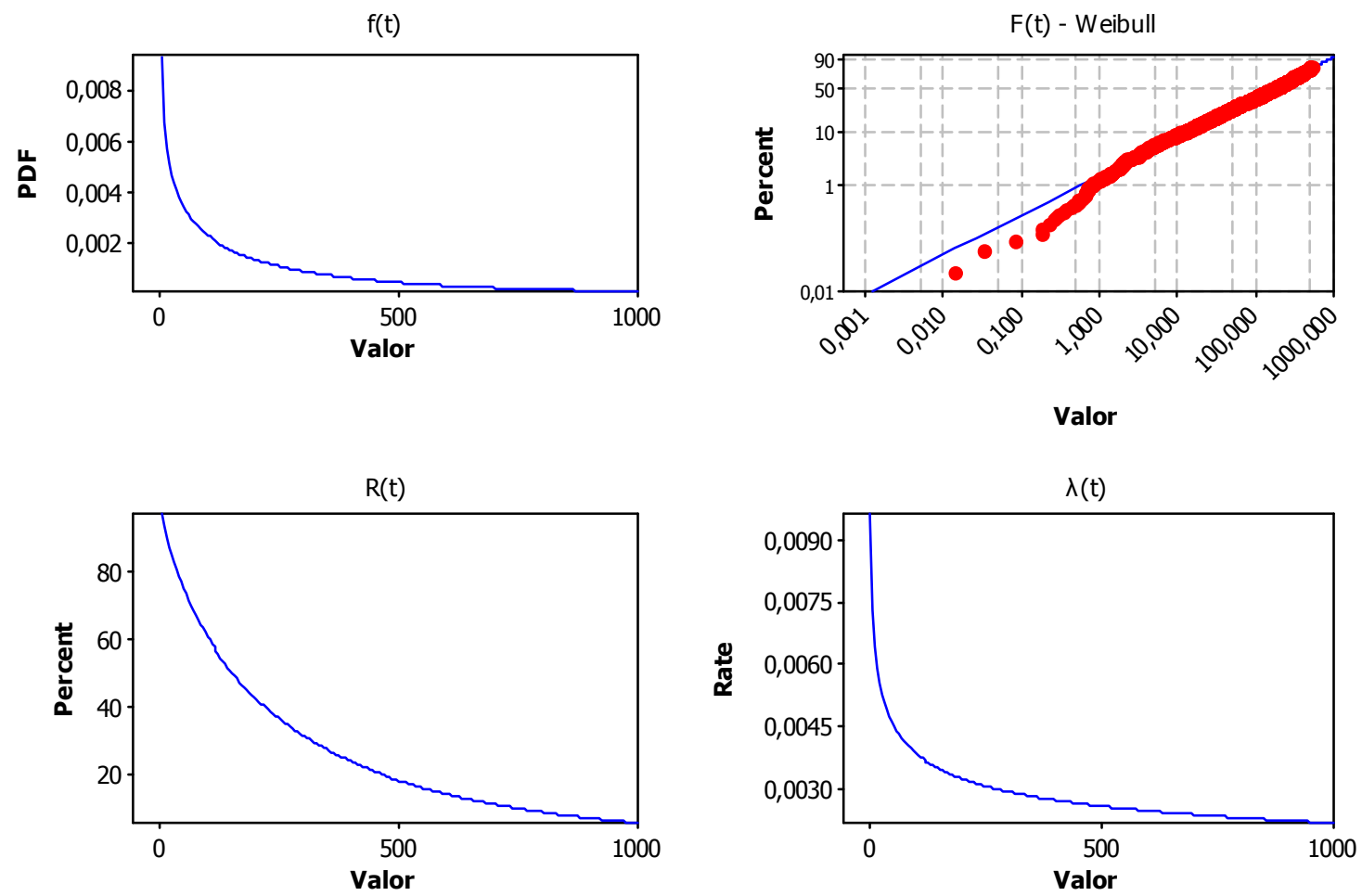

Figura 4-17 $-f(t), F(t), R(t)$ e $\lambda(t)$ para $C C$. 


\subsection{Determinação das Distribuições de Mantenabilidade}

Para o cálculo das distribuições de mantenabilidade foi utilizado um conjunto de modos de falha simplificado em relação à árvore da Figura 4-5. A simplificação feita é mostrada na Tabela 4-9. Isto foi feito pois os reparos dentro de cada um destes grupos são praticamente idênticos, independentemente do modo de falha ocorrido: envolvem sempre algum tipo de desmontagem para acesso aos componentes, substituição de um ou mais componentes, e remontagem. A substituição em si é a etapa mais curta, enquanto que as desmontagens e remontagens tomam mais tempo.

Também foi considerado que todas as máquinas possuem as mesmas mantenabilidades. Esta é uma hipótese bastante factível: todas as máquinas são construtivamente iguais, apresentando todas as mesmas dificuldades de acesso aos componentes. Eventualmente, entretanto, pode ser interessante aprofundar este modelo, calculando as mantenabilidades para cada máquina individualmente: em uma determinada máquina, por exemplo, pode haver parafusos corroídos em uma chaparia, o que dificulta a remoção desta para acesso aos componentes. Esta corrosão não caracteriza uma falha, mas decerto afeta negativamente a mantenabilidade como um todo. Tal aprofundamento não será feito neste texto.

Tabela 4-9 - Modos de falha considerados no cálculo de confiabilidade e de mantenabilidade.

\begin{tabular}{cc}
\hline $\begin{array}{c}\text { Modos de Falha para cálculo } \\
\text { de confiabilidade }\end{array}$ & $\begin{array}{c}\text { Modos de Falha para cálculo } \\
\text { de mantenabilidade }\end{array}$ \\
\hline CC & CC \\
\hline BR1 & BR \\
BR2 & BF \\
\hline BF1 & \\
BF2 & FF \\
\hline FF2 & FR \\
\hline FF1 & CB \\
\hline FR & PT \\
\hline FB & AN \\
\hline AN & RP \\
\hline RP & FO \\
\hline FO & OU \\
\hline OU &
\end{tabular}




\subsubsection{Interpretação dos Resultados}

Para dados de mantenabilidade não há dados suspensos: da forma como o banco de dados foi montado e os dados são colhidos, um reparo não é contabilizado antes de ser finalizado. Assim, o cálculo foi feito utilizando o Método dos Mínimos Quadrados e o coeficiente de correlação $\rho$ (Equação 3.19), não sendo necessário o uso do Método da Máxima Verossimilhança e o parâmetro de Anderson-Darling. Os parâmetros das distribuições resultantes do cálculo estão representados na Tabela 4-10. O detalhamento deste cálculo é mostrado no Apêndice B.

Tabela 4-10 - Distribuições de Mantenabilidade.

\begin{tabular}{lccllcc}
\hline \multicolumn{5}{c}{ Mantenabilidade } \\
\hline Grupo & Reparos & Distribuição & \multicolumn{3}{c}{ Parâmetros } & MTTR (dias) \\
\hline CC & 2613 & Lognormal & $\mu=-0,235$ & $\sigma=$ & 1,346 & 1,95 \\
BR & 1407 & Weibull & $\beta=0,807$ & $\eta=$ & 2,635 & 2,97 \\
BF & 2100 & Lognormal & $\mu=-0,202$ & $\sigma=1,563$ & 2,77 \\
FF & 1125 & Weibull & $\beta=0,906$ & $\eta=1,200$ & 1,26 \\
FR & 455 & Weibull & $\beta=0,858$ & $\eta=1,751$ & 1,89 \\
CB & 965 & Lognormal & $\mu=0,119$ & $\sigma=1,373$ & 2,89 \\
PT & 796 & Weibull & $\beta=0,825$ & $\eta=1,931$ & 2,14 \\
AN & 655 & Lognormal & $\mu=-0,094$ & $\sigma=1,446$ & 2,59 \\
RP & 522 & Lognormal & $\mu=-0,290$ & $\sigma=1,354$ & 1,87 \\
FO & 668 & Weibull & $\beta=0,942$ & $\eta=1,564$ & 1,61 \\
OU & 802 & Weibull & $\beta=1,013$ & $\eta=1,256$ & 1,25 \\
\hline
\end{tabular}

É interessante notar que parte das distribuições de mantenabilidade foram Weibull, ao invés da esperada Lognormal. Isto pode ser explicado pelo fato de que dentro dos dados de tempos de reparo coletados estão implícitas as influências da disponibilidade de mão de obra para execução do reparo, da facilidade desta execução, e do horário da falha. O horário influencia pois as falhas podem acontecer 24 horas por dia, 7 dias por semana, mas os reparos somente são feitos em horário administrativo. Caso haja mais reparos a executar do que pessoas habilitadas disponíveis, há influência da disponibilidade de mão de obra, aumentando o tempo de reparo. Neste caso, é feita pela equipe de manutenção uma priorização pela facilidade aparente de reparo: vale mais a pena reparar os mais simples primeiro. Assim, os modos de falha com reparos simples tendem a ficar mais curtos, e os mais complexos, mais longos. 


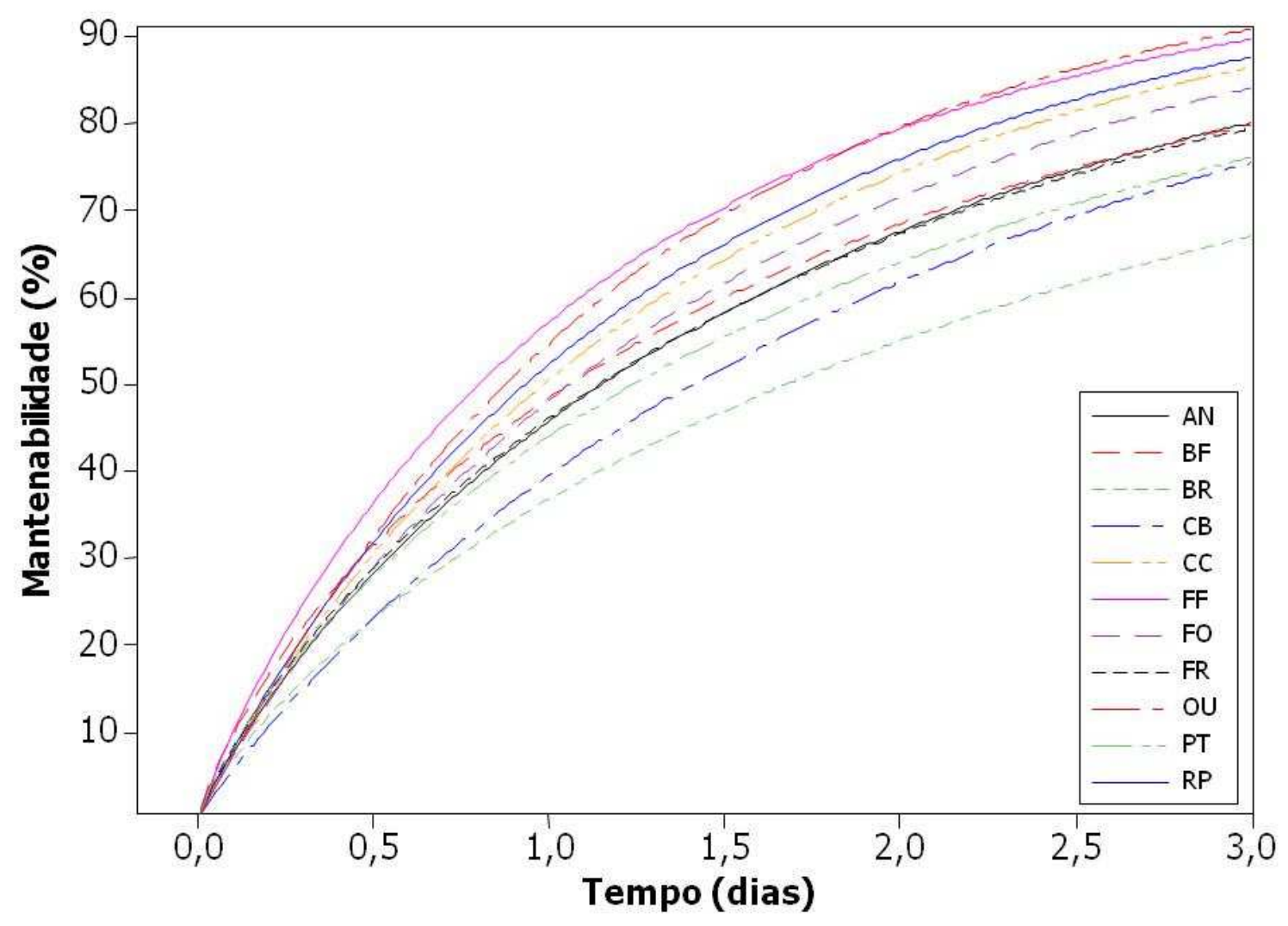

Figura 4-18 - Mantenabilidade.

A Figura 4-18 mostra este mesmo resultado graficamente. Pelo gráfico, conclui-se que $B R$ é o modo de falha com pior mantenabilidade, e deve ser o primeiro foco de ações, se houver a necessidade de aumentar a mantenabilidade. É importante sempre verificar este resultado graficamente, não só com base nos parâmetros das distribuições ou no MTTR. A análise gráfica é sempre uma forma de tornar a interpretação mais simples, rápida e intuitiva.

\subsection{Determinação da Disponibilidade}

A partir das distribuições de confiabilidade e mantenabilidade calculadas nas seções anteriores, podem-se estabelecer modelos computacionais para calcular a disponibilidade do sistema.

\subsubsection{Simulação por posição}

Primeiramente, o sistema a ser considerado será o de uma posição em uma máquina. Cada posição se comporta de acordo com a árvore de falhas da Figura 4-5, que 
pode ser representada por um sistema em série. Este sistema foi criado no software BlockSim, como mostra a Figura 4-19, e alimentado com os parâmetros das distribuições de Confiabilidade e Mantenabilidade da Tabela 4-4 e da Tabela 4-9. O sistema foi então simulado para um período simulado de 540 dias, igual ao período de amostragem, utilizando-se o método de Monte Carlo do BlockSim. Foi considerado que somente a manutenção corretiva é utilizada.

Os resultados obtidos através dizem respeito a uma posição, mas multiplicando pelo número de posições existentes no parque é possível obter o resultado simulado para o parque completo. De acordo com o fluxograma da Figura 4-4, logo após a simulação computacional da Disponibilidade há uma etapa de validação do modelo em que deve ser comparado o número de falhas estimado na simulação com o número de falhas real. Esta comparação é mostrada na Tabela 4-11.

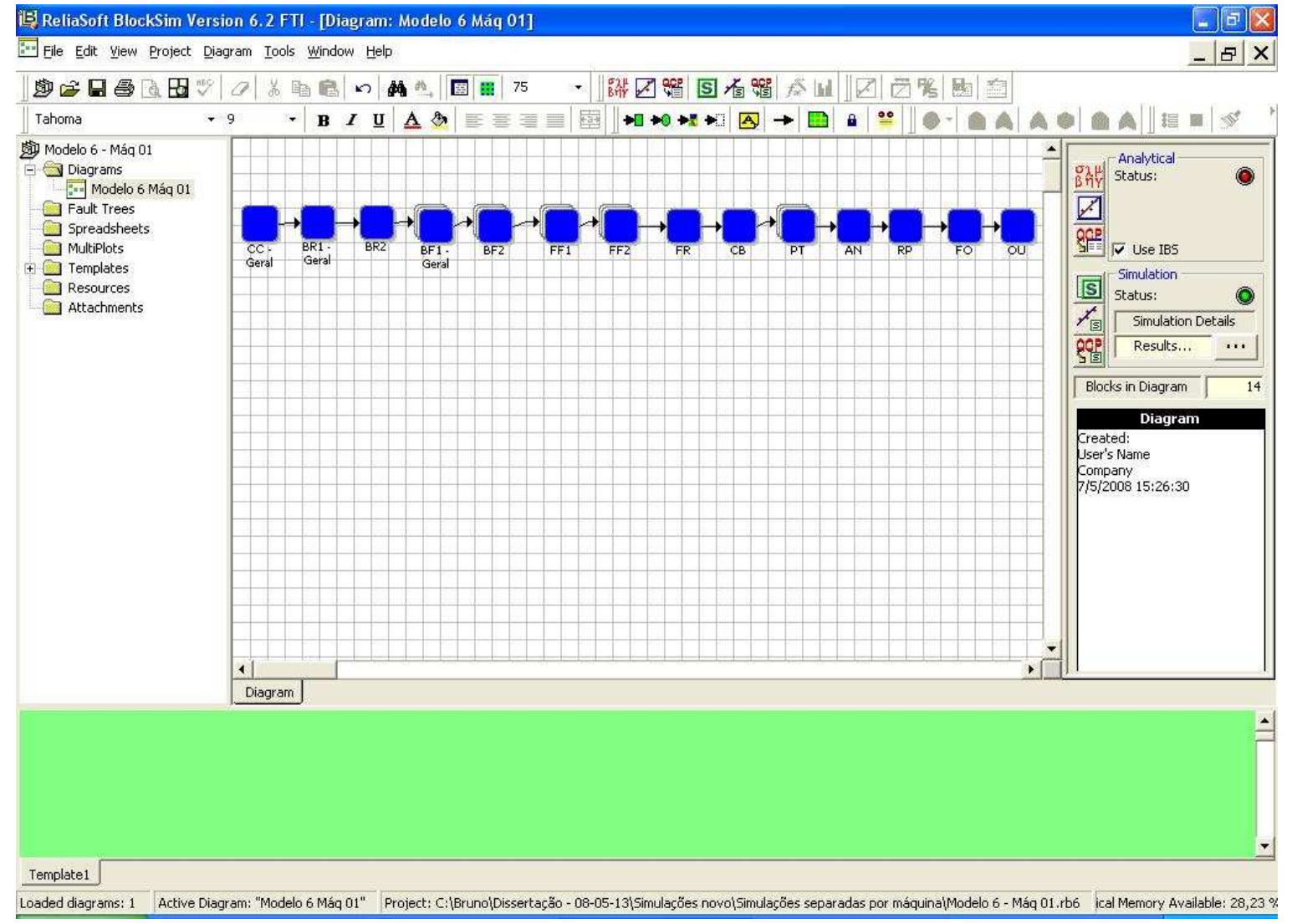

Figura 4-19 - Representação de uma posição de uma máquina no BlockSim.

Olhando para o total, vê-se que o resultado simulado foi $6,6 \%$ maior que o real. Considerando o erro quadrático da soma de todos os modos de falha, a variação é de 
24,3\%. Este resultado que valida o modelo. Tomando os resultados por modo de falha, vê-se que a precisão da simulação varia bastante conforme o caso. Para os modos de falha com grande variação deve-se ter cautela com as conclusões que se pode tirar a respeito, pois a precisão dos resultados é menor.

É esperada certa variação, uma vez que as próprias estimativas de confiabilidade e de mantenabilidade possuem intervalos de confiança dentro dos quais se espera uma variação. Para os casos onde há grande variação, pode ser que tenha havido confusão no momento da coleta dos dados. Cada um dos modos de falha considerados no sistema é um mecanismo com algumas peças, cada uma com a sua identificação, e eventuais similaridades entre as identificações podem ter acarretado em dados anotados incorretamente. Tal hipótese é endossada pelo fato de que, apesar de alguns modos de falha terem uma variação significativa entre o número de falhas simulada e o real, o total de falhas simulado é próximo ao real.

Tabela 4-11 - Número de falhas real versus número de falhas estimado.

\begin{tabular}{cccc}
\hline Modo de Falha & $\begin{array}{c}\text { Número de Falhas } \\
\text { Reais }\end{array}$ & $\begin{array}{c}\text { Número de Falhas } \\
\text { Simuladas }\end{array}$ & $\begin{array}{c}\text { Variação entre o real } \\
\text { e o simulado }\end{array}$ \\
\hline AN & 850 & 945 & $11,1 \%$ \\
BF1 & 1998 & 1722 & $-13,8 \%$ \\
BF2 & 933 & 655 & $-29,8 \%$ \\
BR1 & 1603 & 1570 & $-2,1 \%$ \\
BR2 & 259 & 202 & $-22,0 \%$ \\
CB & 1297 & 1837 & $41,6 \%$ \\
CC & 3111 & 3558 & $14,4 \%$ \\
FF1 & 1009 & 1322 & $31,1 \%$ \\
FF2 & 527 & 695 & $31,8 \%$ \\
FO & 1284 & 838 & $-34,7 \%$ \\
FR & 588 & 617 & $4,9 \%$ \\
OU & 1014 & 1249 & $23,2 \%$ \\
PT & 1159 & 1504 & $29,8 \%$ \\
RP & 691 & 685 & $-0,9 \%$ \\
Total & 16323 & $\mathbf{1 7 3 9 8}$ & $\mathbf{6 , 6 \%}$ \\
& & Erro quadrático: & $\mathbf{2 4 , 3 \%}$ \\
\hline
\end{tabular}

\subsubsection{Simulação por posição e por máquina}

O modelo simulado em 4.7.1 pode ser incrementado: é possível simular uma 
posição de cada uma das máquinas do parque. O modelo construído no BlockSim é o mesmo da Figura 4-19, que já fora previamente alimentado com os dados de confiabilidade da Tabela 4-4 e os dados de mantenabilidade da Tabela 4-10. Para os modos de falha $B F 1, B R 1, C B$ e $C C$, os parâmetros de confiabilidade foram substituídos por aqueles calculados especificamente para cada uma das máquinas, como mostrado em 4.5.1. As simulações então foram feitas, novamente considerando um período de 540 dias e que somente manutenções corretivas são feitas.

A Tabela 4-12 mostra os resultados das simulações para posições de três máquinas. Pode-se esperar que todas as outras posições destas máquinas comportem-se desta mesma forma. Tempo indisponível representa o tempo simulado em que uma posição está em estado de falha no período simulado de 540 dias. Sabendo que o trabalho de cada posição agrega em valor ao produto alguns reais por minuto, esse tempo indisponível faz que com que a empresa deixe de faturar alguns milhares de reais por ano (considerando que toda a produção seja vendida, o que era uma hipótese válida para este mercado durante o período de amostragem dos dados).

Tabela 4-12 - Resultados de Simulação de Monte Carlo para Disponibilidade.

\begin{tabular}{cccc}
\hline $\begin{array}{c}\text { Posições da } \\
\text { Máquina }\end{array}$ & $\begin{array}{c}\text { Disponibilidade } \\
\text { Média }\end{array}$ & $\begin{array}{c}\text { Tempo indisponível } \\
\text { esperado(dias) }\end{array}$ & $\begin{array}{c}\text { Número de } \\
\text { Falhas Esperado }\end{array}$ \\
\hline M & $95,91 \%$ & 22,08 & 10,35 \\
N & $95,44 \%$ & 24,60 & 11,33 \\
O & $96,23 \%$ & 20,37 & 9,50 \\
\hline
\end{tabular}

O número de falhas esperado representa a média do número de falhas ocorrido em cada uma das vezes que o método de Monte Carlo simulou o sistema, para cada posição de uma máquina. Com este parâmetro pode ser possível estimar o tamanho da equipe de manutenção corretiva necessária para atender a demanda, pois o número total de falhas esperado para um período é conhecido, e com as mantenabilidades tem-se o tempo que se leva para resolver uma falha. Uma simulação um pouco mais complexa poderia inclusive simular o número de pessoas na equipe, e mostrar os resultados de disponibilidade em função deste número. Mas para tanto seria necessário que tivéssemos dados de tempos de reparo que independessem do fato de que um reparo pode atrasar por 
não haver pessoas disponíveis no exato instante da falha.

A Tabela 4-13 mostra os resultados da Tabela 4-12 explodidos pelos diversos modos de falha. A Figura 4-20 e a Figura 4-21 mostram este mesmo resultado graficamente. $\mathrm{O}$ total de falhas esperadas para o parque nesta simulação é semelhante ao da simulação anterior, o que mais uma vez valida o modelo.

Tabela 4-13 - Número de falhas e Tempo Indisponível esperados, explodidos por modos de falha.

\begin{tabular}{lcccccc}
\hline Modo de Falha & Número de Falhas Esperado & Tempo indisponível esperado \\
Posições da & $\boldsymbol{M}$ & $\boldsymbol{N}$ & $\boldsymbol{O}$ & $\boldsymbol{M}$ & $\boldsymbol{N}$ & $\boldsymbol{O}$ \\
Máquina: & & & & & & \\
\hline AN & 0,55 & 0,54 & 0,56 & 1,28 & 1,33 & 1,46 \\
BF1 & 1,26 & 1,36 & 0,91 & 3,46 & 3,67 & 2,45 \\
BF2 & 0,38 & 0,38 & 0,38 & 1,10 & 0,92 & 1,06 \\
BR1 & 0,87 & 1,07 & 0,88 & 2,52 & 3,10 & 2,59 \\
BR2 & 0,12 & 0,13 & 0,12 & 0,37 & 0,36 & 0,37 \\
CB & 0,98 & 1,56 & 1,07 & 2,86 & 4,43 & 3,03 \\
CC & 2,04 & 2,16 & 1,44 & 3,89 & 4,06 & 2,78 \\
FF1 & 0,77 & 0,81 & 0,79 & 0,93 & 1,05 & 1,01 \\
FF2 & 0,41 & 0,41 & 0,42 & 0,50 & 0,54 & 0,53 \\
FO & 0,52 & 0,49 & 0,50 & 0,85 & 0,80 & 0,82 \\
FR & 0,37 & 0,37 & 0,36 & 0,70 & 0,68 & 0,70 \\
OU & 0,75 & 0,73 & 0,76 & 0,93 & 0,91 & 0,95 \\
PT & 0,90 & 0,90 & 0,89 & 1,92 & 1,99 & 1,88 \\
RP & 0,42 & 0,42 & 0,42 & 0,76 & 0,75 & 0,74 \\
\hline
\end{tabular}

Os únicos modos de falha que apresentam diferenças significativas de uma máquina para outra são $B F 1, B R 1, C C$ e $C B$. Todos os outros se equivalem. Isto era esperado, pois somente para estes foram determinadas distribuições de confiabilidade específicas por máquina; para os outros modos de falha admitiram-se nos modelos que as distribuições eram as mesmas para todas as máquinas.

Comparando-se $B F 1$ com $C C$, vê-se que $C C$ tem um número de falhas esperado consideravelmente acima de $B F 1$. Mas quando se compara o tempo indisponível, vê-se que a diferença não é tão grande assim. Isto é devido à Mantenabilidade de $B F 1$ ser pior que a de $C C$, como mostrado na Figura 4-18.

Já o modo de falha $C B$ para as posições da máquina $N$ tem um valor de tempo 
indisponível que ultrapassa o CC, que seria o modo de falha mais crítico. Duas razões: a mantenabilidade de $C B$ é pior que a de $C C$, e o modelo de $C B$ leva a $40 \%$ mais falhas, conforme mostrado na Tabela 4-11. Logo, deve-se ter cautela com este resultado.

Com base em resultados deste tipo, podem-se tomar ações de melhoria com muito mais precisão, como onde focar esforços para que os resultados sejam alcançados. Diversas outras interpretações podem ser feitas a partir dos gráficos abaixo, ou de outros semelhantes, que podem ser gerados através dos dados da simulação. Para os modos de falha com pouca variação entre o simulado e o real, pode-se, por exemplo, definir o número de peças reservas, otimizando o estoque. Este tipo de análise pode orientar de maneira muito consistente ações de aumento de produtividade e redução do custo de manutenção.

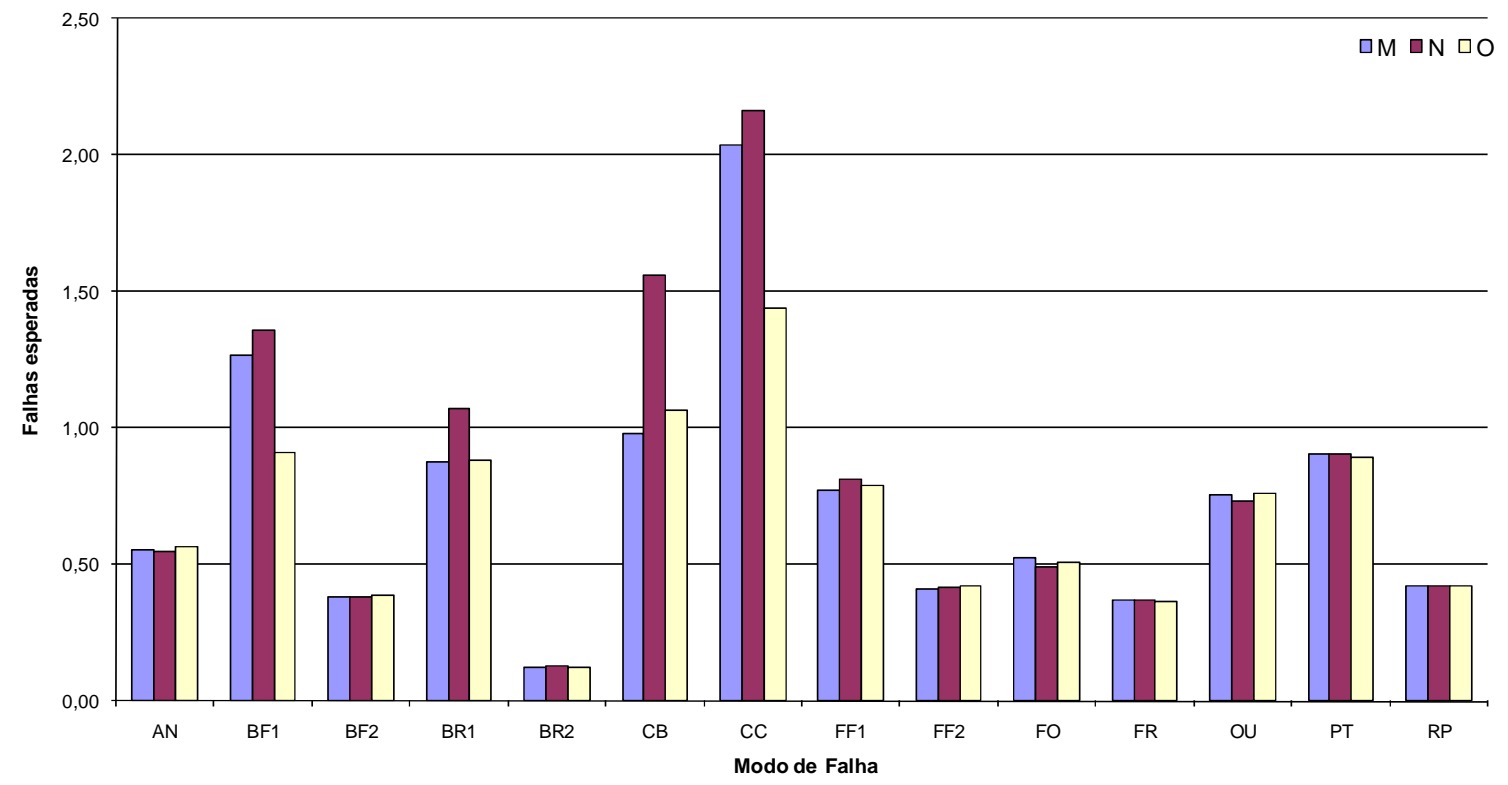

Figura 4-20 - Número de Falhas Esperado. 


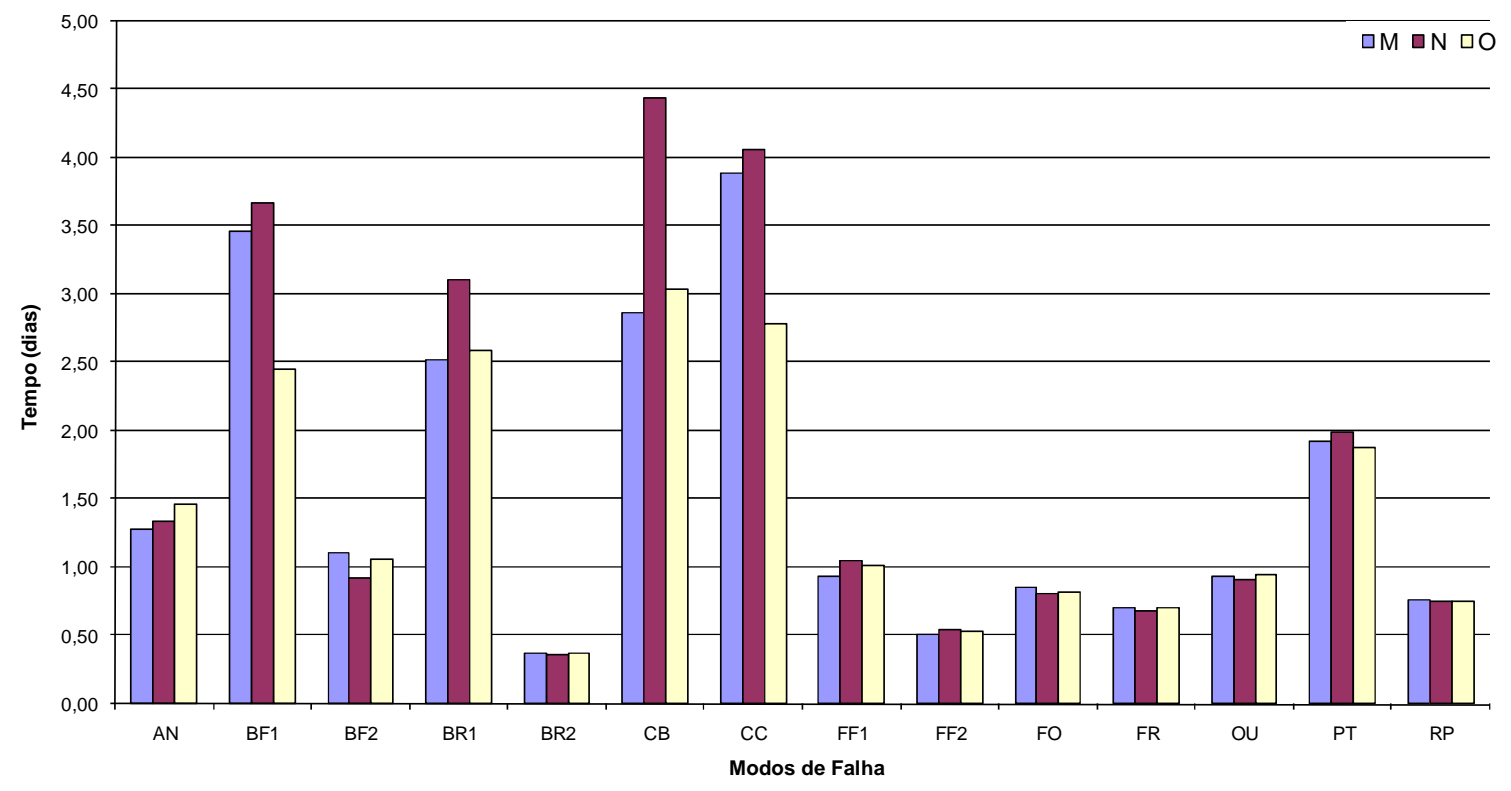

Figura 4-21 - Tempo Indisponível Esperado.

\subsubsection{Simulação do Conjunto de Máquinas}

Nesta seção será simulado um sistema que representada o parque completo máquinas. Uma falha para este sistema é o não atendimento às demandas de produção. Seja um parque que contenha $P$ máquinas, cada uma operando com as suas 168 posições que podem operar e falhar independentemente. $\mathrm{O}$ total de posições é dado por $N=168 x$ $P$. A Figura 4-22 representa este sistema. Suponha que o mercado demande uma produção diária de $90 \%$ da capacidade de produção nominal de $N$. Neste caso, há um sistema em paralelo $m$ de $N$, onde $m$ é o número mínimo de posições necessárias para o sistema atender a demanda, neste caso $0,9 \times N$. Sempre que existirem menos de $90 \%$ de posições operacionais em um determinado instante, o sistema está em falha.

O sistema foi montado conforme a Figura 4-22. A Figura 4-23 mostra este sistema construído no BlockSim. Cada bloco representa uma posição de uma máquina, e foi alimentado com sua respectiva confiabilidade e mantenabilidade. O diagrama ficou bastante grande, sendo impossível mostrá-lo em uma única figura, assim apenas uma parte é mostrada. Apesar de parecer o contrário, os blocos não estão ligados em série no BlockSim; entretanto eles estão nesta disposição pois era impossível enfileirar 
verticalmente todos os blocos.

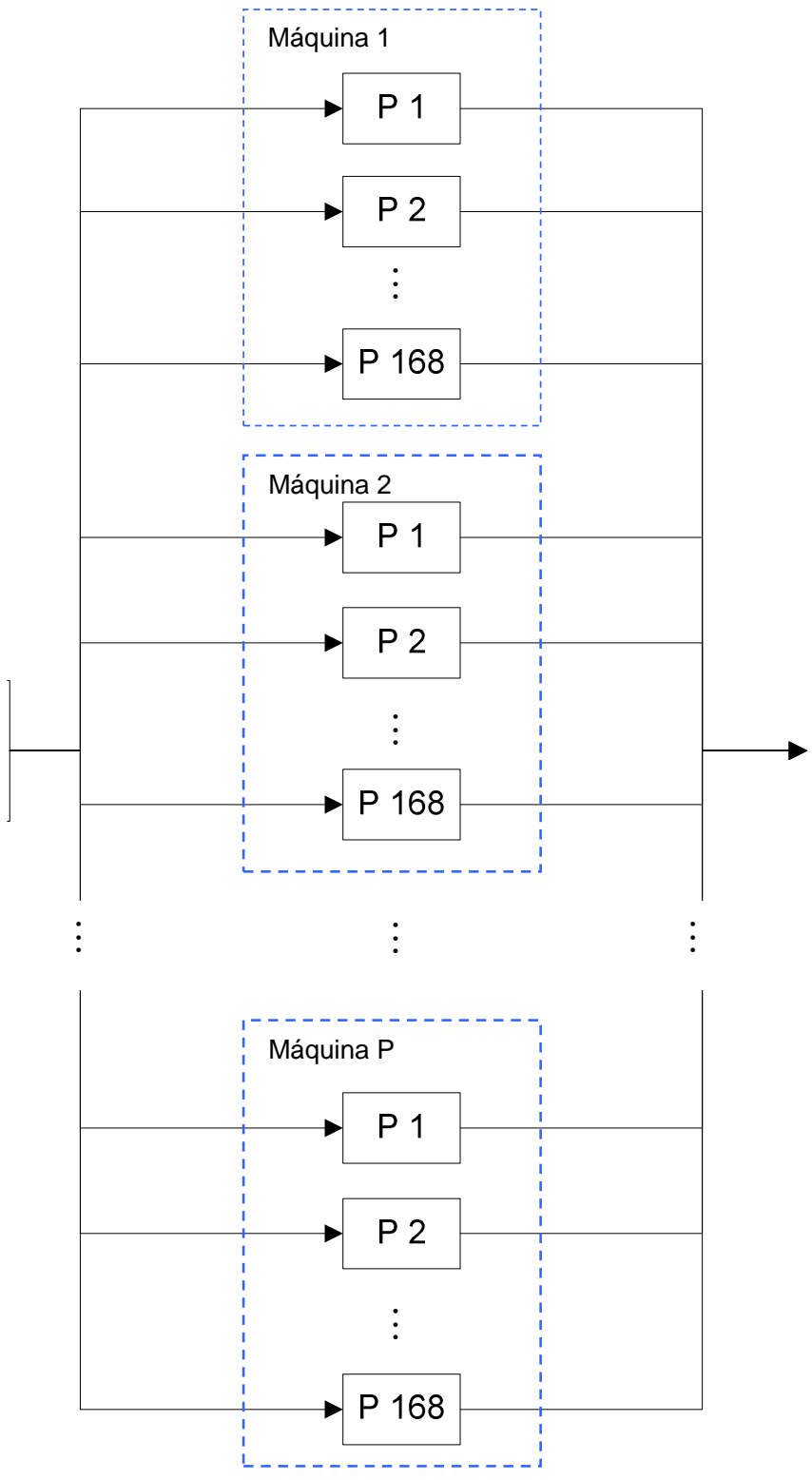

Figura 4-22 - Sistema em paralelo $m$ de $N$. 


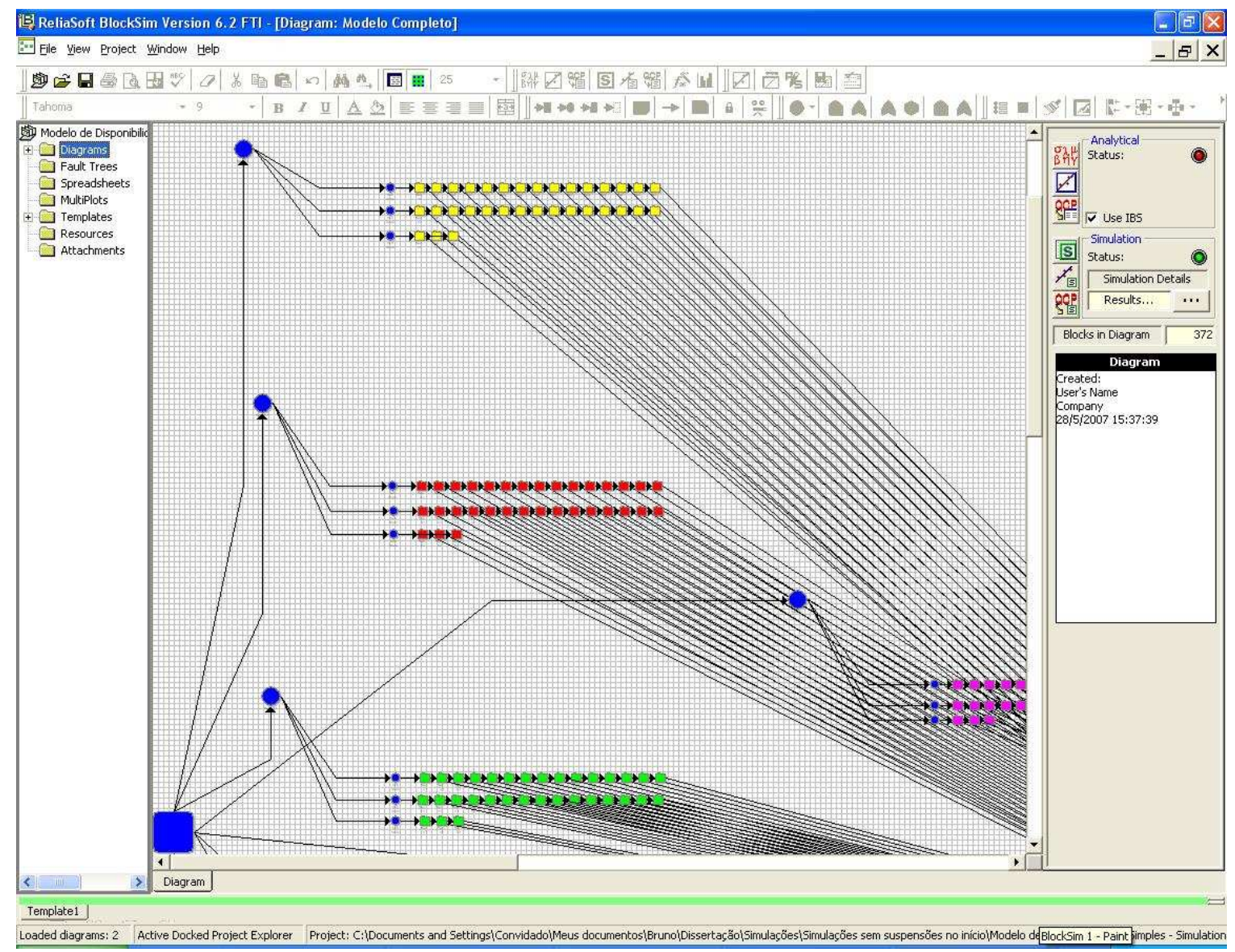

Figura 4-23 - Representação do conjunto de máquinas no BlockSim (visão parcial).

O sistema foi simulado considerando um período de 540 dias e que somente manutenção corretiva é realizada. Esta simulação foi feita diversas vezes, cada uma com um valor diferente da relação $m / N$. Os valores de $m / N$ utilizados foram possíveis pois o valor de $N$ é bem alto, não faria sentido variar tanto este valor para um $N$ pequeno. A Tabela 4-14 mostra os resultados destas simulações, e a Figura 4-24 mostra os mesmos resultados graficamente. Os resultados mostram que quanto maior a relação $m / N$, ou seja, quanto maior a exigência que se faz do sistema, menor a disponibilidade. Este é um comportamento natural, já que quanto maior $m / N$, mais o sistema se aproxima de um sistema em série, e quanto menor, mais se aproxima de um sistema paralelo.

A partir destes dados podemos fazer algumas interpretações: para valores de $m / N$ abaixo de 93\%, a disponibilidade aproxima-se muito de 100\%. Sendo assim, qualquer esforço para aumentar a quantidade de máquinas em backup quando $m / N$ for igual ou menor a 93\% terá resultado praticamente nulo, ou seja, terá sido um esforço 
desnecessário.

Tabela 4-14 - Resultados das Simulações variando $m / N$.

\begin{tabular}{cc}
\hline$m / N$ & Disponibilidade \\
\hline $99,4 \%$ & $15,23 \%$ \\
$98,8 \%$ & $27,51 \%$ \\
$98,2 \%$ & $40,00 \%$ \\
$97,6 \%$ & $52,97 \%$ \\
$97,0 \%$ & $65,47 \%$ \\
$96,4 \%$ & $75,34 \%$ \\
$95,8 \%$ & $84,84 \%$ \\
$95,2 \%$ & $91,07 \%$ \\
$94,5 \%$ & $94,96 \%$ \\
$93,9 \%$ & $97,92 \%$ \\
$93,3 \%$ & $99,08 \%$ \\
$92,7 \%$ & $99,61 \%$ \\
$92,1 \%$ & $99,83 \%$ \\
$91,5 \%$ & $99,95 \%$ \\
$90,9 \%$ & $99,97 \%$ \\
\hline
\end{tabular}

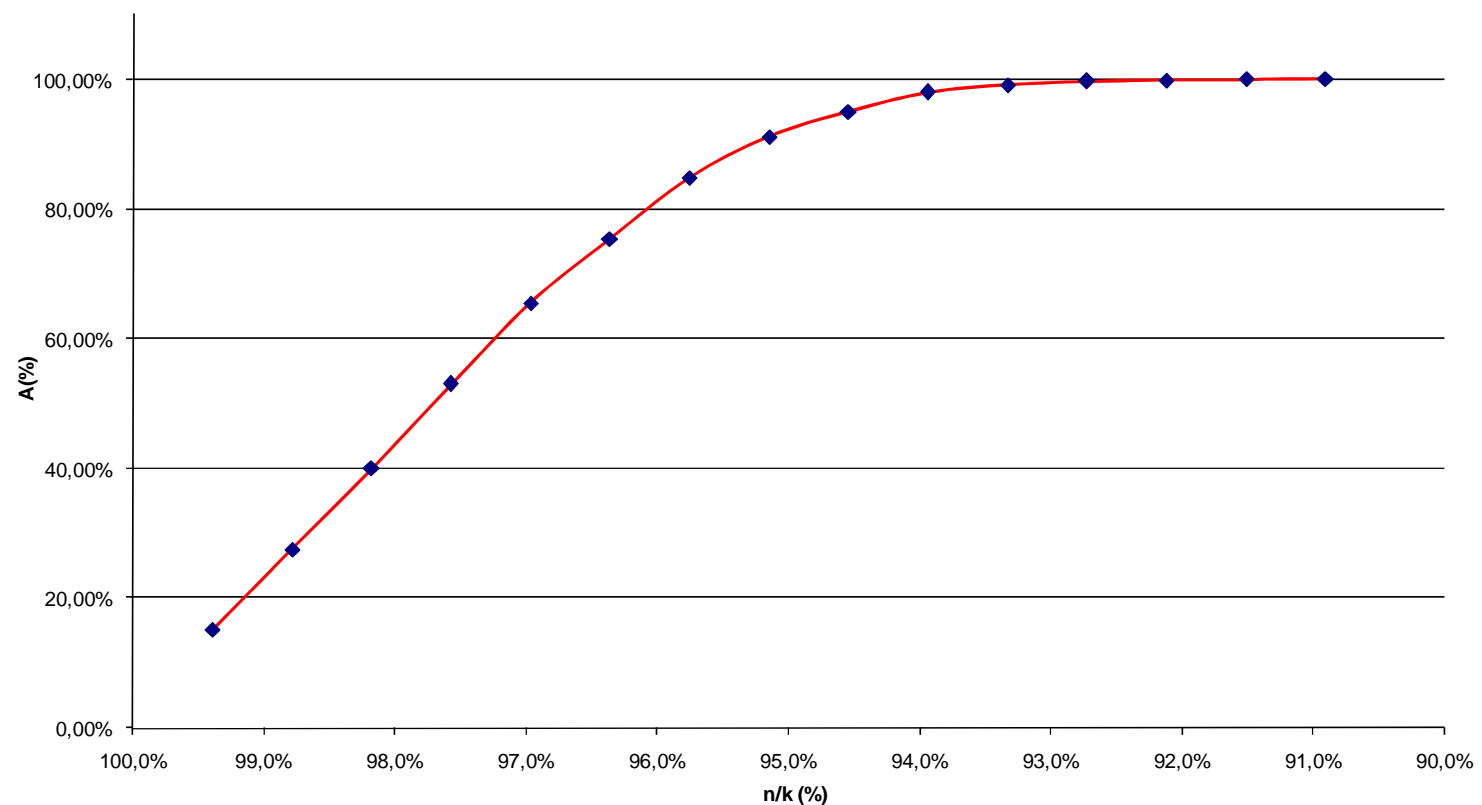

Figura 4-24 - Resultados das Simulações variando $m / N$.

Caso seja necessário que $m / N$ seja próximo de $100 \%$, é muito provável que a produção requerida não seja atingida, já que a disponibilidade cai abaixo de $15 \%$. Neste 
caso, é interessante trabalhar para melhorar a confiabilidade ou a mantenabilidade do sistema, ou aumentar a quantidade de backups, mantendo o valor de $m$ e aumentar o valor de $N$.

\subsubsection{Simulação com melhorias de confiabilidade}

Outra utilização possível para o modelo desenvolvido é calcular o impacto de eventuais melhorias. Para tanto, pode-se estimar uma nova confiabilidade ou nova mantenabilidade, ou ambos, para um modo de falha em que se deseja fazer uma melhoria. Por exemplo, o modo de falha CC. A Figura 4-21 mostra que este modo de falha é o mais crítico do ponto de vista de tempo indisponível. Como já foi discutido na seção 4.5.1.1, o comportamento deste modo de falha é diferente do esperado, com uma mortalidade infantil muito alta, possivelmente devido a problemas de especificação do material ou de instalação. Caso melhorias sejam implantadas, e o comportamento da confiabilidade torne-se como o esperado, qual será o impacto na disponibilidade das posições e do parque?

Para responder esta pergunta, foi estimada uma possível distribuição de confiabilidade característica de falhas por desgaste, com taxa de falha crescente e sem mortalidade infantil. Os parâmetros desta possível distribuição estão mostrados na Tabela 4-15, e são comparados com os parâmetros da distribuição real. As Figuras 4-25 e 4-26 comparam respectivamente a confiabilidade e a taxa de falha para estas duas distribuições.

Tabela 4-15 - Parâmetros de Confiabilidade de uma eventual melhoria no modo de falha $C C$.

\begin{tabular}{lcccccccc}
\hline & & \multicolumn{4}{c}{ Confiabilidade CC } & & & \\
\hline & \multirow{2}{*}{ Distribuição } & \multicolumn{2}{c}{ Parâmetros } & MTBF & \multicolumn{4}{c}{ Confiabilidade em (\%): } \\
& & & (dias) & 180 dias & 360 dias & 540 dias & 720 dias \\
\hline Real & Weibull & $\beta=0,752$ & $\eta=2,46 \mathrm{E}+02$ & $2,93 \mathrm{E}+02$ & $45,4 \%$ & $26,4 \%$ & $16,5 \%$ & $10,7 \%$ \\
Melhorado & Weibull & $\beta=1,500$ & $\eta=8,00 \mathrm{E}+02$ & $7,24 \mathrm{E}+02$ & $89,9 \%$ & $73,9 \%$ & $57,4 \%$ & $\mathbf{4 2 , 6 \%}$ \\
\hline
\end{tabular}




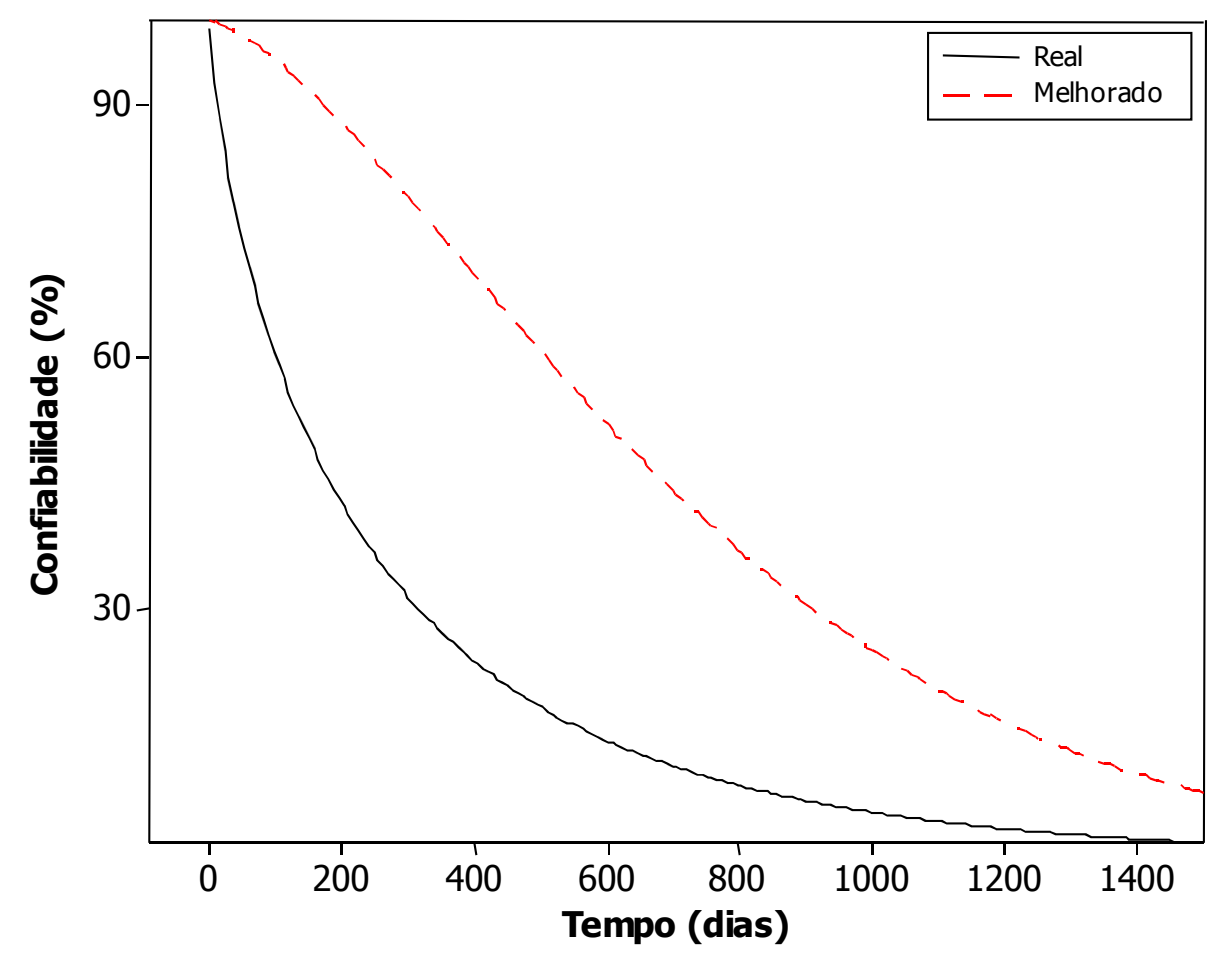

Figura 4-25 - Confiabilidade de uma eventual melhoria no modo de falha $C C$.

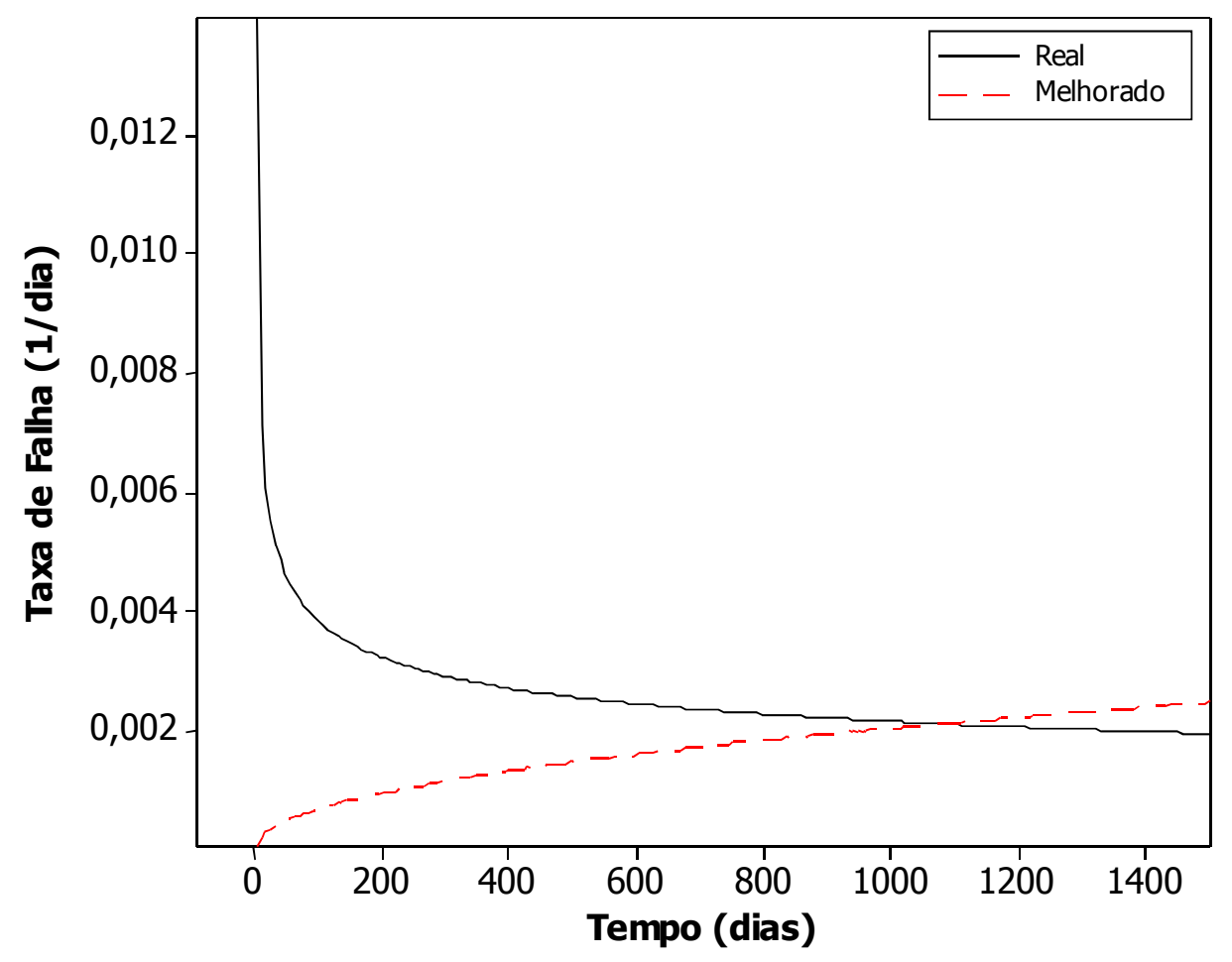

Figura 4-26 - Taxa de Falha de uma eventual melhoria no modo de falha $C C$.

Estes parâmetros "melhorados" foram inseridos no modelo apresentado em 4.7.2, 
a as simulações foram refeitas da mesma maneira como descrita naquela seção. Os resultados para uma posição das mesmas máquinas $M, N$ e $O$ são mostrados na Tabela 4-16, e são comparados com os resultados da simulação feita com os dados reais.

Tabela 4-16 - Resultados da simulação considerando uma eventual melhoria no modo de falha $C C$.

\begin{tabular}{ccccccc}
\hline \multirow{2}{*}{$\begin{array}{c}\text { Posições da } \\
\text { Máquina }\end{array}$} & Disponibilidade Média & \multicolumn{2}{c}{$\begin{array}{c}\text { Tempo indisponível } \\
\text { esperado (dias) }\end{array}$} & \multicolumn{2}{c}{$\begin{array}{c}\text { Número de Falhas } \\
\text { Esperado }\end{array}$} \\
\cline { 2 - 7 } & $\begin{array}{c}\text { Dados } \\
\text { Reais }\end{array}$ & Melhorado & $\begin{array}{c}\text { Dados } \\
\text { Reais }\end{array}$ & Melhorado & $\begin{array}{c}\text { Dados } \\
\text { Reais }\end{array}$ & Melhorado \\
\hline M & $95,91 \%$ & $96,45 \%$ & 22,08 & 19,16 & 10,35 & 8,82 \\
N & $95,44 \%$ & $96,02 \%$ & 24,60 & 21,50 & 11,33 & 9,63 \\
O & $96,23 \%$ & $96,59 \%$ & 20,37 & 18,41 & 9,50 & 8,54 \\
\hline
\end{tabular}

Percebe-se que na simulação feita com os dados "melhorados", o tempo indisponível esperado por posição de máquina foi sempre de 2 a 3 dias menor que na simulação original. Multiplicando este resultado pelo número de posições existentes no parque, e sabendo o valor por tempo que cada posição trabalhando agrega, teremos o valor de retorno de um eventual trabalho de melhoria. Se for considerado que uma posição produz em média 1 quilograma por hora, lembrando que cada máquina tem 168 posições, temos que, a cada 540 dias, a máquina $M$ produziria 11,7 toneladas a mais, a máquina $N$ 12,5 toneladas e a máquina $O$ 7,9 toneladas. Além disto, o número de falhas esperado também caiu, o que geraria também uma economia em custos de manutenção. Na Tabela 4-16 o número de falhas esperado refere-se a todos os modos de falha, mas estes resultados podem ser explodidos, como pode ser visto na Figura 4-27, que mostra o tempo indisponível somente para este modo de falha. 


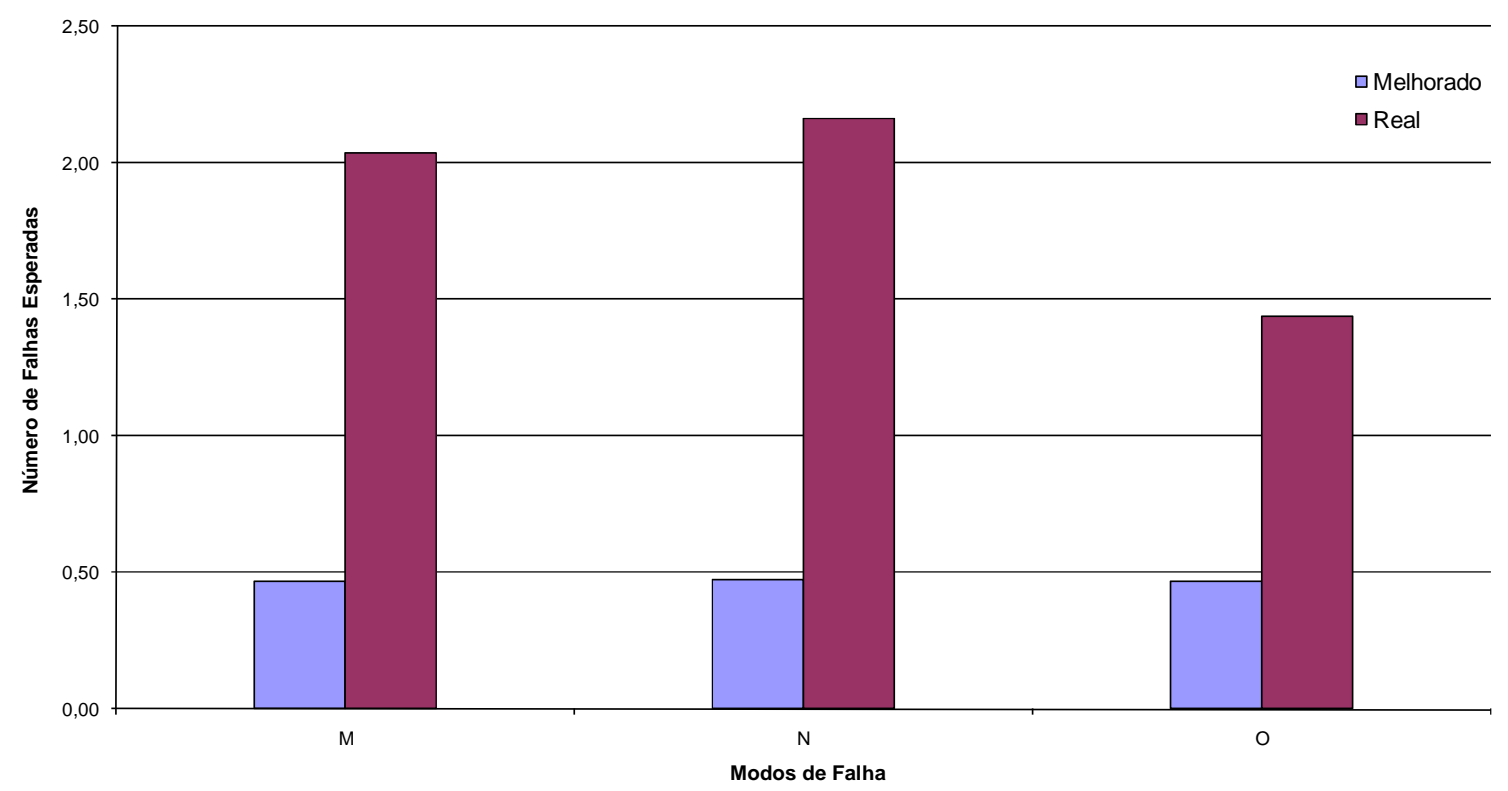

Figura 4-27 - Comparação entre o número de falhas esperado para as duas simulações.

\subsection{Plano de manutenção}

Pode-se ver pelos resultados acima que um plano de manutenção genérico que atenda todas as máquinas não é o ideal para este parque, já que cada máquina e cada modo de falha tem o seu comportamento próprio. A manutenção corretiva é a mais indicada para a maioria dos casos, mas não em todos. $\mathrm{O}$ ideal neste caso é que cada máquina tenha o seu plano de manutenção individual, criado a partir das análises dos dados de falha e de reparo individuais para cada máquina e, no caso de preventivas, com intervalos também individualizados. Isto deve ser seguido pelo menos para os modos de falha mais críticos. Para os modos de falha menos críticos, uma opção é generalizar o uso da manutenção corretiva, pois, como mostra a Figura 4-4, a grande maioria destes possui um valor de $\beta$ abaixo ou muito próximo de 1 .

O plano de manutenção atual deste parque é igual para todas as máquinas e prevê dois tipos de manutenção preventiva. O primeiro é realizado a cada 3000 horas de operação, equivalente a cerca de 4,5 meses, e contém tarefas somente de lubrificação limpeza e retirada de resíduos, sem desmontagem de componentes. Esta manutenção deve ser mantida para todos os casos: apesar de ser classificada como "preventiva", não 
envolve troca de componentes, e com componentes limpos e lubrificados corretamente a tendência é sempre que a vida aumente independentemente do respectivo comportamento estatístico. O intervalo de 3000 horas, porém, pode ser ajustado de acordo com o restante do plano de manutenção da máquina.

O segundo tipo de preventiva é realizado a cada 6000 horas, e suas tarefas não são muito bem definidas, variam de acordo com o orçamento disponível. Envolvem além das mesmas tarefas da manutenção de 3000 horas, a eventual manutenção corretiva de falhas ocorridas logo antes da parada, e a substituição preventiva de componentes decididos subjetivamente, de forma a se adequar ao orçamento.

É fato que diversas empresas convivem com restrições orçamentárias, mas esta restrição não deve ser usada para decidir o que fazer em uma determinada manutenção preventiva: a restrição deve ser usada como objetivo do custo total de manutenção, estimulando a otimização do plano de manutenção como um todo e de decisões cada vez mais pautadas em dados e análises quantitativas, deixando o subjetivismo de lado.

Da maneira como esta manutenção é feita, além de haver dificuldade para se ajustar ao orçamento, muitas das substituições de componentes não seriam necessárias, somente a manutenção corretiva seria suficiente. Assim sendo, pode-se crer que a reorganização do plano de manutenção, tornando-o individualizado, e seguindo as recomendações deste texto, levaria a uma significativa redução do custo de manutenção total deste parque. 


\section{CAPÍTULO 5 - CONCLUSÕES}

\subsection{Conclusões e Recomendações}

O procedimento desenvolvido neste trabalho para a análise de disponibilidade mostrou-se adequado. Ressalta-se a grande importância de se seguir o fluxograma proposto na Figura 4-4 para que um modelo seja desenvolvido corretamente. Os loops onde se volta ao início são inerentes às análises de disponibilidade de sistemas complexos e devem ser encarados como etapas de desenvolvimento até se chegar ao melhor modelo. Isto acontece pois decisões devem ser tomadas quanto ao que considerar como sendo um modo de falha no modelo, face a todos os possíveis modos de falha reais, cada um possivelmente com diversas subdivisões. O limite de detalhamento nunca é claro no início, e somente em um processo iterativo ele pode ser bem definido. O modelo apresentado neste texto, por exemplo, foi validado somente depois de 4 tentativas.

Constatou-se a complexidade da filtragem dos dados de campo que foram colhidos de maneira não precisa. Filtragens como estas são tarefas trabalhosas para o engenheiro de confiabilidade, mas são de suma importância para que se obtenha um bom resultado, e não existe maneira única ou automática de se fazer. As considerações apresentadas na seção 4.3 são específicas para este trabalho, uma vez que cada banco de dados terá características que o tornam único, e que requererão atenção e interpretação do engenheiro responsável por extrair os dados. Mas apesar de ser específica, a seção 4.3 pode servir como guia para outras filtragens de dados.

Para os cálculos de confiabilidade e mantenabilidade, foram definidas as distribuições a serem usadas por meio de parâmetros estatísticos. Estas distribuições foram usadas para simular o comportamento da disponibilidade. As simulações foram feitas partindo-se de um modelo mais simples, considerando somente uma posição de uma máquina, até o modelo mais complexo, que considera todo o parque instalado. Por último, foi possível fazer uma simulação levando em consideração uma possível melhoria para um modo de falha. Com isso, é possível estabelecer um cálculo do retorno esperado para um investimento de melhoria.

Em função dos resultados das simulações pode-se concluir: 
i. Os modos de falha mais críticos, de todos os considerados no modelo, são $B F 1, B R 1$, $C B$ e $C C$.

ii. O modo de falha $C C$ apresenta uma mortalidade infantil muito acentuada, o que não condiz com um modo de falha para um componente estritamente mecânico ( $C C$ é a sigla de um tipo de correia de transmissão). Descobrir o real motivo para a alteração do comportamento esperado pode resultar em grandes benefícios para esta empresa, como pode ser verificado na simulação feita na seção 4.7.3, em que os resultados de uma eventual melhoria implantada neste modo de falha foram simulados.

iii. As confiabilidades dos modos de falha $B F 1$ e $B R l$ seguem comportamento distinto em máquinas que deveriam ser iguais. Isto chama bastante atenção, pois também não é um comportamento típico. A confiabilidade de $C C$, por exemplo, apesar de baixa, segue um comportamento semelhante para todas as máquinas, como mostrado nas figuras 4-8 e 4-9. Pode-se especular que esta diferença de comportamentos pode sofrer influências do tipo de fio que é produzido em cada máquina, da idade e do histórico das máquinas. Como os comportamentos são distintos, a melhor política de manutenção varia conforme o caso.

iv. O modo de falha $C B$ também apresenta variação no comportamento quando se comparam diversas máquinas, mas não de forma tão acentuado como em $B F 1$ e $B R l$.

v. Apenas metade das distribuições de mantenabilidade foi definida como sendo a esperada Lognormal: a outra metade segue a distribuição de Weibull. Isto pode ser explicado pela influência da disponibilidade de mão de obra, facilidade de reparo e horário de ocorrência. Isto porque todas as falhas concorrem pela mesma mão de obra para serem resolvidas.

vi. O modelo foi validado com o resultado da simulação de uma posição de uma máquina, seção 4.7.1, onde foi obtido um número esperado de falhas total que difere em $6,6 \%$ do real.

vii. Também foi obtido através das simulações o tempo indisponível esperado por posição por máquina, como mostrado na seção 4.7.2. Com base em resultados deste tipo, além de mostrar o que realmente se pode esperar de capacidade produtiva do 
maquinário instalado, podem-se tomar ações de melhoria com muito mais precisão de onde focar esforços para que os resultados sejam alcançados.

viii. Na simulação feita para o conjunto de máquinas, seção 4.7.3, considerou-se o parque como sendo um sistema em paralelo $m$ de $N$, onde $N$ é o número de posições existentes e $m$ é o número mínimo de posições necessárias para o sistema atender a uma determinada demanda de produção. A simulação mostrou que para $m / N$ abaixo de $93 \%$ a disponibilidade aproxima-se muito de $100 \%$, e que caso $m / N$ seja próximo de $100 \%$, a disponibilidade cai abaixo de $15 \%$. Isto mostra os limites onde eventuais backups adicionais seriam irrelevantes, no caso do primeiro caso, e onde backups adicionais seriam extremamente benéficos.

Por último, as recomendações geradas foram comparadas com o plano atual de manutenção, mostrando a economia potencial que pode gerar um novo plano de manutenção criado a partir destas recomendações.

\subsection{Recomendações para Trabalhos Futuros}

O método proposto neste trabalho pode ser utilizado para modelar qualquer outro sistema presente em indústrias têxteis, assim como sistemas industriais diversos.

Ainda dentro do escopo de máquinas retorcedeiras desta empresa, pode-se investigar mais a fundo a causa dos comportamentos de confiabilidade não esperados para os modos de falha $C C$, com alta mortalidade infantil, e $B R l$ e $B F 1$, com mudança de comportamento conforme a máquina.

Recomenda-se que os dados de falha e reparo sejam colhidos ininterruptamente, e que periodicamente os cálculos de confiabilidade e mantenabilidade sejam atualizados. Isto é interessante para averiguar se as condições de operação mudam com o passar do tempo, e também para averiguar o efeito de eventuais modificações. Isto também seria útil para refinar o modelo, principalmente para os modos de falha em que o número de falhas resultantes das simulações teve variação significativa em relação ao número de falhas real. A partir de então, pode-se usar os resultados da simulação para definir a quantidade de peças reservas e otimizar o estoque de manutenção. 
Para os casos onde foi recomendada a manutenção preventiva, pode-se implantar um modelo baseado em análise de custo para definir o intervalo ideal entre preventivas, ou gerar um modelo de simulação no BlockSim.

Pode-se investigar também mais a fundo a influência da disponibilidade de mão de obra nas distribuições de mantenabilidade. Para isto precisa ser criado no banco de dados um campo no qual é anotado não só o instante de ocorrência da falha e o instante de volta a operação, mas também o instante em que o reparo começou a ser executado. Os tempos de reparo seriam então considerados como sendo o intervalo entre o início e o fim do reparo, desconsiderando o tempo em que não houve reparo por indisponibilidade de mão de obra. As mantenabilidades teriam então de ser recalculadas, e poderia ser criado no BlockSim um modelo que simularia o comportamento das mantenabilidades para diferentes tamanhos de equipe de manutenção. 


\section{CAPÍTULO 6 - REFERÊNCIAS BIBLIOGRÁFICAS}

ANDERSON, T. W.; DARLING, D. A. Asymptotic theory of certain goodness of fit criteria based on stochastic processes. Ann. Math. Statis, v. 23, p. 193-212, 1952.

ARUNRAJ, N. S.; MAITI, J. Risk-Based Maintenance - Techniques and Applications. Journal of Hazardous Materials, v. 142, i. 3, p. 653-661, 2007.

AVALLONE, E. A.; BAUMEISTER III, T. Mark's Standard Handbook for Mechanical Engineers. New York: Ed. McGraw Hill, 1995. 1 CD-ROM.

CARAZAS, F. J. G. Análise de Disponibilidade de Turbinas a Gás em Usinas Termelétricas a Ciclo Combinado. Dissertação de mestrado. São Paulo: EPUSP, 2006. $123 p$.

CARAZAS, F. J. G.; et al. Método para Evaluacón de Disponibilidad en Sistemas de Generación de Energía Eléctrica - Aplicado a Turbinas de Gas. $8^{\mathrm{o}}$ Congresso Iberoamericano de Ingenieria Mecânica. Cusco, 2007.

CARDOSO, I. A. P. Desenvolvimento de Método para Seleção de Políticas de Manutenção Baseado em Análise de Risco. Tese de Doutorado. São Paulo: EPUSP; 2004. 296 p.

CARDOSO, I. A. P. Elaboração de Políticas de Manutenção: Uma Abordagem Voltada à Análise de Confiabilidade. Dissertação de Mestrado. São Paulo: EPUSP, 2000. 189p.

COSTA NETO, P. L. O.; CYMBALISTA, M. Probabilidades. $2^{\text {a }}$ Edição. São Paulo: Editora Edgard Blücher, 2005. 185p.

DEPARTMENT OF DEFENSE US MIL-STD 1629; “Procedures for Performing a Failure Mode, Effects and Criticality Analysis"; [S.1.], 1974

IRESON, W. G.; COOMBS, C. F. Jr.; MOSS, R. Y. Handbook of Reliability Engineering and Management. $2^{\text {nd }}$ Edition. New York: McGraw Hill, 1995.

JAPAN MANAGEMENT ASSOCIATION. Kanban Just-in-Time at Toyota: Management Begins at the Workplace. Rev. ed. Cambridge: Productivity Press, 1989. 
190p.

KHAN, F. I.; HADDARA, M. M. Risk-Based Maintenance: a quantitative approach for maintenance/inspection scheduling and planning. Journal of Loss Prevention in the Process Industries; n. 16, p. 561-573; 2003.

KHAN, F. I.; HADDARA M. M. Risk-Based Maintenance of Ethylene Oxide Production Facilities. Journal of Hazard Materials, n. 108, p. 147-159, 2004.

KRISHNASAMY, L.; KHAN, F.; HADDARA M. Development of Risk-Based Maintenance (RBM) Strategy for a Power-generating Plant. Journal of Loss Prevention in the Process Industries, n. 18, p. 69-81, 2005.

KUMAMOTO, H.; HENLEY, E. J. Probabilistic Risk Assessment: Reliability Engineering, Design, and Analysis. New York: IEEE Press, 1991. 568p.

KVALOY, J. T.; LINDQVIST, B. H. TTT-based Tests for a Trend in Repairable System Data. Reliability Engineering and System Safety, n. 60, p. 13-28, 1998.

LEITCH, R. D.; “Reliability Analysis for Engineers: An Introduction”; Oxford, Oxford Science Publication; 1995, 230p.

LEMES, D. V.; "Proposta de Método de Análise de Confiabilidade de Sistemas Eletrônicos Empregando Dados de Retorno em Garantia”; Dissertação de Mestrado; São Paulo, EPUSP; 2006, 153p.

LEWIS, E. E. Introduction to Reliability Engineering. $2^{\text {nd }}$ Edition. EUA: John Wiley and Sons Inc, 1996. 435p.

MARQUEZ, A. C.; HEGUEDAS, A. S.; IUNG, B. Monte Carlo-Based Assessment of System Availability. A Case Study for Cogeneration Plants. Reliability Engineering \& System Safety, v. 88, n. 3, p. 273-289, 2005.

MIAO, M.; CHEN, R. Yarn Twisting Dynamics. Textile Research Journal, v. 63, p. 150$158,1993$.

MOUBRAY, J. RCM II Reliability-Centered Maintenance. $2^{\text {nd }}$ Edition. New York: 
Industrial Press Inc., 1997. 426p.

NELSON, W. How to Analyze Reliability Data. Wiscosin (EUA): ASQC QualityPress, 1982.

PALADY, P. FMEA: Análise dos Modos de Falha e Efeitos: Prevendo os Problemas Antes que Ocorram. $3^{\text {a }}$ Edição. São Paulo: IMAM, 2004.

O'CONNOR, P. D. T. Practical Reliability Engineering. $2^{\text {nd }}$ Edition. New York: John Wiley\&Sons, 1985. 398p.

SIX SIGMA ACADEMY. The Black Belt Memory Jogger: A Pocket Guide for Six Sigma Success. EUA: GOAL/QPC, 2002. 264p.

SOUZA, G. F. M. Análise de Confiabilidade Aplicada ao Projeto de Sistemas Mecânicos. Apostila de Curso. São Paulo: EPUSP, 2003. 210p.

SPINDELFABRIK NEUDORF GMBH. Spindellagerungen $H L$ - Spindle Bearings $H L$. Catálogo de Produto. Alemanha, 2004.

RELIASOFT. Weibull ++ Version 7 User's Guide. Tucson (EUA): Reliasoft Corporation; 2005. 708p.

XENOS, H. G. Gerenciamento da Manutenção Produtiva. Nova Lima: INDG Tecnologia e Serviços Ltda., 2004. 302p. 


\section{APÊNDICE A - GRÁFICOS UTILIZADOS PARA DETERMINAÇÃO DAS DISTRIBUIÇÕES DE CONFIABILIDADE}

A seguir são apresentados para todos os modos de falha os gráficos de probabilidade de falha para diferentes distribuições, utilizados para a definição de qual a distribuição que melhor se adequa ao modelo, e, uma vez que a distribuição é definida, os gráficos de $f(t), F(t), R(t)$ e $\lambda(t)$. 
- Modo de Falha: $A N$
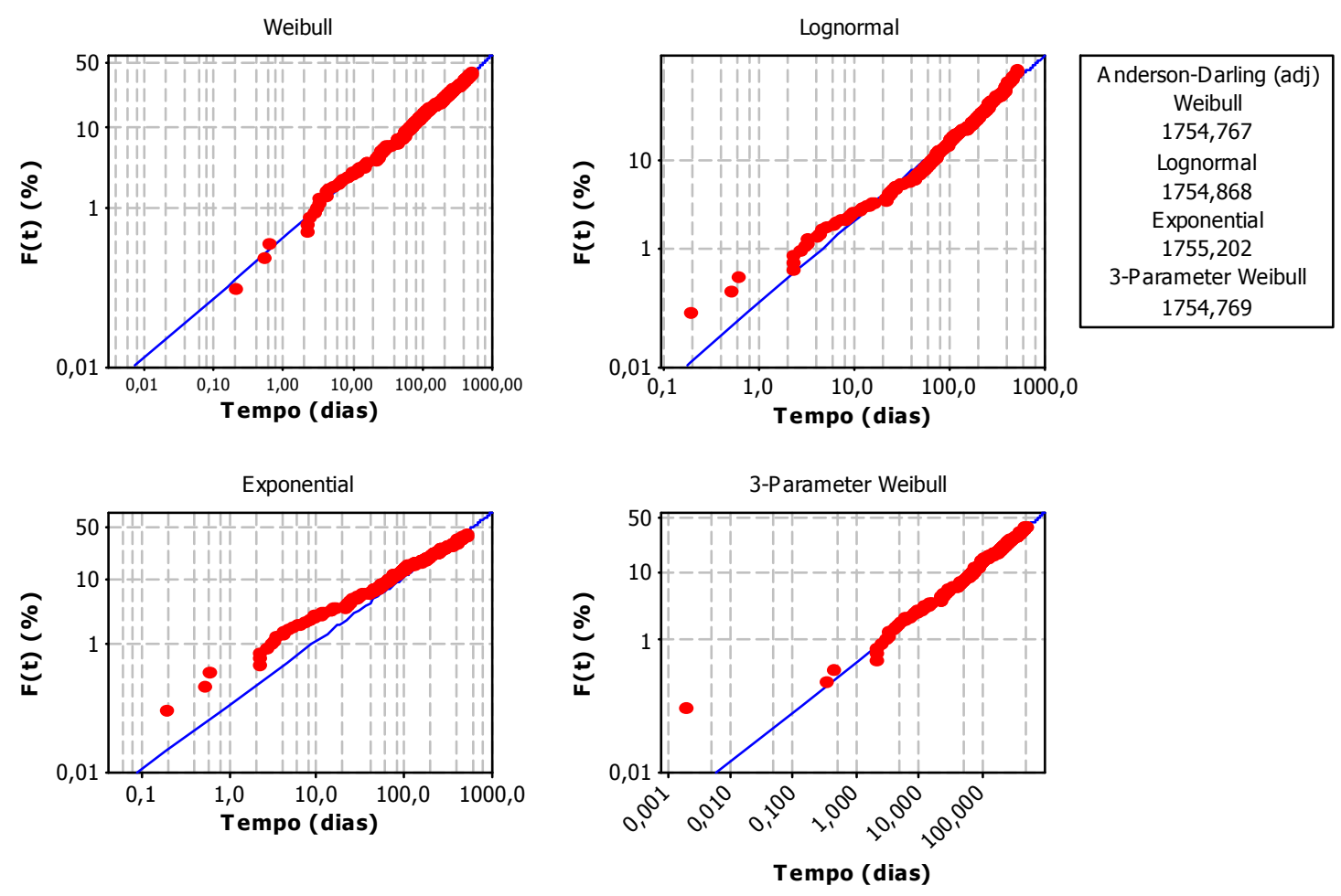

Figura A-1 - Probabilidades de Falha para $A N$, para diferentes distribuições.

$f(t)$
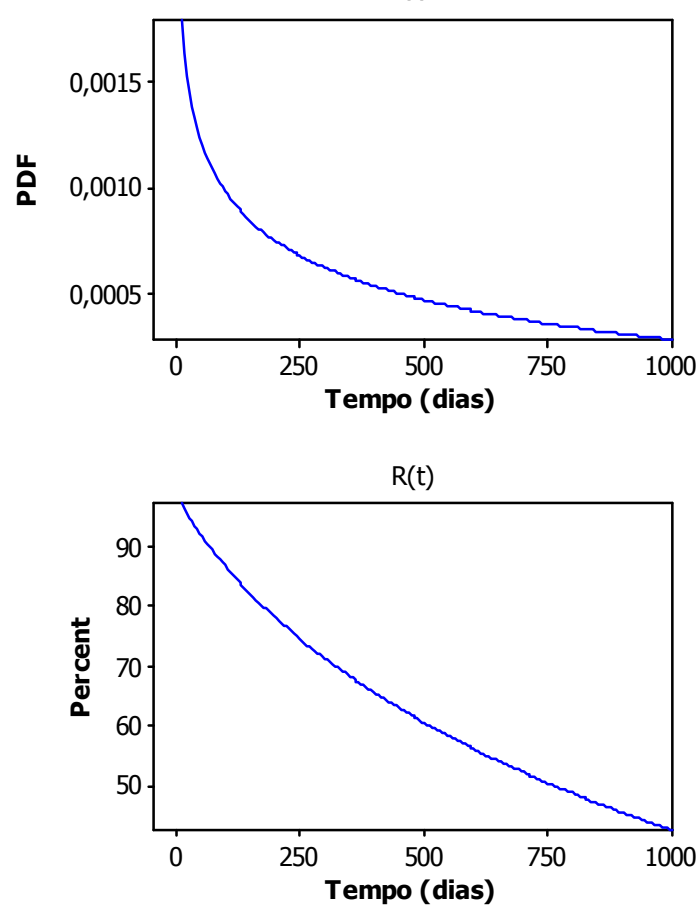
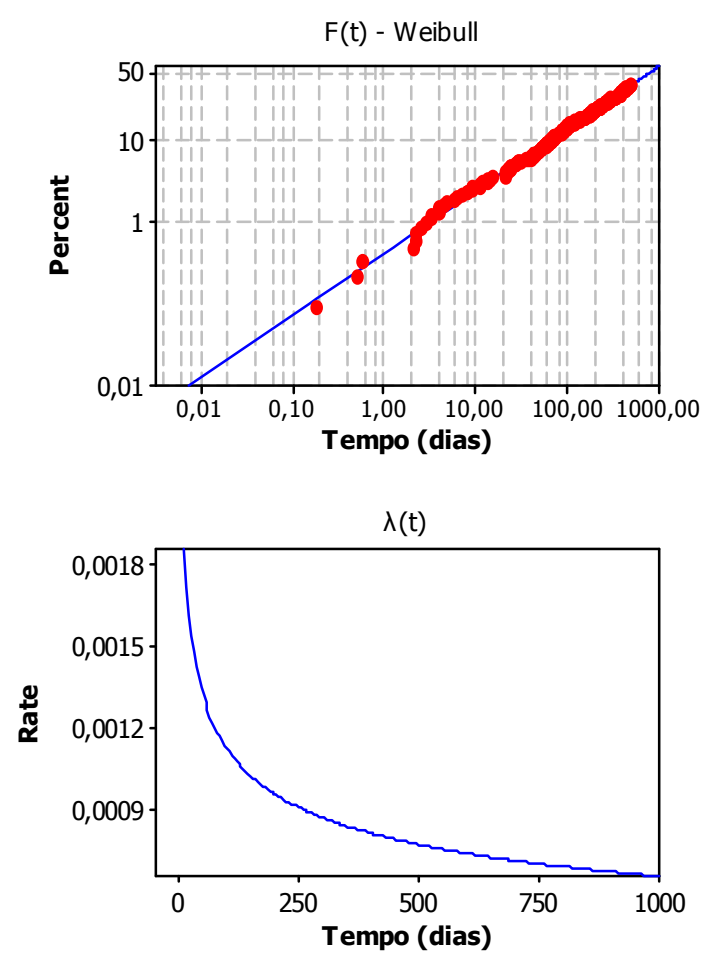

Figura A-2 - f(t), F(t), R(t) e $\lambda(\mathbf{t})$ para $A N$. 
- $\quad$ Modo de Falha: BF 1
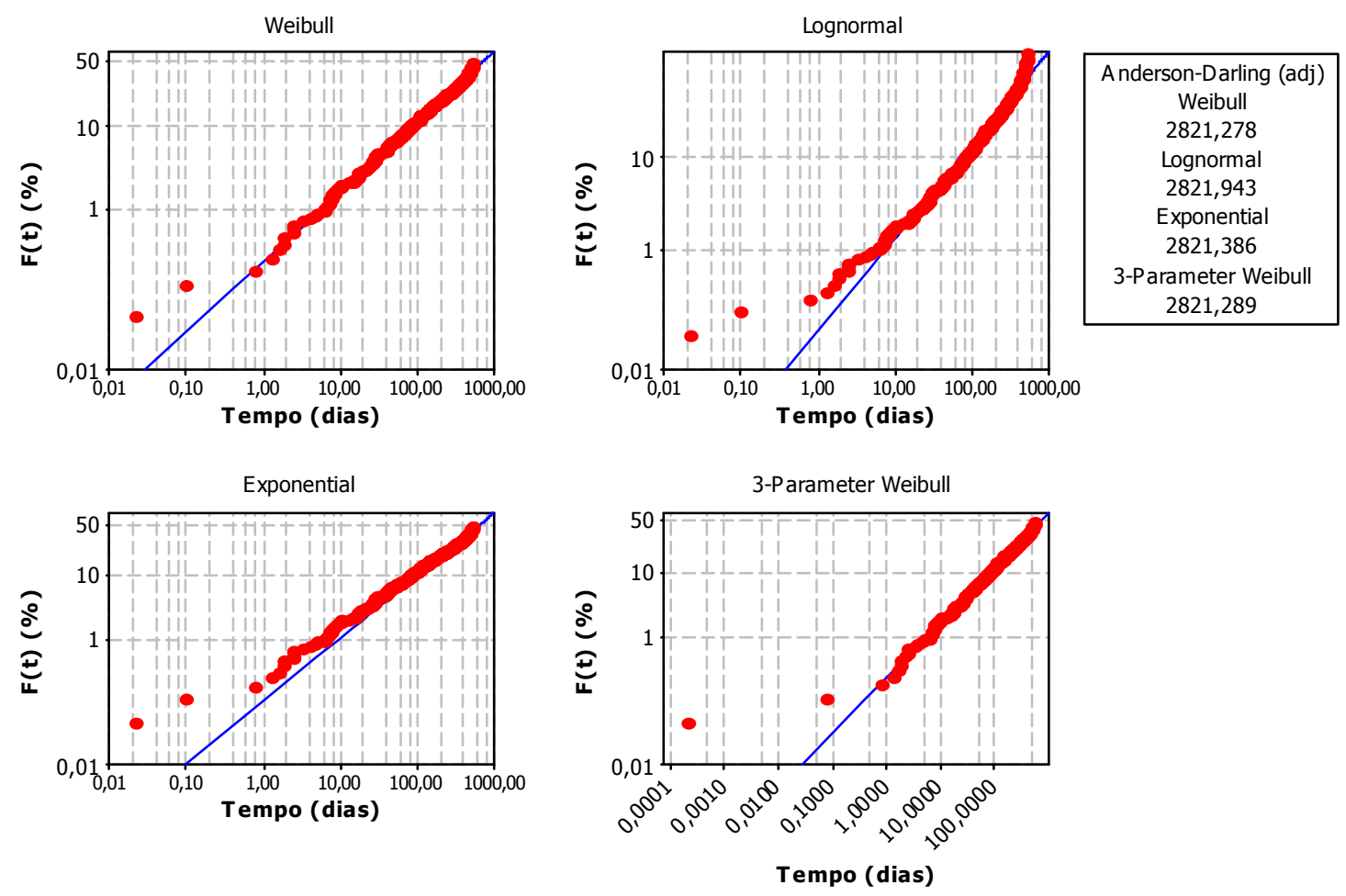

Figura A-3 - Probabilidades de Falha para BF1, para diferentes distribuições.
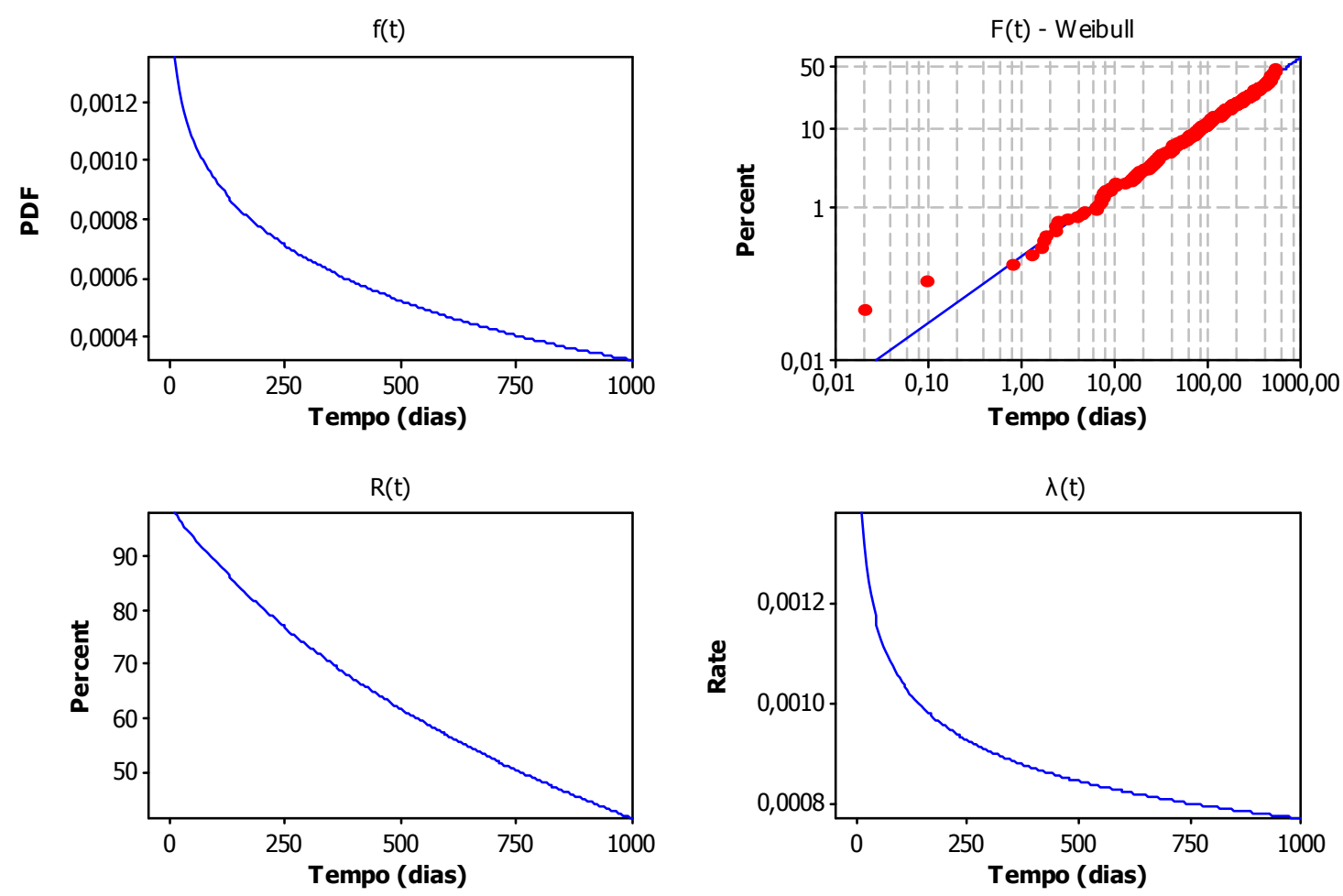

Figura A-4 - $f(t), F(t), R(t)$ e $\lambda(t)$ para $B F 1$. 
- $\quad$ Modo de Falha: BF2
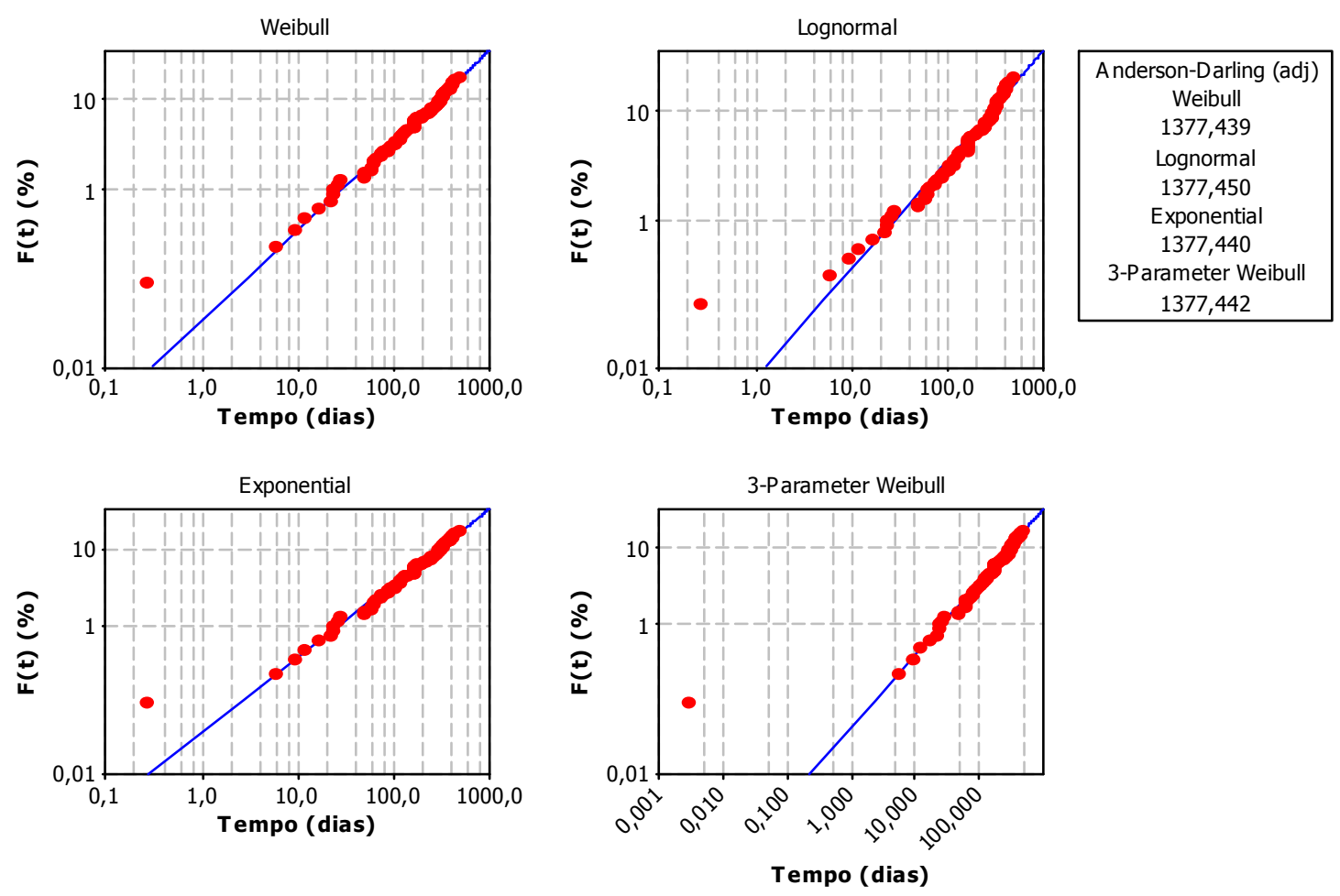

Figura A-5 - Probabilidades de Falha para BF2, para diferentes distribuições.
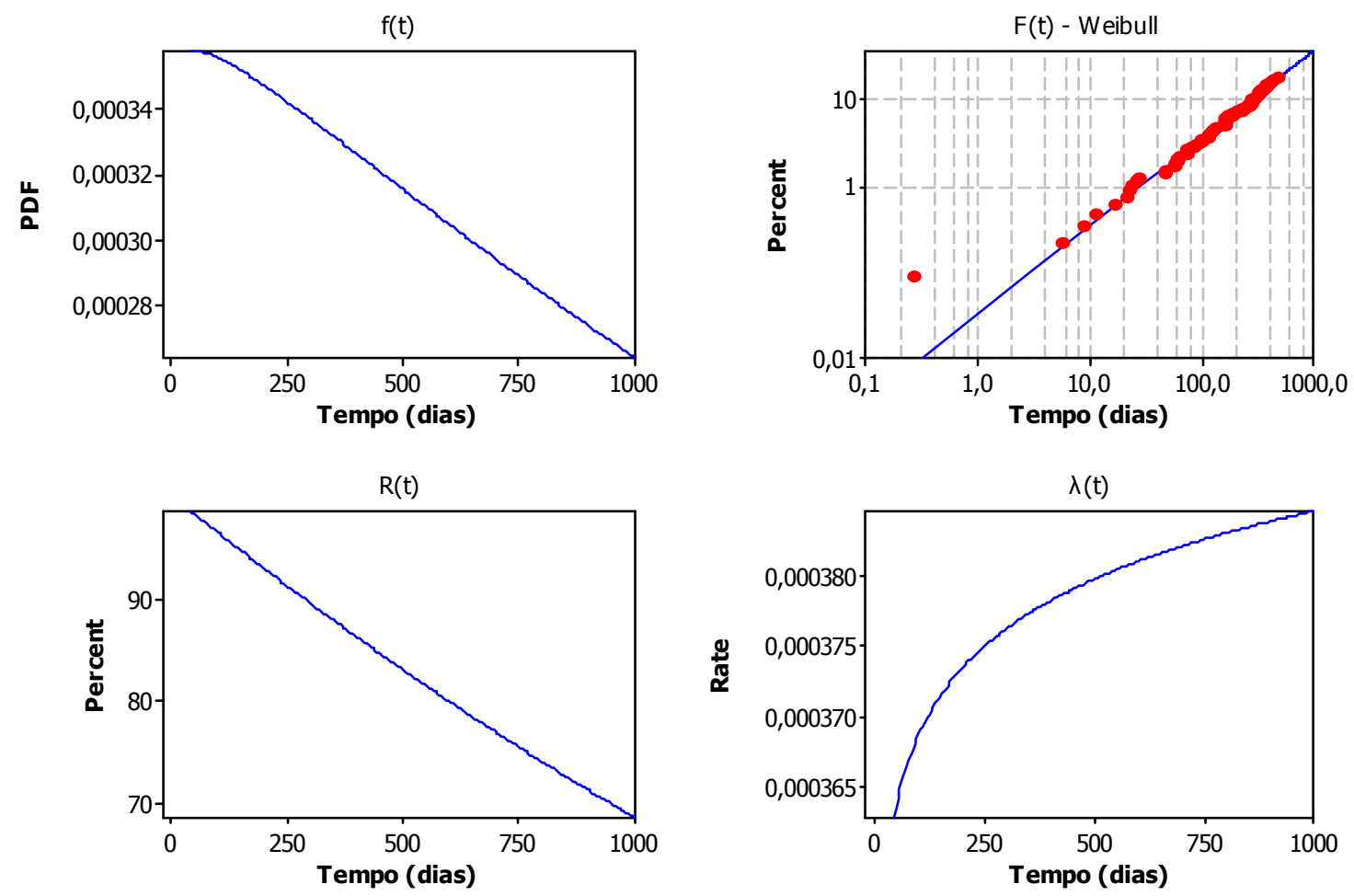

Figura A-6 - $f(t), F(t), R(t)$ e $\lambda(t)$ para $B F 2$. 
- $\quad$ Modo de Falha: BRI
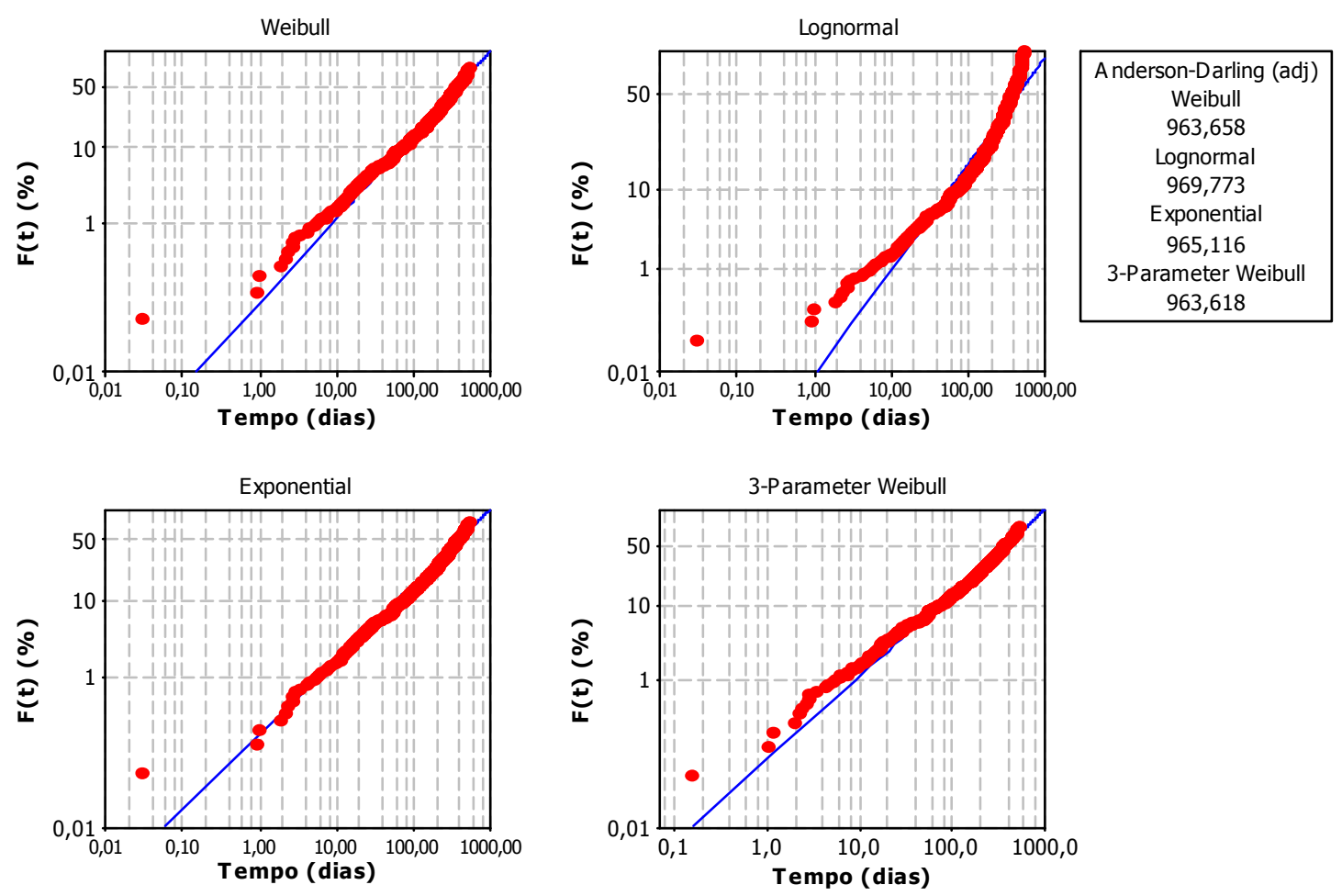

Figura A-7 - Probabilidades de Falha para BR1, para diferentes distribuições.

$f(t)$
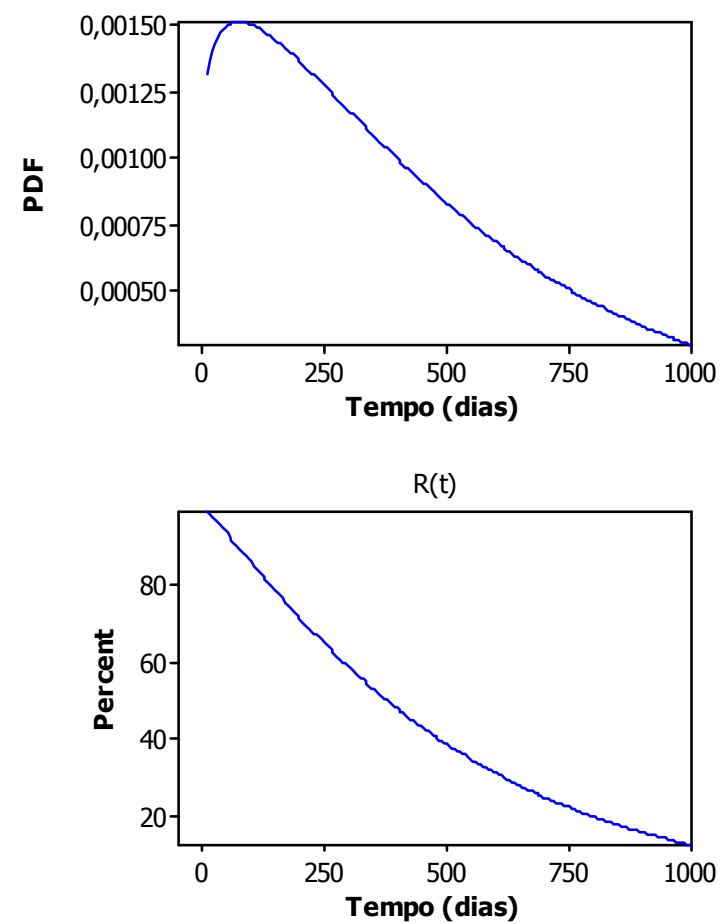

$F(t)$ - Weibull
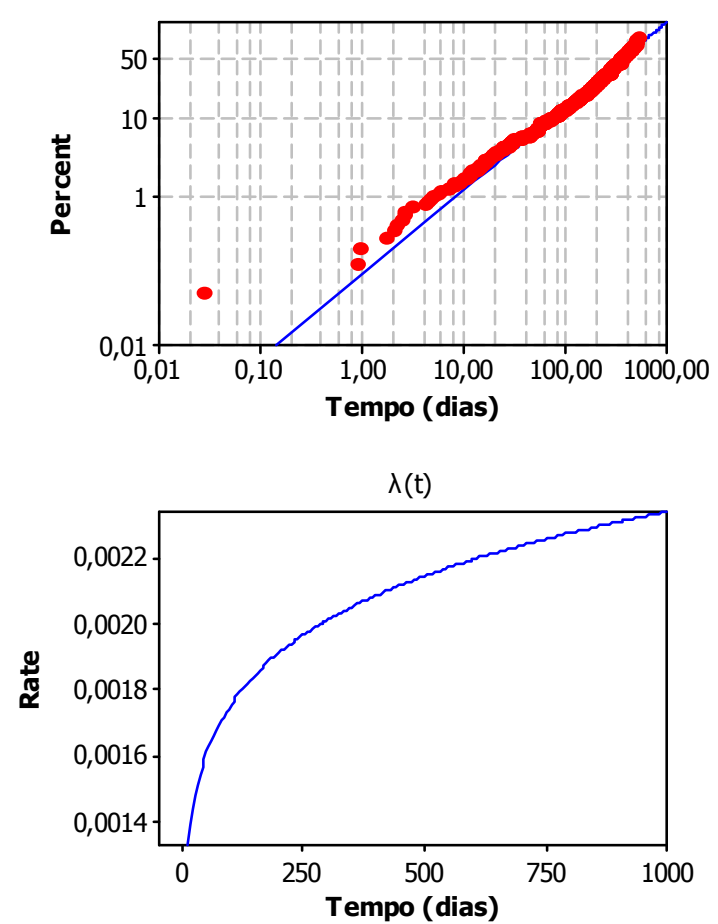

Figura A-8 - $\mathbf{f}(\mathbf{t}), \mathbf{F}(\mathbf{t}), \mathbf{R}(\mathrm{t})$ e $\lambda(t)$ para $B R 1$. 
- Modo de Falha: BR2
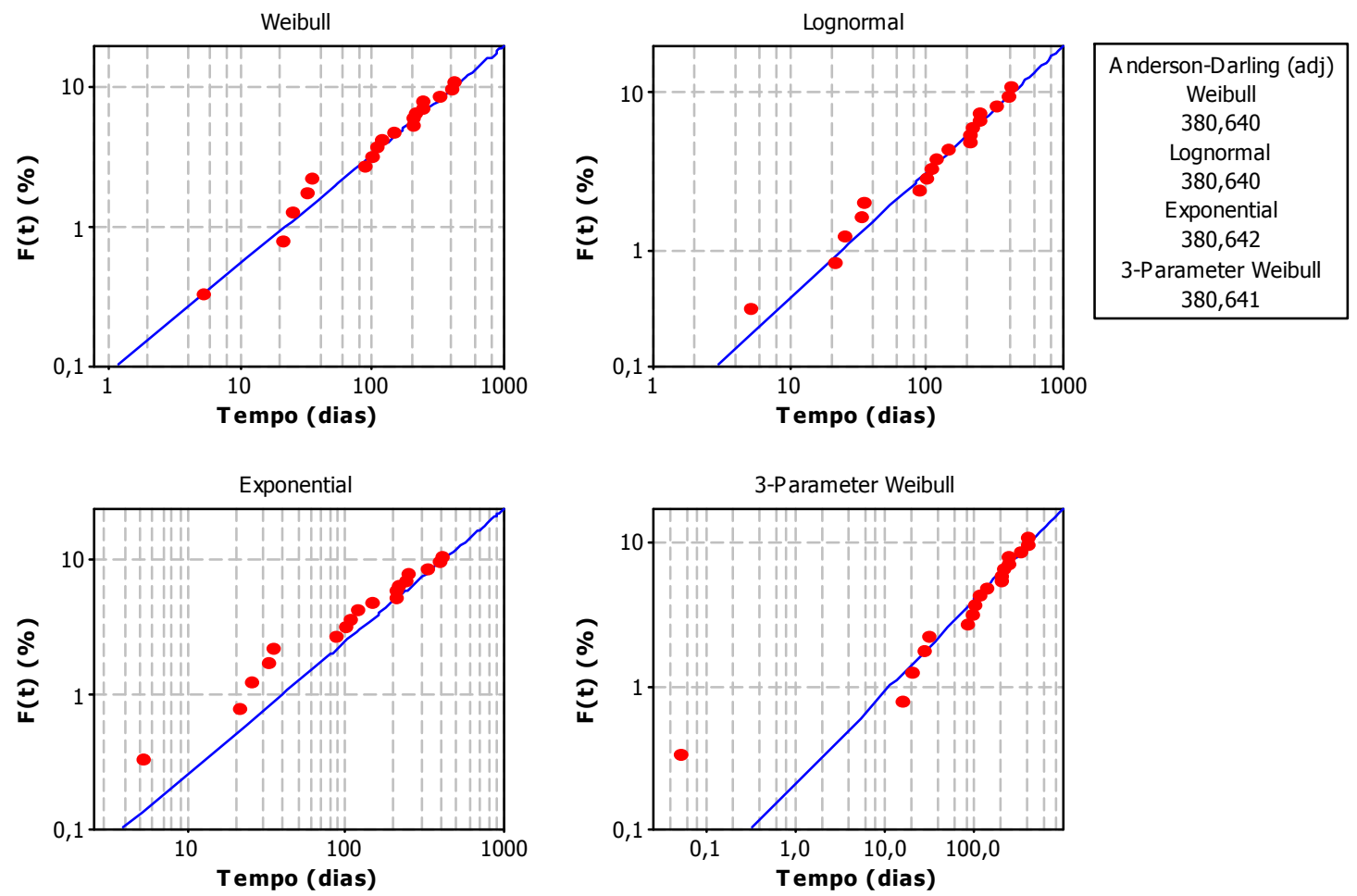

Figura A-9 - Probabilidades de Falha para BR2, para diferentes distribuições.
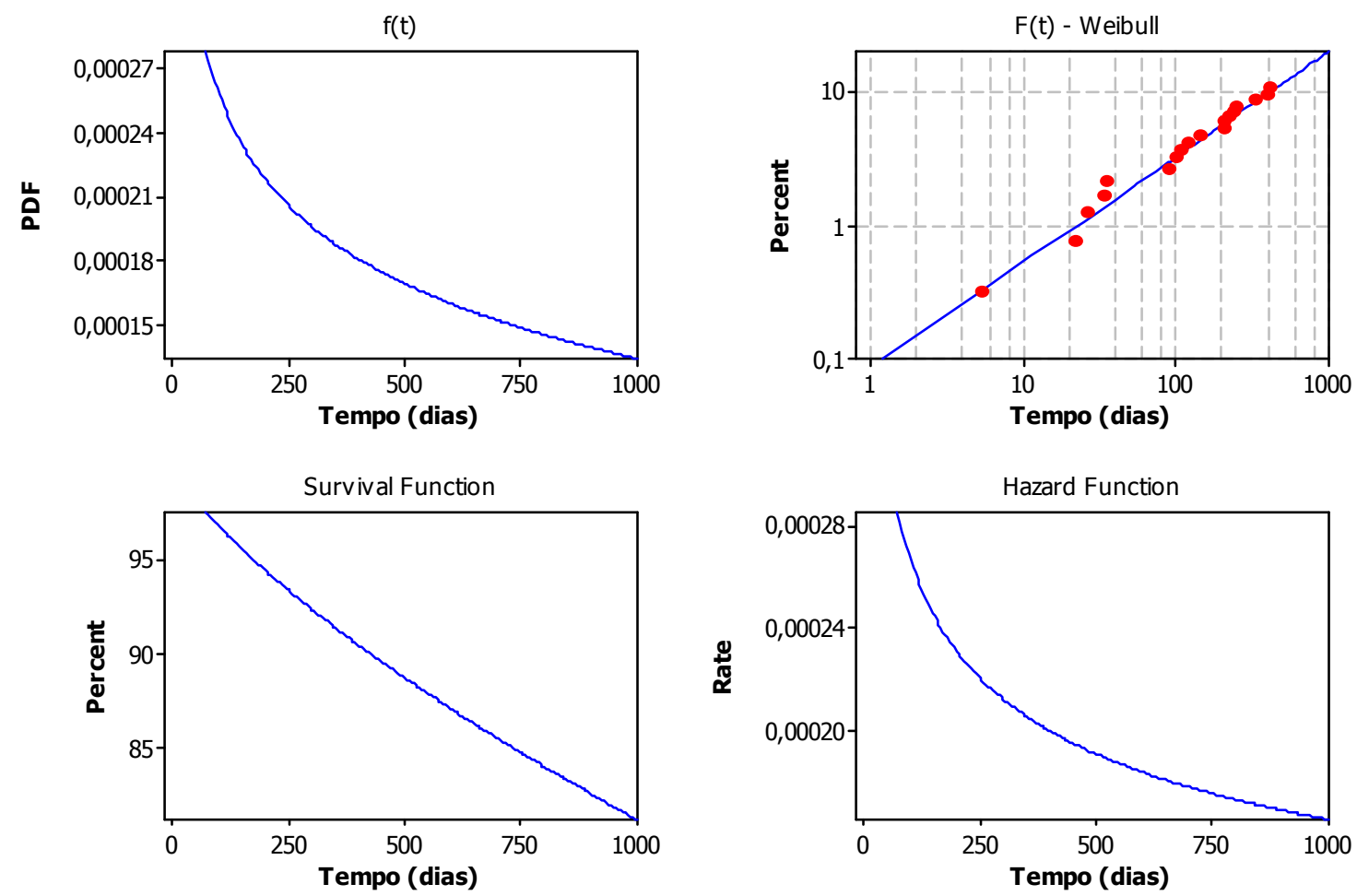

Figura A-10 - f(t), F(t), R(t) e $\lambda(t)$ para $B R 2$. 
- Modo de Falha: $C B$
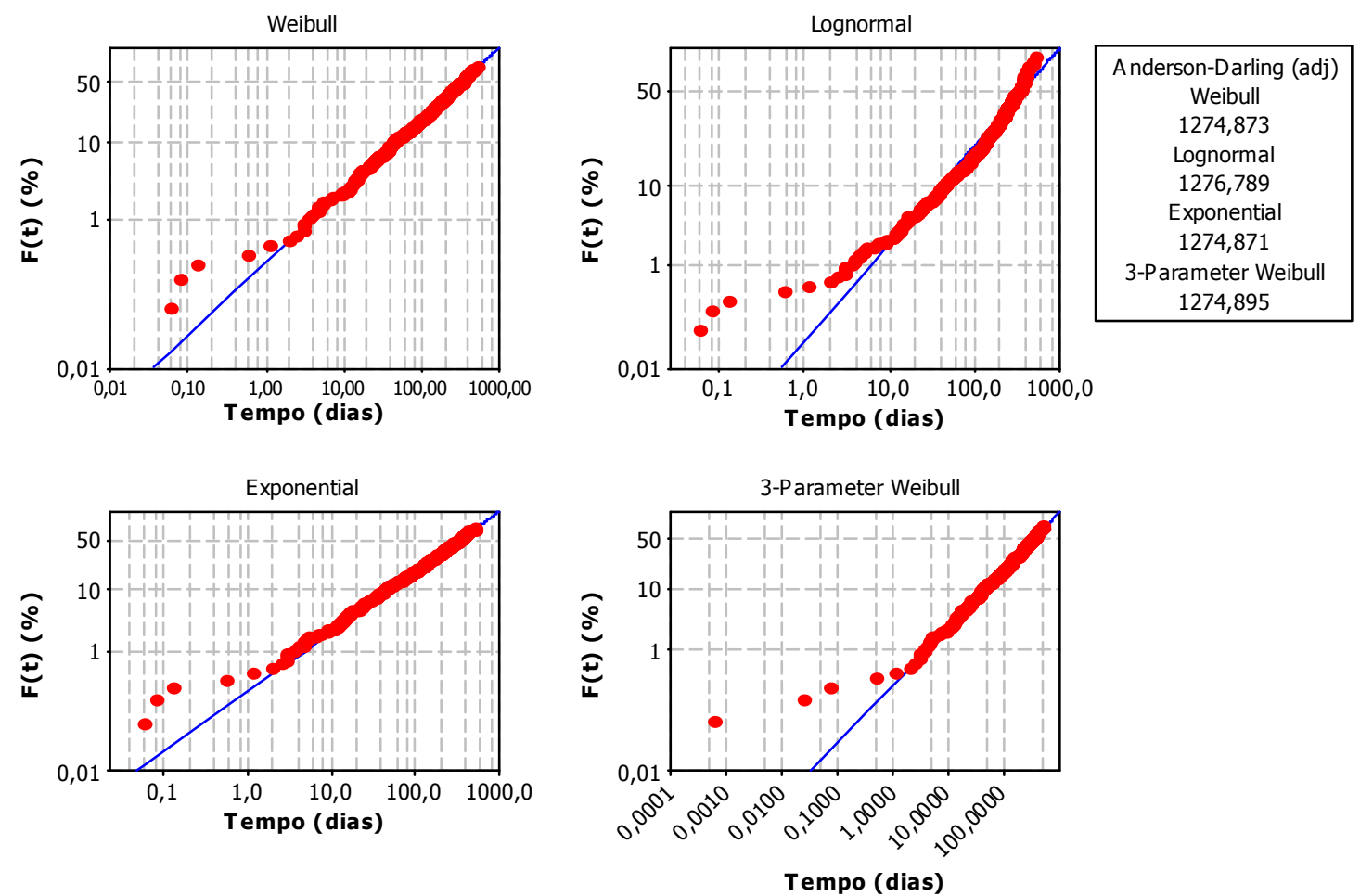

Figura A-11 - Probabilidades de Falha para $C B$, para diferentes distribuições.
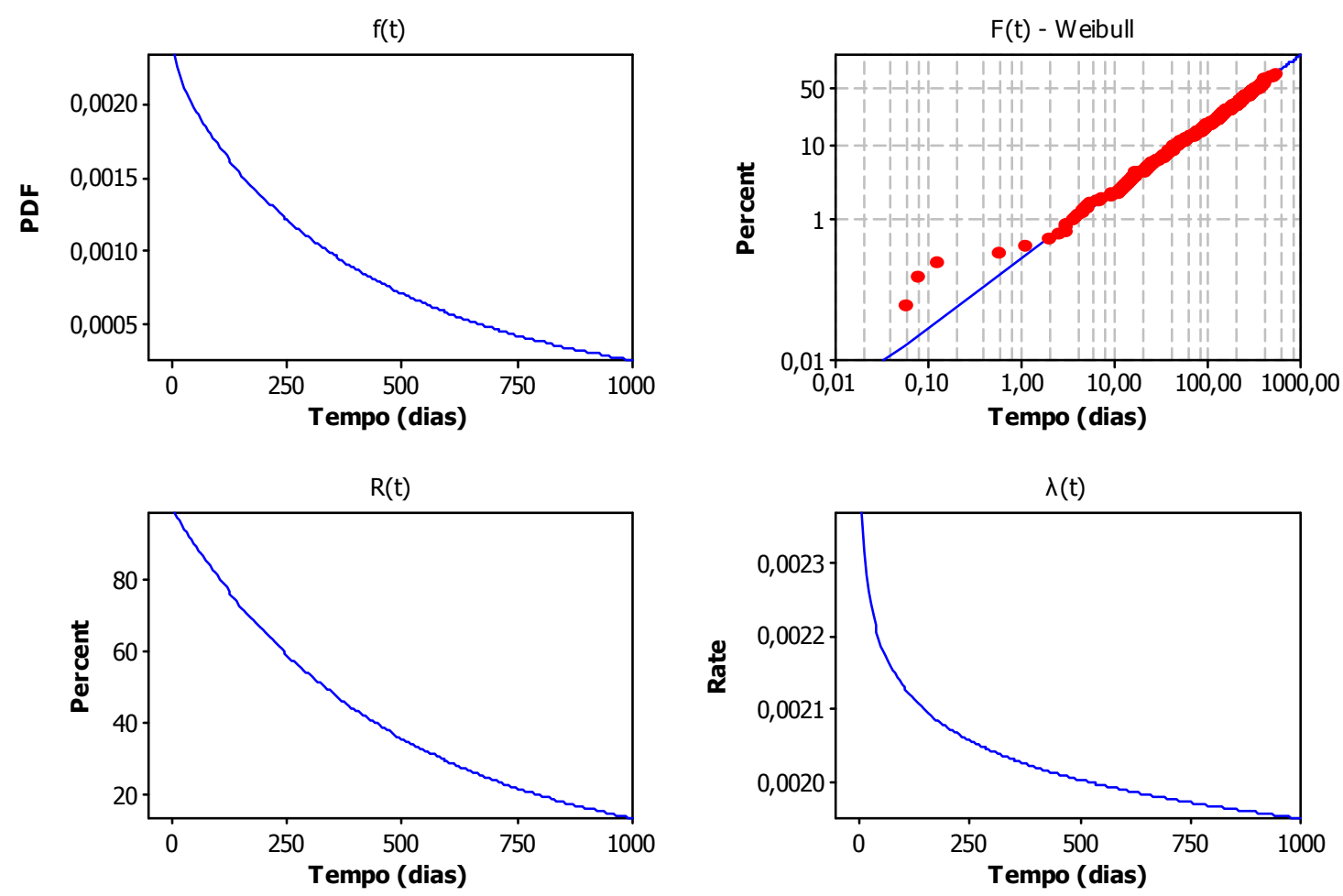

Figura A-12 - f(t), F(t), R(t) e $\lambda(t)$ para $C B$. 
- Modo de Falha: $C C$
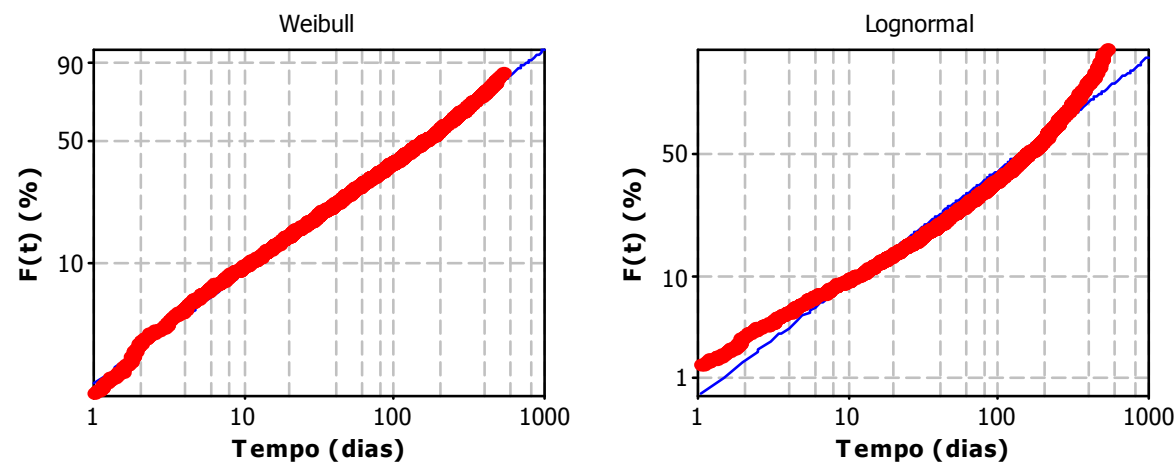

A nderson-Darling (adj) Weibull 819,050

Lognormal 831,193

Exponential

845,085

3-Parameter Weibull 819,051
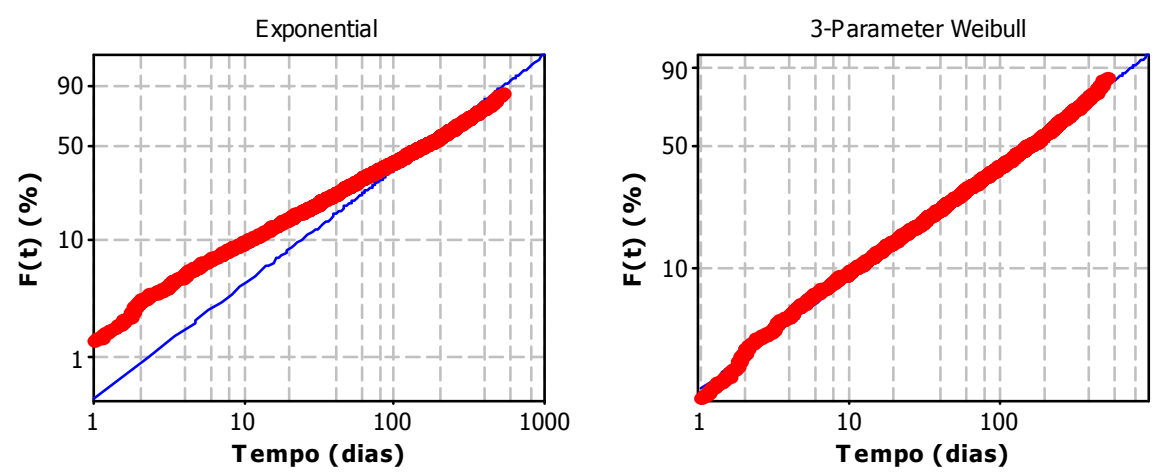

Figura A-13 - Probabilidades de Falha para $C C$, para diferentes distribuições.

$f(t)$
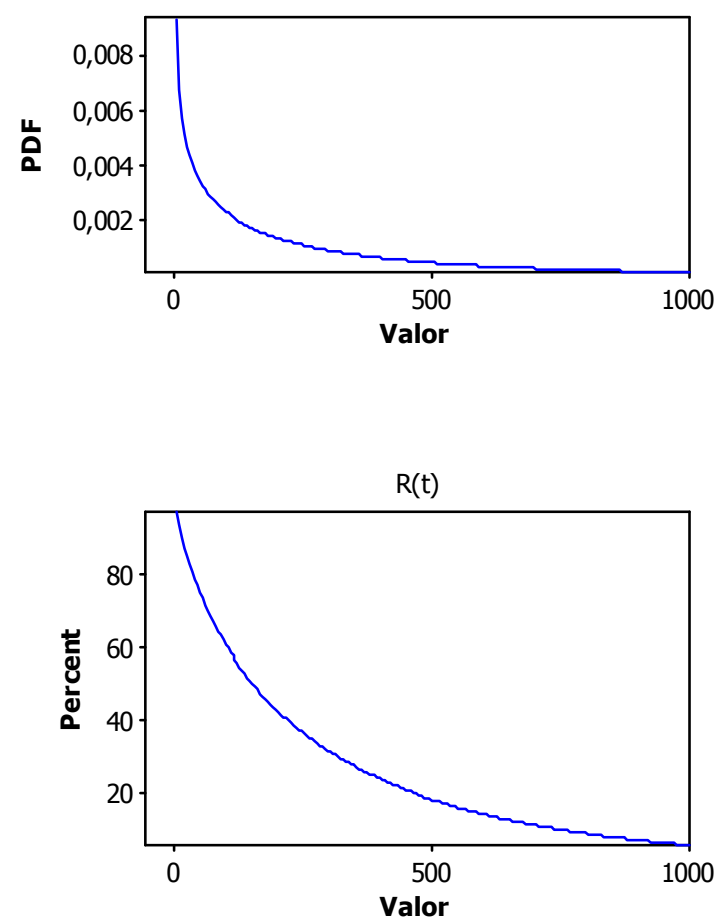
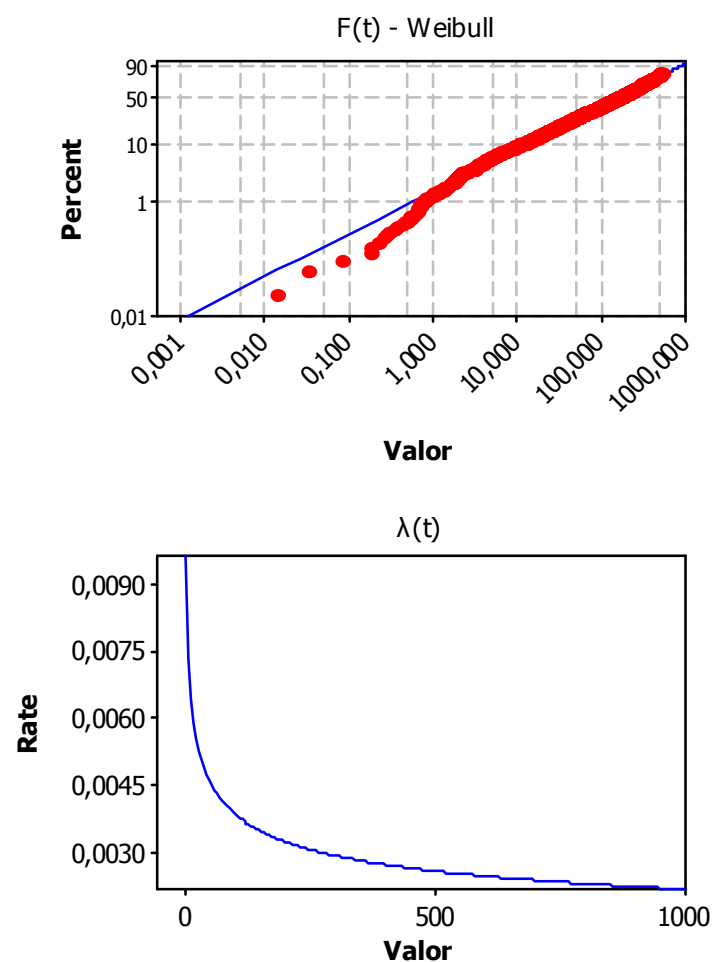

Figura A-14 - f(t), F(t), R(t) e $\lambda(t)$ para $C C$. 
- Modo de Falha: FF1
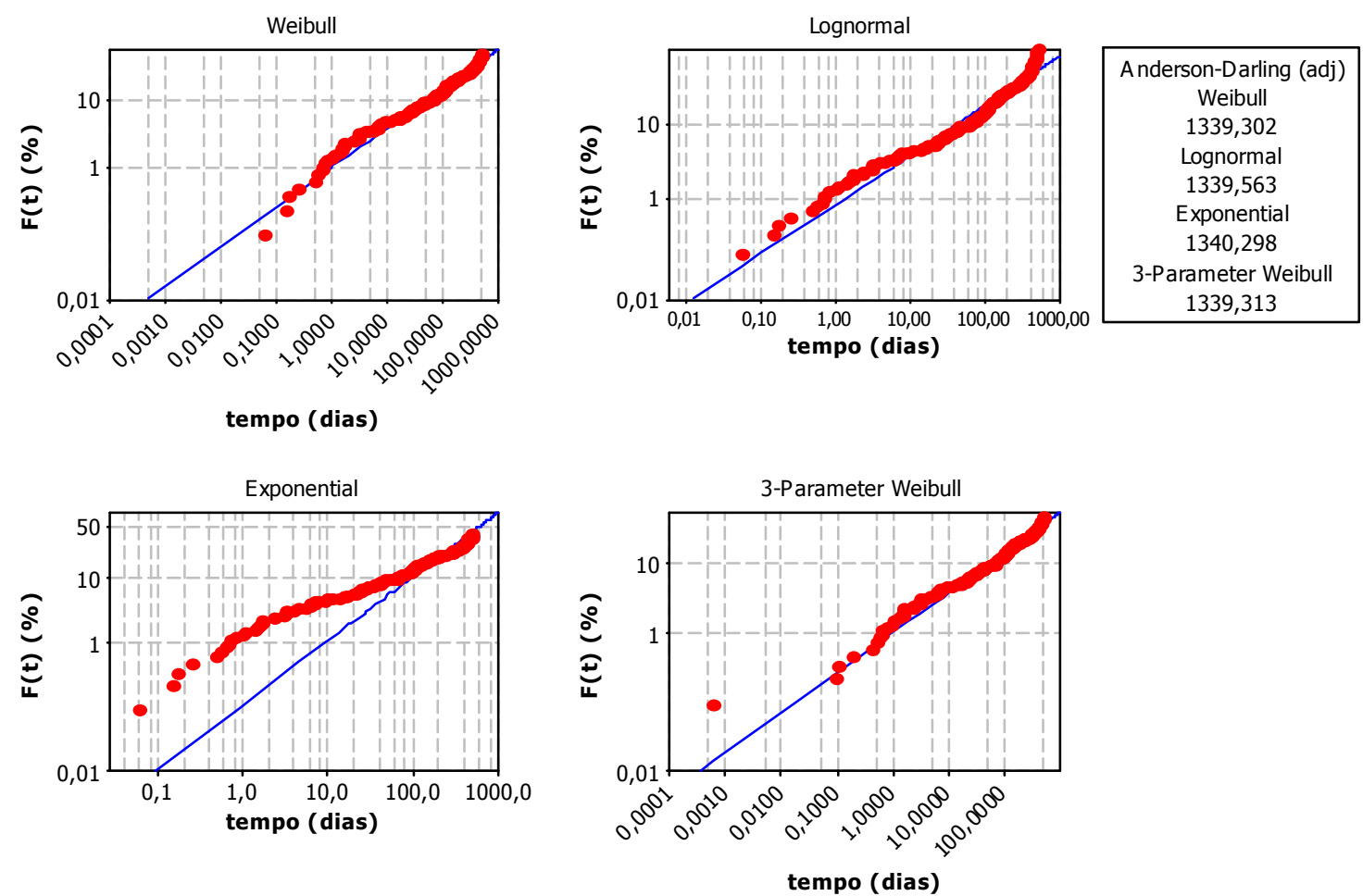

Figura A-15 - Probabilidades de Falha para FF1, para diferentes distribuições.

$f(t)$
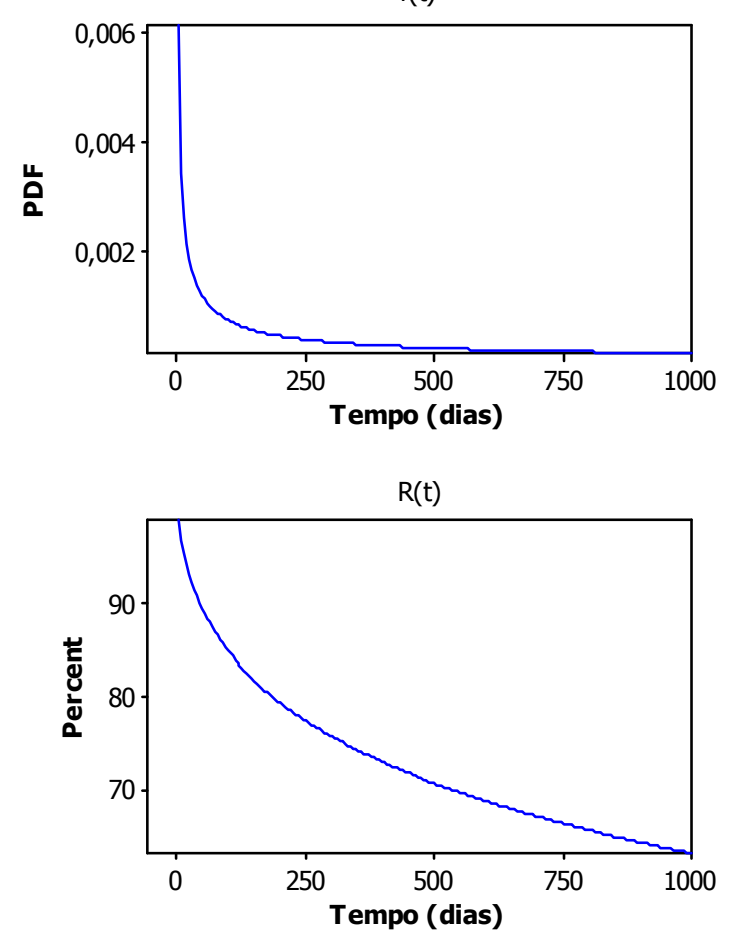
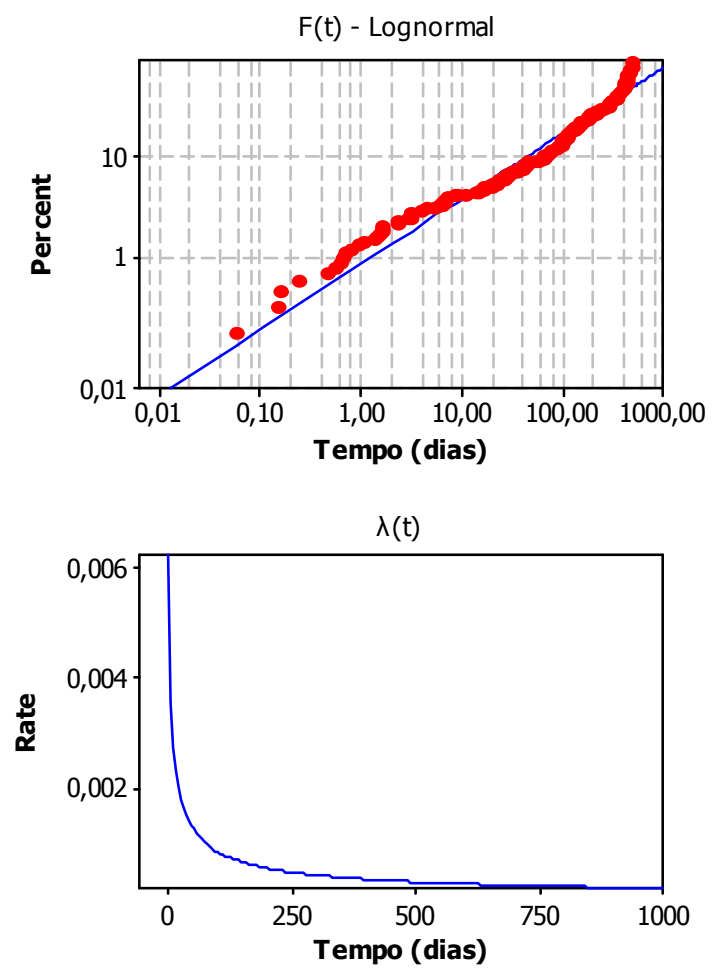

Figura A-16 - f(t), F(t), R(t) e $\lambda(t)$ para $F F 1$. 
- Modo de Falha: FF2
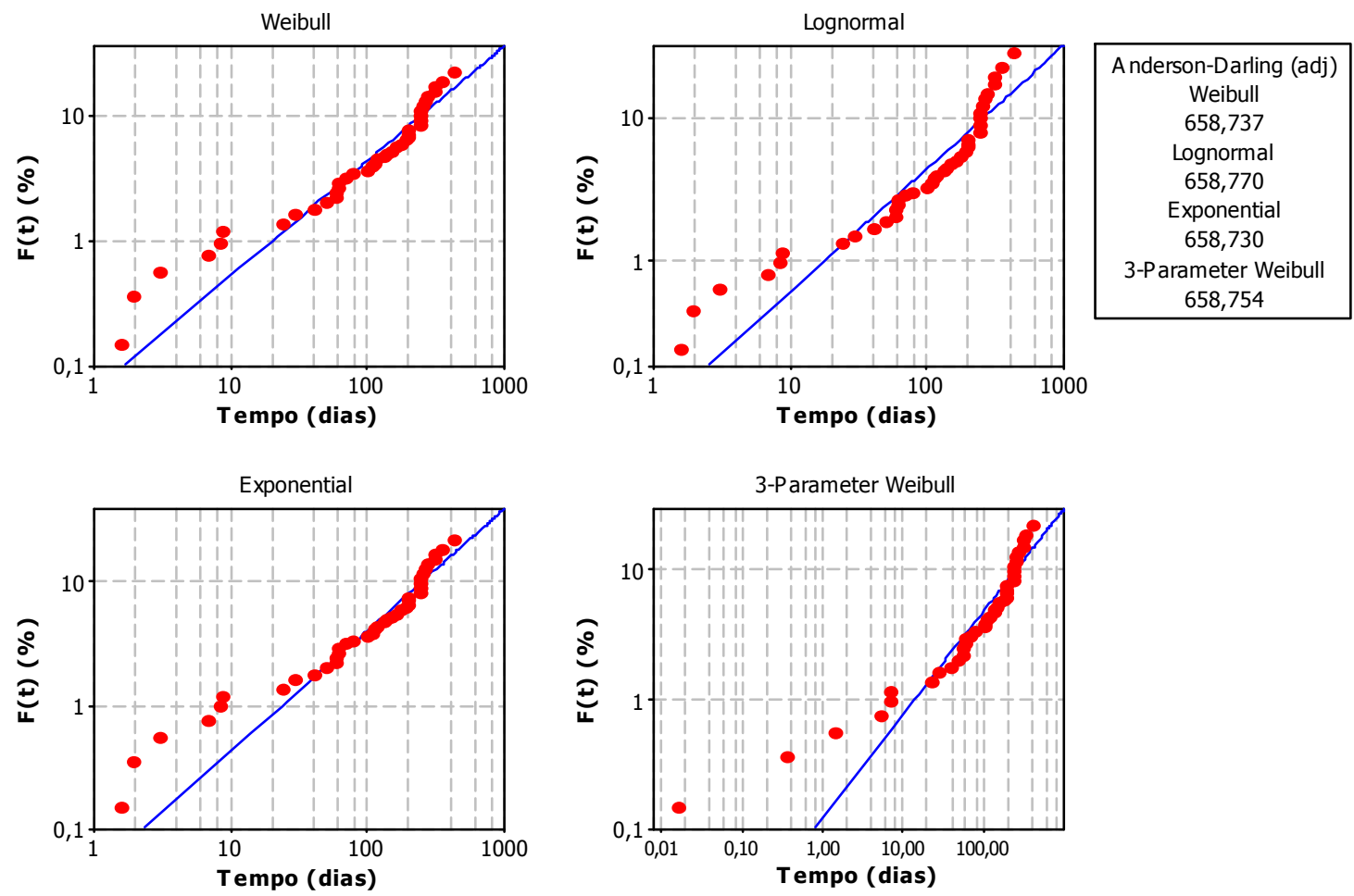

Figura A-17 - Probabilidades de Falha para FF2, para diferentes distribuições.
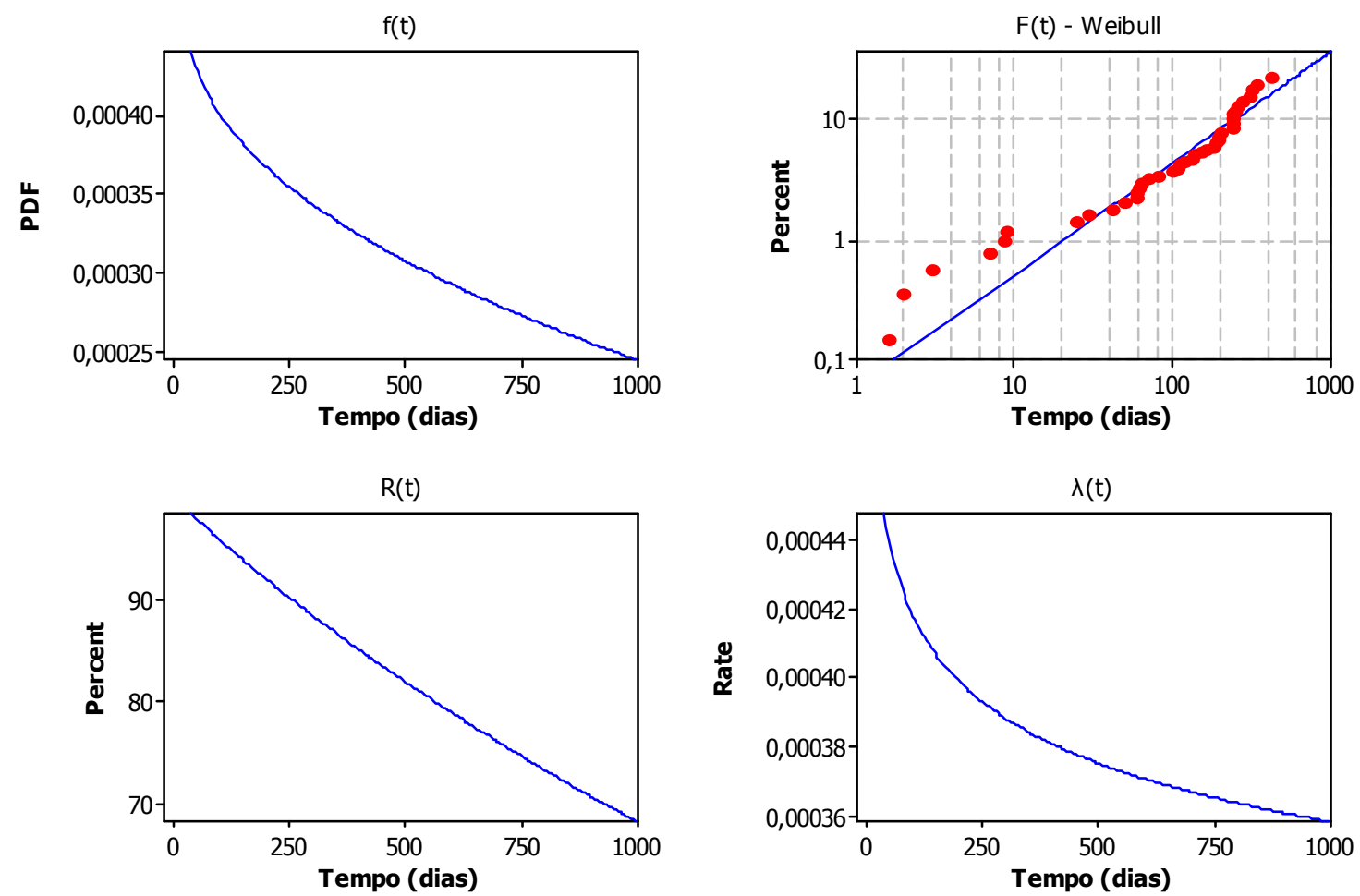

Figura A-18 - f(t), F(t), R(t) e $\lambda(t)$ para $F F 2$. 
- Modo de Falha: FO
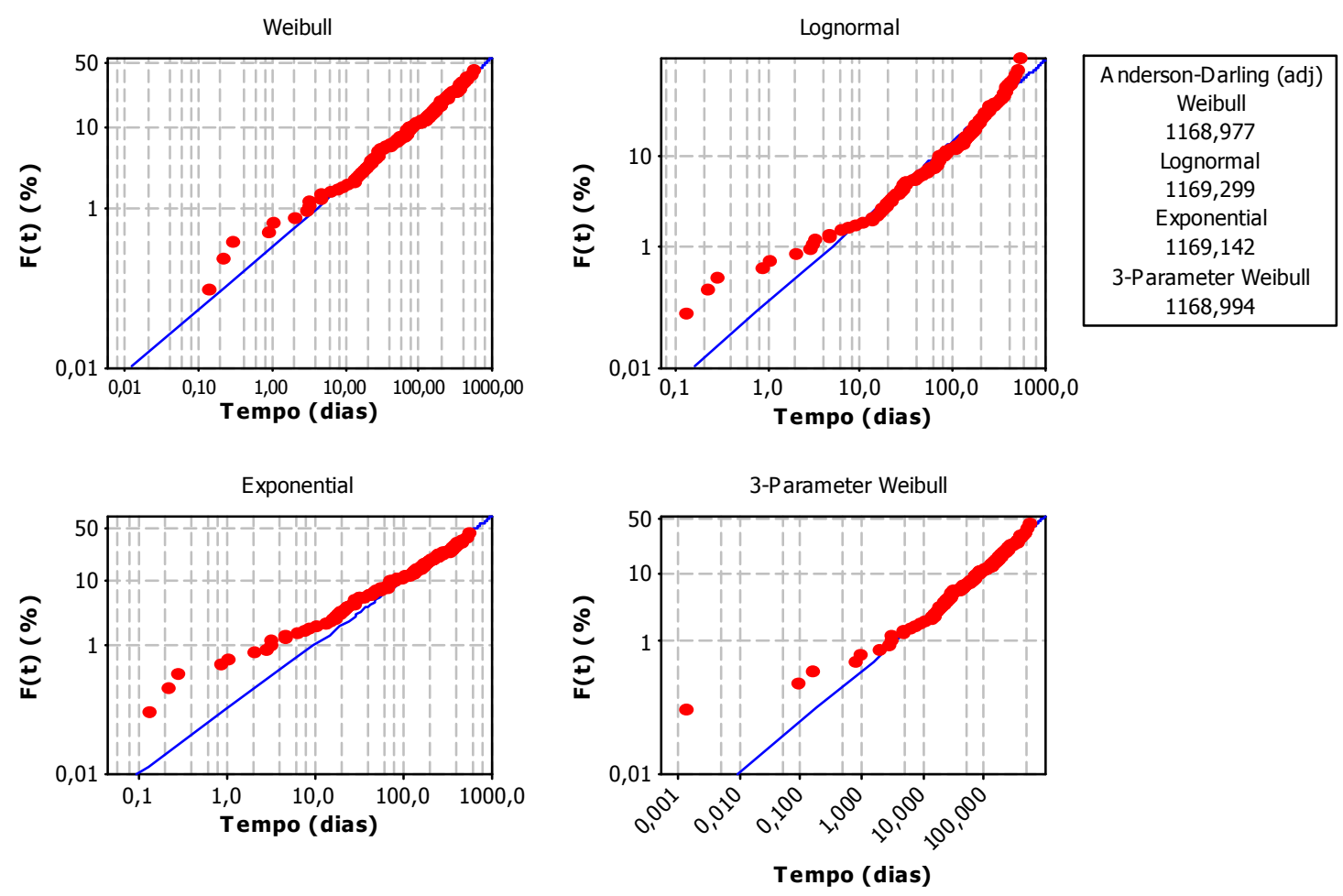

Figura A-19 - Probabilidades de Falha para FO, para diferentes distribuições.

$f(t)$
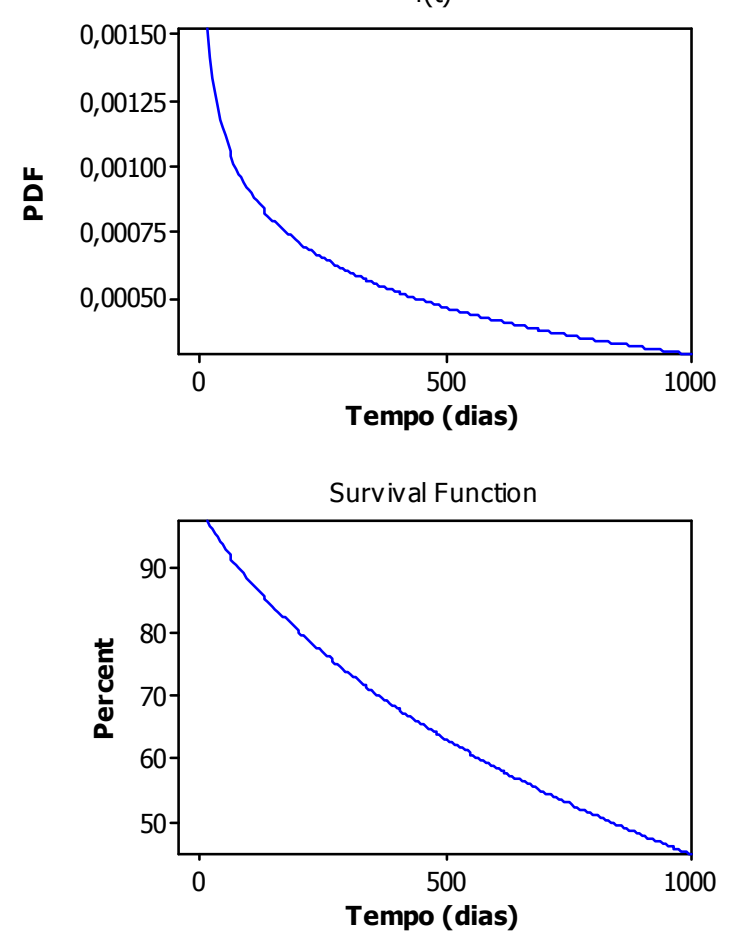

$F(t)$ - Weibull
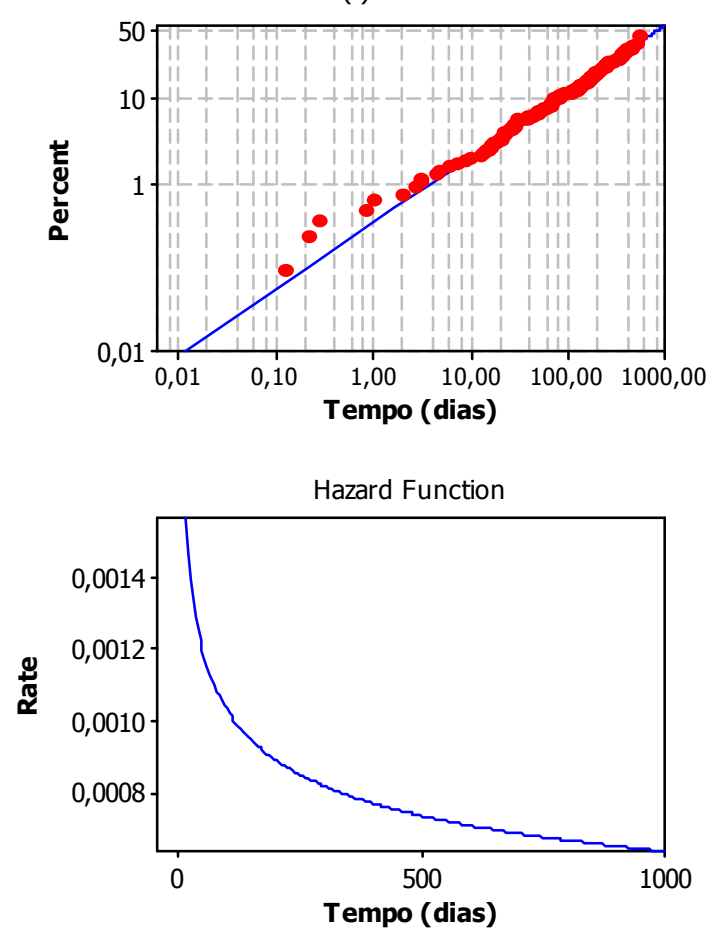

Figura A-20 - $f(t), F(t), R(t)$ e $\lambda(t)$ para $F O$. 
- Modo de Falha: FR
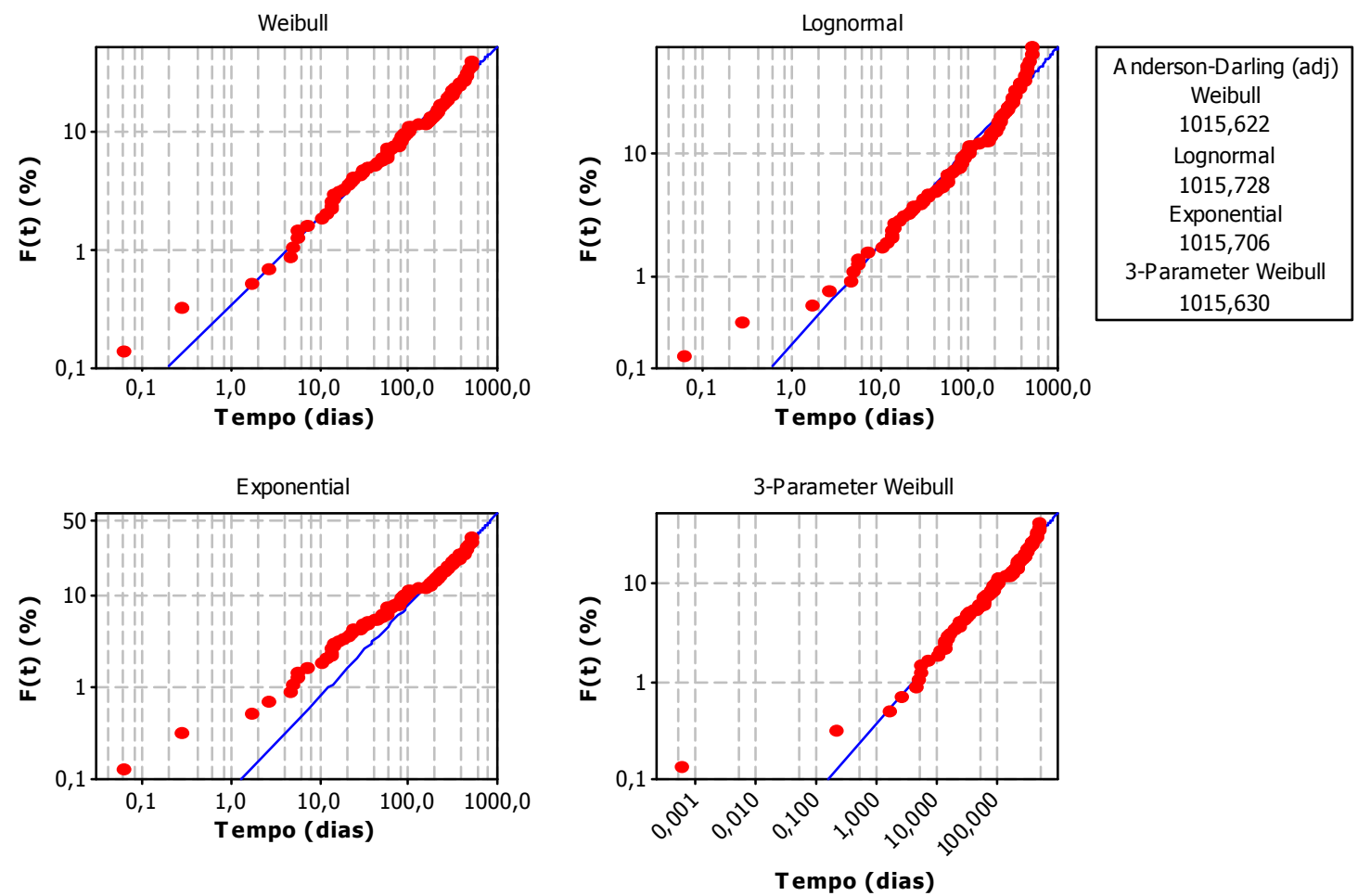

Figura A-21 - Probabilidades de Falha para FR, para diferentes distribuições.
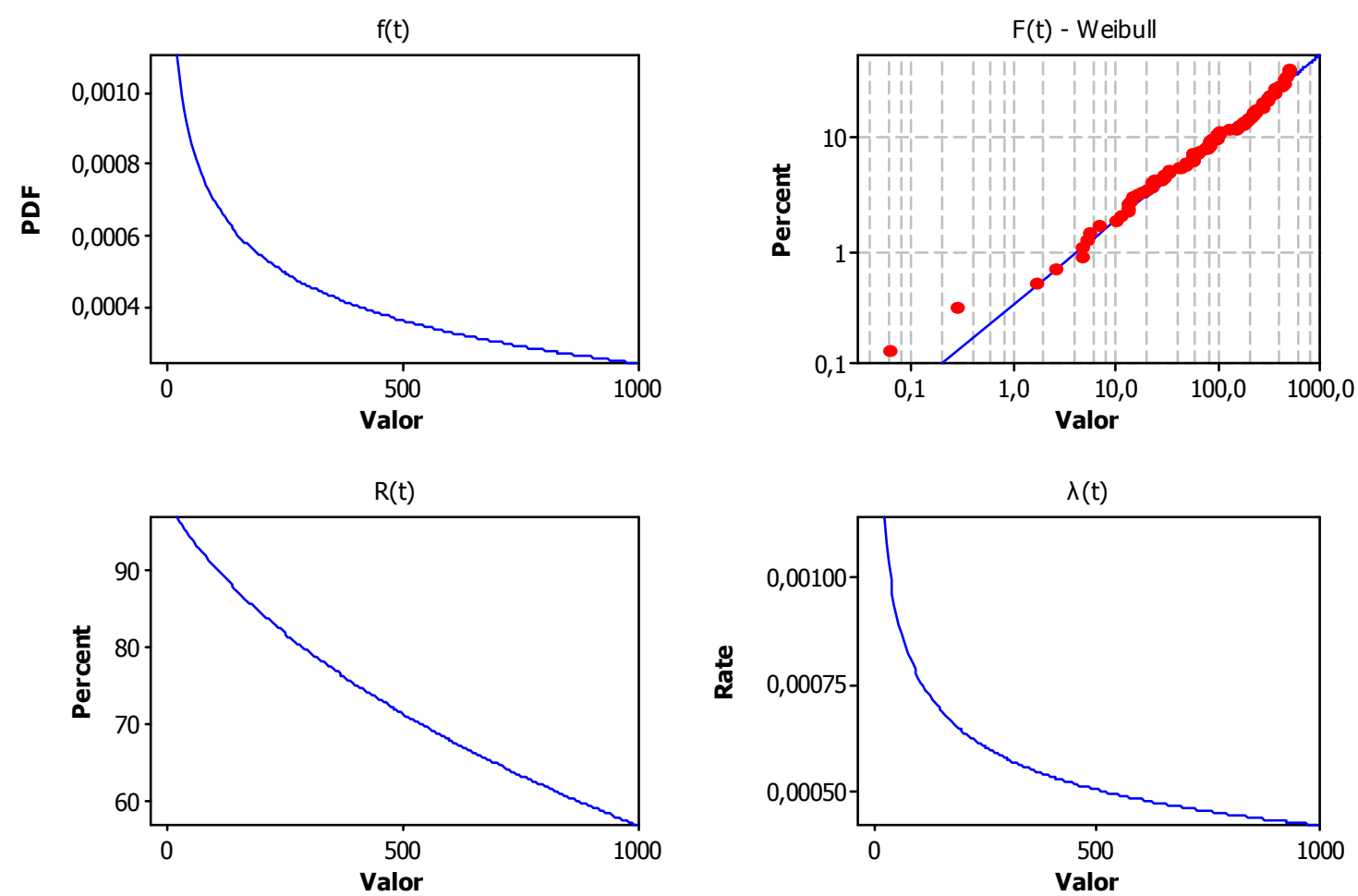

Figura A-22 - f(t), F(t), R(t) e $\lambda(t)$ para $F R$. 
- Modo de Falha: $O U$
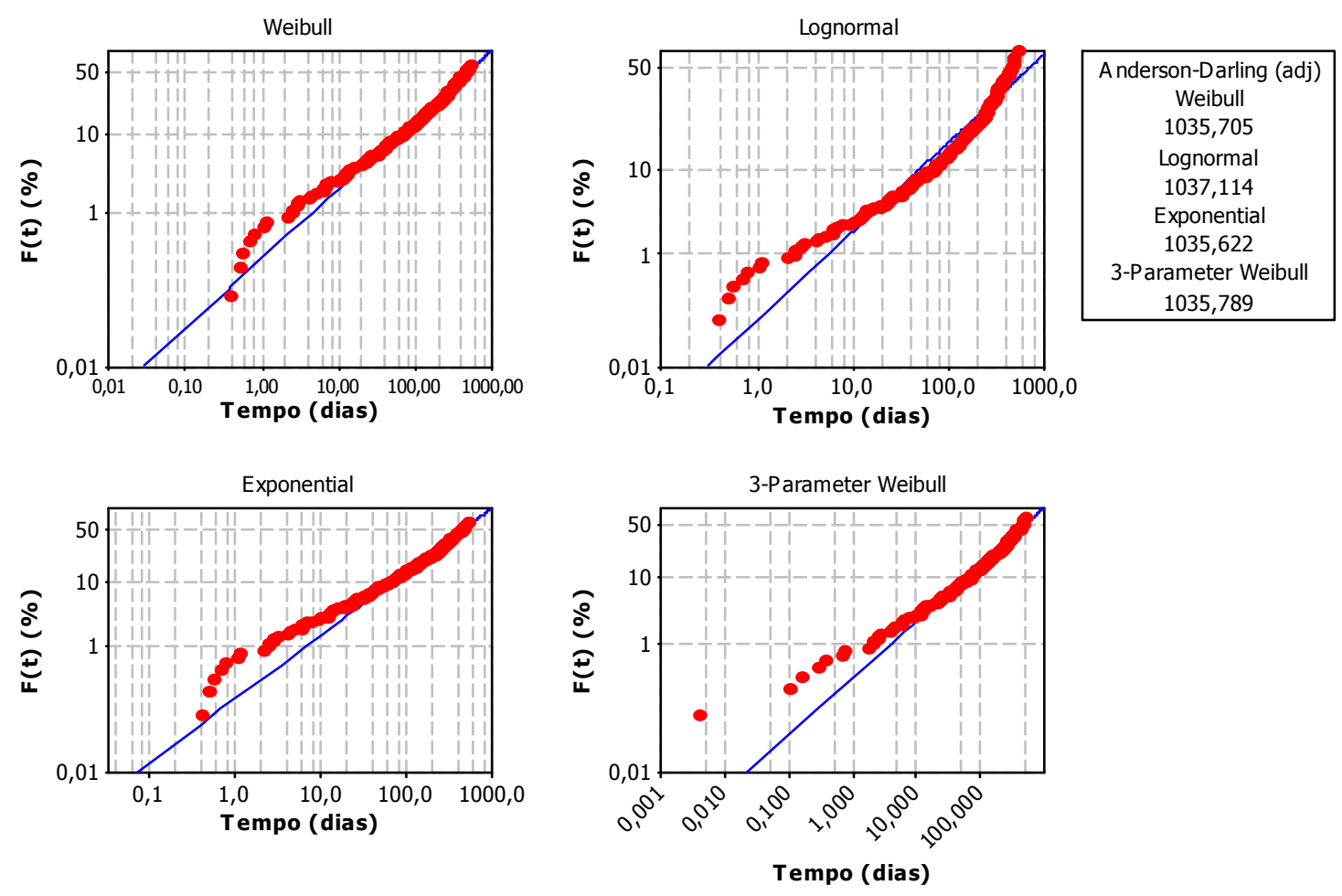

Figura A-23 - Probabilidades de Falha para $O U$, para diferentes distribuições.
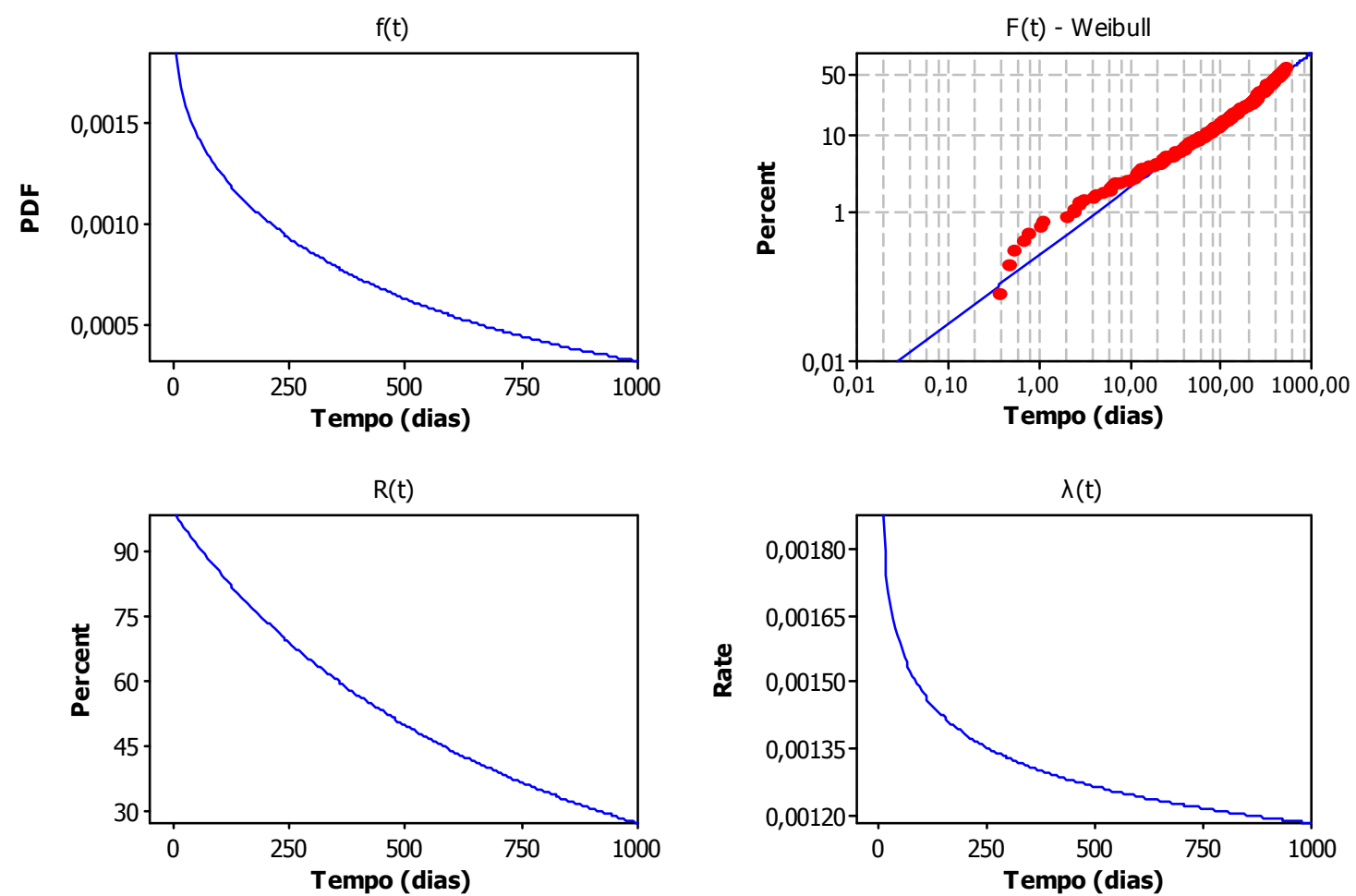

Figura A-24 - f(t), F(t), R(t) e $\lambda(\mathbf{t})$ para $O U$. 
- Modo de Falha: PT
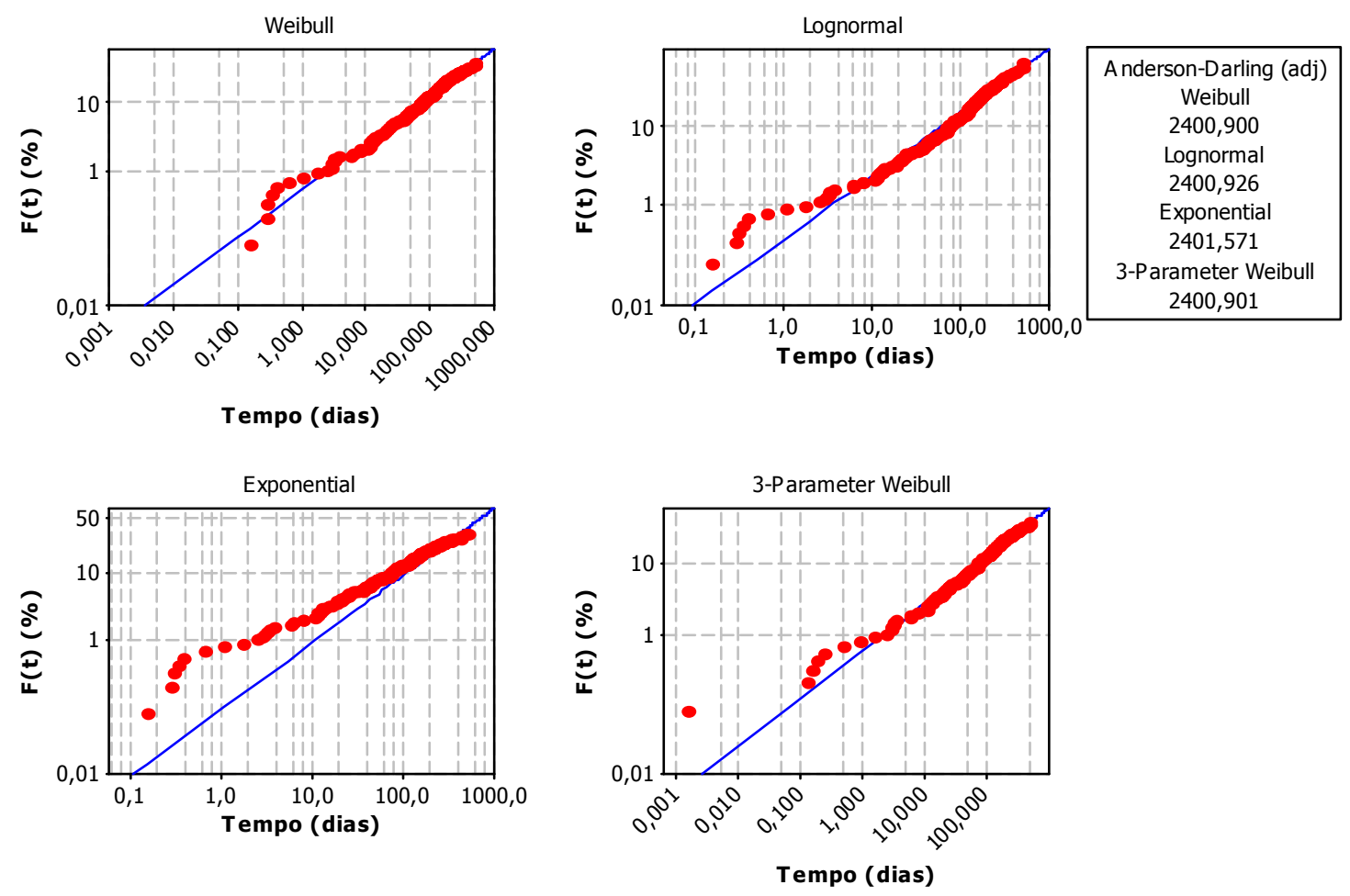

Figura A-25 - Probabilidades de Falha para PT, para diferentes distribuições.
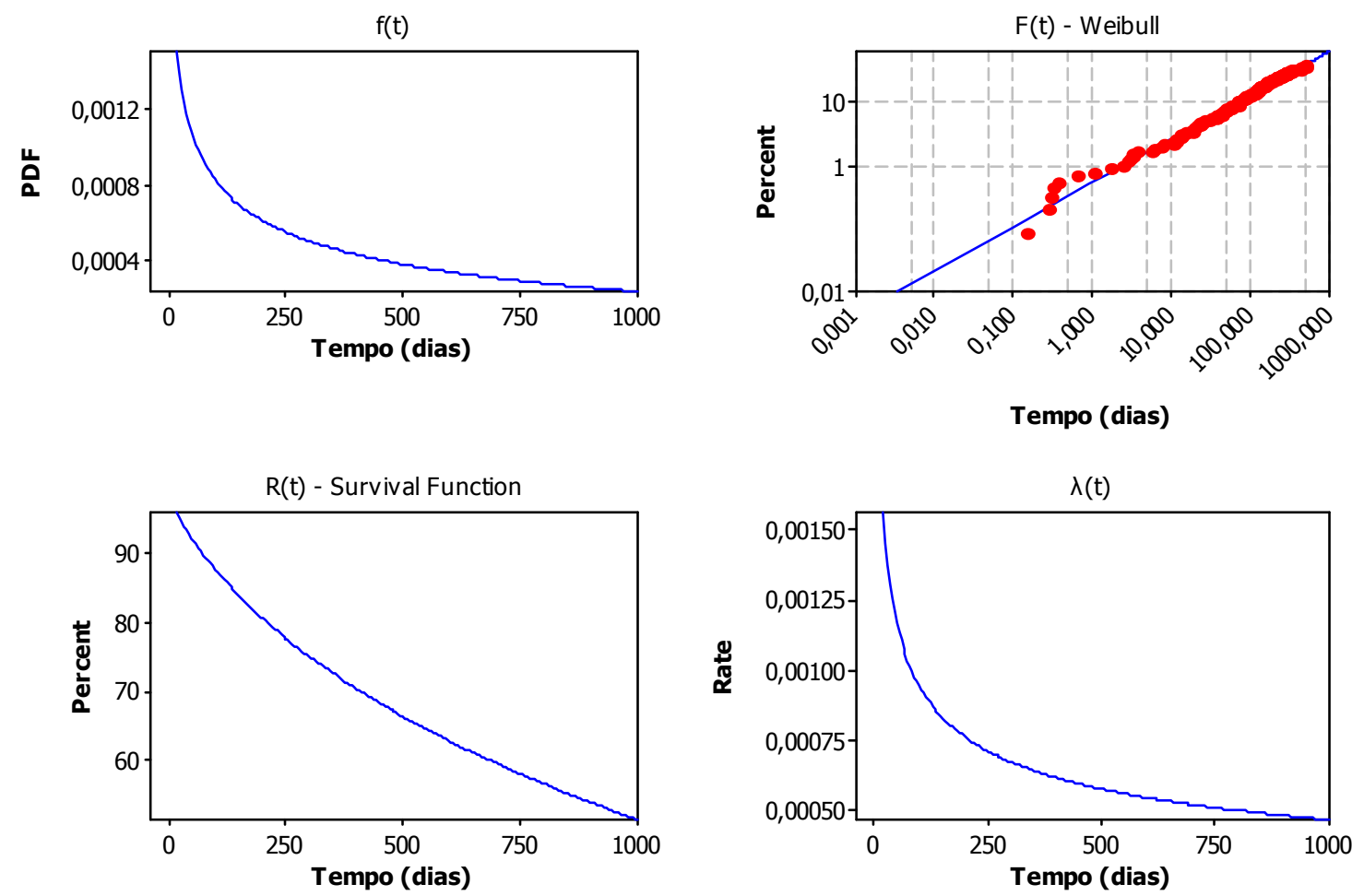

Figura A-26 - f(t), F(t), R(t) e $\lambda(t)$ para $P T$. 
- Modo de Falha: $R P$
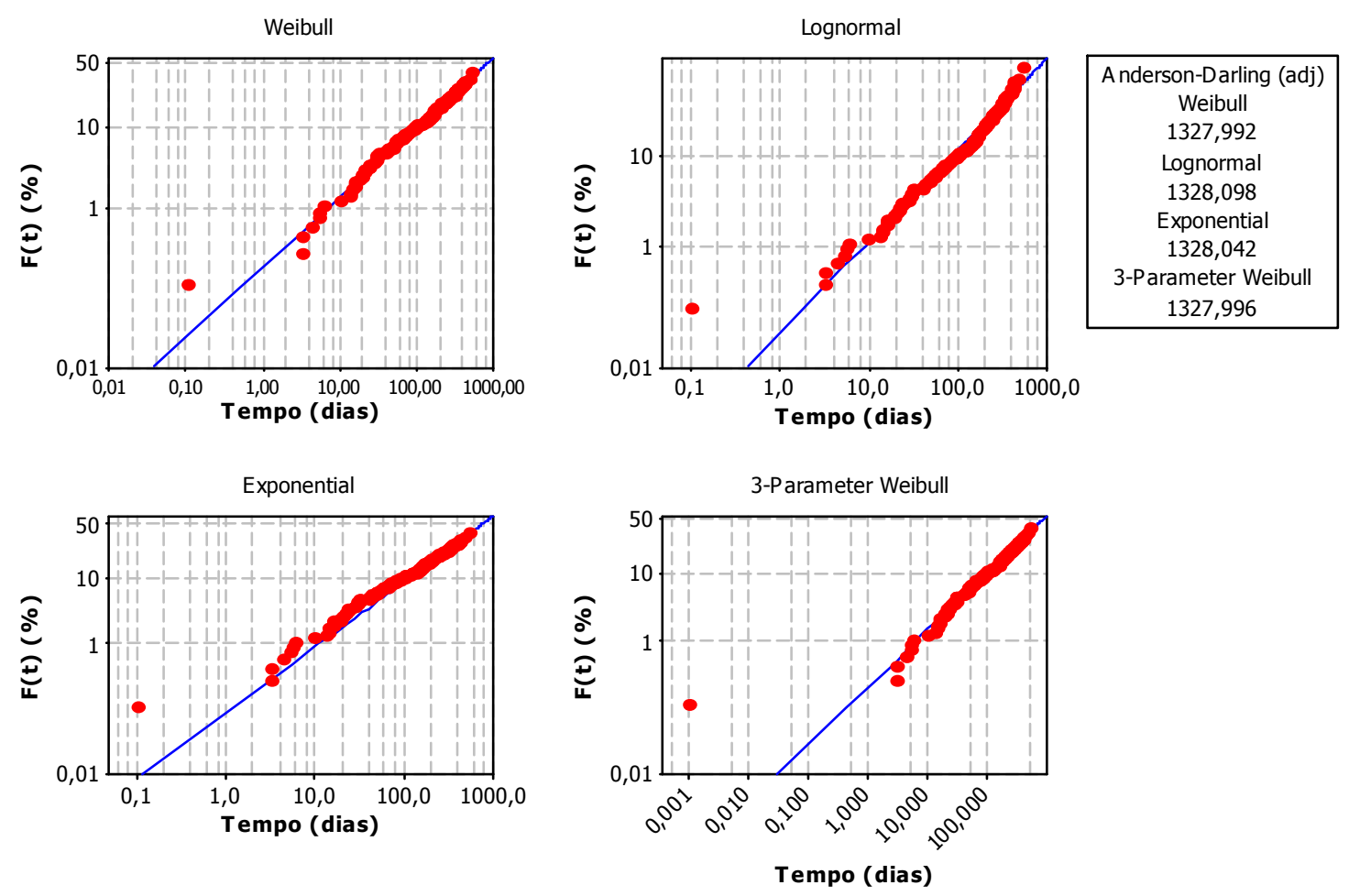

Figura A-27 - Probabilidades de Falha para RP, para diferentes distribuições.
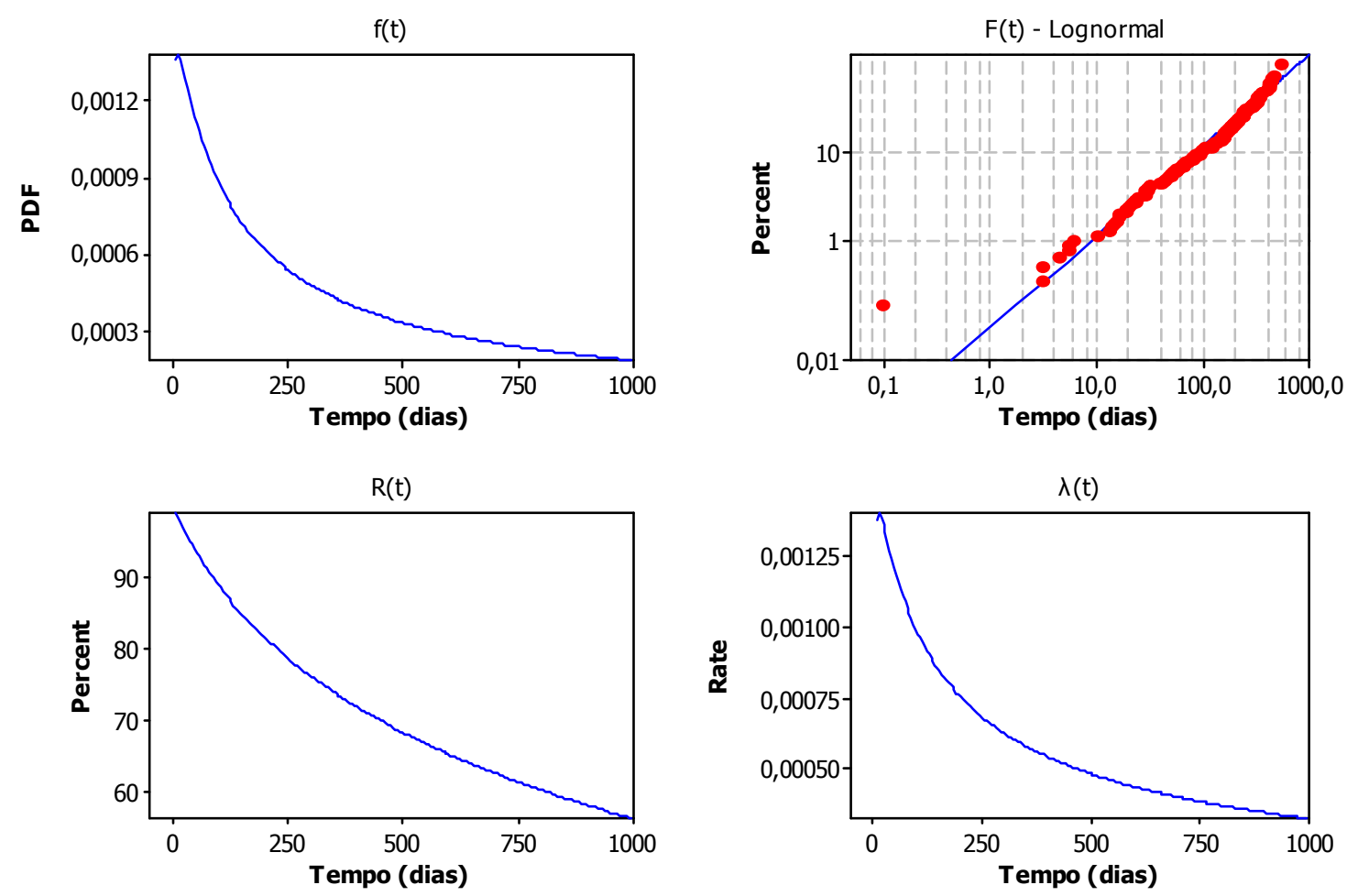

Figura A-28 - f(t), F(t), R(t) e $\lambda(t)$ para $R P$. 


\section{APÊNDICE B - GRÁFICOS UTILIZADOS PARA DETERMINAÇÃO DAS DISTRIBUIÇÕES DE MANTENABILIDADE}

A seguir são apresentados para todos os modos de falha os gráficos de probabilidade de reparo para diferentes distribuições, utilizados para a definição de qual a distribuição que melhor se adequa ao modelo, e, uma vez que a distribuição é definida, os gráficos de $m(t), 1-M(t), M(t)$ e $v(t)$. 
- Modo de Falha: $A N$
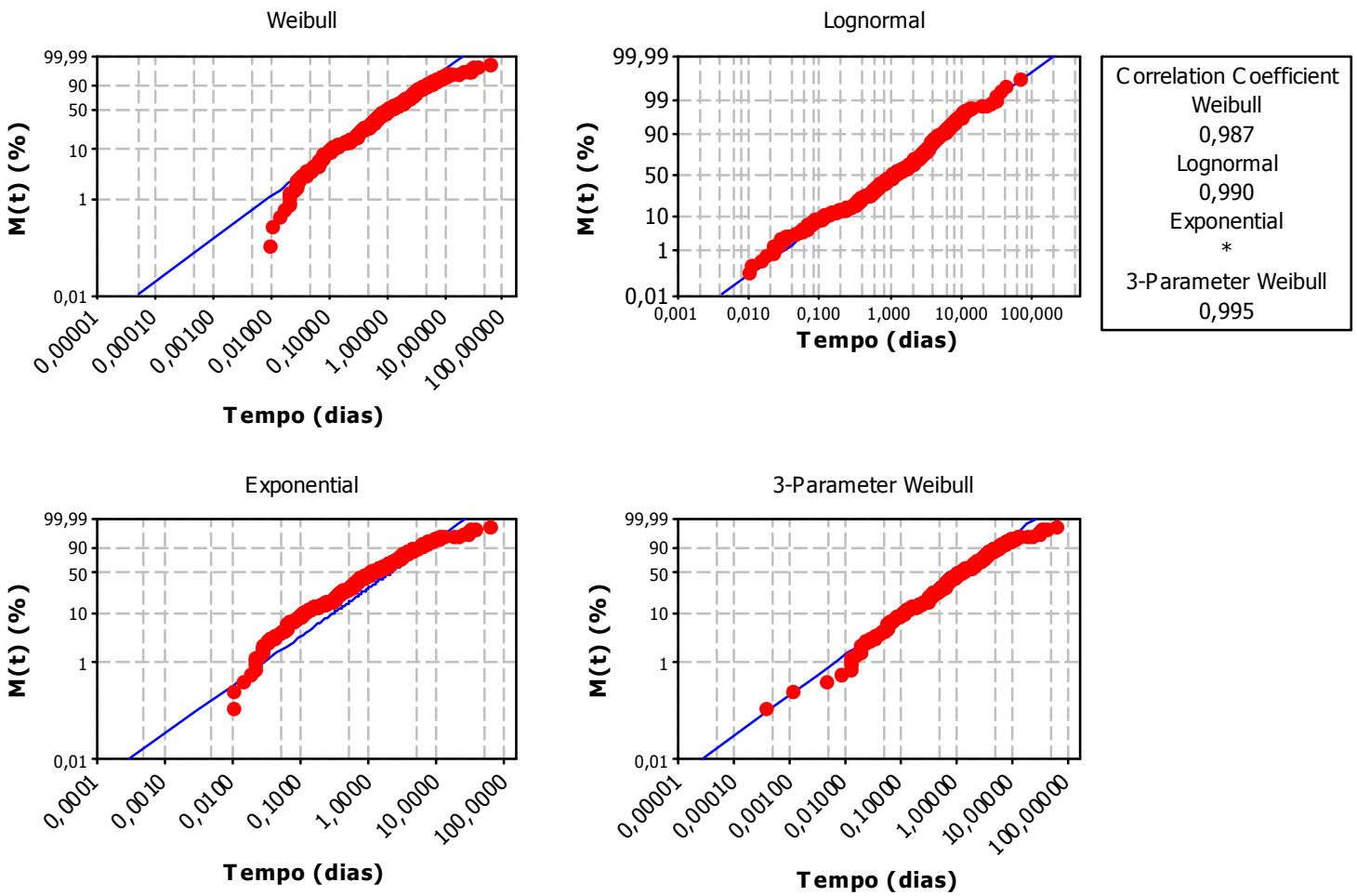

Figura B-1 - Probabilidades de Reparo para AN, para diferentes distribuições.
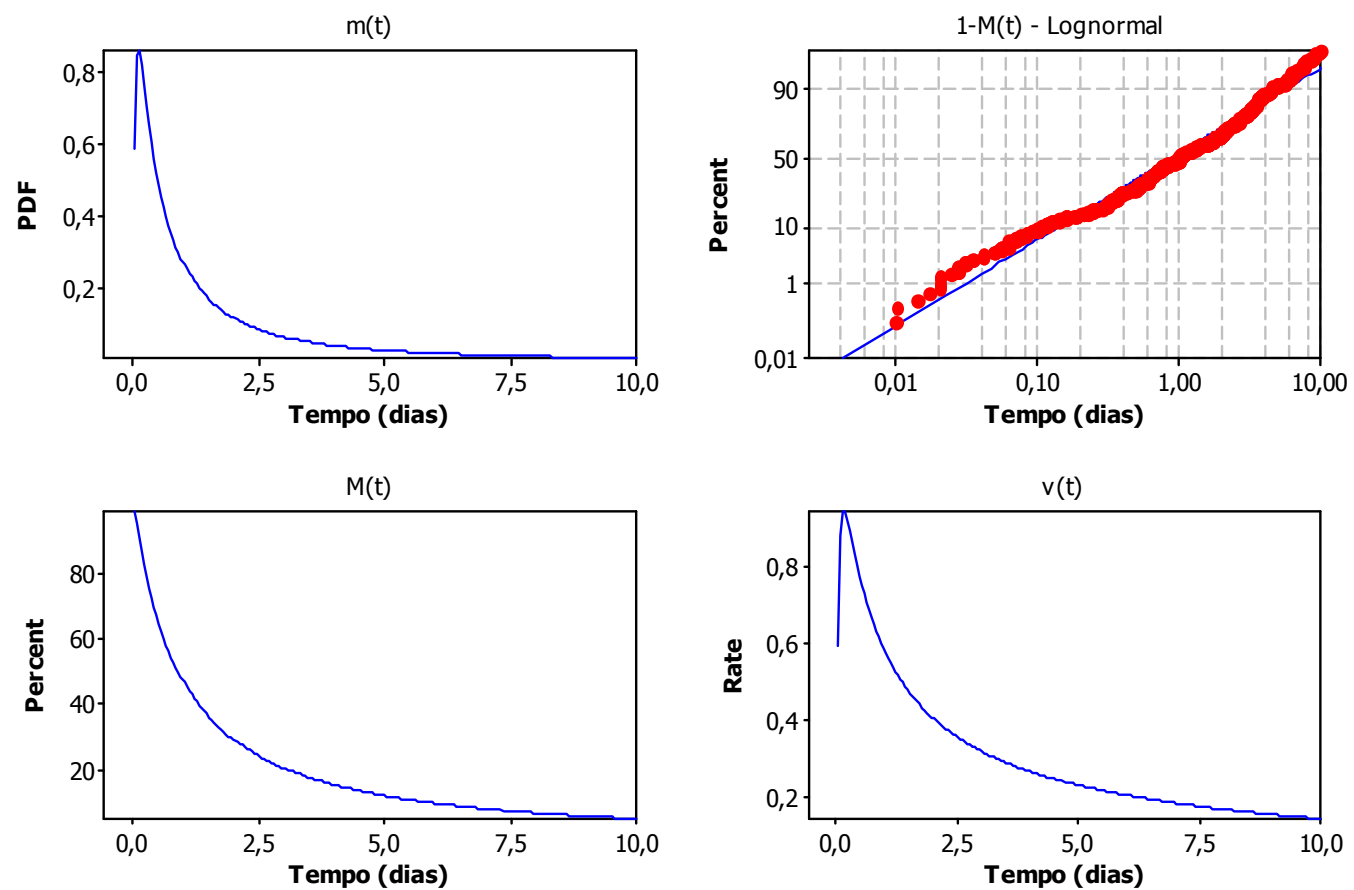

Figura B-2 - m(t), M(t), 1-M(t) e v(t) para $A N$. 
- Modo de Falha: $B F$
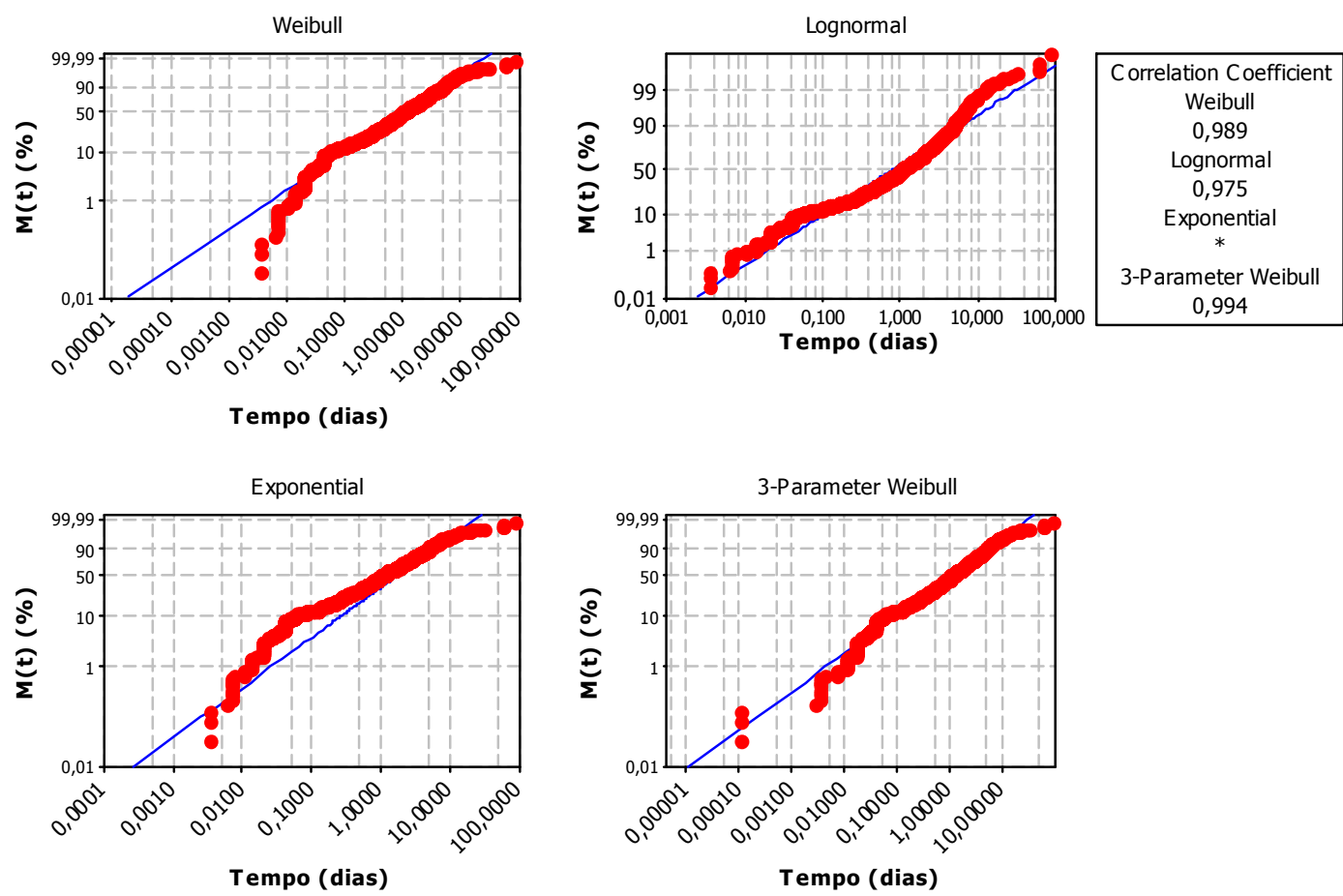

Figura B-3 - Probabilidades de Reparo para BF, para diferentes distribuições.
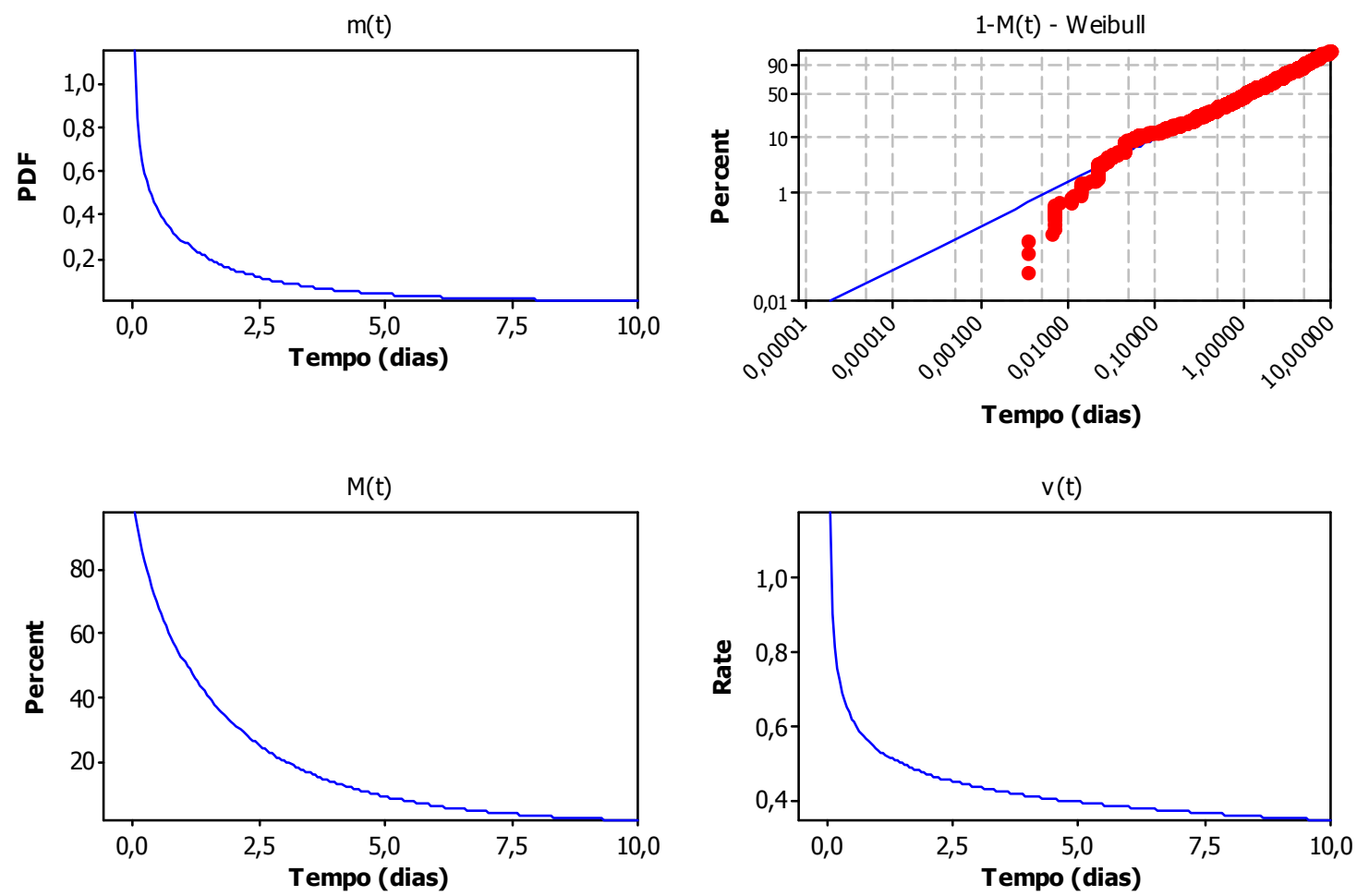

Figura B-4 - m(t), M(t), 1-M(t) e v(t) para $B F$. 
- Modo de Falha: $B R$
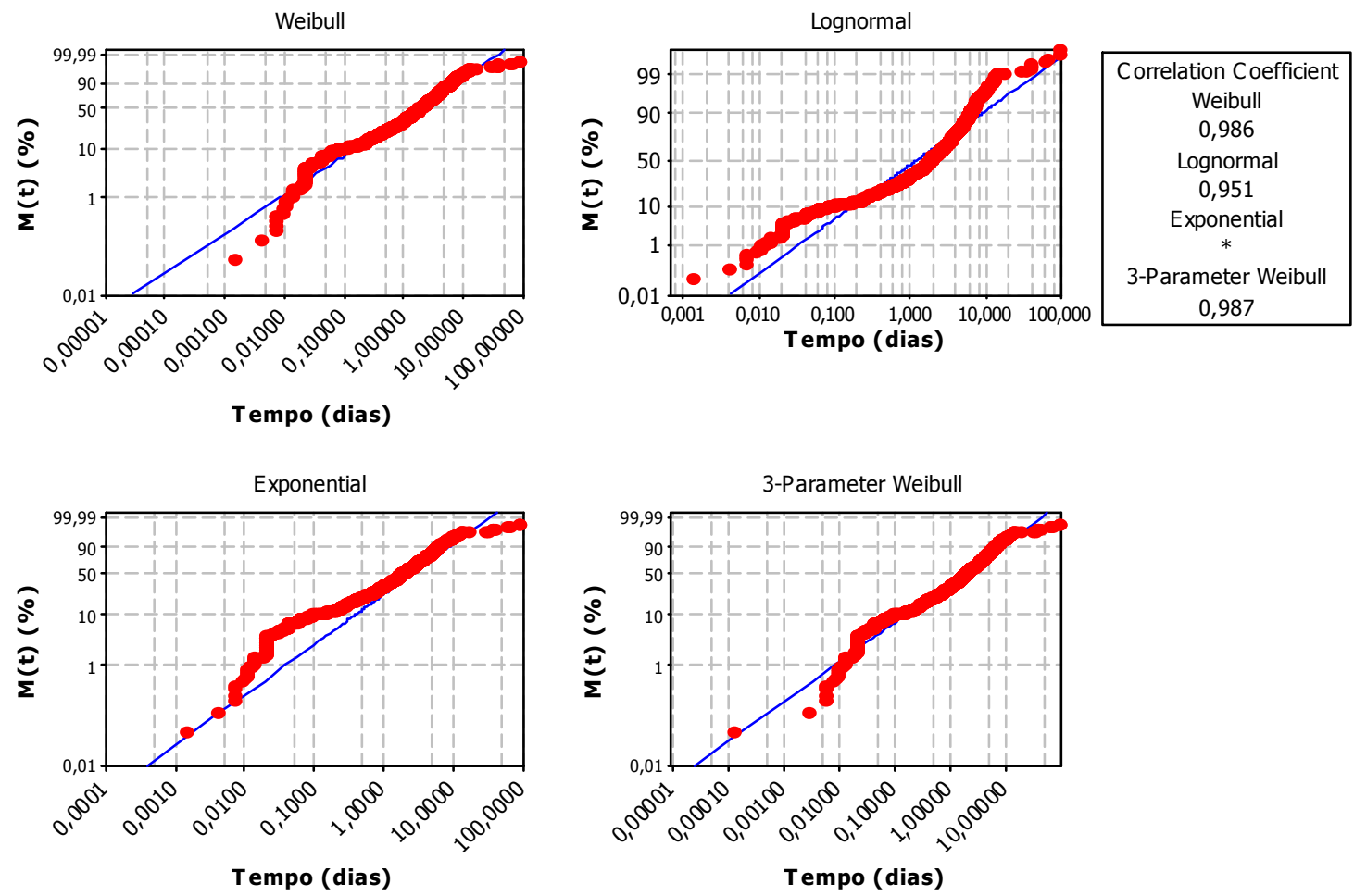

Figura B-5 - Probabilidades de Reparo para BR, para diferentes distribuições.
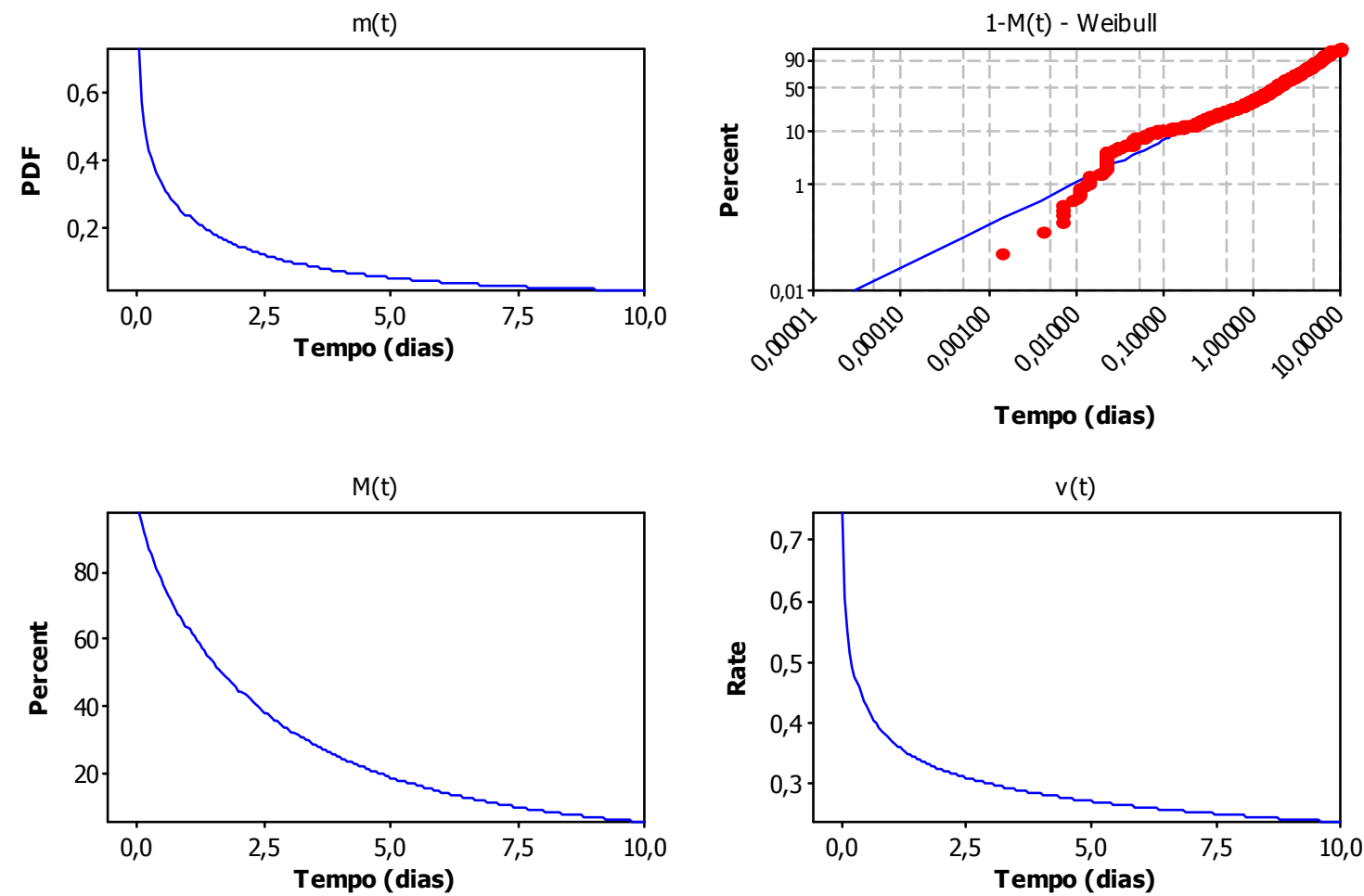

Figura B-6 - m(t), M(t), 1-M(t) e v(t) para $B R$. 
- Modo de Falha: $C B$
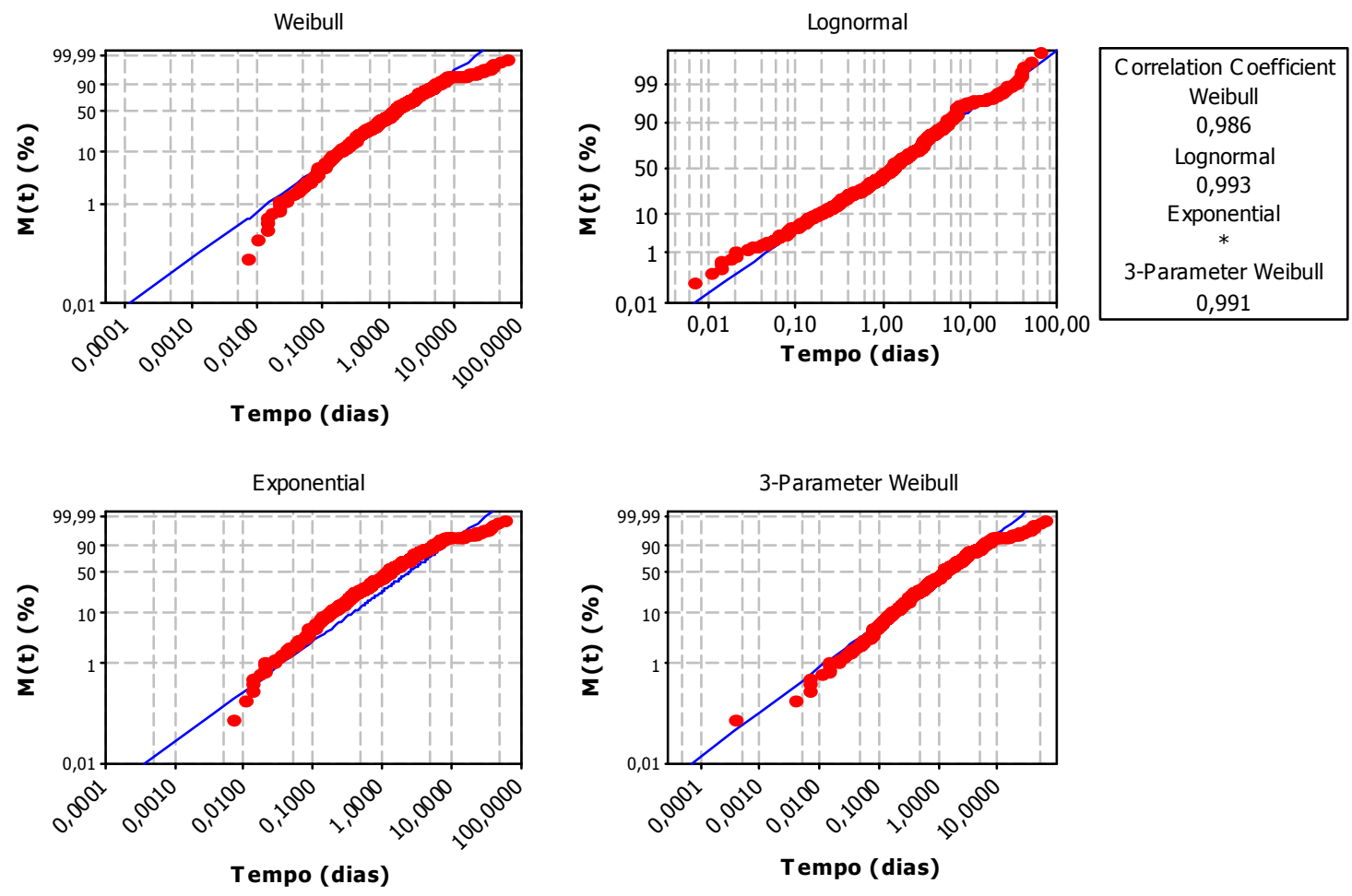

Figura B-7 - Probabilidades de Reparo para $C B$, para diferentes distribuições.
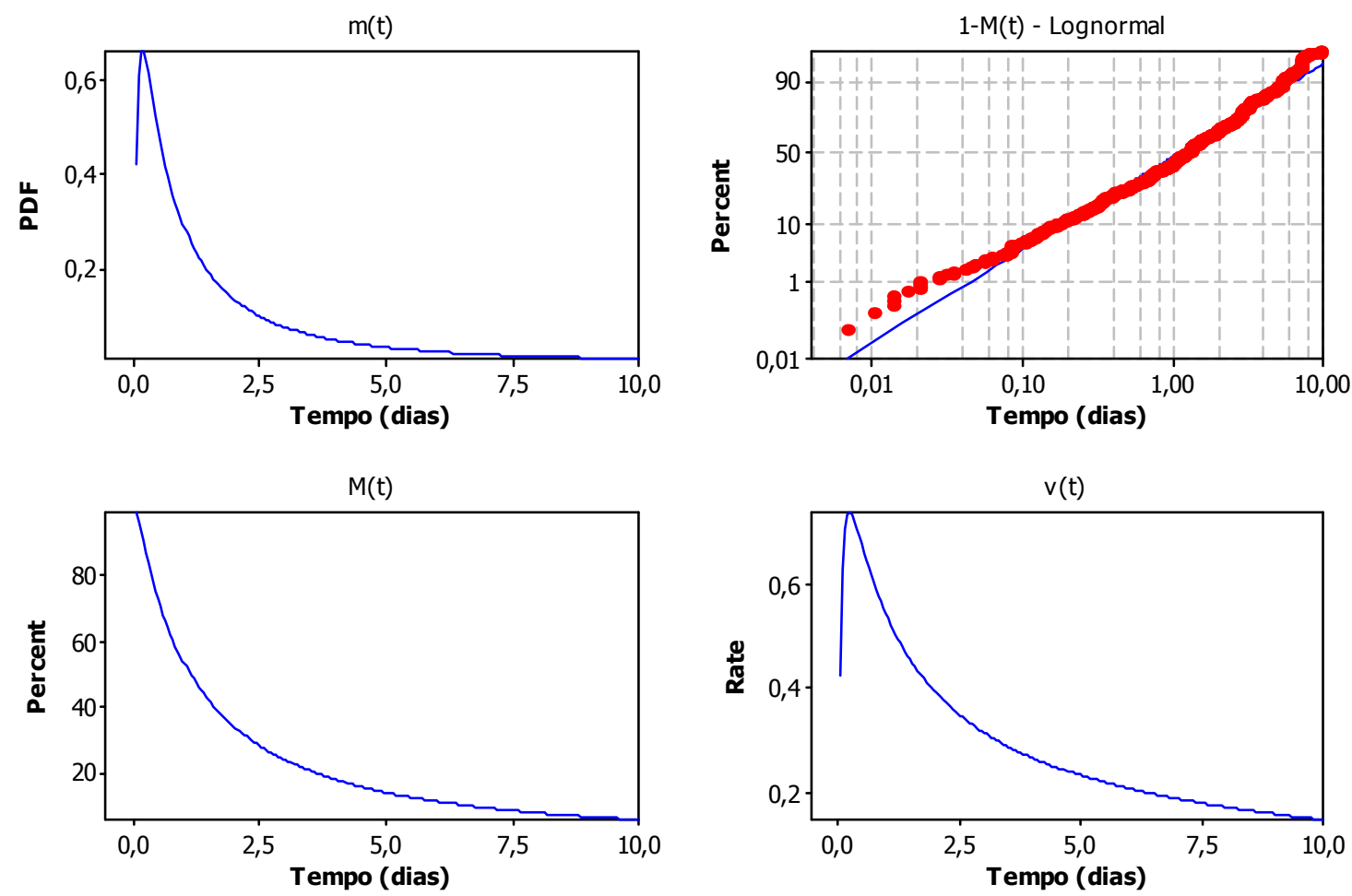

Figura B-8 - m(t), M(t), 1-M(t) e v(t) para $C B$. 
- Modo de Falha: $C C$
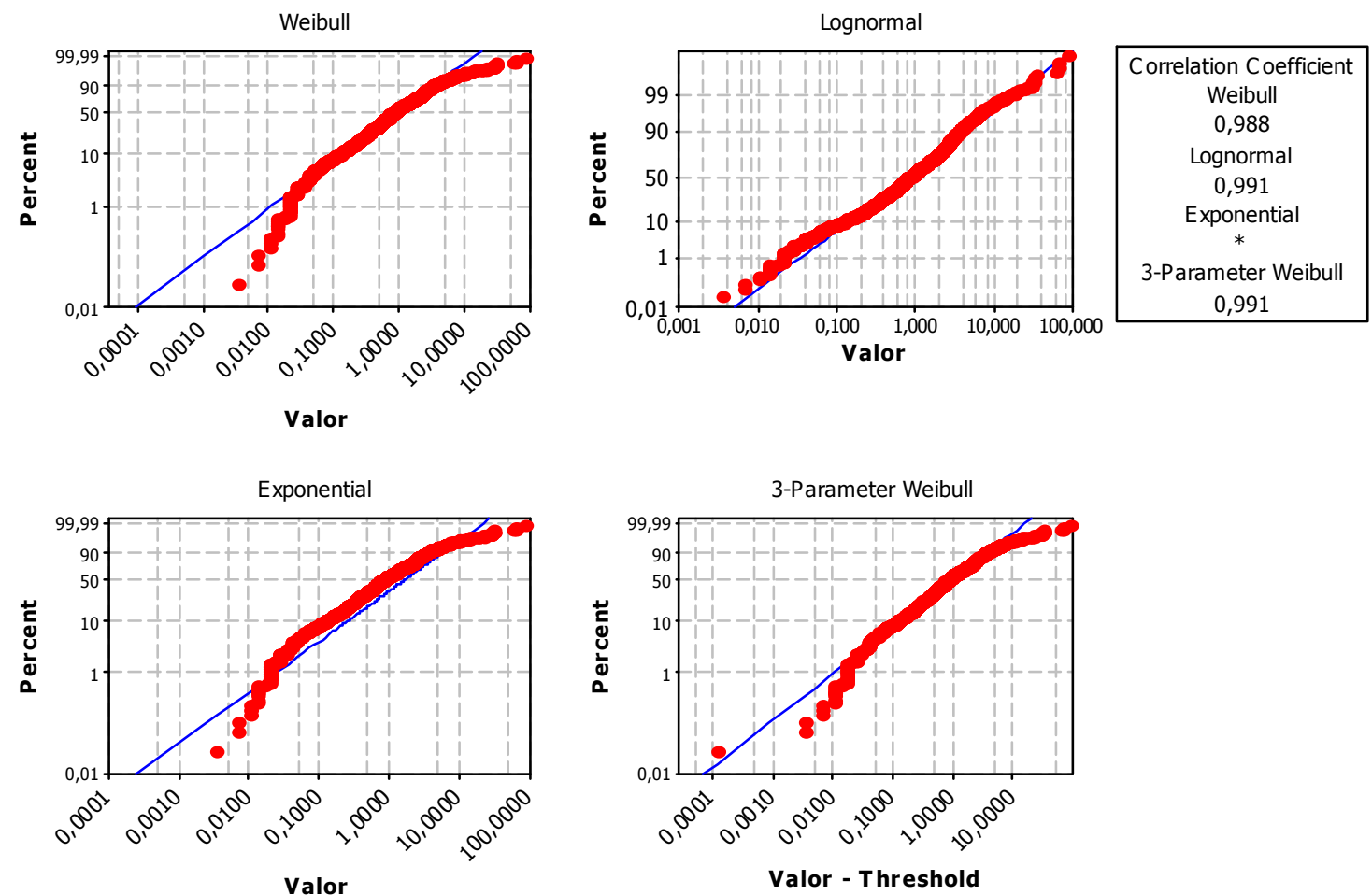

Figura B-9 - Probabilidades de Reparo para $C C$, para diferentes distribuições.
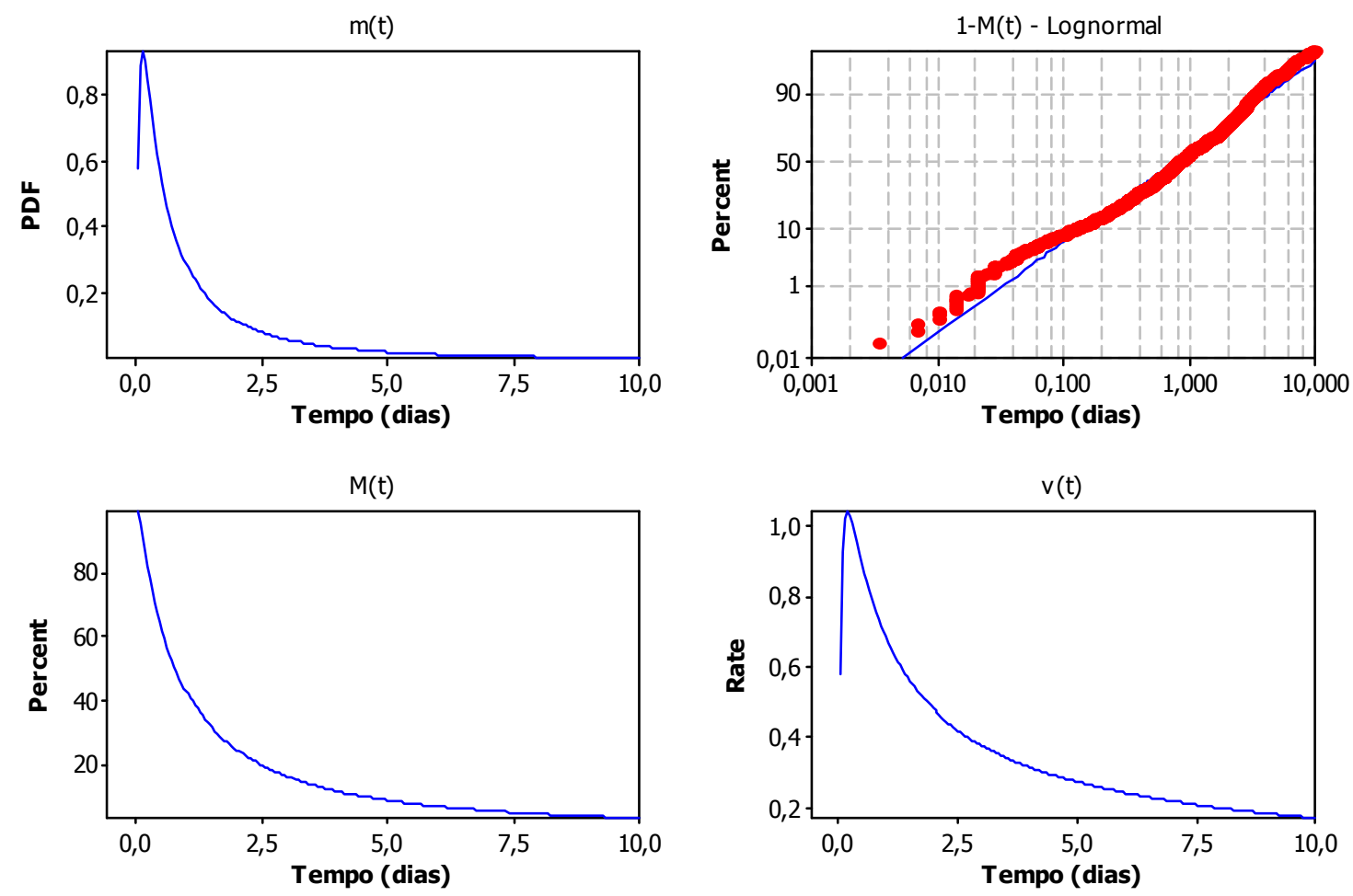

Figura B-10 - m(t), M(t), 1-M(t) e v(t) para $C C$. 
- Modo de Falha: FF
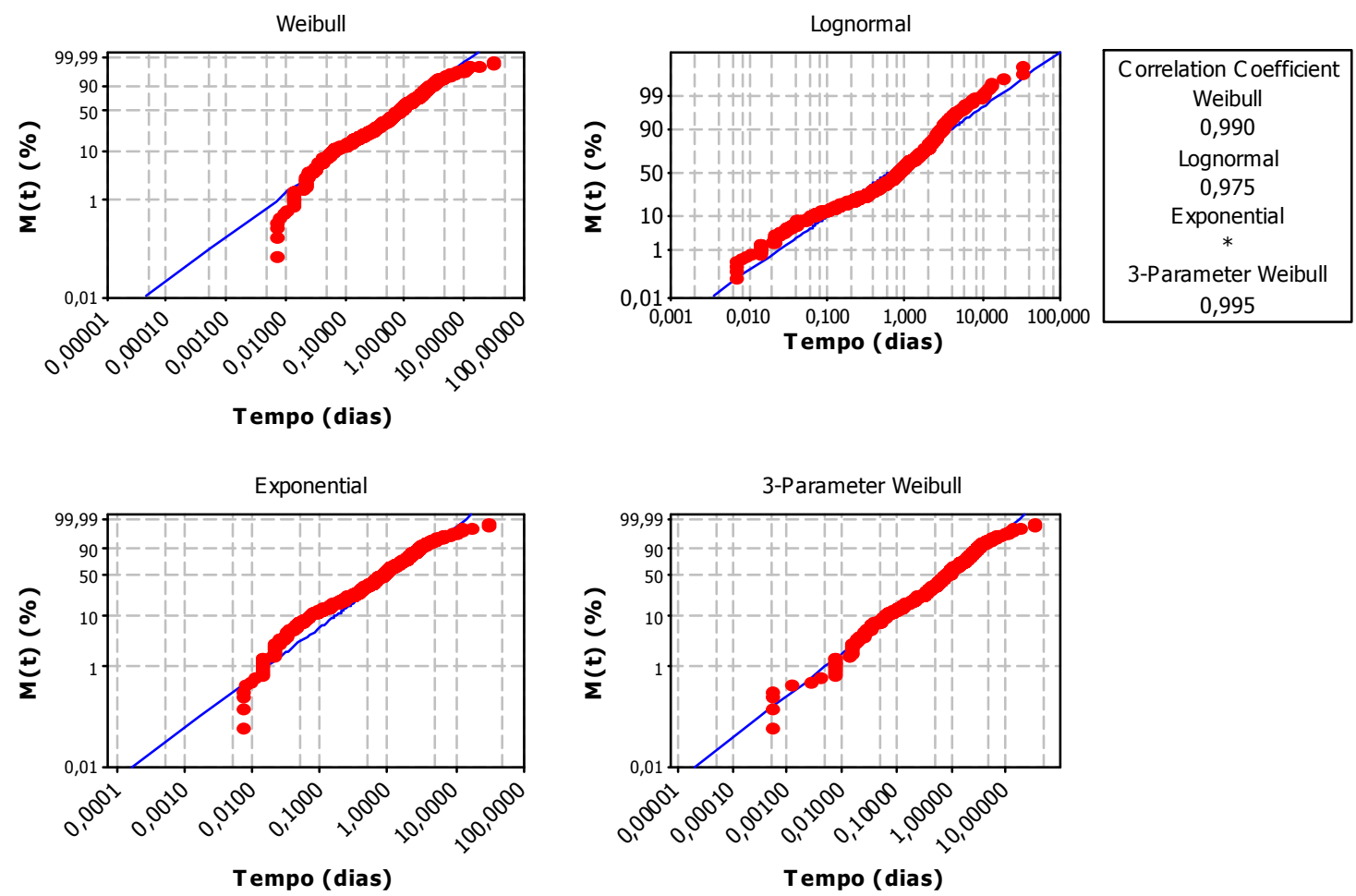

Figura B-11 - Probabilidades de Reparo para FF, para diferentes distribuições.
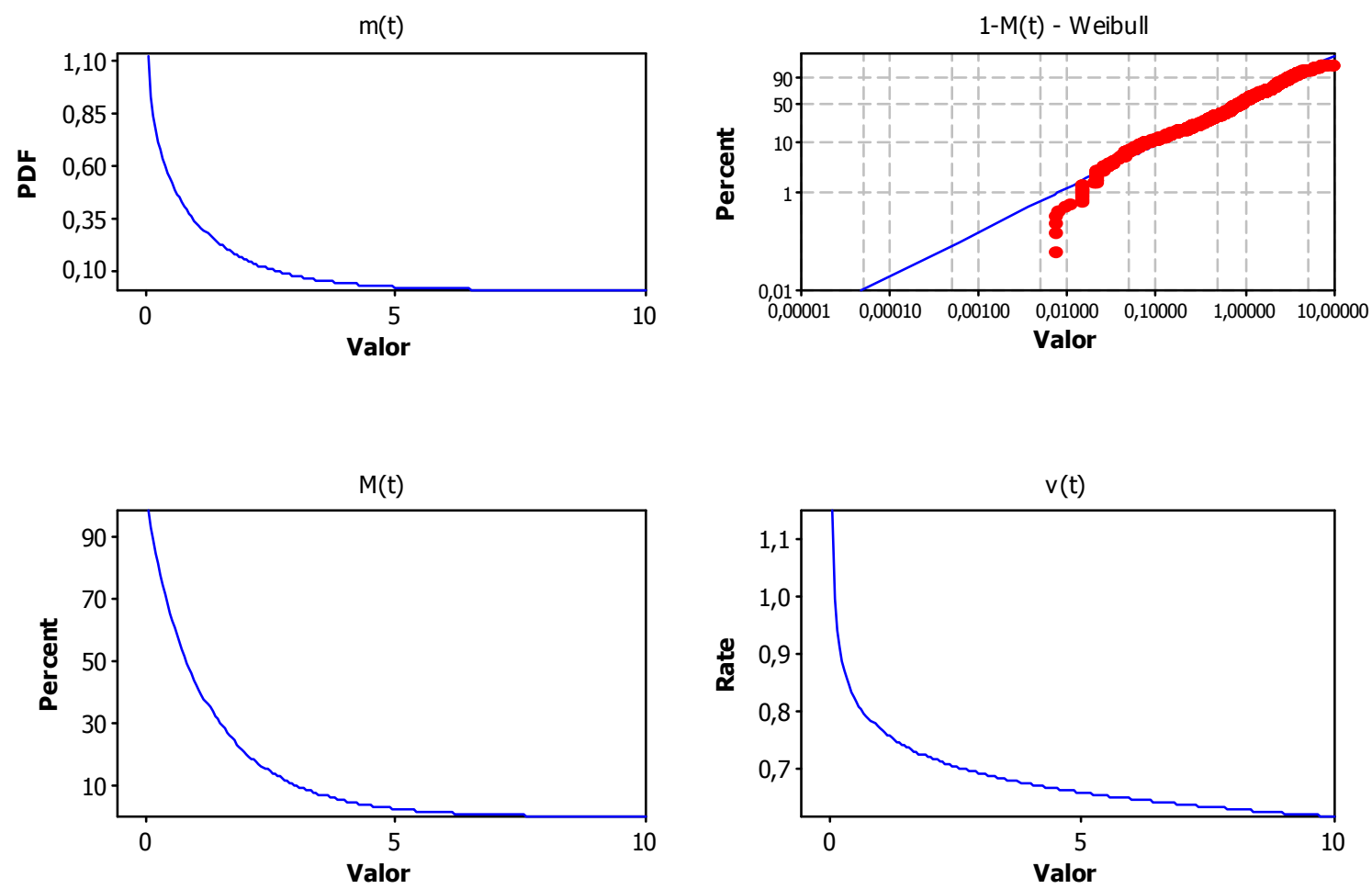

Figura B-12 - m(t), M(t), 1-M(t) e v(t) para $F F$. 
- Modo de Falha: $F O$
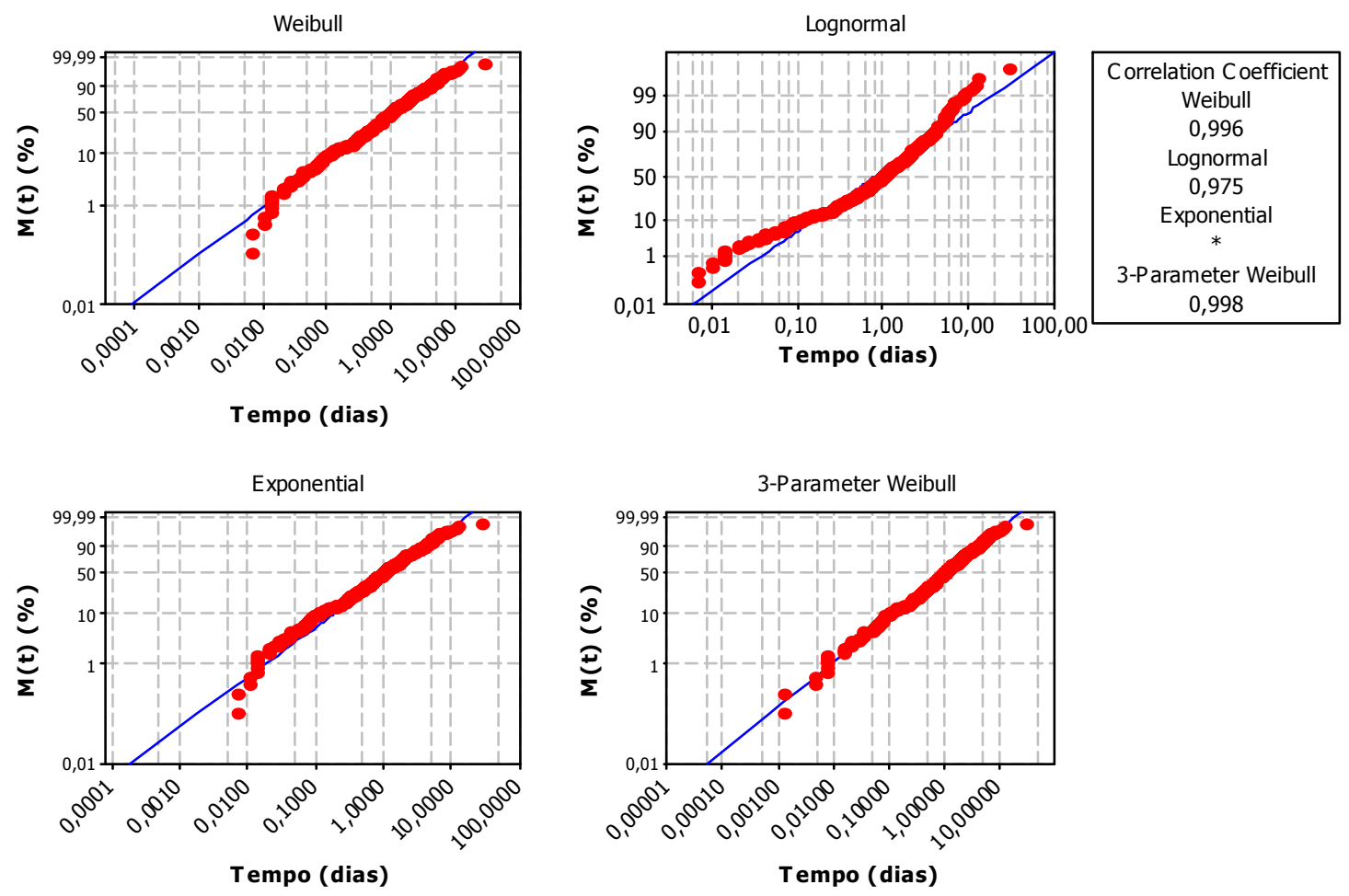

Figura B-13 - Probabilidades de Reparo para FO, para diferentes distribuições.
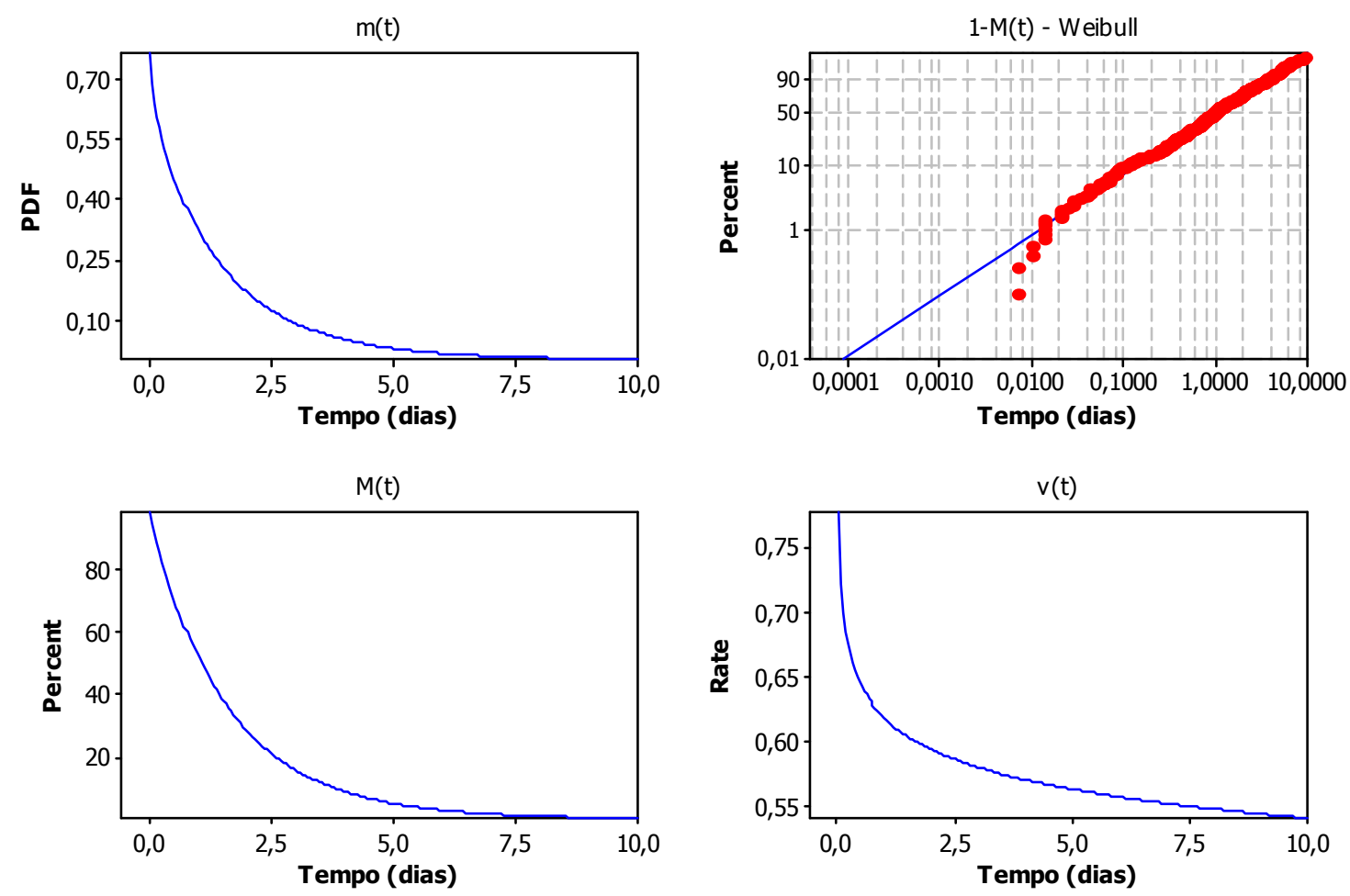

Figura B-14 - m(t), M(t), 1-M(t) e v(t) para FO. 
- Modo de Falha: FR
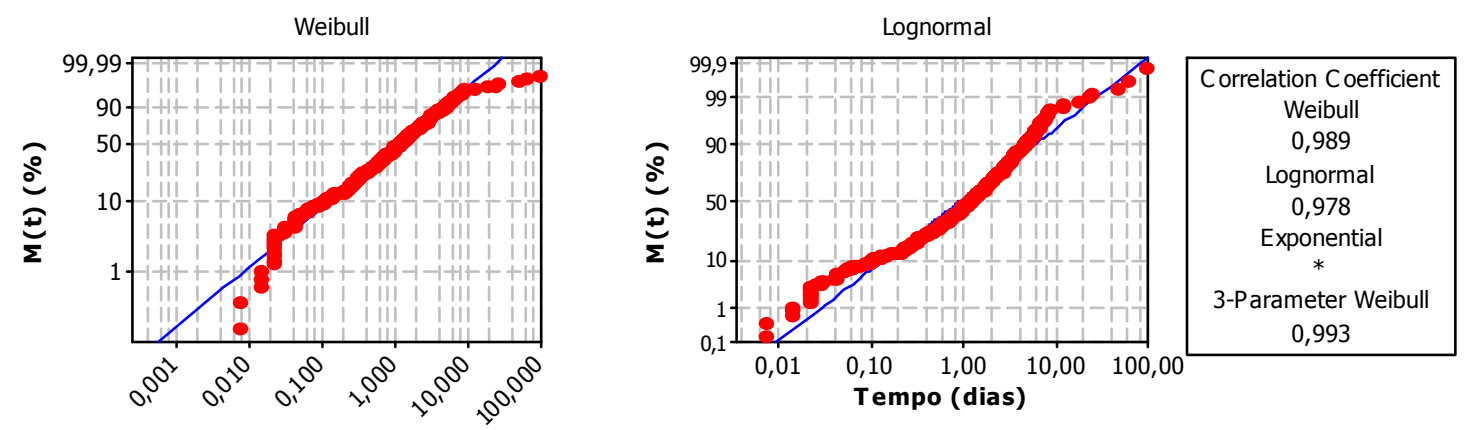

Tempo (dias)
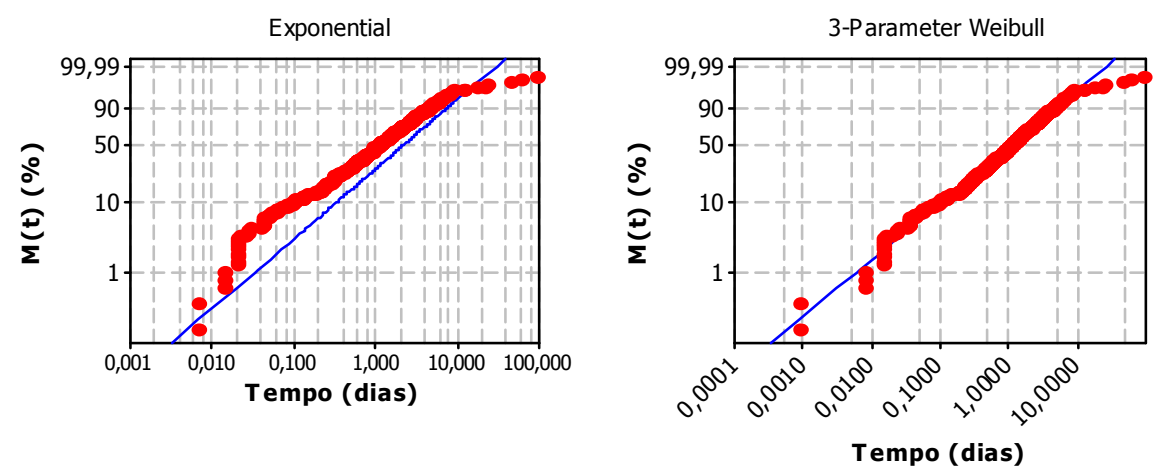

Figura B-15 - Probabilidades de Reparo para FR, para diferentes distribuições.
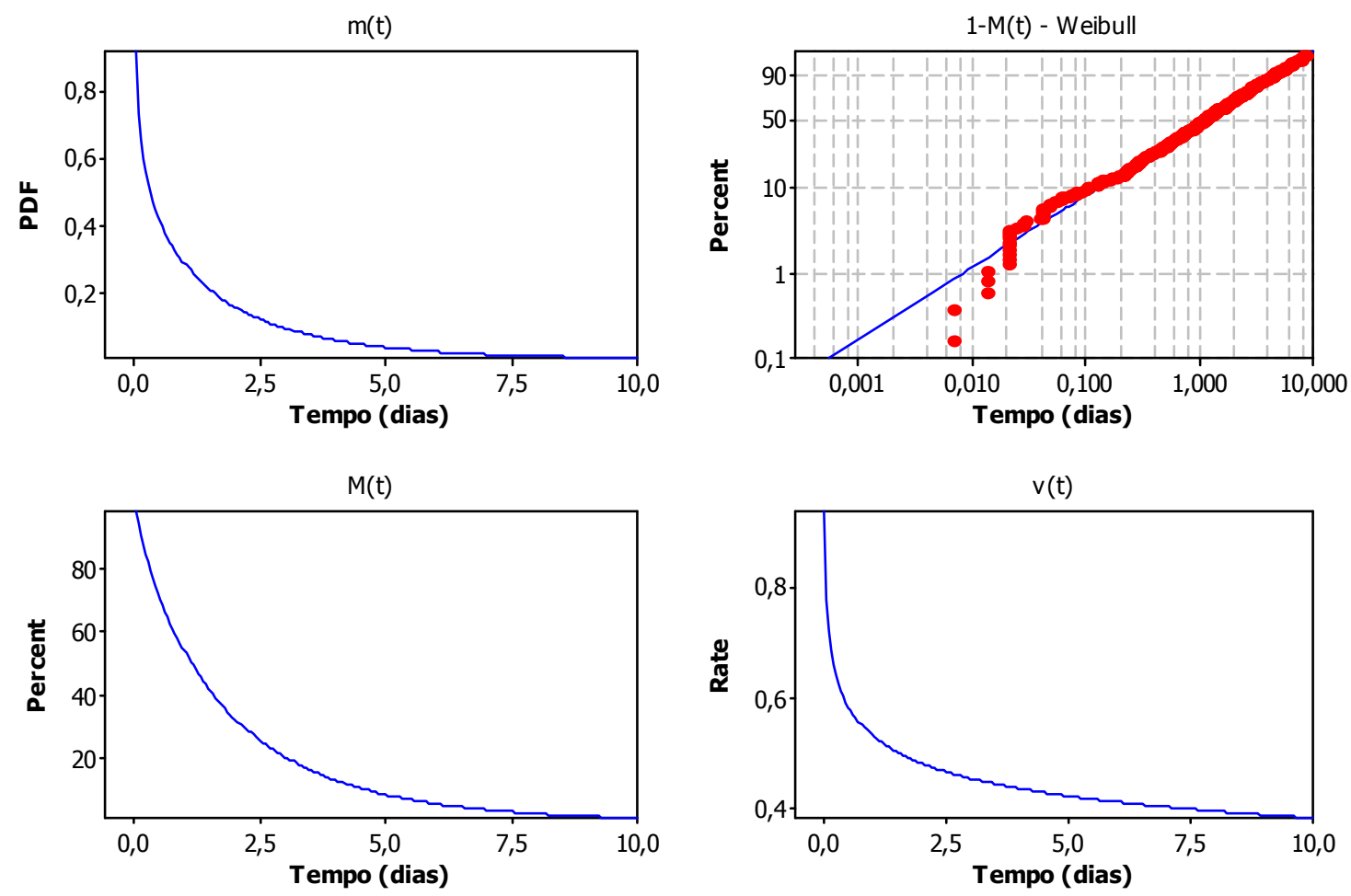

Figura B-16 - m(t), M(t), 1-M(t) e v(t) para $F R$. 
- Modo de Falha: $O U$
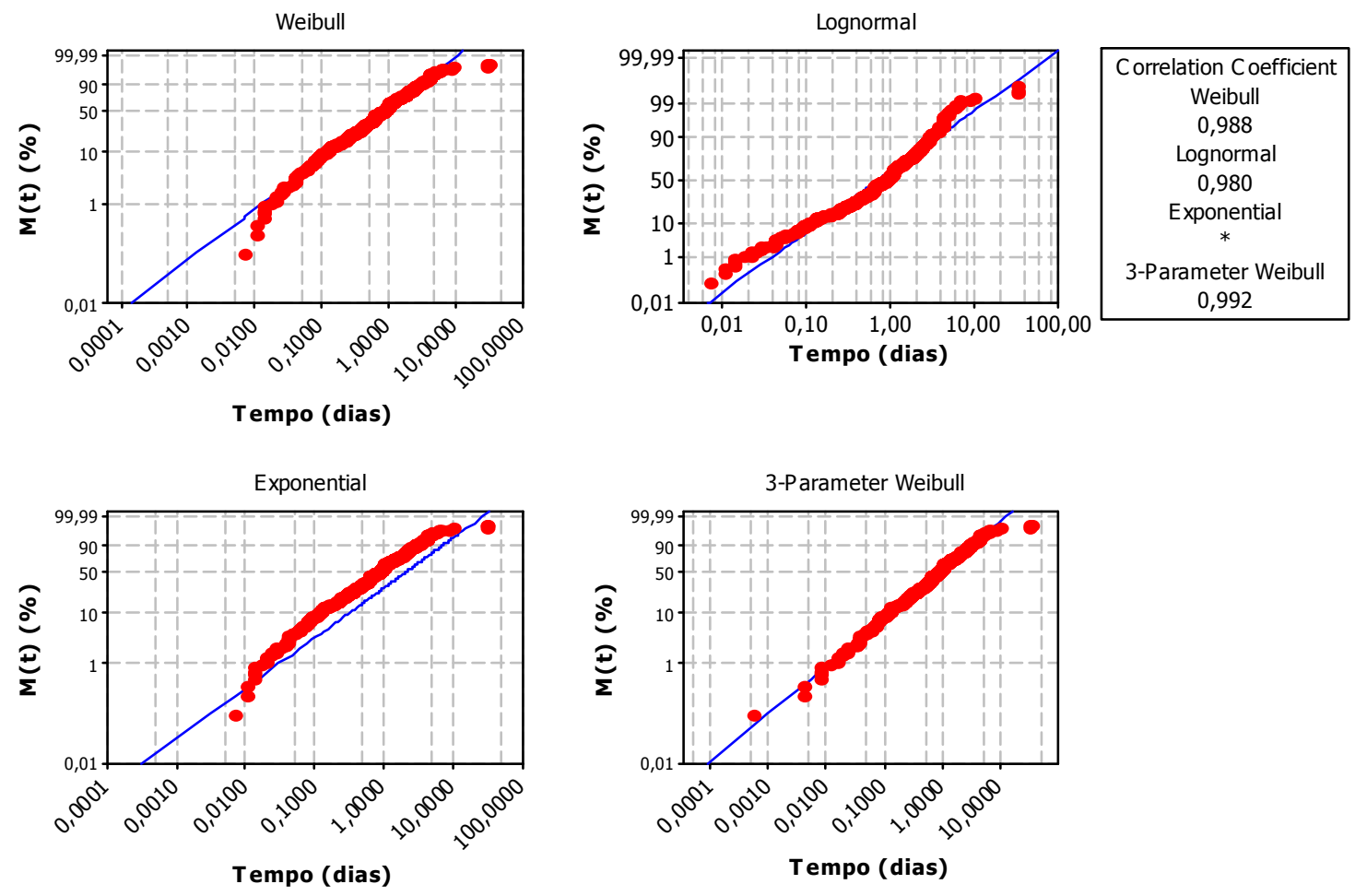

Figura B-17 - Probabilidades de Reparo para $O U$, para diferentes distribuições.
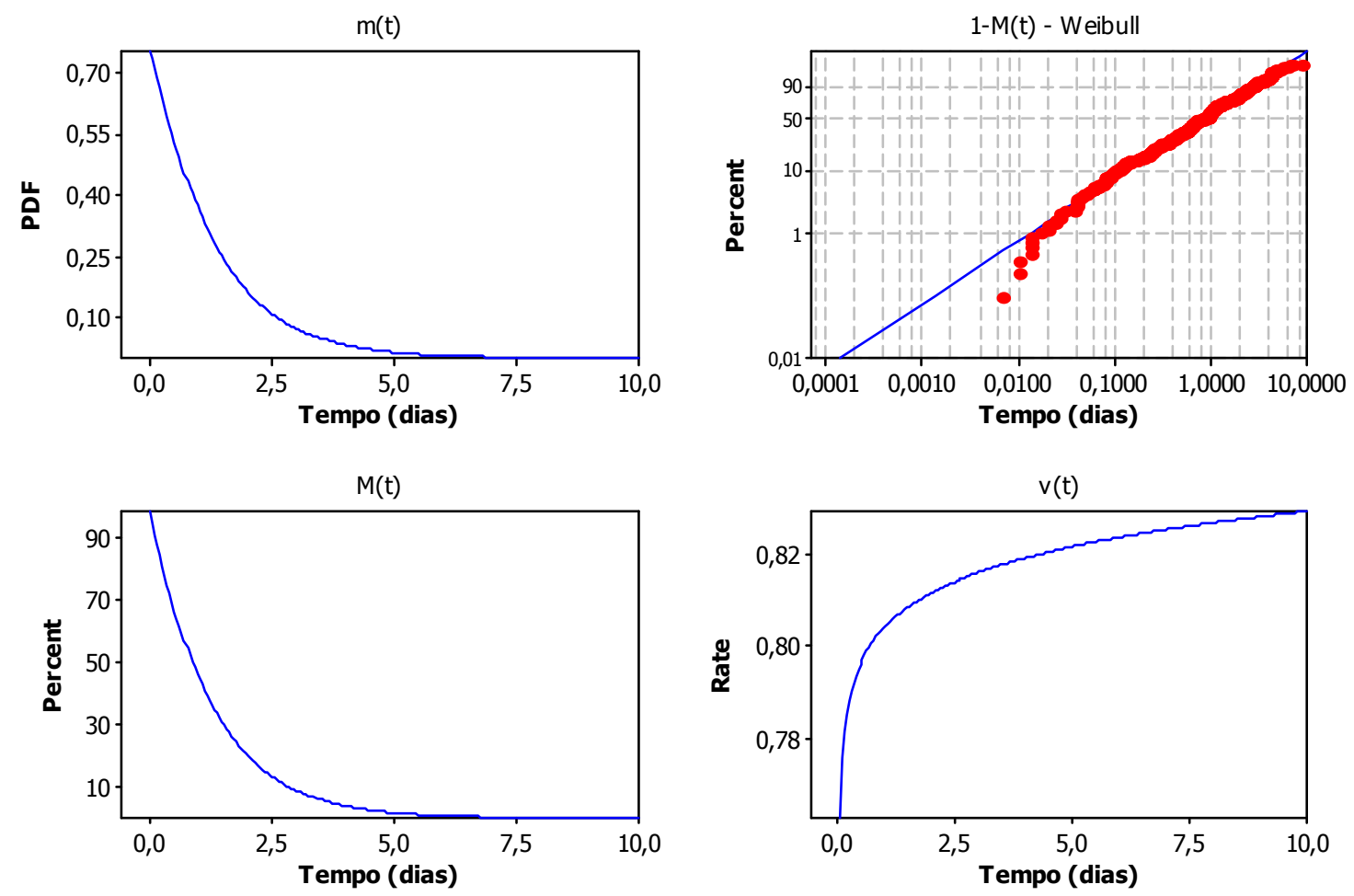

Figura B-18 - m(t), M(t), 1-M(t) e v(t) para $O U$. 
- Modo de Falha: PT
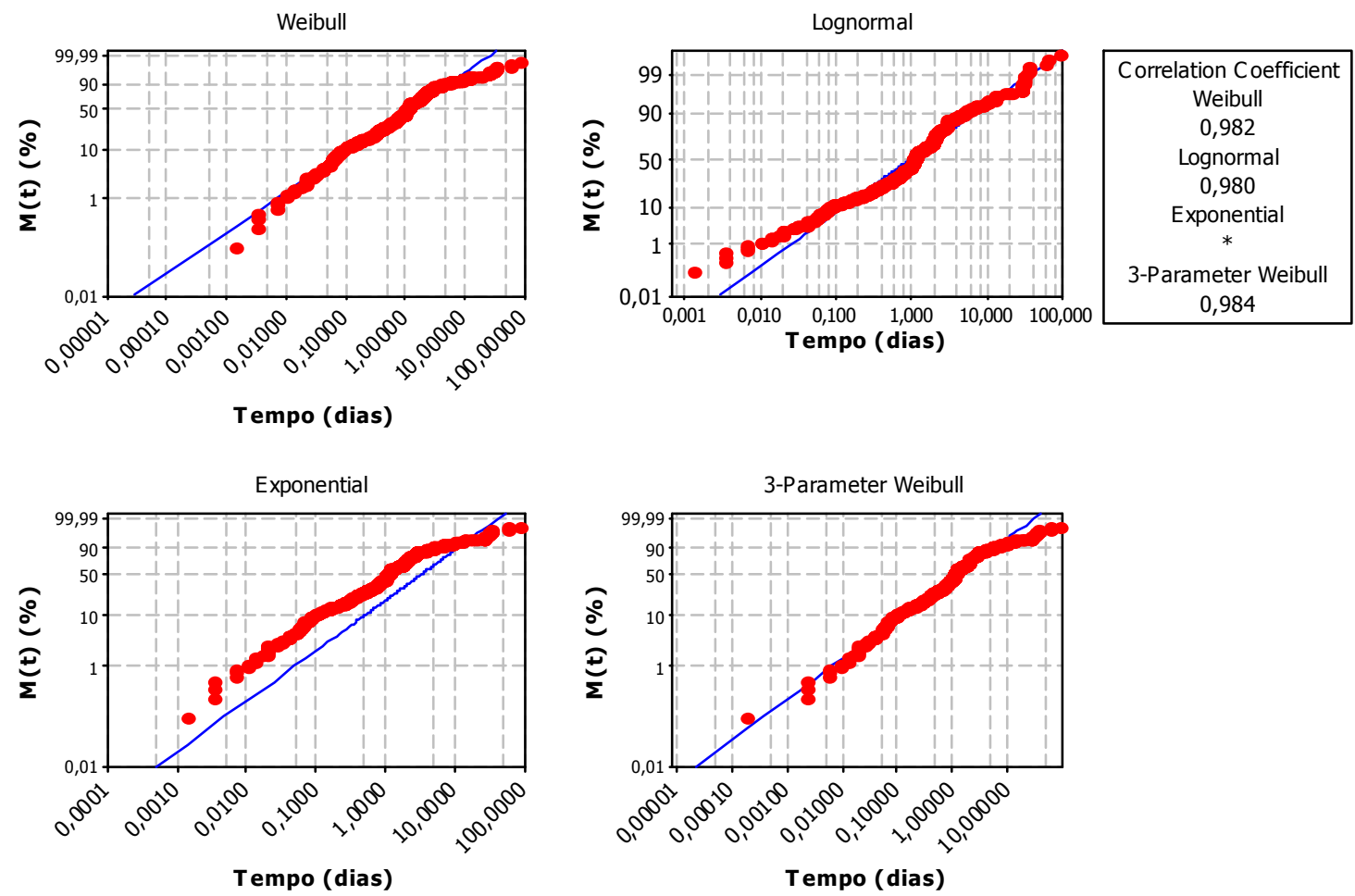

Figura B-19 - Probabilidades de Reparo para $P T$, para diferentes distribuições.
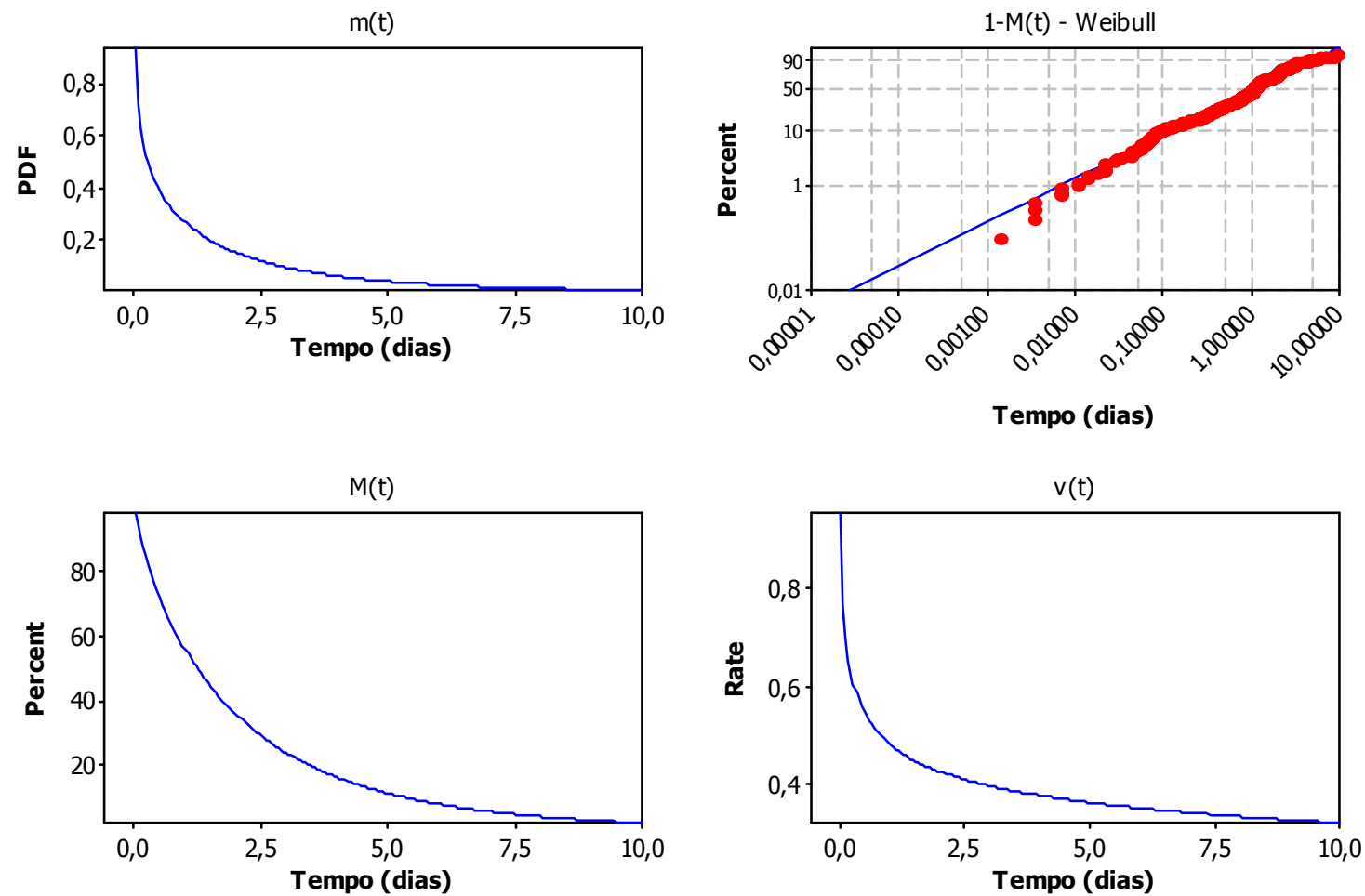

Figura B-20 - m(t), M(t), 1-M(t) e v(t) para $P T$. 
- Modo de Falha: $R P$
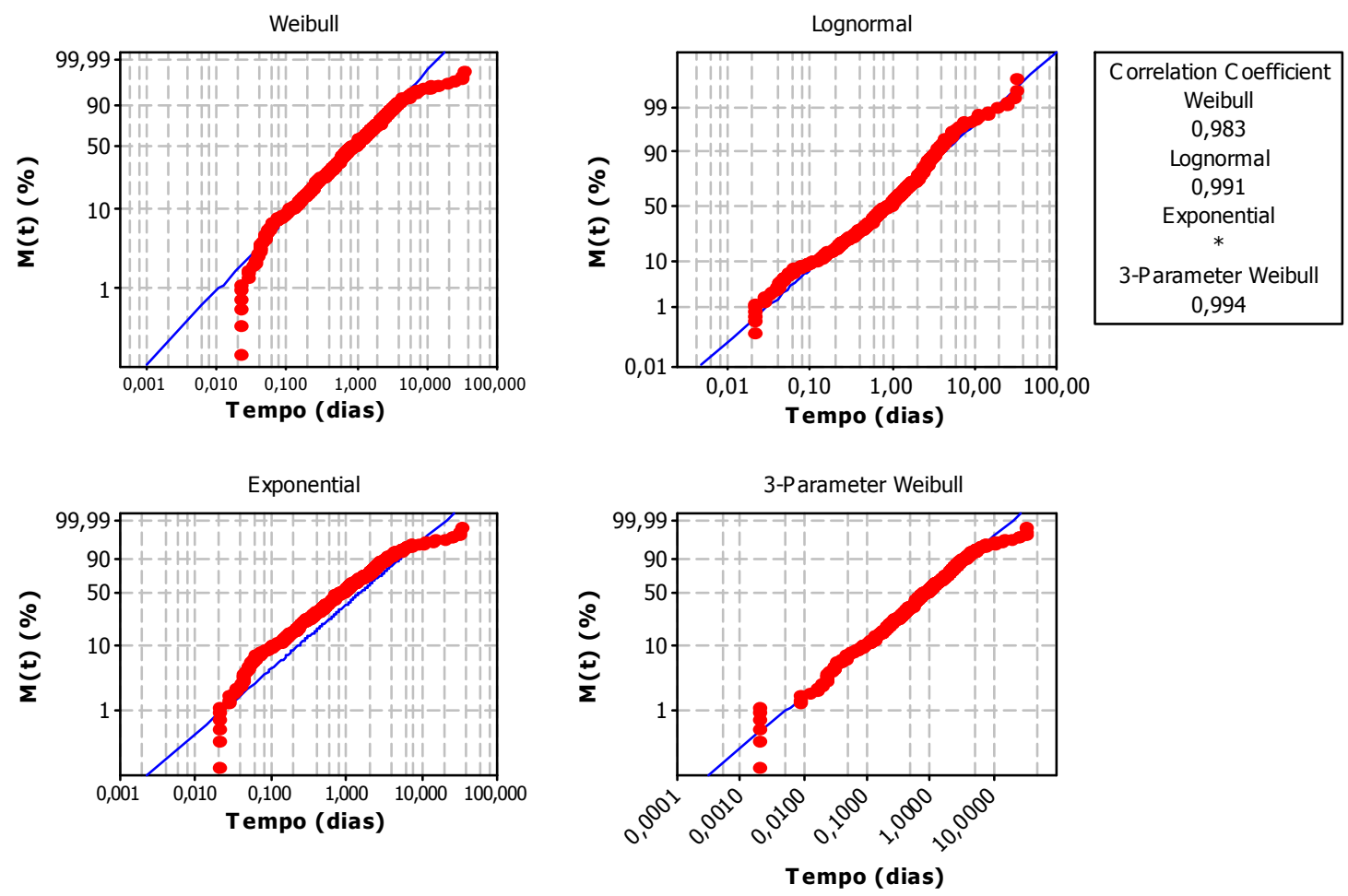

Figura B-21 - Probabilidades de Reparo para $R P$, para diferentes distribuições.

$m(t)$

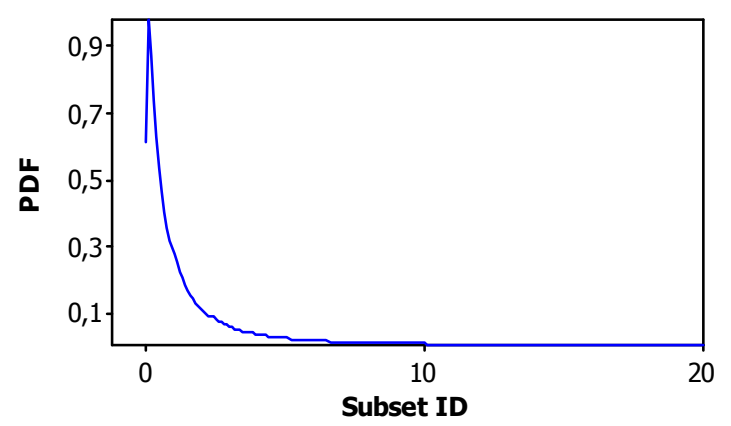

$1-M(t)$

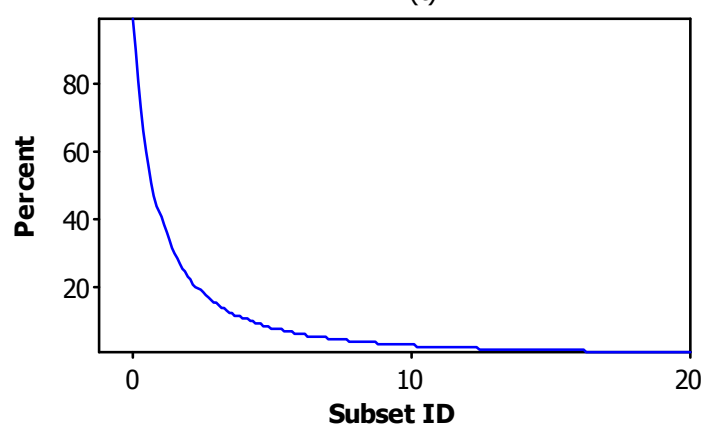

$M(t)$ - Lognormal

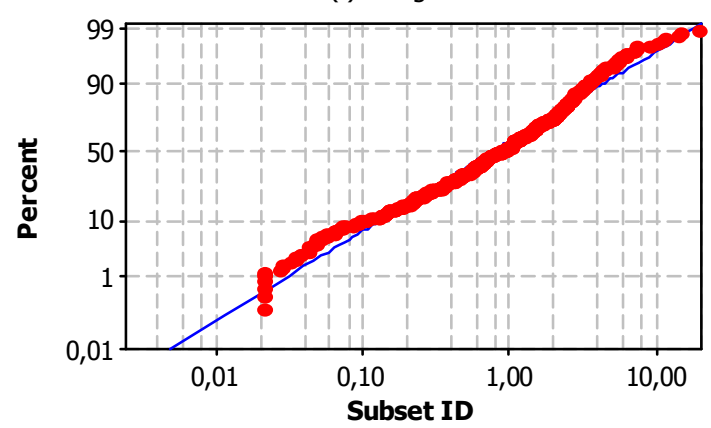

$\mathrm{v}(\mathrm{t})$

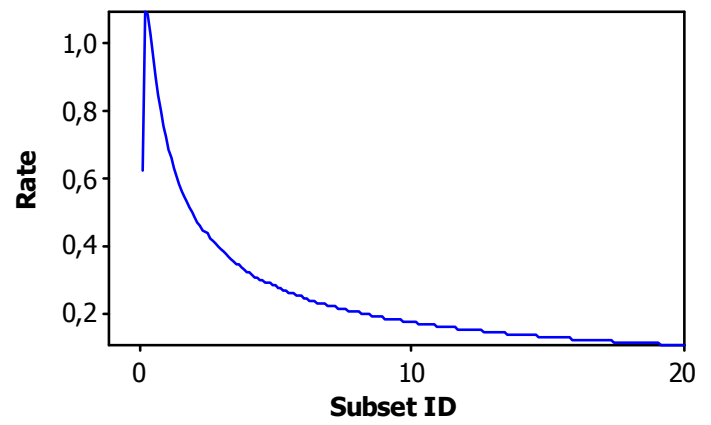

Figura B-22 - m(t), M(t), 1-M(t) e v(t) para $R P$. 